\title{
17. BENTHIC FORAMINIFER STABLE ISOTOPE RECORD FROM SITE 849 (0-5 MA): LOCAL AND GLOBAL CLIMATE CHANGES ${ }^{1}$
}

\author{
A.C. Mix,${ }^{2}$ N.G. Pisias, ${ }^{2}$ W. Rugh, ${ }^{2}$ J. Wilson, ${ }^{2}$ A. Morey, ${ }^{2}$ and T.K. Hagelberg ${ }^{2,3}$
}

\begin{abstract}
Benthic foraminifer and $\delta^{13} \mathrm{C}$ data from Site 849 , on the west flank of the East Pacific Rise $\left(0^{\circ} 11^{\prime} \mathrm{N}, 110^{\circ} 31^{\prime} \mathrm{W} ; 3851 \mathrm{~m}\right)$, give relatively continuous records of deep Pacific Ocean stable isotope variations between 0 and $5 \mathrm{Ma}$. The mean sample spacing is 4 k.y. Most analyses are from Cibicides wuellerstorfi, but isotopic offsets relative to Uvigerina peregrina appear roughly constant. Because of its location west of the East Pacific Rise, Site 849 yields a suitable record of mean Pacific Ocean $\delta^{13} \mathrm{C}$, which approximates a global oceanic signal. The $\sim 100$-k.y.-period climate cycle, which is prevalent in $\delta^{18} \mathrm{O}$ does not dominate the long-term $\delta^{13} \mathrm{C}$ record. For $\delta^{13} \mathrm{C}$, variations in the $\sim 400$ - and 41 -k.y. periods are more important. Phase lags of $\delta^{13} \mathrm{C}$ relative to ice volume in the 41 - and 23-k.y. bands are consistent with $\delta^{13} \mathrm{C}$ as a measure of organic biomass. A model-calculated exponential response time of 1-2 k.y. is appropriate for carbon stored in soils and shallow sediments responding to glacial-interglacial climate change. Oceanic $\delta^{13} \mathrm{C}$ leads ice volume slightly in the 100-k.y. band, and this suggests another process such as changes in continental weathering to modulate mean river ${ }^{13} \mathrm{C}$ at long periods.

The $\delta^{13} \mathrm{C}$ record from Site 849 diverges from that of Site 677 in the Panama Basin mostly because of decay of ${ }^{13} \mathrm{C}$-depleted organic carbon in the relatively isolated Panama Basin. North Atlantic to Pacific $\delta^{13} \mathrm{C}$ differences calculated using published data from Sites 607 and 849 reveal variations in Pliocene deep water within the range of those of the late Quaternary. Maximum $\delta^{13} \mathrm{C}$ contrast between these sites, which presumably reflects maximum influx of high- $\delta{ }^{13} \mathrm{C}$ northern source water into the deep North Atlantic Ocean, occurred between 1.3 and $2.1 \mathrm{Ma}$, well after the initiation of Northern Hemisphere glaciation. Export of high- $\delta^{13} \mathrm{C}$ North Atlantic Deep Water from the Atlantic to the circumpolar Antarctic, as recorded by published $\delta^{13} \mathrm{C}$ data from Subantarctic Site 704 , appears unrelated to the North Atlantic-Pacific $\delta^{13} \mathrm{C}$ contrast. To account for this observation, we suggest that deep-water formation in the North Atlantic reflects northern source characteristics, whereas export of this water into the circumpolar Antarctic reflects Southern Hemisphere wind forcing. Neither process appears directly linked to ice-volume variations.
\end{abstract}

\section{INTRODUCTION}

Our primary goal is to develop a standard deep Pacific stable isotopic record over the last $5 \mathrm{~m}$.y. As the largest of the ocean basins, the deep Pacific Ocean is the most important to the global budget of carbon and oxygen isotopes. We analyze $\delta^{18} \mathrm{O}$ and $\delta^{13} \mathrm{C}$ in benthic foraminifers at an average time spacing of $\sim 4$ k.y. in Site $849\left(0^{\circ} 11^{\prime} \mathrm{N}\right.$, $110^{\circ} 31^{\prime} \mathrm{W}, 3851 \mathrm{~m}$ water depth; Fig. 1). We compare this record to the only other long, high-resolution record available from the area: Site 677 from the Panama Basin $\left(1^{\circ} 12^{\prime} \mathrm{N}, 83^{\circ} 44^{\prime} \mathrm{W}, 3461 \mathrm{~m}\right.$ water depth), which was analyzed by Shackleton et al. (1990). To evaluate the global implications of this new Pacific Ocean data set, we also compare the isotope record from Site 849 to that of Site 607 from the North Atlantic Ocean $\left(41^{\circ} 00^{\prime} \mathrm{N}, 32^{\circ} 37^{\prime} \mathrm{W}, 3427 \mathrm{~m}\right.$ water depth), which was assembled by Raymo et al. (1990), as well as to subantarctic Site 704 ( $46^{\circ} 53^{\prime} \mathrm{S}, 7^{\circ} 25^{\prime} \mathrm{E}, 2532 \mathrm{~m}$ water depth), which was reported by Hodell (1993) and Hodell and Venz (1992).

Until now, the closest approximation to a standard deep Pacific Ocean reference section for stable isotopes has been the highresolution record of the last $\sim 2.5 \mathrm{Ma}$. from Site 677 in the Panama Basin (Shackleton et al., 1990). The $\delta^{13} \mathrm{C}$ record from this site was used by others (e.g., Raymo et al., 1990, 1992; Hodell and Venz, 1992) for comparison with Atlantic and Southern Ocean records, to assess long-term variations in deep-ocean circulation. For $\delta^{13} \mathrm{C}$, however, Site 677 may not be an ideal Pacific Ocean isotopic reference section. Modern $\delta^{13} \mathrm{C}$ values of $\Sigma \mathrm{CO}_{2}$ in Panama Basin bottom water are lower than values in the open Pacific. This results from the combined effects of local bathymetric isolation, mixing of source

'Pisias, N.G., Mayer, L.A., Janecek, T.R., Palmer-Julson, A., and van Andel, T.H. (Eds.), 1995. Proc. ODP, Sci. Results, 138: College Station, TX (Ocean Drilling Program).

${ }^{2}$ College of Oceanic and Atmospheric Sciences, Oceanography Administration Bldg. 104, Oregon State University, Corvallis, OR 97331-5503, U.S.A.

${ }^{3}$ Present address: Graduate School of Oceanography, University of Rhode Island, Narragansett Bay Campus, Narragansett, RI 02882, U.S.A. waters from the southeastern and central Pacific Ocean, and in-situ oxidation of ${ }^{13} \mathrm{C}$-depleted organic matter (Kroopnick, 1974; Lonsdale, 1977). Because the Panama Basin is relatively small and is located under one of the highest productivity open-ocean areas in the world (Chavez and Barber, 1987), it is very sensitive to the organic influx effect (Fig. 2). Any variation in this local effect on $\delta^{13} \mathrm{C}$ in the Panama Basin would be superimposed on global or regional signals.

The ideal place to monitor central Pacific Ocean waters is the west flank of the East Pacific Rise. Site 849 is located about $860 \mathrm{~km}$ west of the East Pacific Rise on oceanic crust generated about 11-12 Ma. Recovered from $3851 \mathrm{~m}$ water depth, the site has been above the carbonate compensation depth (CCD) throughout its history. Thermal subsidence of the site is negligible over the interval we have studied here. The water mass bathing this site is characteristic of average deep Pacific Ocean water, with potential temperature of $1.2^{\circ} \mathrm{C}$ and salinity of $34.68 \%$ (Lonsdale, 1976). This is identical to that of the most abundant water-mass class in the world ocean, often referred to as "Common Water" (Worthington, 1981). Concentration of oxygen at the site is about $155 \mu \mathrm{mole} / \mathrm{kg}$ (Lonsdale, 1976), which is about average for the deep Pacific Ocean (Levitus, 1982). Sedimentation rates at Site 849 are high enough (on average, $25-30 \mathrm{~m} / \mathrm{m} . \mathrm{y}$.) that bioturbation does not severely attenuate the glacial/interglacial amplitudes, because a 20-k.y. or longer cycle would comprise $>50 \mathrm{~cm}$ depth, much longer than a typical bioturbation smoothing depth of $5-10 \mathrm{~cm}$. Total sediment thickness at the site is about $340 \mathrm{~m}$, but the results here present data from the top $\sim 140 \mathrm{~m}$ of the sediment column.

\section{RESULTS}

All isotope data from Site 849 reported here were analyzed at the College of Oceanic and Atmospheric Sciences Stable Isotope Laboratory at Oregon State University (OSU) between December 1991 and August 1993, using a Finnigan/MAT 251 mass spectrometer equipped with an Autoprep Systems automated carbonate device. Foraminifera were hand picked from the $>150-\mu \mathrm{m}$ size fraction, and 


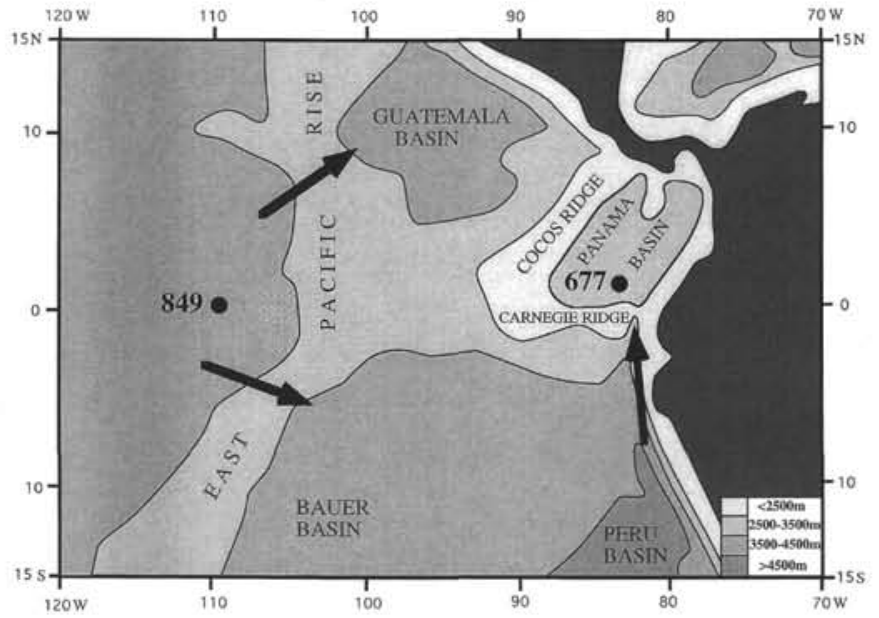

Figure 1. Site 849 , at $0^{\circ} 11^{\prime} \mathrm{N}, 110^{\circ} 31^{\prime} \mathrm{W}$, at a water depth of $3851 \mathrm{~m}$, is located about $860 \mathrm{~km}$ west of the East Pacific Rise on oceanic crust generated about 11-12 Ma. Site 849 is presently bathed by Pacific "Common Water," with potential temperature $=1.2^{\circ} \mathrm{C}$ and salinity $=34.68 \%$. For comparison, Site 677, at $1^{\circ} 12^{\prime} \mathrm{N}, 83^{\circ} 44^{\prime} \mathrm{W}$, at a water depth of $3461 \mathrm{~m}$, is in the relatively isolated Panama Basin. Arrows indicate the deep-water flow paths inferred by Lonsdale (1977).

were ultrasonically cleaned in alcohol and roasted for $1 \mathrm{hr}$ at $400^{\circ} \mathrm{C}$ under high vacuum to remove organic contaminants. Reactions of carbonates occurred at $90^{\circ} \mathrm{C}$, in $\sim 100 \%$ phosphoric acid. Precision of the OSU local carbonate standard (WILEY) over the period of analysis was $\pm 0.06 \%$ for $\delta^{18} \mathrm{O}$ and $\pm 0.03 \%$ for $\delta^{13} \mathrm{C}( \pm 1 \sigma, N=567)$. Primary calibration to the PDB standard was through NBS-20, supplied by the U.S. National Institute for Standards and Technology, assuming $\delta^{18} \mathrm{O}=-4.14 \%$ and $\delta^{13} \mathrm{C}=-1.06 \%$. Precision on this standard over the same period as the foraminiferal analyses was $\pm 0.08 \%$ for $\delta^{18} \mathrm{O}$ and $\pm 0.05 \%$ for $\delta^{13} \mathrm{C}( \pm 1 \sigma, N=55)$.

Benthic foraminifers were analyzed in 1241 samples from Site 849, at a typical depth spacing of $10 \mathrm{~cm}$. We made 1219 analyses of the species Cibicides wuellerstorfi and 200 analyses of the species Uvigerina peregrina. Both species were analyzed in 140 samples. Oxygen and carbon isotopic differences between species within the same samples are illustrated in Figure 3. The mean isotopic differences $(\mathrm{Ci}$ bicides - Uvigerina) are $-0.60 \% \pm \pm 0.18 \%$ for $\delta^{18} \mathrm{O}$ (Fig. 3A) and $+0.91 \% \pm 0.16 \%$ for $\delta^{13} \mathrm{C}$ (Fig. 3B). Most of the scatter in these offsets is the result of analytical error (about $\pm 0.15 \%$ for the difference between species, using a conservative estimate of $\pm 0.1 \%$ random error on any individual foraminiferal analysis; Mix et al., 1991). Any additional error results from the combination of true variability (either random or systematic) in the isotopic offset between different species of foraminifers, plus the possible effects of bioturbation having mixed together specimens from different times.

We found no evidence for systematic relationships of oxygen and carbon isotopic offsets between species (Fig. 3C) and no systematic changes in the species offsets as a function of age or ice volume (as recorded by $\delta^{18} \mathrm{O}$ ). Thus, we consider the variations in the species offsets for both $\delta^{18} \mathrm{O}$ and $\delta^{13} \mathrm{C}$ in this data set to be random. Although the variability is larger than the precision of the mass spectrometer, it is not significantly different from the analytical noise of typical foraminiferal measurements, and we assume that the true offsets are constant. The bioturbation effect appears to be negligible.

In the combined record, we added the constant $0.64 \%$ to $\delta^{18} \mathrm{O}$ values from Cibicides wuellerstorfi to approximate values from Uvigerina peregrina (Shackleton, 1974). This value is consistent with our measured offset and is used by most analysts. For the $\delta^{13} \mathrm{C}$ values from $U$. peregrina, we used with the standard adjustment of $0.90 \%$ (Duplessy et al., 1984), which is statistically identical to the offset of $0.91 \%$ $\pm 0.16 \%$ found here. The final composite records of both $\delta^{18} \mathrm{O}$ and $\delta^{13} \mathrm{C}$ in Site 849 contains 1415 analyses, of which 174

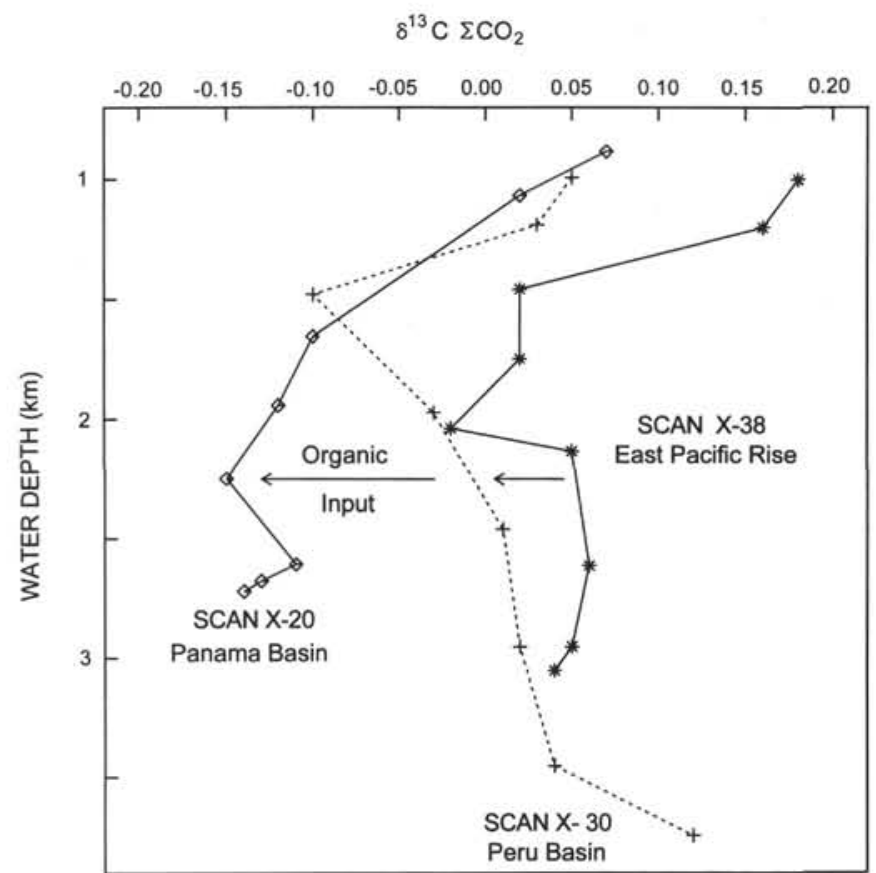

Figure 2. The $\delta^{13} \mathrm{C}$ value of $\Sigma \mathrm{CO}_{2}$ in the deep waters of the Panama Basin (SCAN X-20) is about $0.2 \%$ lower than values of the open Pacific (SCAN $\mathrm{X}-38$ ), mostly because of the decomposition of ${ }^{13} \mathrm{C}$-depleted organic matter in the basin. Sites in the Peru Basin (SCAN X-30) are intermediate between the two others. All water column data are from Kroopnick (1974).

replicate analyses of the same sample. All analyses are listed in Appendix A.

Before plotting the isotope data as a function of sediment depth, we must develop a composite depth model to assemble data from adjacent holes drilled a few tens of meters away from each other. This is because cores obtained by the Ocean Drilling Program (ODP) are recovered in discrete intervals of about $9.5 \mathrm{~m}$, with small gaps or overlaps between them. Depths assigned during drilling, referred to as meters below sea floor (mbsf), are not precise enough for correlation between holes. The initial composite section for Site 849 was developed at sea during Leg 138 using high-resolution (1- to 4-cm intervals) measurements of gamma-ray attenuation porosity evaluator (GRAPE) density, magnetic susceptibility, and light reflectance in triple-cored sites. The shipboard composite depth model moved each core up or down relative to overlapping intervals of adjacent holes, so as to maximize the correlation among holes in these intervals. This process defined linear offsets to the mbsf depths assigned for each core as it was drilled. The offsets tend to increase at greater subbottom depths. Thus, the process created a new depth scale, referred to as meters composite depth (mcd), reported by Hagelberg et al. (1992). A reference section, referred to as the "shipboard splice," assembled representative intervals from all the holes at a site (jumping between holes at a point of excellent match of a distinctive feature) to define a single reference record on the mcd scale.

The mcd scale used to determine the shipboard splice, therefore, was derived from the linear adjustment of whole cores. It does not take into account distortions within individual cores; as a result, some features found in corresponding cores from different holes may not match precisely. To maintain a good correlation among all the holes sampled, the depth in each core must be adjusted to correct for distortion relative to the shipboard splice. Final depth corrections were done by adjusting the depth scale in each core continuously, using the technique of Martinson et al. (1982) to maximize the fit of high-resolution GRAPE data in each core to the corresponding inter$\mathrm{val}$ of the shipboard splice. This adjustment defines a third depth scale, referred to as revised meters composite depth (rmcd). It is docu- 

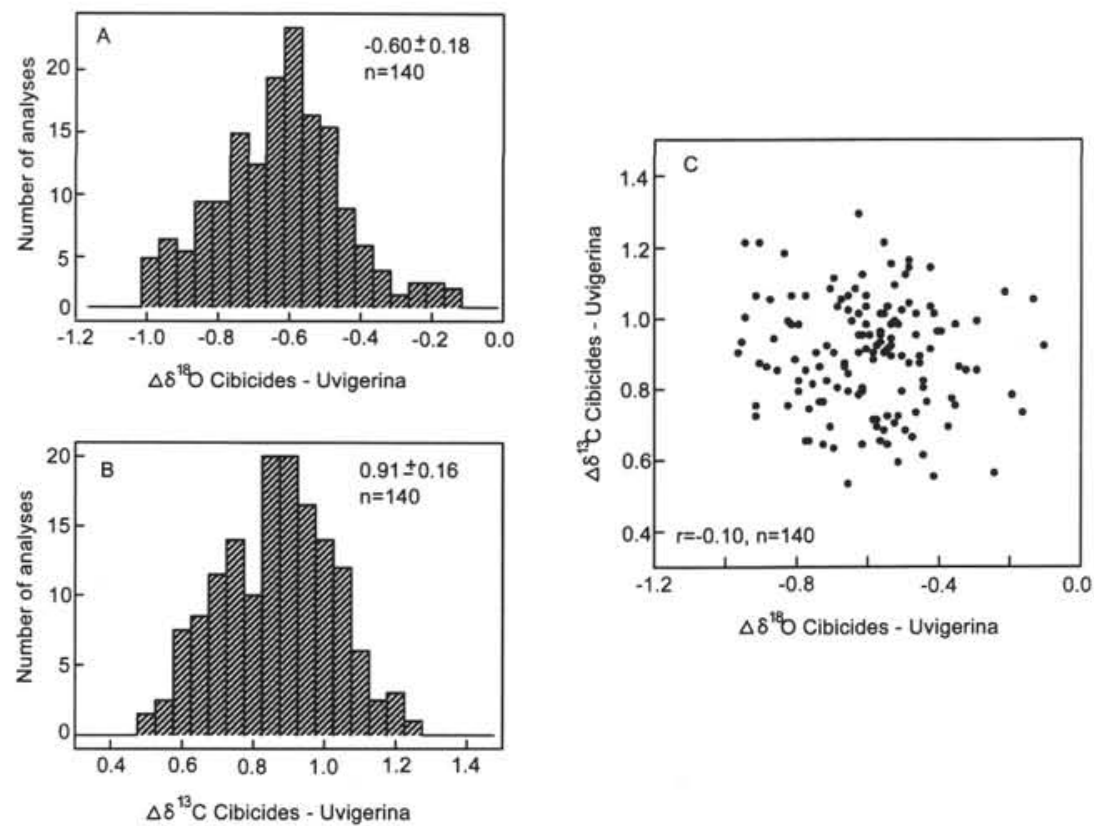

Figure 3. Isotopic offsets between paired analyses of Cibicides wuellerstorfi and Uvigerina peregrina at Site 849. A. Histogram of $\Delta \delta^{18} \mathrm{O}$ Cibicides - Uvigerina (mean $=-0.60 \%$ Histogram of $\Delta \delta^{13} \mathrm{C}$ Cibicides - Uvigerina (mean $=0.91 \% \pm 0.16 \%$ ). C. Scatter plot of individual paired analyses of $\Delta \delta^{13} \mathrm{C}$ Cibicides - Uvigerina vs. $\Delta \delta^{13} \mathrm{C}$ Cibicides - Uvigerina, showing that variations in the carbon and oxygen isotopic offsets between species are not related to each other.

mented for all cores by Hagelberg et al. (this volume). The adjustment from med to rmcd is small, typically on the order of decimeters. By definition, the adjustment is $0 \mathrm{~cm}$ in all intervals that defined the shipboard splice. All three depth scales for our samples in Site 849 are given in Appendix A, but we use the rmcd depth scale.

Figure 4 illustrates the combined isotope data from Site 849 plotted vs. rmcd. Different symbols represent the different holes. The stable isotope data, an independent check of the matches among holes in the rmcd scale, yielded no evidence for gaps or the duplication of intervals in the Site 849 composite. The composite isotope record from 0 to 155 rmcd is shown in detail in 30-m intervals (Figs. 5A-5J). The holes, cores, and sections analyzed are noted here, and different species are illustrated by symbol size. Note that advanced hydraulic piston corer (APC) cores extend to $123 \mathrm{rmcd}$. Below this depth, the isotope records are based on extended core barrel (XCB) cores from Hole 849D only, and the record is therefore discontinuous. Where sampled intervals in different holes overlap, the match of the isotope data is generally excellent. The only exception appears to be the match between Core 138-849D-12X and $-13 \mathrm{X}$ at $\sim 133 \mathrm{rmcd}$. The composite depths for $\mathrm{XCB}$ cores, such as these, are less reliable than are depths for APC cores shallower in the sediment column.

\section{AGE MODEL}

The age model developed here for Site 849 is defined relative to rmcd depths. It should be equally applicable to the intervals that define the "shipboard splice" on the mcd depth scale, assuming all cores analyzed here were correlated accurately by means of GRAPE, magnetic susceptibility, and reflectance to the shipboard spliced records (Hagelberg et al., this volume). The age model developed here is not applicable to the mbsf depth scale.

The shipboard paleomagnetic reversal record at Site 849 was not useful (Mayer, Pisias, Janecek, et al., 1992). Thus, development of the Site 849 age model started with shipboard biostratigraphic data (which was excellent for all fossil groups) and GRAPE density stratigraphy linked to the magnetic reversal sequence in other Leg 138 sites (Shackleton et al., 1992). This first step was followed by correlation of the $\delta^{18} \mathrm{O}$ record from Site 849 directly to the $\delta^{18} \mathrm{O}$ record from Site 677, using the SPECMAP time scale (Imbrie et al., 1984) at ages $<0.6 \mathrm{Ma}$, and the age model of Shackleton et al. (1990) from 0.6 to $2.5 \mathrm{Ma}$. At ages $>2.5 \mathrm{Ma}$, Site 677 is discontinuously cored and sampled, and the correlations between Sites 849 and 677 are not obvious. For this interval, we used the tuned GRAPE age model for Site 849 from Shackleton et al. (this volume).

We refer here to the result as the Site 849 oxygen isotope age model. When comparing Site 849 with other sites, we correlate them directly to the $\delta^{18} \mathrm{O}$ record from Site 849 . The Site 849 age model makes many events older than other isotopic age models in use by about 6\% (Ruddiman et al., 1989; Raymo et al., 1990, 1992; Hodell and Venz, 1992). For example, the " 2.4 Ma glacial event" (Sykes et al., 1991), thought by some workers to represent the earliest stage of major Northern Hemisphere glaciation (Stage 100 of Raymo et al., 1990), occurs at $2.54 \mathrm{Ma}$ in this time scale. It predicts older ages for paleomagnetic reversals than previously thought (Berggren et al., 1985), but these older dates for the paleomagnetic record have since been accepted by Cande and Kent (1992).

To accomplish the correlation of Site 849 with Site 677 at ages $<2.5 \mathrm{Ma}$, secondary selection of ages in Site 849 were made by visually comparing its $\delta^{18} \mathrm{O}$ record with that of Site 677 . Our final age model (tabulated in Appendix B) used the inverse correlation method of Martinson et al. (1982), which mapped $\delta^{18} \mathrm{O}$ variations in the Site 849 record to those of the Site 677 reference. This method adjusts ages continuously down the core with a Fourier mapping function, which is modified iteratively to maximize the correlation coefficient between $\delta^{18} \mathrm{O}$ records. To avoid artificially correlating high-frequency noise with this method, we first smoothed the Site $677 \delta^{18} \mathrm{O}$ record as a function of time, with a time step of 4 k.y. and a Gaussian smoothing window of 19-k.y width at the $\pm 3 \sigma$ points. This smoothing effectively removed variations with wavelength less than $10 \mathrm{k} . \mathrm{y}$., but preserved all the variance in the primary orbital bands of $19 \mathrm{k} . \mathrm{y}$. and longer. For correlation purposes only, we smoothed the raw data from Site 849 in the depth domain with a sample interval of $10 \mathrm{~cm}$ and a Gaussian 

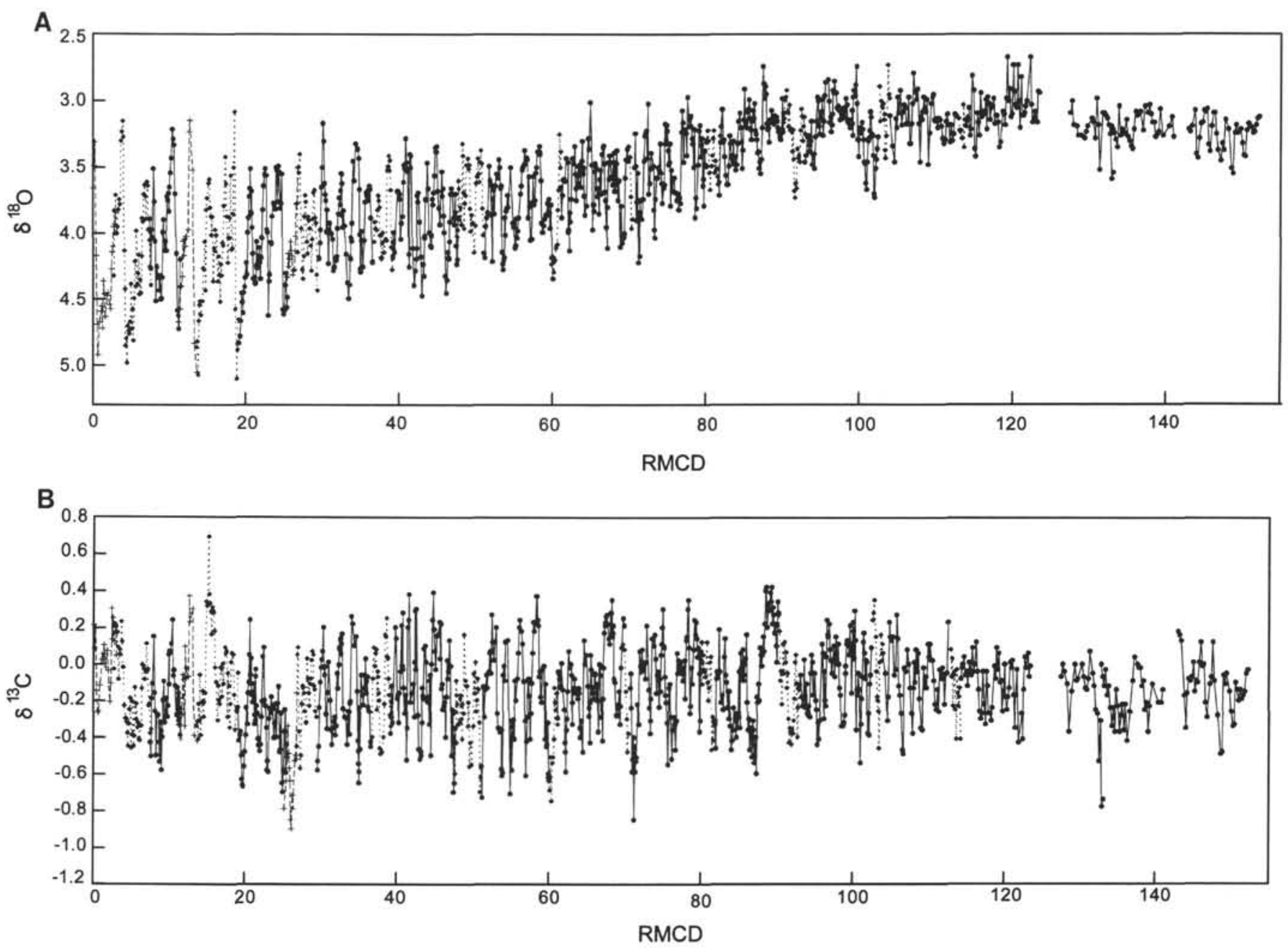

Figure 4. Benthic foraminifer isotope analyses from Site 849 vs. depth (rmcd). Replicate analyses are averaged. Dashed lines $=$ Hole $849 \mathrm{~B}$, dotted lines $=$ Hole $849 \mathrm{C}$, and solid lines $=$ Hole $849 \mathrm{D}$. A. $\delta^{18} \mathrm{O}$. B. $\delta^{13} \mathrm{C}$. The time span covered is $\sim 5 \mathrm{Ma}$.

smoothing window of $50 \mathrm{~cm}$. This is roughly equivalent to the timedomain smoothing of Site 677, given an average sedimentation rate of $2.8 \mathrm{~cm} / \mathrm{k} . \mathrm{y}$. in Site 849 . Before final data analysis, the age model was applied to the raw (unsmoothed) data, and a 19-k.y. Gaussian smoothing function was applied in the time domain.

For the interval from 0 to $2.5 \mathrm{Ma}$, the Site 849 oxygen isotope age model developed here and the Leg 138 tuned GRAPE age model developed by Shackleton et al. (this volume) are similar, but not identical. Both age models are shown in Figures $6 \mathrm{~A}(0-80 \mathrm{rmcd})$ and $6 \mathrm{C}$ ( $80-160 \mathrm{rmcd})$. The differences between the age models, generally less than \pm 20 k.y, are documented in Figures $6 \mathrm{~B}(0-80 \mathrm{rmcd})$ and $6 \mathrm{D}(80-160 \mathrm{rmcd})$. Because of their similarities, either time scale is equally suitable for analyzing climatic variability at periods $\geq 100$ k.y. For analysis of shorter periods of variability and for detailed comparisons to other sites with stable isotope records, the isotopic time scale used here is more appropriate.

The stable isotope records from Sites 849 and 677 are shown as a function of age, after interpolation and smoothing as noted above, in Figure 7. The match between the $\delta^{18} \mathrm{O}$ records is exceptionally good above $2.5 \mathrm{Ma}$. All the isotopic events detected and named by Shackleton et al. (1990) and Raymo et al. (1990) are present and easily identified in the Site 849 record. One additional small interglacial event may be present in Site 849 , at $1.74 \mathrm{Ma}(48.3 \mathrm{rmcd})$. This appears to be a part of $\delta^{18} \mathrm{O}$ stage 61 , which is adjacent to a core break in Site 677, but this event clearly is present in Atlantic Ocean Site 607 (Ruddiman et al., 1989).

\section{DISCUSSION}

\section{$\delta^{18} \mathrm{O}$ and $\delta^{13} \mathrm{C}$}

Over the past $2.5 \mathrm{Ma}$, Site 849 benthic foraminifers have $\delta^{18} \mathrm{O}$ values $0.17 \%$ $\pm 0.15 \%$ less than Site 677 . This would suggest bottom water slightly colder, saltier, or otherwise enriched in $\delta^{18} \mathrm{O}$ at Site 677 relative to that at Site 849 . Modern bottom-water temperatures in the Panama Basin, however, are about $0.6^{\circ} \mathrm{C}$ warmer than those at Site 849 (Lonsdale, 1976, 1977). There may be a slight difference in mass spectrometer calibration because the OSU mass spectrometer is presently calibrated for $\delta^{18} \mathrm{O}$ primarily through NBS-20, and the University of Cambridge instrument is calibrated primarily through NBS-19 (N.J. Shackleton, pers. comm., 1992). However, other comparisons of isotopic results from OSU and Cambridge suggest no significant calibration offsets for either $\delta^{18} \mathrm{O}$ or $\delta^{13} \mathrm{C}$ (Zahn and Mix, 1991; Mix, Le, et al., this volume; Shackleton, this volume).

Relationships among the isotope records of Sites 677 and 849 are explored in more detail using spectra and cross spectra. Details of methods are given by Imbrie et al. (1989). For consistency of phase calculations with SPECMAP conventions (Imbrie et al., 1989), all $\delta^{18} \mathrm{O}$ records are multiplied by -1 , so that larger values indicate interglacial conditions. Positive phase indicates a lag of variable 2 relative to variable 1 . If variable 1 is $-\delta^{18} \mathrm{O}$, this indicates a lag of variable 2 relative to interglacial conditions. In the spectral calculations, unless otherwise noted, the bandwidth is $0.0017 \mathrm{k.y.}{ }^{-1}$, and spectra were 
calculated from 601 points with 4-k.y. spacing, using 200 lags in the cross-covariance calculation.

The $\delta^{18} \mathrm{O}$ records from Sites 849 and 677 contain essentially identical distributions of variance as a function of frequency, with the strongest concentrations of variance at the orbital periods of 100,41 , 23 , and 19 k.y. (Fig. 8A). The two $\delta^{18} \mathrm{O}$ records are highly coherent with each other and in phase in all dominant bands with wavelengths $\geq 19$ k.y. (Fig. 8B-C). We conclude that the $\delta^{18} \mathrm{O}$ records are sufficiently well correlated that we can consider differences between their $\delta^{13} \mathrm{C}$ records at periods $\geq 19$ k.y.

The carbon isotope records at the two sites share many similarities, but they are not identical (Fig. 7B). Over most of the record, the $\delta^{13} \mathrm{C}$ values from Site 677 are significantly lower than those from Site 849, consistent with the modern water column difference (Fig. 2), which is driven mostly by organic carbon influx to the Panama Basin. This difference is especially obvious in the intervals from 1.2 to $1.6 \mathrm{Ma}$ and from 2.1 to $2.4 \mathrm{Ma}$, where the $\delta^{13} \mathrm{C}$ values from Site 677 are typically $0.5 \%$ lower than those from Site 849 . Site 677 contains a long-term trend toward lower $\delta^{13} \mathrm{C}$ values in older intervals. This trend was interpreted by Raymo et al. (1990) as reflecting higher global-average nutrient contents in the Pliocene ocean. Site 849 has no trend. This lack of a long-term trend in $\delta^{13} \mathrm{C}$ is confirmed for the past $1.8 \mathrm{Ma}$ in the benthic $\delta^{13} \mathrm{C}$ record from Site 846 (Mix et al., this volume). Therefore, we think that the $\delta^{13} \mathrm{C}$ trend in Site 677 is a local signal associated with the unique setting of the Panama Basin. This new view of stable long-term average $\delta^{13} \mathrm{C}$ in Site 849 will force a reexamination of inferences about long-term ocean history that have depended on the Site 677 record.

After removing the long-term trend in Site 677 , the $\delta^{13} \mathrm{C}$ records from Sites 849 and 677 are highly coherent and nearly in phase with each other over the last $2.4 \mathrm{Ma}$, at almost all periods (1/frequency) longer than 40 k.y. (Fig. 8E-F). With the narrow bandwidth of this analysis relative to those commonly used for shorter paleoceanographic records, we can clearly distinguish some of the lower frequency bands that often have been lumped into the 100-k.y. cycle. On this time frame, the Pacific Ocean $\delta^{13} \mathrm{C}$ record does not have as strong a concentration of variance at the 100-k.y. climate cycle as does $\delta^{18} \mathrm{O}$. Instead, the dominant long-period variations in $\delta^{13} \mathrm{C}$ are at a longer period (near $400 \mathrm{k.y}$.) and about equally at three periods of 80 , 100 , and 133 k.y. (Fig. 8D). The strong $41-k$.y. period in $\delta^{13} \mathrm{C}$ is similar to that of orbital obliquity. The variations in $\delta^{13} \mathrm{C}$ near the precessional periods of 23 and 19 k.y. are not well defined at Site 677 and are not strongly coherent in these two $\delta^{13} \mathrm{C}$ records, even though they were strong in $\delta^{18} \mathrm{O}$ measured on the same samples in both cores.

The presence of similar rhythmic signals in deep Pacific Ocean $\delta^{13} \mathrm{C}$ (Fig. 8D) and $\delta^{18} \mathrm{O}$ (Fig. 8A) is expected for periods much shorter than the 200- to 300-k.y. residence time of carbon in the oceans (Broecker and Peng, 1982). On these time frames, variations in the mass of organic matter stored in forests, soils, and shallow-marine sediments, presumably related to glacial-interglacial climate change, are thought to dominate the $\delta^{13} \mathrm{C}$ record (Shackleton, 1977). At periods longer than a few 100 k.y., however, the isotopic balance of long-term erosion and deposition of carbon must play a more important role in driving oceanic $\delta^{13} \mathrm{C}$. At these long periods, the ocean is flushed by an influx of carbon from rivers and by burial of carbon to balance the river flux. Transient effects such as biomass change are not expressed in this long-term balance. Long-term changes in oceanic $\delta^{13} \mathrm{C}$ could reflect either the $\delta^{13} \mathrm{C}$ of the mean river flux, the $\delta^{13} \mathrm{C}$ of buried carbonate and organic carbon, or the fraction of carbon buried as organic matter. It is not clear which mechanisms dominate the spectrum in the range of periods from 100 to 300 k.y.

To examine the significance of relationships between $\delta^{13} \mathrm{C}$ and $\delta^{18} \mathrm{O}$, we plot spectra and cross spectra between $-\delta^{18} \mathrm{O}$ and $\delta^{13} \mathrm{C}$ at each site (Fig. 9). At Site $849, \delta^{13} \mathrm{C}$ is coherent with $-\delta^{18} \mathrm{O}$ in all the major orbital bands except the 19-k.y. precessional period (Figs. 9A-9B). Information on phase of $\delta^{13} \mathrm{C}$ relative to $-\delta^{18} \mathrm{O}$ (Fig. 9C) is meaningful where there is significant shared variance (peaks in Fig. 9A) and where these peaks are coherent (Fig. 9B). In these coherent bands, the phases of $\delta^{13} \mathrm{C}$ relative to $-\delta^{18} \mathrm{O}$ are not constant. Variations in $\delta^{13} \mathrm{C}$ lead those of $-\delta^{18} \mathrm{O}$ at longer periods such as $100 \mathrm{k}$.y. (phase $=-12^{\circ} \pm$ $12^{\circ}$ ), and lag behind $-\delta^{18} \mathrm{O}$ at shorter periods such as $41 \mathrm{k} \cdot \mathrm{y}$. (phase $=$ $+15^{\circ} \pm 8^{\circ}$ ) and 23 k.y. ( phase $=+22^{\circ} \pm 15^{\circ}$ ).

A similar analysis of the relationships between the $\delta^{13} \mathrm{C}$ and $-\delta^{18} \mathrm{O}$ records in the interval $0-2.4 \mathrm{Ma}$ in Site 677 agrees in most features with Site 849 , but does not reveal any significant bands of concentrated variance common to $\delta^{13} \mathrm{C}$ and $-\delta^{18} \mathrm{O}$ at periods shorter than 41 k.y., and has lower integrated coherency (Figs. 9D-9F). Site 846 , analyzed over the interval $0-1.8 \mathrm{~m}$.y. by Mix et al. (this volume), yields relationships between the $\delta^{13} \mathrm{C}$ and $-\delta^{18} \mathrm{O}$ records that are essentially identical to those of Site 849.

In the interval 2.4-4.42 Ma in Site 849, the distribution of variance is somewhat different in $\delta^{13} \mathrm{C}$ and $-\delta^{18} \mathrm{O}$ than in the younger record (Fig. 9G). The total variance is less, and $-\delta^{18} \mathrm{O}$ contains variance at long periods ( $>400$ k.y.) as well as at the primary orbital bands of 100,41 , and $23 \mathrm{k} . \mathrm{y}$. The $\delta^{13} \mathrm{C}$ record contains significant variance in the $41-\mathrm{k} . \mathrm{y}$. band that is coherent with that of $-\delta^{18} \mathrm{O}$ (Fig. 9H). The phase spectrum, however, is nearly identical to that from $0-2.4 \mathrm{Ma}$, with $\delta^{13} \mathrm{C}$ leading $-\delta^{18} \mathrm{O}$ at the 100 -k.y. period, and lagging in the shorter periods (Fig. 9I). This feature of the phase spectrum appears to be robust and not sensitive to the radically different global climate regimes of the Pliocene and Pleistocene. This has not been noticed before, because most records from late Pleistocene time are too short to allow calculation of phase with sufficient precision to detect such small phase shifts.

Assuming that Site 849 represents the global average record, the observation that $\delta^{13} \mathrm{C}$ lags $-\delta^{18} \mathrm{O}$ at shorter periods is consistent with the biosphere behaving as a simple exponential system responding with a single time constant. Following modeling concepts in Imbrie (1985) and Pisias et al. (1990), the phase of biomass relative to presumed forcing in such a system would be described by $\phi=$ $\arctan \left(2 \pi \mathrm{f} \tau_{\mathrm{b}}\right)$, where $\phi$ is the phase angle at a given frequency, $\mathrm{f}$ is frequency $(=1 /$ period $)$, and $\tau_{\mathrm{b}}$ is the time constant for changing biomass. A model such as this produces a phase shift, with greater lags of the response behind the forcing at shorter periods. If we assume that the climatic forcing of biomass is glaciation, as recorded by $\delta^{18} \mathrm{O}$, the phase of $\delta^{13} \mathrm{C}$ relative to $-\delta^{18} \mathrm{O}$ can be simulated with $\tau_{\mathrm{b}}=1-2 \mathrm{k}$.y. This time constant is too long for living forest biomass, which should respond by factor of 10 times faster (Sundquist, 1993). If $\tau_{\mathrm{b}}$ is indeed $>1$ k.y., then changes in the mass of carbon in soils and shallow sediments must be involved, as these would take longer to respond than living forests.

This model cannot simulate the lead of $\delta^{13} \mathrm{C}$ relative to $-\delta^{18} \mathrm{O}$ at the $100-k . y$. period. A lead of $\delta^{13} \mathrm{C}$ would require either some unknown climatic forcing of biomass unique to this band, which leads $-\delta^{18} \mathrm{O}$ by $10^{\circ}$ to $20^{\circ}$, or the addition of another process such as changes in mean river $\delta^{13} \mathrm{C}$ that could occur on climatic transitions (perhaps related to rise and fall of sea level). This latter process seems more plausible, as it could reflect changes in chemical weathering that would only be expressed significantly by $\delta^{13} \mathrm{C}$ at longer time scales because of the long residence time of carbon in the ocean. It is consistent with recent evidence for changes in the ${ }^{87} \mathrm{Sr} /{ }^{86} \mathrm{Sr}$ value of seawater with a 100-k.y. rhythm (Clemens et al, 1993), which if true would require massive changes in chemical weathering on the continents leading ice-volume change,

The roughly equal strength of $\delta^{13} \mathrm{C}$ variations over a range of periods from $\sim 80$ to $\sim 133$ k.y. (Figs. 9A and 9D) may reflect nonlinear processes related to orbital eccentricity controlling $\delta^{13} \mathrm{C}$ in these bands, as these periods match those of sum and difference interactions of the primary orbital eccentricity bands of $\sim 100$ and $\sim 400$ k.y. (i.e., $1 / 80=1 / 100+1 / 400$, and $1 / 133=1 / 100-1 / 400)$. The existence of these bands, however, is not sufficient to establish clear nonlinear linkage. These possibilities will need to be examined with higher order spectral techniques (Hagelberg et al., 1991) to confirm a rela- 

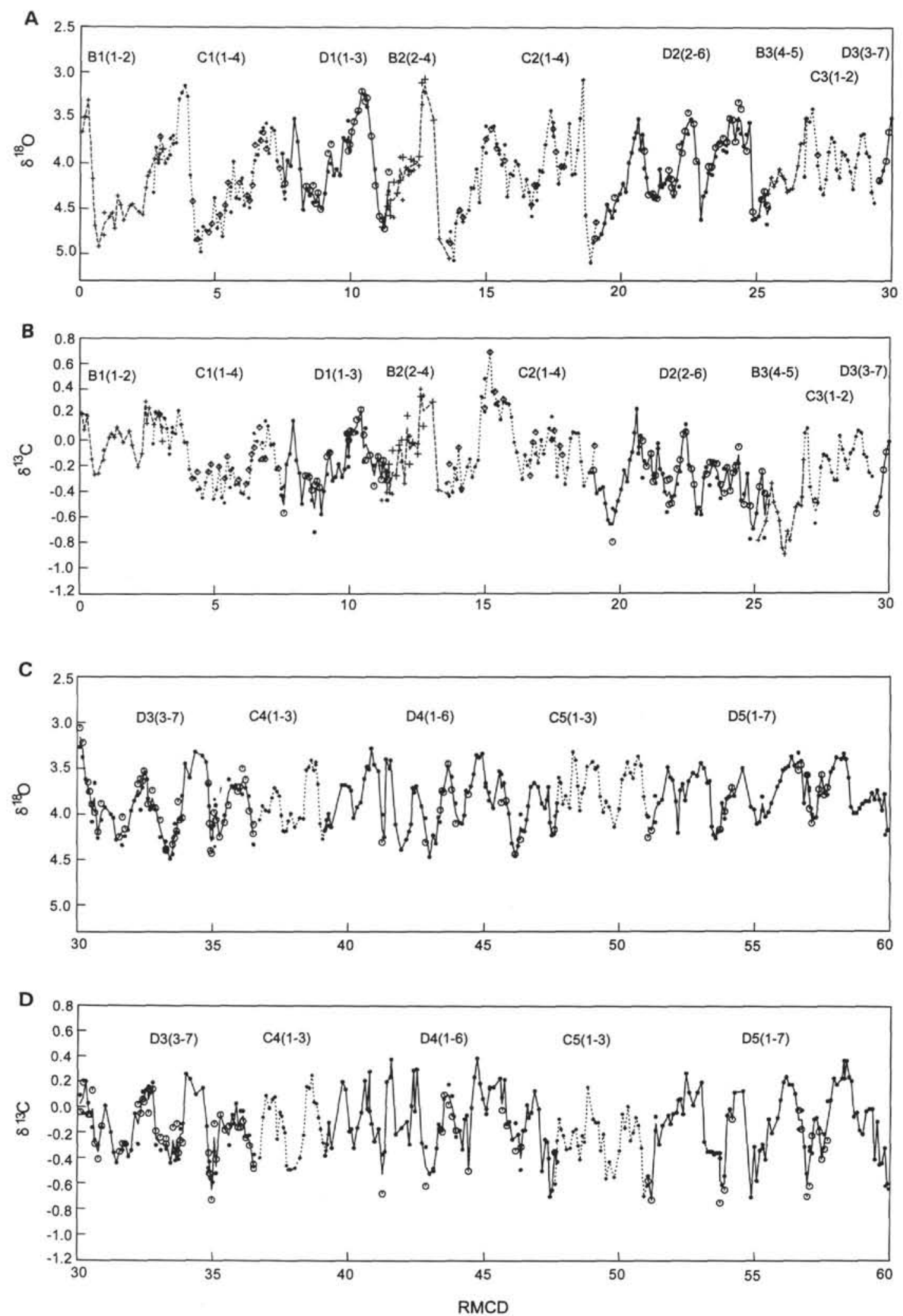

Figure 5. Data as in Figure 4, but shown at a larger scale to illustrate the cores and sections measured, and the matches of the composite depth section between holes. Replicate analyses are averaged for the lines, but all individual analyses are shown without averaging as discrete points. Small symbols are from Cibicides wuellerstorfi, and large symbols are from Uvigerina peregrina. Hole $849 \mathrm{~B}$ has dashed lines and plus symbols. Hole $849 \mathrm{C}$ has dotted lines and diamond symbols. Hole $849 \mathrm{D}$ has solid lines and circle symbols. A. $\delta^{18} \mathrm{O}(0-30 \mathrm{rmcd})$. B. $\delta^{13} \mathrm{C}(0-30 \mathrm{rmcd})$. C. $\delta^{18} \mathrm{O}(30-60 \mathrm{rmcd})$. D. $\delta^{13} \mathrm{C}(30-60 \mathrm{rmcd})$. E. $\delta^{18} \mathrm{O}(60-90 \mathrm{rmcd})$. F. $\delta^{13} \mathrm{C}(60-90 \mathrm{rmcd})$. G. $\delta^{18} \mathrm{O}(90-120 \mathrm{rmcd})$. H. $\delta^{13} \mathrm{C}(90-120 \mathrm{rmcd})$. I. $\delta^{18} \mathrm{O}(120-155 \mathrm{rmcd})$. J. $\delta^{13} \mathrm{C}(120-155 \mathrm{rmcd})$. All cores were cored with the APC, except in Figures 5I and 5J, where Cores 138-849D-12X, -13X, and -14X were taken with the XCB. 

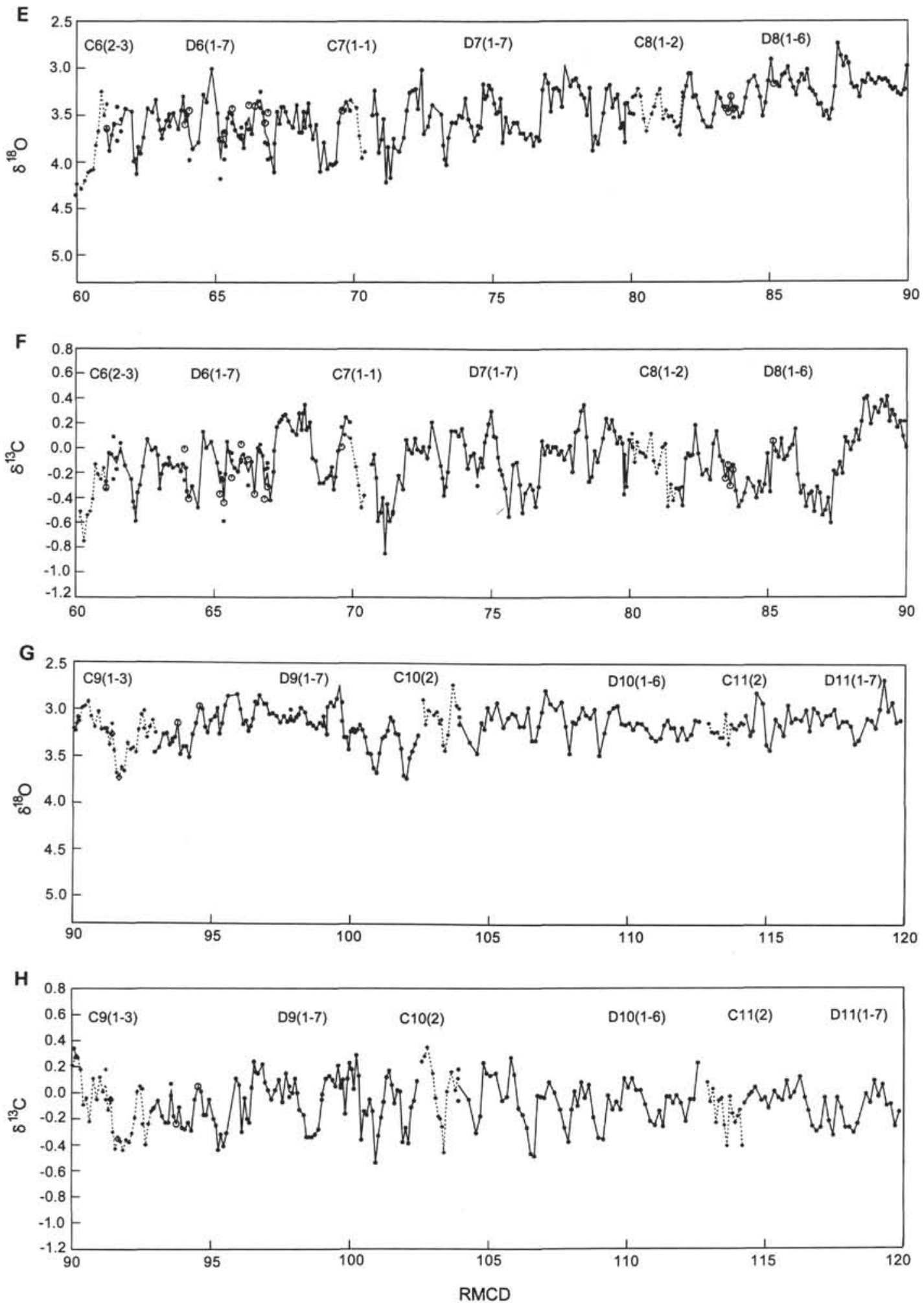

Figure 5 (continued).

tionship. The relatively strong and consistent $41-k . y$. rhythm in $\delta^{13} \mathrm{C}$ suggests that variations in high-latitude organic carbon mass may be a critical contributor to the signal. In contrast, tropical climates (especially in the tropical Atlantic and Amazon region) appear to vary more strongly with the 23-k.y. precessional rhythm, which dominates seasonal insolation at low latitudes (Imbrie et al., 1989).

\section{$\delta^{13} \mathrm{C}$ Gradients: Panama Basin-Pacific}

Based on modern water column information in Figure 2, it is likely that some local carbon isotope signals are present in the deep Panama Basin record from Site 677, which have been superimposed on global variations. To examine this possibility in more detail, we calculate the 

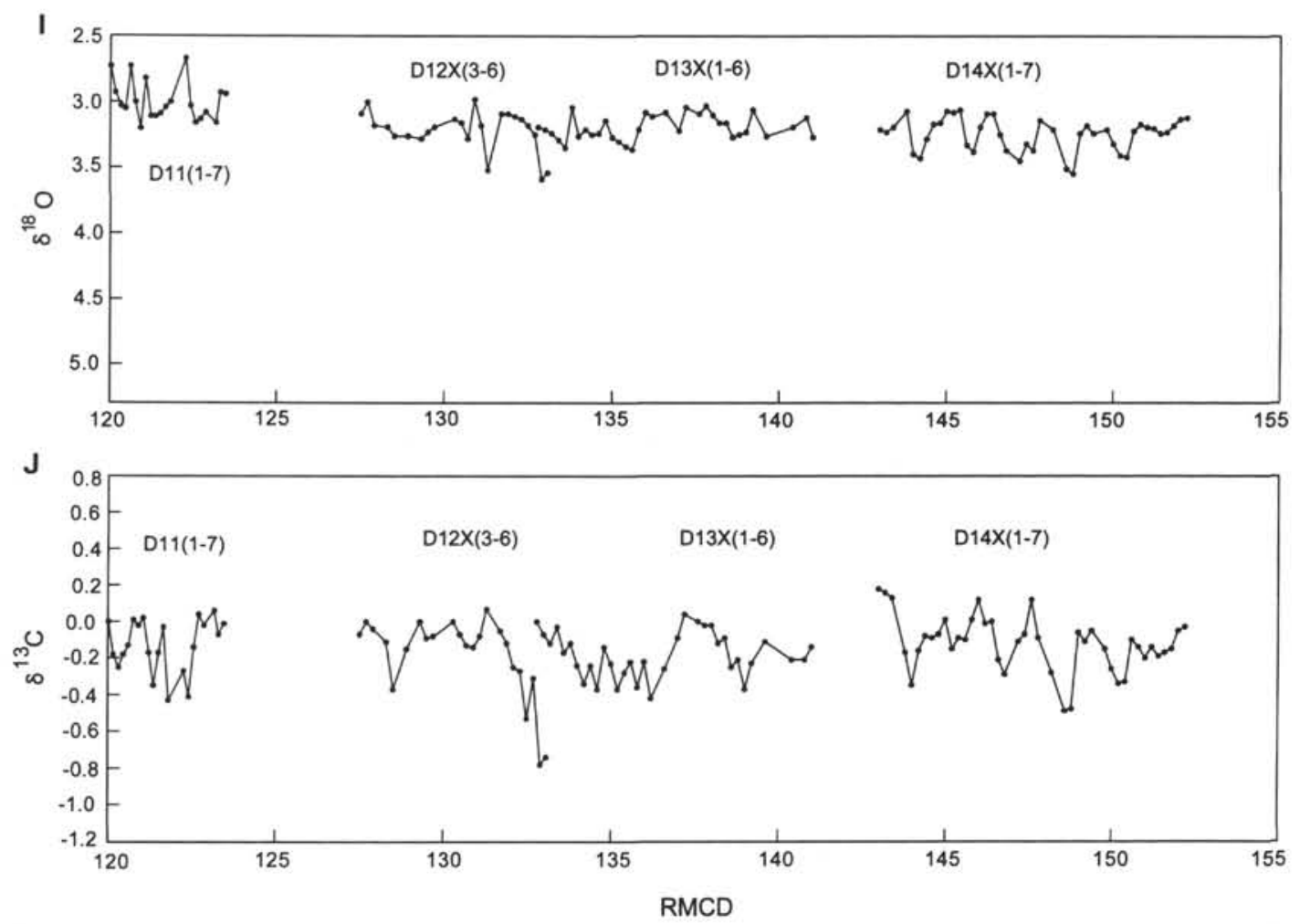

Figure 5 (continued).
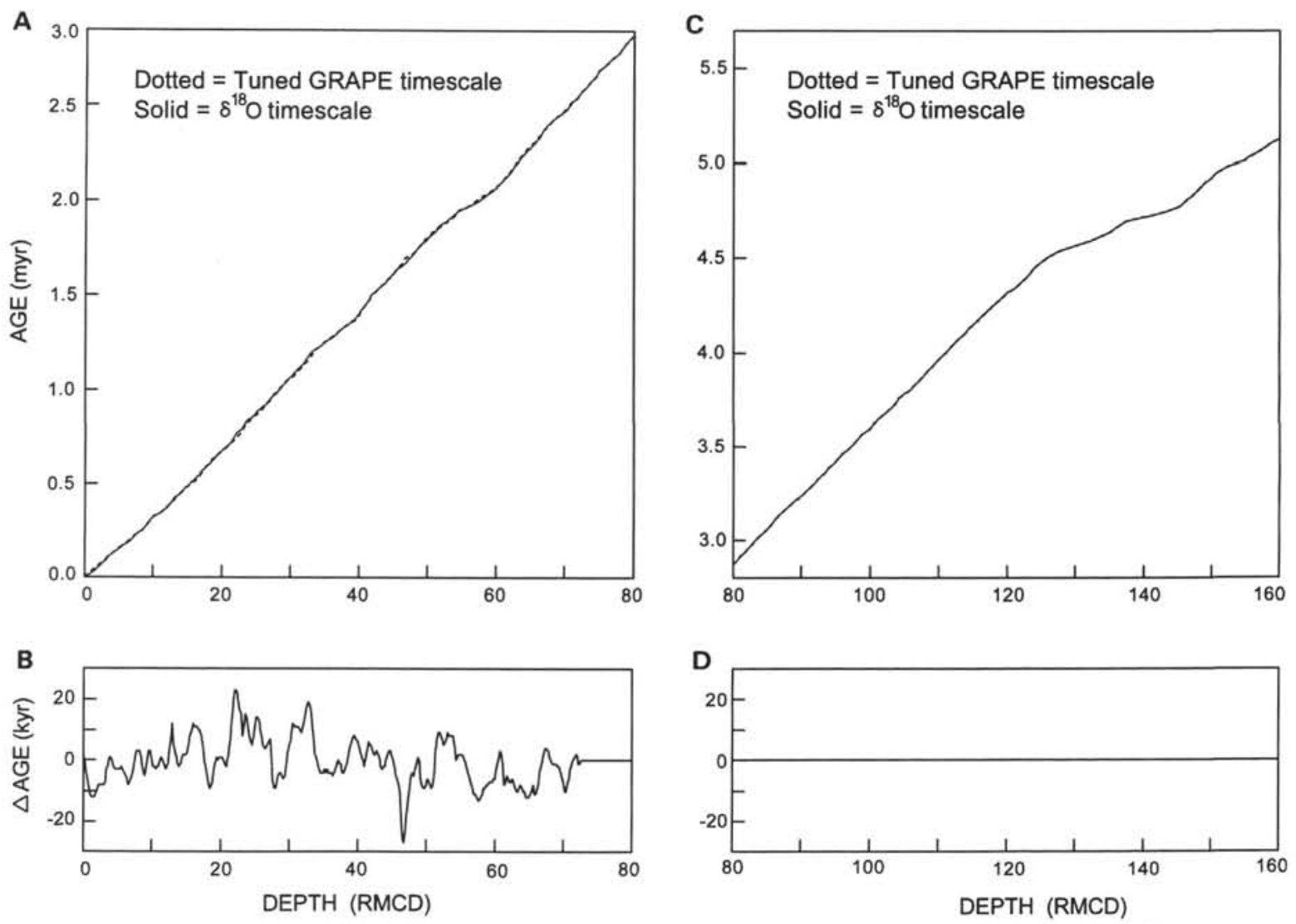

Figure 6. Age models for Site 849 . A. Depth vs. age $(0-80 \mathrm{rmcd})$. The solid line is the $\delta^{18} \mathrm{O}$ age model developed here, and the dotted line is the tuned GRAPE age model of Shackleton et al (this volume). B. Difference between the two age models in Figure 6A. Positive values indicate that the isotope age model is older than the tuned GRAPE age model. Differences are generally within $\pm 20 \mathrm{k}$.y. C. Depth vs. age $(80-160 \mathrm{rmcd})$. D. Difference between the two age models in Figure 6C. Note that below $\sim 70 \mathrm{rmcd}$, independent age models were not generated, so the difference between the two models is 0.0 . Over the interval we analyzed here, mean sedimentation rates are $28 \mathrm{~m} / \mathrm{m} . \mathrm{y}$. 

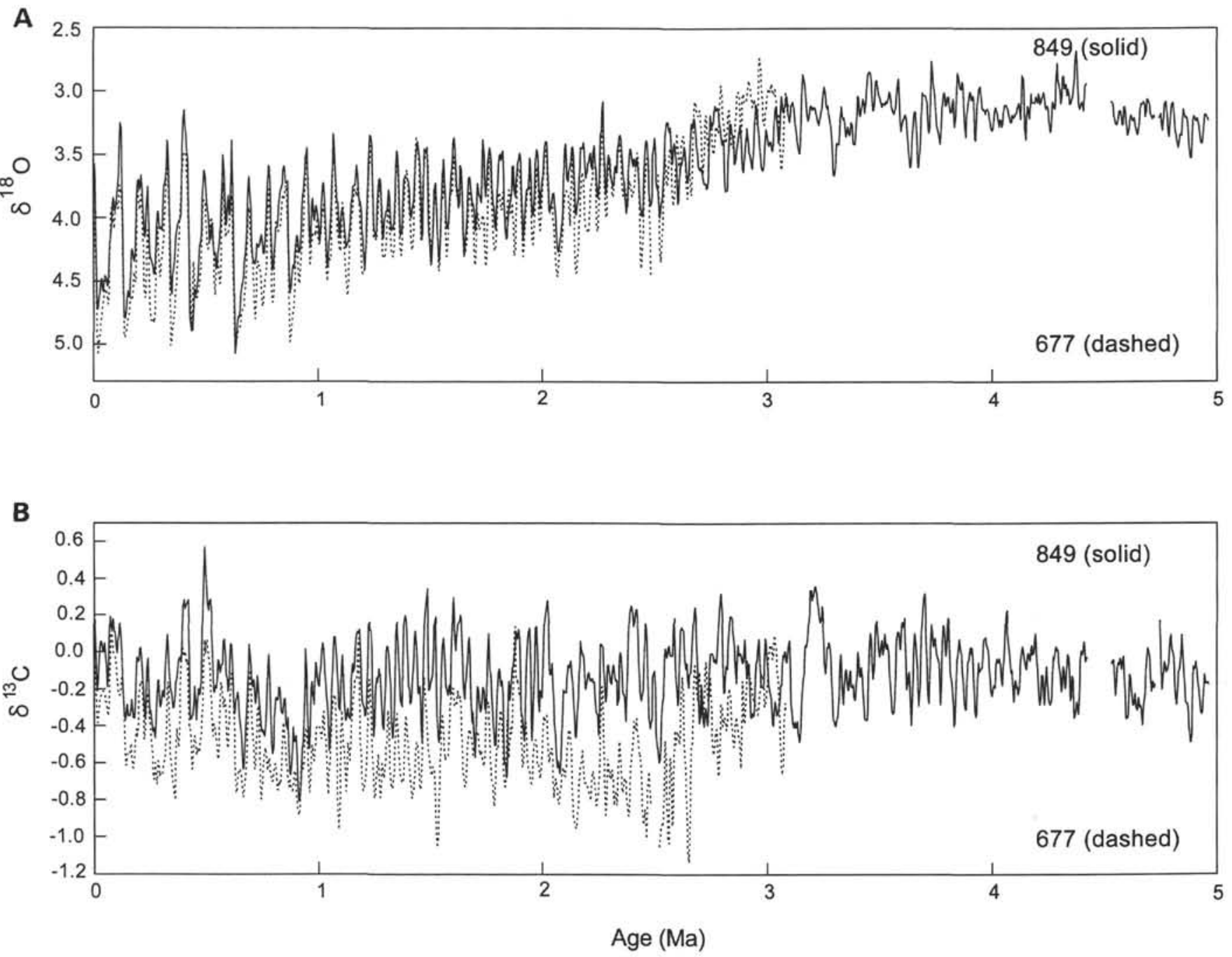

Figure 7. Isotope records from Sites 849 and 677 vs. age, after interpolation to 4-k.y. intervals and smoothing with a 19-k.y. Gaussian filter. A. $\delta^{18} \mathrm{O}$ vs. age. B. $\delta^{13} \mathrm{C}$ vs. age. No attempts were made to force correlations below $2.48 \mathrm{Ma}$, because Site 677 is discontinuous here. The record from Site 849 is essentially continuous over the full transition from mid-Pliocene warmth (3.4-4.4 Ma) to the late Pleistocene glacial extremes.

$\delta^{13} \mathrm{C}$ difference between Panama Basin Site 677 and Pacific Ocean Site 849 (Fig. 10), $\Delta \delta^{13} \mathrm{C}_{(\mathrm{PB}-\mathrm{P})}$. When making this difference calculation, we first interpolated both records to constant sampling intervals of 4 k.y., using a Gaussian smoothing window 19 k.y. wide. The interpolated, smoothed records are shown in Figure 10A. Where less than two data points exist within a smoothing window, the record has been left blank and the isotopic difference was not calculated.

The variance in $\Delta \delta^{13} \mathrm{C}_{(\mathrm{PB} \cdot \mathrm{P})}\left(0.037 \% \mathrm{o}^{2}\right)$ is large, nearly the same as the variance in either the $\delta^{13} \mathrm{C}$ record from either Site $677\left(0.049 \% 0^{2}\right)$ or Site $849\left(0.047 \% o^{2}\right)$. It is significantly greater than the variance expected from conservative estimates of random analytical noise that exists in any difference between records $\left(0.020 \% 0^{2}\right)$. Clearly the local signals in the Panama Basin are great enough to preclude the use of the Site 677 record as a proxy for global $\delta^{13} \mathrm{C}$. The $\delta^{13} \mathrm{C}$ difference between sites is almost always negative, reflecting lower $\delta^{13} \mathrm{C}$ values in the Panama Basin than in the open Pacific because of degradation of low- $\delta^{13} \mathrm{C}$ organic matter in the Panama Basin. A significant longterm trend can be seen in the $\delta^{13} \mathrm{C}$ difference record (Fig. 10B). Over the last 300 k.y., the average $\delta^{13} \mathrm{C}$ difference between Sites 849 and 677 is $-0.2 \%$ (about the same as the modern value), whereas for the period from 2.2 to $2.5 \mathrm{Ma}$, the average is $-0.6 \%$. In some parts of the record, such as near 1.5 and $2.4 \mathrm{Ma}$, the $\delta^{13} \mathrm{C}$ gradients between the Panama Basin and the deep Pacific Ocean reached $-1.0 \%$. Using modern relationships of oxygen and $\delta^{13} \mathrm{C}$ in the eastern Pacific (Kroopnick, 1974), this $\delta^{13} \mathrm{C}$ contrast suggests that Panama Basin bottom waters approached anoxia at these times. It is difficult, however, to constrain the oxygen level with certainty, because the point of anoxia recorded by $\delta^{13} \mathrm{C}$ within the basin depends on both the concentration of oxygen in source waters outside the basin, and the $\delta^{13} \mathrm{C}$ of organic matter decaying in the basin, and these values only partially known in the past.

To explore what processes may drive such large differences in $\delta^{13} \mathrm{C}$ between the Panama Basin and the Pacific, we consider a simple one-box model that calculates the $\delta^{13} \mathrm{C}$ gradient between the deep Panama Basin and the open Pacific Ocean at equivalent depths $\left(\Delta \delta^{13} \mathrm{C}_{(\mathrm{PB}-\mathrm{P})}\right)$, for variations in water residence times and upper ocean export productivity. Figure 11 shows this box model structure.

The volume of the Panama Basin deeper than $1.9 \mathrm{~km}$ is $4.4 \times 10^{5}$ $\mathrm{km}^{3}$. Depths of the basin are typically $3100-4000 \mathrm{~m}$, whereas ridges around the basin average depths of 1000-1500 m (Van Andel et al., 1971). Primary ventilation of water is through the Peru Trench, with a sill depth of about $2900 \mathrm{~m}$ (Laird, 1971; Lonsdale, 1977), but the entire basin is relatively isolated from the open Pacific below $2 \mathrm{~km}$ depth. The water residence time in the basin is relatively short, about 

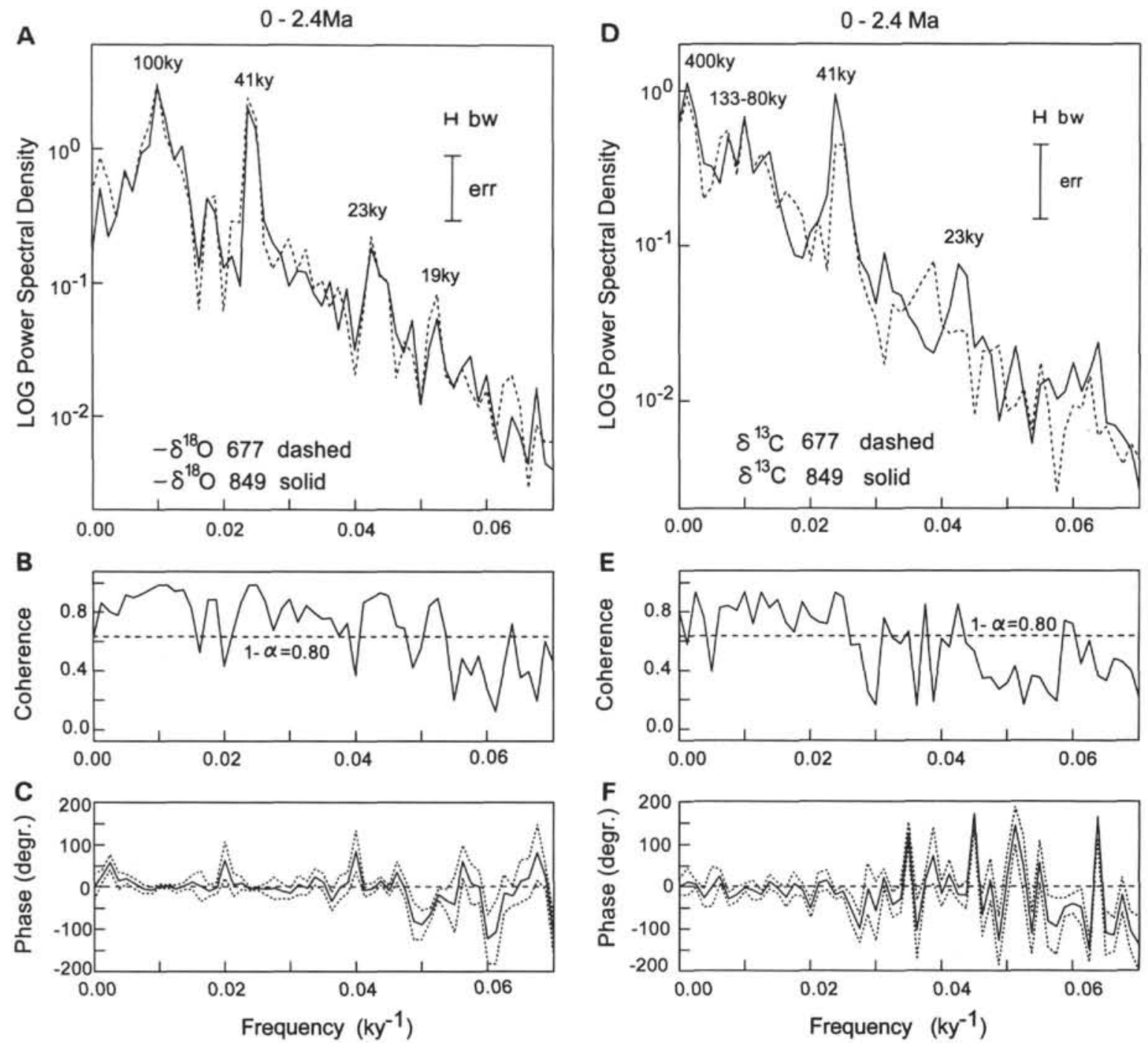

Figure 8. Spectra and cross spectra comparing the $\delta^{18} \mathrm{O}$ and $\delta^{13} \mathrm{C}$ records between Sites 849 and 677 from 0 to 2.4 Ma. The bandwidth (bw) is 0.0017 k.y. ${ }^{1}$. A. Power spectra. B. Coherency spectrum, between $\delta^{18} \mathrm{O}$ in Sites 849 and 677 . Values higher than the dashed line are significant at the $80 \%$ confidence level. C. Phase spectrum, $\delta^{18} \mathrm{O}$ in Sites 849 and 677 . Dashed lines outline $80 \%$ confidence envelope. Positive phase indicates Site 849 lags Site 677. All coherent bands are essentially in phase. D. Power spectra. E. Coherency spectrum, $\delta^{13} \mathrm{C}$ in Sites 849 and 677. F. Phase spectrum, $\delta^{13} \mathrm{C}$ in Sites 849 and 677.

40-50 yr (Lonsdale, 1977). This rapid flushing is driven by the intense hydrothermal heat flow into the basin (Detrick et al., 1974), which raises the temperature and thus lowers the density of deep water in the Panama Basin relative to that at equivalent depths just outside the basin.

In the box model, water outside the basin (which is the source water for ventilation) has a $\delta^{13} \mathrm{C}$ value fixed at $0.0 \%$, and a $\Sigma \mathrm{CO}_{2}$ value of $2300 \mu \mathrm{m} \mathrm{kg}^{-1}$. We set advection so that the modern water residence time in the basin $\tau_{0}=42 \mathrm{yr}$ (Lonsdale, 1977). Vertical diffusion is also included for exchange with overlying waters, with diffusivity of $0.3 \mathrm{~cm}^{2} \mathrm{~s}^{-1}$ between depths of 1.9 and $3.1 \mathrm{~km}$, but this term is small relative to the advection and may be ignored. The modern influx and oxidation of low- $\delta^{13} \mathrm{C}$ organic matter, $J_{0}$ is $\sim 3.3$ $\mathrm{gC} / \mathrm{m}^{2} / \mathrm{yr}$, based on sediment trap data at the $2400-\mathrm{m}$ depth (Honjo et al., 1992). The organic matter decaying in the deep Panama Basin has a $\delta^{13} \mathrm{C}$ value of $-21 \%$ (Pedersen et al., 1991), and for the purpose of this model we assume it stays constant through time. We ignore the contributions of carbon from hydrothermal venting in the Panama Basin (with a mantle $\delta^{13} \mathrm{C}$ of $-6 \%$; Des Marais, 1985). We justify this by estimating volcanic carbon flux from heat-flow data, knowing the total heat flow is $1.5 \times 10^{18} \mathrm{cal} / \mathrm{yr}$ (Detrick et al., 1974), the enthalpy $/{ }^{3} \mathrm{He}$ ratio is $7.6 \times 10^{-8} \mathrm{cal} /$ atom (Craig and Lupton, 1981), and the $\mathrm{C} /{ }^{3} \mathrm{He}$ ratio is $1.4 \times 10^{9}$ in the Galapagos region (Des Marais, 1985). This yields an estimate for the volcanic carbon flux of $5 \times 10^{10}$ $\mathrm{gC} / \mathrm{yr}$ in the Panama Basin, nearly 2 orders of magnitude less than the degradation of organic carbon in the deep basin $\left(2 \times 10^{12} \mathrm{gC} / \mathrm{yr}\right)$. In spite of the rapid flushing of water in the basin, this organic carbon flux is sufficient to lower the $\delta^{13} \mathrm{C}$ value of $\Sigma \mathrm{CO}_{2}$ in the model by $0.15 \%$ relative to values outside the basin, roughly consistent with water column data (Fig. 2).

To examine the sensitivity of the model to changing circulation and productivity, we solve the model for $\Delta \delta^{13} \mathrm{C}_{(\mathrm{PB}-\mathrm{P})}$ over a range of water residence times and organic carbon fluxes relative to modern values (Fig. 12). With a tripling of either $J$ or $\tau$, the $\delta^{13} \mathrm{C}$ gradient would also roughly triple, to a value of $-0.45 \%$. Tripling both $J$ and $\tau$ would increase the $\delta^{13} \mathrm{C}$ gradient by a factor of about 9 , to $-1.35 \%$.

Thus, to explain the long-term variations in $\Delta \delta^{13} \mathrm{C}_{(\mathrm{PB}-\mathrm{P})}$ observed in Figure 10, either the Panama Basin was more isolated and water residence times longer in the earlier period, or average productivity over the basin was much higher in this older interval than in the late 
Pleistocene interval. Major changes in the volume or ventilation of Panama Basin associated with sequential closing of the Panamanian Isthmus (completed between 3 and 4 m.y. ago; Keigwin, 1982), might induce local $\delta^{13} \mathrm{C}$ signals in the basin by changing deep-water residence times or productivity of overlying surface waters. Christie et al. (1992) inferred surprisingly rapid tectonic subsidence of parts of the Carnegie Ridge in the last few million years. Holding other variables (such as geothermal heating) constant, this would increase ventilation of the deep Panama Basin through time and thus drive local $\delta^{13} \mathrm{C}$ toward that of the open Pacific, as observed. It is likely that longterm tectonic control of the shape and size of the Panama Basin or its bounding ridges would induce only gradual change in $\Delta \delta^{13} \mathrm{C}_{(\mathrm{PB}-\mathrm{P})}$.

Shorter period variations cannot be explained by tectonics. Were the benthic foraminifer $\delta^{13} \mathrm{C}$ gradient between the Panama Basin and the deep Pacific to covary with surface-ocean signals or ice-age rhythms, then the most likely cause of local $\delta^{13} \mathrm{C}$ change in the basin would be changing productivity of near-surface waters. Independent evidence exists for changing productivity over the Panama Basin, with glacial productivity perhaps several-fold higher than modern values (Pedersen, 1983). Variations in water residence time most likely would respond to changes in hydrothermal heating in the basin, which is probably random and unrelated to ice-age rhythms. To distinguish between the productivity and hydrothermal hypotheses, we ask whether the shorter term variations in $\Delta \delta^{13} \mathrm{C}_{(\mathrm{PB}-\mathrm{P})}$ are random or related systematically to rhythmic climate changes of the ice ages. Spectra and cross spectra between $\Delta \delta^{13} \mathrm{C}_{(\mathrm{PB}-\mathrm{P})}$ and $-\delta^{18} \mathrm{O}$ (Pacific) over the last $2.4 \mathrm{Ma}$ reveal no concentrations of variance in $\Delta \delta^{13} \mathrm{C}_{(\mathrm{PB}-\mathrm{P})}$ that stand out as spectral peaks greater than the error of estimate (Fig. 13A), and no significant coherence with the dominant spectral bands of $\delta^{18} \mathrm{O}$ (Fig. 13B). The spectrum of $\Delta \delta^{13} C_{(\mathrm{PB}-\mathrm{P})}$ is to first approximation "red" noise. This is also the case when the spectrum of $\Delta \delta^{13} \mathrm{C}_{(\mathrm{PB}-\mathrm{P})}$ is calculated only within the late Quaternary interval. This suggests either that much of the variation in the Panama Basin to Pacific $\delta^{13} \mathrm{C}$ gradient is driven by changes in the rate of basin flushing, with no obvious link to global climate or orbital variation, or that our assumption that productivity changes are systematically related to climate change was wrong.

\section{$\delta^{13} \mathrm{C}$ Gradients: Atlantic-Pacific}

If the Site $849 \delta^{13} \mathrm{C}$ record is taken as the most representative measure of Pacific deep-water $\delta^{13} \mathrm{C}$, how does this change our view of the history of global deep-ocean circulation? To address this question, we first compare the isotope record from Site 849 with the North Atlantic Ocean record from Site 607 (Raymo et al., 1990, with additions by Raymo et al., 1992). The record from Site 607 contains analyses from the genus Uvigerina in the upper $\sim 300$ k.y. (from nearby piston Core V30-97 analyzed by Mix and Fairbanks, 1985), and we have not attempted to remove those analyses from the record. To make this comparison, we placed the Site 607 record on the same time scale as the Site 849 and 677 records, using the inverse correlation methods discussed above (the revised time scale for Site 607 is tabulated in Appendix E).

Figure 14 illustrates the $\delta^{18} \mathrm{O}$ and $\delta^{13} \mathrm{C}$ isotope records from Atlantic Site 607 and Pacific Site 849 on the Site 849 time scale. The two $\delta^{18} \mathrm{O}$ records (Fig. 14A) are exceptionally coherent with each other. The two $\delta^{13} \mathrm{C}$ records are significantly different from each other. The Pacific site almost always has $\delta^{13} \mathrm{C}$ values lower than the Atlantic site, consistent with earlier studies.

To examine the interocean $\delta^{13} \mathrm{C}$ contrast, we calculated the Atlantic-Pacific differences $\Delta \delta^{13} \mathrm{C}_{(\mathrm{A}-\mathrm{P})}$ with the same smoothing and interpolation used for the Panama Basin-Pacific comparisons. Smoothed versions of the Site 849 and $607 \delta^{13} \mathrm{C}$ records are shown in Figure $15 \mathrm{~A}$. We calculated the interocean differences in two ways: first, the $\delta^{13} \mathrm{C}$ differences between Atlantic Site 607 and Panama Basin Site 677 are shown as a dashed line in Figure 15B; second, we made a similar calculation of the $\delta^{13} \mathrm{C}$ differences between Atlantic Site 607 and Pacific Site 849, which is shown as a solid line in Figure 15B.
We did not make the "\%ATL/PAC" calculation of Raymo et al. (1990), which involves the relative position of $\delta^{13} \mathrm{C}$ in Site 607 between the data from a Pacific site and a shallower Atlantic site (DSDP Site $552,56^{\circ} \mathrm{N}, 23^{\circ} \mathrm{W}, 2301 \mathrm{~m}$ depth). This calculation would attempt to remove the effect of changing pre-formed $\delta^{13} \mathrm{C}$ in the NADW source water. Although we agree in principle that this calculation is a useful way to look at the data, we avoided it here for three reasons. First, this double-difference calculation tends to amplify analytical noise, which makes all but the largest amplitude signals impossible to interpret. Second, it is not clear that Site 552 always monitors pure northern Atlantic source waters (deMenocal et al., 1992). Third, the data from Site 552 are not sufficiently complete to construct a long, continuous time series of isotope differences. Raymo et al. (1990) were left with some large gaps in their \%ATL/PAC calculation, and we sought to avoid these gaps as much as possible.

The largest amplitude variations in the $\delta^{13} \mathrm{C}$ contrast between the oceans occur between $\sim 0.4$ and 0.9 Ma (Fig. 15B). Most likely, this results from large variations in the influence of low-nutrient, high$\delta^{13} \mathrm{C}$ northern Atlantic waters in the deep Atlantic Ocean. These findings are completely consistent with the inferences of Raymo et al. (1990). Furthermore, for these results, it does not matter whether Site 849 or Site 677 is used to represent the Pacific Ocean in the calculation. With the new data from Site 849 , however, $\Delta \delta^{13} \mathrm{C}_{(\mathrm{A}-\mathrm{P})}$ values as low as the last glacial maximum occur back to $\sim 1.5 \mathrm{Ma}$. Thus, variations in Atlantic water masses as large as those of the latest Pleistocene must have been common before the expanded glacial cycles of the last million years.

The interval from about 1.3 to $2.1 \mathrm{Ma}$ stands out as having mean Atlantic-Pacific $\delta^{13} \mathrm{C}$ contrast values larger than those typical for late Pleistocene interglacial events (Fig. 15B). This feature implies either (1) greater nutrient contrast between the ocean basins at that time, (2) greater pre-formed $\delta^{13} \mathrm{C}$ in NADW source waters relative to nutrients, or (3) lower pre-formed $\delta^{13} \mathrm{C}$ in waters feeding the deep Pacific. The nutrient-contrast scenario might reflect a greater role for import of nutrient-poor upper ocean waters relative to nutrient-rich bottom waters into the Atlantic, which combine to balance the export of deep water in the modern ocean. Were the total nutrient content of the global oceans higher at that time, this would increase the net nutrient and $\delta^{13} \mathrm{C}$ gradient between oceans without requiring changes in circulation (Boyle, 1986). The pre-formed $\delta^{13} \mathrm{C}$ scenario comes from the role of partial gas exchange in setting the $\delta^{13} \mathrm{C}$ value of source waters leaving the sea surface. Broecker and Maier-Reimer (1992) argued that, today, southern source waters to the deep Pacific (actually a mixture of Weddell Sea Bottom Water and NADW) have a preformed $\delta^{13} \mathrm{C}$ value about $0.5 \%$ higher than that in the North Atlantic. Were this contrast in pre-formed $\delta^{13} \mathrm{C}$ lower, a greater Atlantic-Pacific $\delta^{13} \mathrm{C}$ gradient would result.

Before 2.1 Ma, the mean Atlantic-Pacific $\delta^{13} \mathrm{C}$ difference calculated using Site 849 to represent the Pacific is similar to that of late Pleistocene interglacial extremes, but lower than the mean difference between 1.3 and $2.1 \mathrm{Ma}$. The values of $\Delta \delta^{13} \mathrm{C}_{(\mathrm{A}-\mathrm{P})}$ between 2.1 and 3.2 $\mathrm{Ma}$ often are within the range of the glacial and interglacial events of the last 120 k.y. (marked by horizontal dashed lines in Fig. 15B). This suggests that variations in deep circulation in the Atlantic were nearly as large during some intervals of the late Pliocene as they have been during the last glacial cycle.

The simplest scenario to explain the long-period variations in $\Delta \delta^{13} \mathrm{C}_{(\mathrm{A}-\mathrm{P})}$ is (1) that influx of northern-source water to the deep North Atlantic (analogous to modern NADW) was stronger than today on average between 1.3 and $2.1 \mathrm{Ma}$, and (2) that the earlier portions of the glacial ages (from 2.1 to $3.2 \mathrm{Ma}$ ) had a lower influx of northern source waters (but not as low as that during the late Pleistocene glacial extremes). This view contrasts with that of Raymo et al. (1992), who argued that progressive (though perhaps nonlinear) decreases in NADW formation were associated with increasing intensity of Northern Hemisphere glaciation over this interval. It also conflicts with the opposing view of Sykes et al. (1991), who inferred influx of north- 

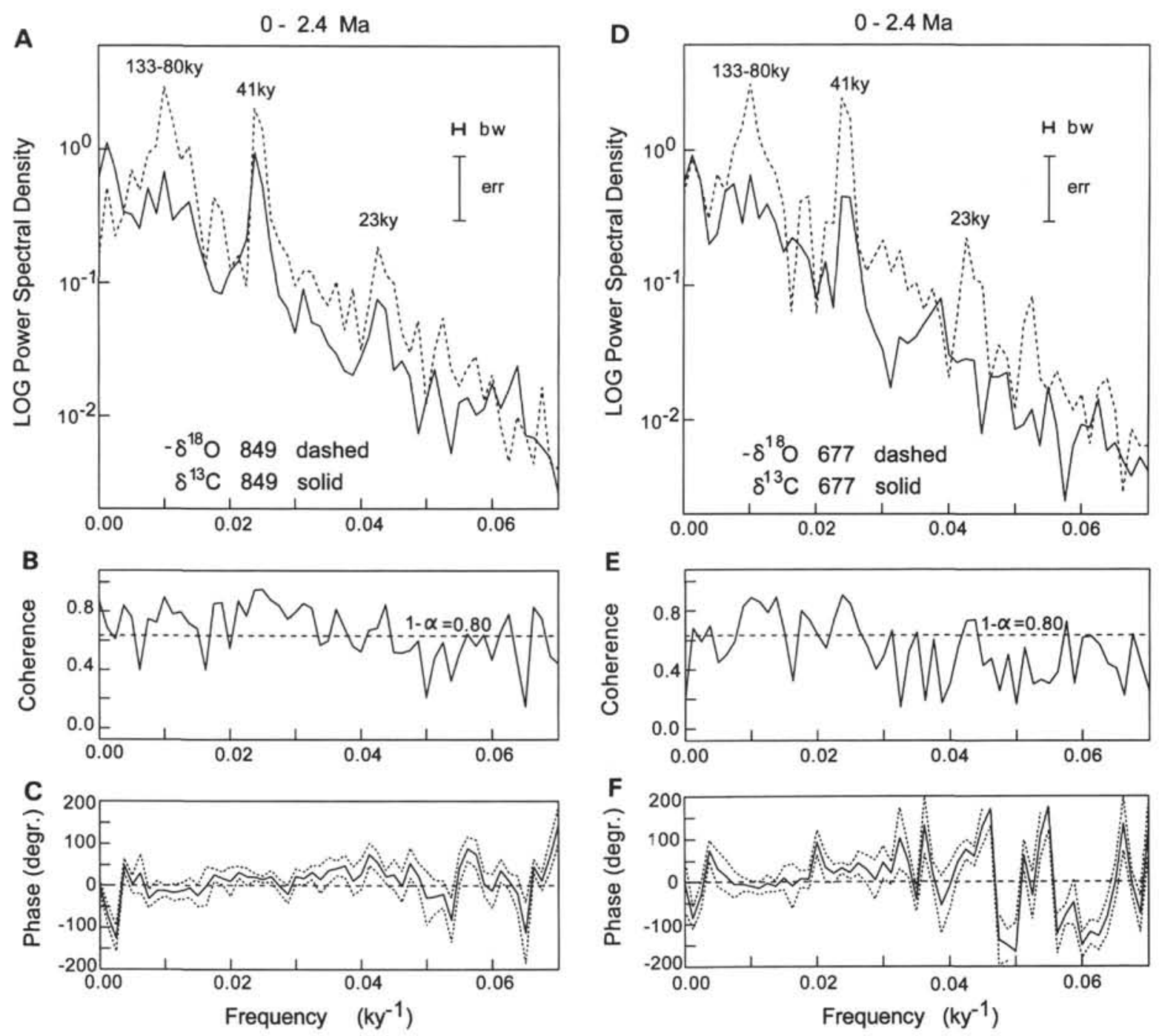

Figure 9. Spectra and cross spectra comparing the $\delta^{18} \mathrm{O}$ and $\delta^{13} \mathrm{C}$ records within Sites 849 and 677 . For the interval from 0 to $2.4 \mathrm{Ma}$, bandwidth (bw) is $0.0017 \mathrm{k.y}^{-1}$; for the interval from 2.4 to $4.42 \mathrm{Ma}$, bandwidth is $0.0025 \mathrm{k.y}^{-1}$. A. Power spectra, 0-2.4 Ma. B. Coherency spectrum, $\delta^{18} \mathrm{O}$ vs. $\delta^{13} \mathrm{C}$ in Site $849,0-2.4 \mathrm{Ma}$. Values higher than the dashed lines indicate $>80 \%$ confidence level for significant coherency. C. Phase spectrum, $\delta^{13} \mathrm{C}$ vs. $-\delta^{18} \mathrm{O}$ in Site $849,0-2.4 \mathrm{Ma}$. Dashed lines outline $80 \%$ confidence envelope. Positive phase angle (in degrees) indicates that $\delta^{13} \mathrm{C}$ lags $-\delta^{18} \mathrm{O}$. D. Power spectra, 0-2.4 Ma. E. Coherency spectrum, $\delta^{13} \mathrm{C}$ vs. $-\delta^{18} \mathrm{O}$ in Site $677,0-2.4 \mathrm{Ma}$. F. Phase spectrum, $\delta^{13} \mathrm{C}$ vs. $-\delta^{18} \mathrm{O}$ in Site 677, 0-2.4 Ma. G. Power spectra, 2.4-4.42 Ma. H. Coherency spectrum, $\delta^{13} \mathrm{C}$ vs. $-\delta^{18} \mathrm{O}$ in Site $849,2.4-4.42 \mathrm{Ma}$. I. Phase spectrum, $\delta^{13} \mathrm{C}$ vs. $-\delta^{18} \mathrm{O}$ in Site 849, 2.4-4.42 Ma.

ern-source relative to southern-source waters lower than at present at most times during the Pliocene.

Relationships among the variations in Atlantic-Pacific $\delta^{13} \mathrm{C}$ differences and $-\delta^{18} \mathrm{O}$ are explored in Figure 16. Because the character of $\Delta \delta^{13} \mathrm{C}_{(\mathrm{A}-\mathrm{P})}$ clearly evolved through time, we have divided the record into thirds before calculating spectra. Over the last 1.1 Ma (Fig. $16 \mathrm{~A}-\mathrm{C}), \Delta \delta^{13} \mathrm{C}_{(\mathrm{A}-\mathrm{P})}$ contained concentrations of variance at periods of $\geq 100$ k.y., and significant coherency with $-\delta^{18} \mathrm{O}$ in the $100-\mathrm{k} . y$. band. We did not detect a significant concentration of variance in $\Delta \delta^{13} \mathrm{C}_{(\mathrm{A}-\mathrm{P})}$ in the 41- or 23-k.y. bands over the last $1.1 \mathrm{Ma}$. A phase estimate of $24^{\circ} \pm 13^{\circ}$ in the $100-\mathrm{k} . y$. band indicates that maximal interocean $\delta{ }^{13} \mathrm{C}$ differences on average follow 3-10 k.y. after interglacial maxima (and minimal differences follow 3-10 k.y. after extreme glacial events in this band). This is slightly different from the conventional wisdom that formation rates of NADW were reduced relative to those of Antarctic Bottom Water (AABW) in the deep Atlantic Ocean coincident with glacial maxima (e.g., Broecker and Denton, 1989; Raymo et al., 1990).
In the interval 1.1-2.2 Ma, the relationships between $\Delta \delta^{13} \mathrm{C}_{(\mathrm{A}-\mathrm{P})}$ and $\delta^{18} \mathrm{O}$ changed (Figs, 16D-16F). Here, the dominant variations in $\Delta \delta^{13} \mathrm{CMV}_{(\mathrm{A} \cdot \mathrm{P})}$ were at very long periods ( $>200-\mathrm{k}$.y. period), unlike those of $\delta^{18} \mathrm{O}$. The only band where coherent relationships between these variables were detected is the 41-k.y. period; and even in this band, the relationship is weak. The phase in this band $\left(-43^{\circ} \pm 16^{\circ}\right)$ indicates that maximum Atlantic-Pacific $\delta^{13} \mathrm{C}$ gradients in this interval occurred during deglacial episodes. This pattern suggests that the modulation of NADW was not always a direct, in-phase response to Northern Hemisphere ice volume. Perhaps with the smaller variations in ice volume of the early Pleistocene and late Pliocene, the direct role of insolation is more important than the role of ice-sheet modulation of winds for driving changes in large-scale ocean circulation and thus interocean $\delta^{13} \mathrm{C}$ contrast. In this case, times of relatively high seasonal contrast in insolation in the high latitudes (i.e., colder winters) would be associated with higher NADW formation. This speculation requires confirmation in further detailed study at a range of water depths in the North Atlantic. 

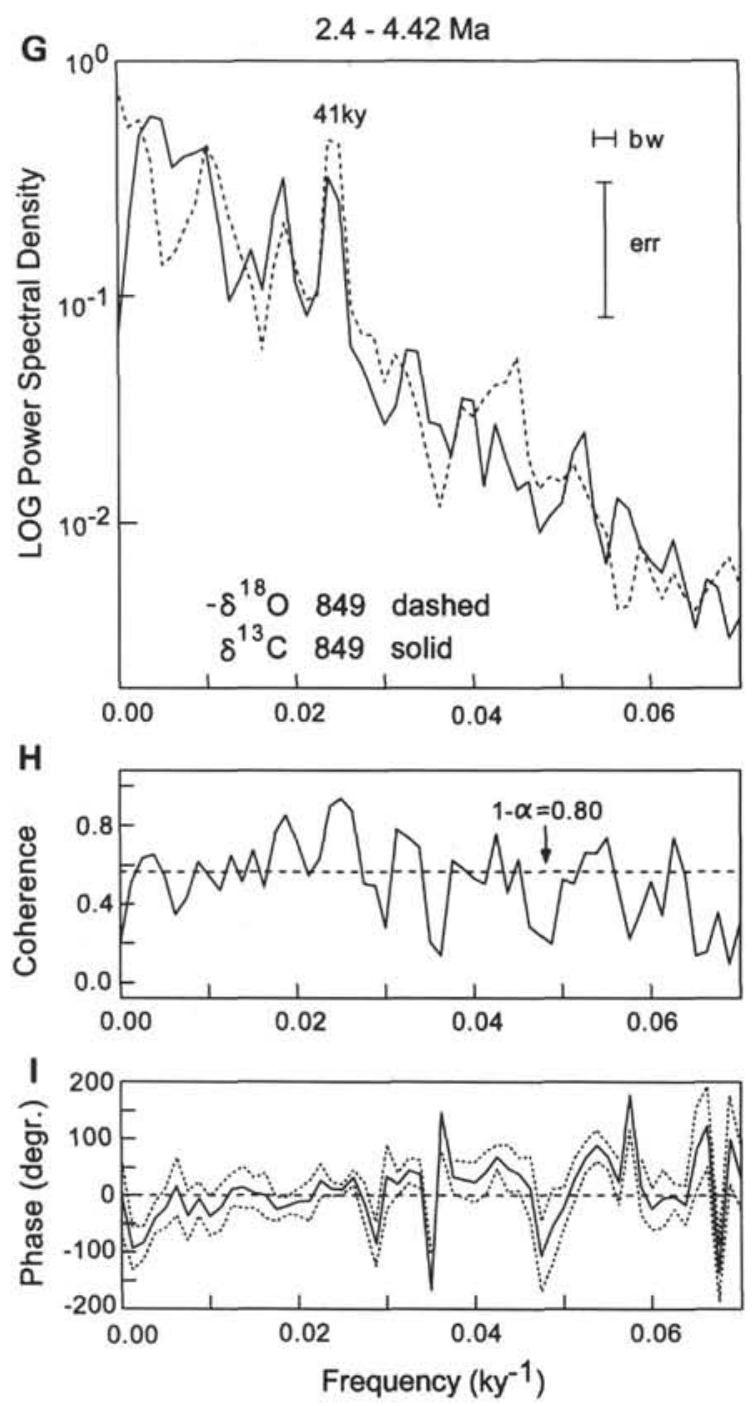

Figure 9 (continued).

In the interval older than $2.2 \mathrm{Ma}$, the variance in $\Delta \delta^{13} \mathrm{C}_{(\mathrm{A}-\mathrm{P})}$ was low enough $\left(0.029 \% \mathrm{o}^{2}\right)$ that it approached conservative estimates of analytical noise in the difference between two records $\left(0.020 \% o^{2}\right)$. With this low signal/noise ratio, we did not attempt to analyze the variability in the frequency domain. Some of the variations here may be real, however. For example, during the relatively large glacial event at $2.54 \mathrm{Ma}$ (stage 100, thought to reflect the first major glaciation in the Northern Hemisphere), $\Delta \delta^{13} \mathrm{C}_{(\mathrm{A}-\mathrm{P})}$ has attained a value more than half way between those of the Holocene and the last glacial maximum. Clearly, some of the early glacial events were associated with reduced influence of nutrient-depleted deep waters in the North Atlantic. Looking at the entire record, however, one cannot see any major change in the character of the $\Delta \delta^{13} \mathrm{C}_{(\mathrm{A}-\mathrm{P})}$ variations near $2.5 \mathrm{Ma}$, which argues against a unique link between Northern Hemisphere glaciation and deep-water formation.

\section{$\delta^{13} \mathrm{C}$ Gradients: Subantarctic-Pacific}

A further constraint on past variability of deep-ocean circulation comes from comparing the Pacific $\delta^{13} \mathrm{C}$ record from Site 849 with a record from the subantarctic portion of the Atlantic Ocean. At Site 704, a high-resolution isotope record of Cibicides wuellerstorfi is available for the interval older than $\sim 1 \mathrm{Ma}$ (Hodell and Venz, 1992), and a partial record is available at this site over the past $0.7 \mathrm{Ma}$ (Hodell, 1993). Site
704 lies in the mixing zone between modern NADW and Circumpolar Deep Water (CPDW) and is thus well placed to monitor variations in export of deep water from the Atlantic in the past.

Consistent with the treatment of other data here, we added $0.64 \%$ to the published $\delta^{18} \mathrm{O}$ data from $C$. wuellerstorfi in Site 704. We modified the published time scale in Site 704 to make it consistent with that of Pacific Site 849. To do this, we first increased the published ages of Site 704 by $6 \%$, as recommended by Hodell and Venz (1992) and Raymo et al. (1992). We then made minor adjustments to the age assignments at Site 704 to improve the fit between the $\delta^{18} \mathrm{O}$ record at this site with those of Site 849 between 1.1 and $2.4 \mathrm{Ma}$. The resulting isotope records are illustrated in Figure 17. In most cases, the match of $\delta^{18} \mathrm{O}$ records between Site 704 and Site 849 is good. Hodell and Venz (1992) suggest, based on diatom biostratigraphy, that a hiatus is present at Site 704 at about $166 \mathrm{mbsf}$, which on our time scale is from 2.44 to $\sim 2.77 \mathrm{Ma}$. Below this point, the Site $704 \delta^{18} \mathrm{O}$ values are higher than those of Site 849 by an average of $0.6 \%$. This isotopic offset, if real, would suggest that deep Pacific water at a depth of $\sim 3850 \mathrm{~m}$ was $2^{\circ}-3^{\circ} \mathrm{C}$ warmer, or considerably fresher, than deep waters of the subantarctic at a depth of 2500 m during that time interval. The similarity of $\delta^{18} \mathrm{O}$ values from North Atlantic Site 607 with those of Pacific Site 849 at this time (Fig. 15A), however, make the anomalously high $\delta^{18} \mathrm{O}$ values at Site 704 difficult to explain. It would require that both the deep North Atlantic and the deep Pacific oceans were warmer and/ or fresher (and thus less dense) than shallower locations of the deep subantarctic ocean. This is physically implausible. A possible explanation is that the duration of the hiatus in Site 704 was overestimated; however, in the absence of other supporting data, we use the stratigraphy as given by Hodell and Venz (1992) and do not attempt to force isotopic correlations below the suspected hiatus.

The $\delta^{13} \mathrm{C}$ values from Site 704 are shown along with those of North Atlantic Site 607 and Pacific Site 849, after all records have been interpolated to 4-k.y. intervals and smoothed with a 19-k.y. Gaussian filter, as discussed above (Fig. 18A). Carbon isotopic differences between subantarctic and Pacific $\Delta \delta^{13} \mathrm{C}_{(\mathrm{S} \text {-P) }}$ and North Atlantic and Pacific $\Delta \delta^{13} \mathrm{C}_{(\mathrm{A}-\mathrm{P})}$ are shown together in Figure 18B. On average, subantarctic $\delta{ }^{13} \mathrm{C}$ values are lower than Pacific values from $\sim 1.1$ to 1.7 $\mathrm{Ma}$. They are roughly similar to Pacific values from 1.7 to $2.9 \mathrm{Ma}$ (but, of course, they are not constrained in the hiatus from $\sim 2.44$ to $\sim 2.77 \mathrm{Ma}$ in Site 704). Subantarctic $\delta^{13} \mathrm{C}$ values are much higher than Pacific values (but similar to Atlantic values) below 2.9 Ma. Significant variability exists around these general trends.

The younger portion of the $\Delta \delta^{13} \mathrm{C}_{(\mathrm{S}-\mathrm{P})}$ record is reminiscent of the late Pleistocene glacial intervals, in which Antarctic $\delta^{13} \mathrm{C}$ values are lower than deep Pacific values (Curry et al., 1988). This pattern appears to hold back to at least $1.7 \mathrm{Ma}$ and occurs at times throughout the record (Fig. 18B). For much of the time considered here, $\Delta \delta^{13} \mathrm{C}_{(\mathrm{S}-\mathrm{P})}$ was much lower than the Holocene gradient (marked by the solid horizontal line in Fig. 18B), suggesting less influence of high- $\delta^{13} \mathrm{C}$ northern source waters at Site 704 than at present. There must have been little or no export of high- $\delta^{13} \mathrm{C}$ NADW into the circumpolar Antarctic at Site 704 during times of extremely low $\Delta \delta^{13} \mathrm{C}_{(\mathrm{S}-\mathrm{P})}$. To achieve lower $\delta^{13} \mathrm{C}$ in the Antarctic than in the Pacific at these times, either a different source of low-nutrient and/or high pre-formed $\delta^{13} \mathrm{C}$ Pacific deep water must have existed (perhaps in the North Pacific), or the circumpolar waters must have been sufficiently isolated from Pacific waters that they acted as a local nutrient trap (Imbrie et al., 1992). Obtaining high-resolution benthic foraminifer isotope data from the North Pacific, as well as a transect of isotope data across the circumpolar Antarctic, should help to constrain these options.

In the interval older than $\sim 2.9 \mathrm{Ma}$ (noting the age uncertainty caused by poor correlation of the $\delta^{18} \mathrm{O}$ records here), the $\delta^{13} \mathrm{C}$ values from the deep North Atlantic and the subantarctic are similar, and the $\delta^{13} \mathrm{C}$ gradient from both areas to the central Pacific is about $1 \%$. This suggests strong export of NADW-like water to the Antarctic much of the time before $2.9 \mathrm{Ma}$, which is consistent with the inferences of Hodell and Venz (1992) and Raymo et al. (1992). 
A

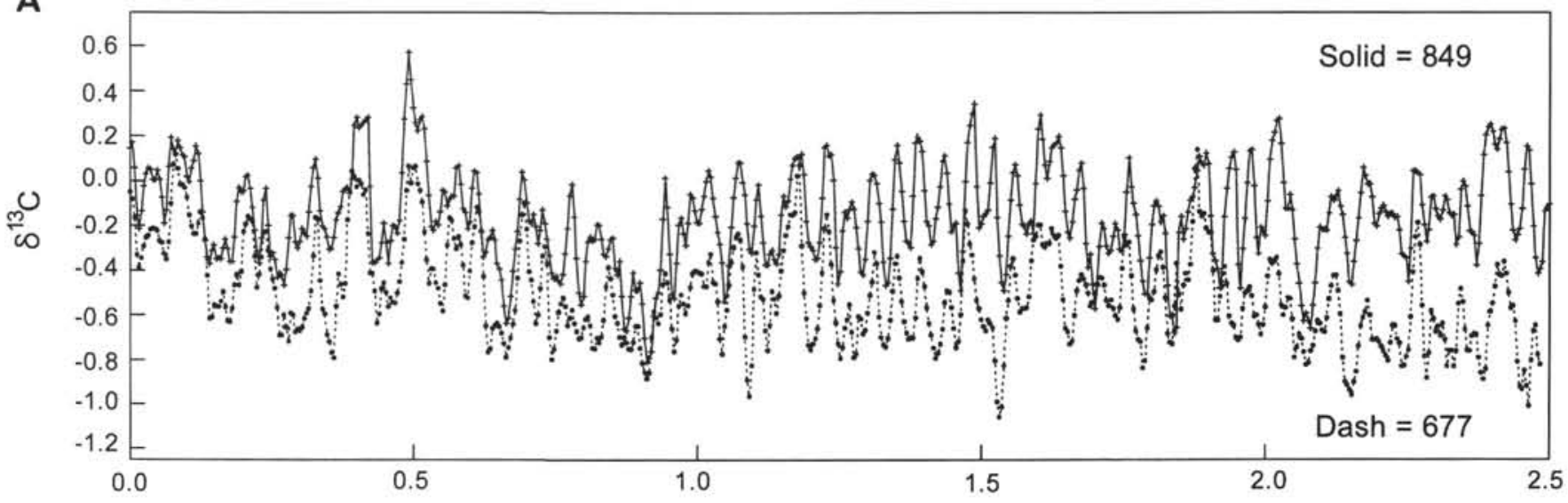

B

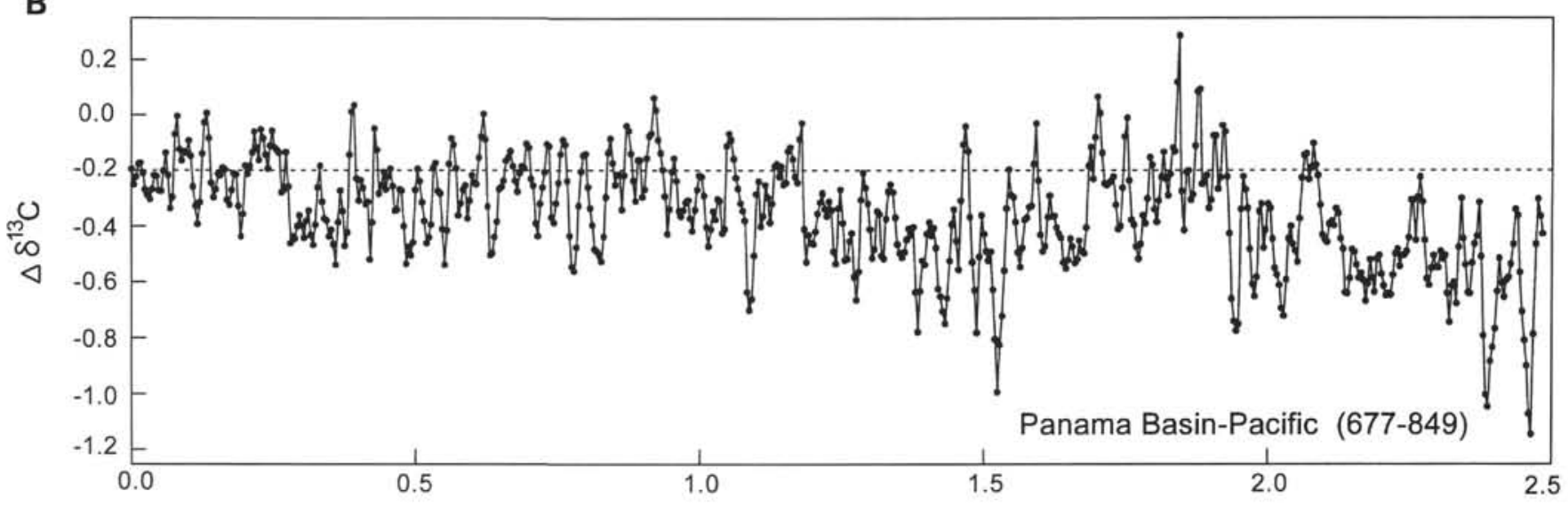

Age (Ma)

Figure 10. A. $\delta^{13} \mathrm{C}$ in Sites 849 and 677, after interpolation to 4-k.y. intervals and smoothing with a 19-k.y. Gaussian filter. B. Isotopic difference between the deep Pacific Ocean west of the East Pacific Rise and the Panama Basin $\left(\Delta \delta^{13} \mathrm{C}_{(\mathrm{PB}-\mathrm{P})}\right)$. Horizontal dashed line is the modern (core top) difference between the sites.

The change from high to low export of NADW-like Atlantic deep water, which appears to occur near $2.9 \mathrm{Ma}$ (and perhaps again near $2.0 \mathrm{Ma}$ ) was not accompanied by any change in the Atlantic-Pacific $\delta^{13} \mathrm{C}$ gradient (Fig. 18B). Curiously, the interval of highest average $\Delta \delta^{13} \mathrm{C}_{(\mathrm{A}-\mathrm{P})}$, from $\sim 1.3$ to $\sim 2.1 \mathrm{Ma}$, which most likely reflects dominance of low-nutrient northern source waters within the North Atlantic, was associated with low, or even negative, Antarctic-Pacific gradients. This suggests little or no NADW export to the CPDW. Hodell and Venz (1992) and Raymo et al. (1992) examined the subantarctic data and favored the view that the record was driven primarily from the Northern Hemisphere, by decreasing rates of NADW formation after $2.7 \mathrm{Ma}$ (the same as $2.9 \mathrm{Ma}$ on our time scale). They argued that Site 704 was especially sensitive to mixing between NADW and CPDW, and that this might account for larger amplitude signals here than in the deep North Atlantic. We would accept this inference were the patterns of $\delta^{13} \mathrm{C}$ change similar in the two locations relative to the Pacific. But our finding here that $\Delta \delta^{13} \mathrm{C}_{(\mathrm{S}-\mathrm{P})}$ and $\Delta \delta^{13} \mathrm{C}_{(\mathrm{A}-\mathrm{P})}$ do not covary at all, presents a problem for an interpretation that drives both signals from the North Atlantic.

We think a second mechanism must exist, operating independently from the Northern Hemisphere ice sheets to allow the Southern Ocean to evolve so differently from the deep North Atlantic. One possible mechanism was proposed in the modeling study of Toggweiler and Samuels (1993). They argued that modern export of Atlantic deep waters into the circumpolar Antarctic is presently driven from the south, by westerly wind stress at the latitude of the southern tip of
South America (Trenberth et al., 1990). Today, the axis of maximum westerly winds is a few degrees north of the Drake Passage. Were this axis a few degrees farther south during warmer climatic episodes near $3 \mathrm{Ma}$, it would tend to draw more high- $\delta^{13} \mathrm{C}$ NADW southward to Site 704. As the wind axis migrated north, the Atlantic outflow would diminish and, along with it, $\Delta \delta^{13} \mathrm{C}_{(\mathrm{S} \text {-P) }}$ would decrease.

Formation of deep water in the North Atlantic may have increased as the Northern Hemisphere cooled in the early stages of glaciation as envisioned by Raymo et al. (1992). However, if Toggweiler and Samuels (1993) are correct, these waters would not have reached subantarctic Site 704 unless Southern Hemisphere winds were favorable. With weaker wind forcing in the south, we speculate that Atlantic deep waters would either leak into the Indian Ocean along the South African margin, or recirculate within the Atlantic, with relatively little export into the circumantarctic circulation. If so, the apparent lack of covariation of the $\Delta \delta^{13} \mathrm{C}_{(\mathrm{S}-\mathrm{P})}$ and $\Delta \delta^{13} \mathrm{C}_{(\mathrm{A}-\mathrm{P})}$ records would make sense. This leaves us with several unanswered questions, however, that beg for more data acquisition and modeling of the linkage of global circulation in the Antarctic:

1. Can circumantarctic circulation be isolated from the Atlantic and Pacific sufficiently to maintain large $\delta^{13} \mathrm{C}$ (and presumably nutrient) gradients?

2. Did Southern Hemisphere westerly winds vary significantly in intensity or position, and if so, why? 


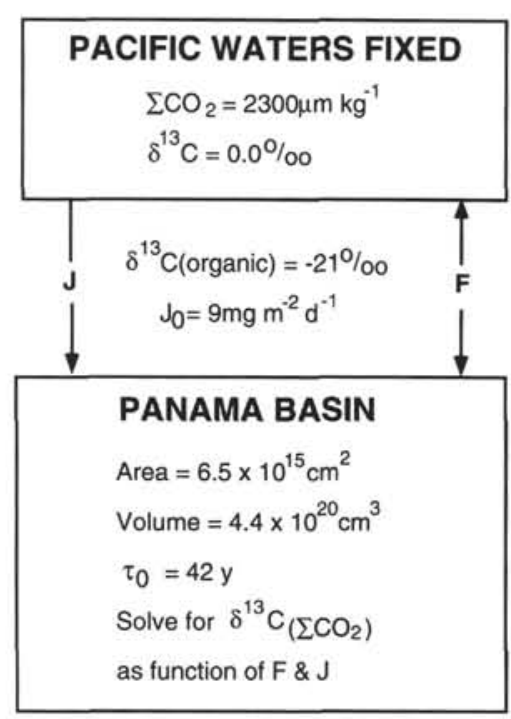

Figure 11. Box model designed to assess the sensitivity of the deep Panama Basin to influxes and oxidation of organic matter (J), and flushing of water in the basin (F). Volume (V) of the Panama Basin below $1.9 \mathrm{~km}$ is $4.4 \times 10^{5} \mathrm{~km}^{3}$, and the modern residence time of water in the basin, $\tau=V / F$, is $42 \mathrm{yr}$ (Lonsdale, 1977). At present, organic carbon degradation in the basin is $\sim 1.8 \times 10^{11}$ moles/yr (Honjo et al., 1992).

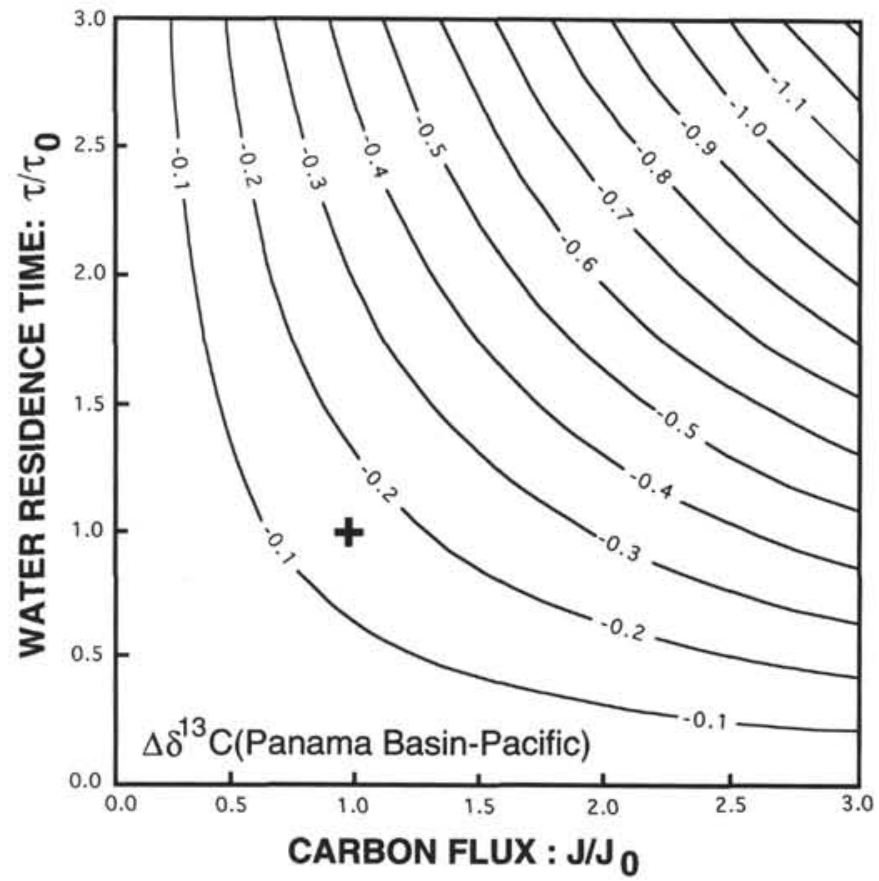

Figure 12. The $\delta^{13} \mathrm{C}$ gradient between the Panama Basin and the deep Pacific Ocean $\left(\Delta \delta^{13} \mathrm{C}_{(\mathrm{PB}-\mathrm{P})}\right)$ is contoured, as a function of water residence time relative to modern values $\left(\tau / \tau_{0}\right)$ and organic carbon influxes relative to modern values $\left(J / J_{0}\right)$. The value of $\Delta \delta^{13} \mathrm{C}_{(\mathrm{PB}-\mathrm{P})}$ for the modern carbon flux and water residence time is $-0.15 \%$ in this model, approximately consistent with the water column data in Figure 2.

3. Is there a plausible mechanism for upwelling and recirculation of deep water within a relatively isolated Atlantic?

4. Can small amounts of deep water be transported out of the Atlantic around Africa without influencing Site 704 ?

5. What would this circulation imply for heat, salt, and other property distributions within the ocean?
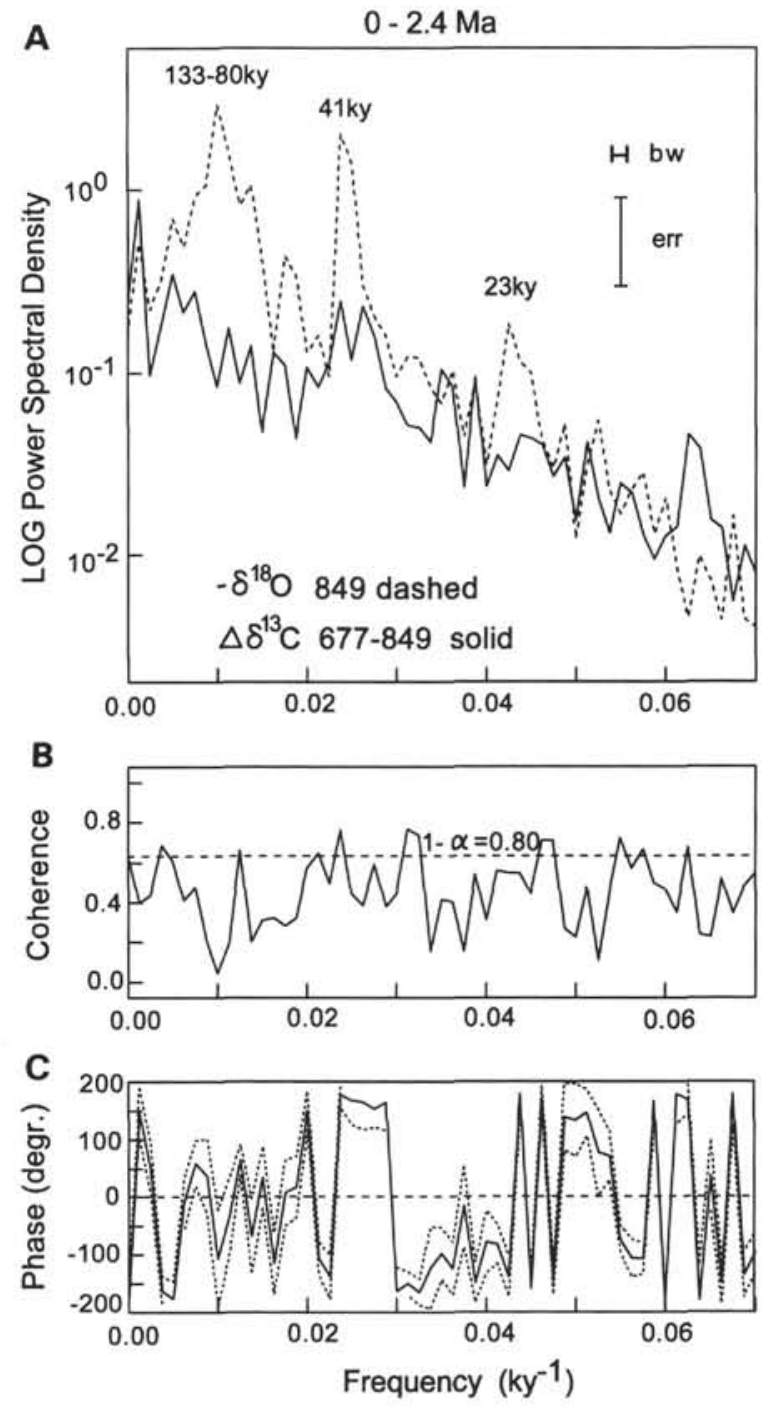

Figure 13. Spectra and cross spectra comparing $\delta^{18} \mathrm{O}$ (ice volume) and $\Delta \delta^{13} \mathrm{C}_{(\mathrm{PB}-\mathrm{P})}$. Bandwidth (bw) is $0.0017 \mathrm{k} \cdot \mathrm{y}^{-1}$. A. Power spectra. B. Coherency spectrum, $-\delta^{18} \mathrm{O}$ vs. $\Delta \delta^{13} \mathrm{C}_{(\mathrm{PB}-\mathrm{P})}$. Values higher than the dashed line are significant at the $80 \%$ confidence level. C. Phase spectrum, $-\delta^{18} \mathrm{O}$ vs. $\Delta \delta^{13} \mathrm{C}_{\text {(PB-P). }}$. Dashed lines outline $80 \%$ confidence envelope. Positive phase indicates $\Delta \delta^{13} \mathrm{C}_{(\mathrm{PB}-\mathrm{P})}$ lags $-\delta^{18} \mathrm{O}$. The lack of discrete spectral peaks in Figure $13 \mathrm{~A}$ and the low coherency in Figure 13B argue that $\Delta \delta^{13} \mathrm{C}_{(\mathrm{PB}-\mathrm{P})}$ is essentially "red" noise, unrelated to systematic changes in global climate.

We cannot answer these questions adequately at present but pose them to stimulate further research.

\section{CONCLUSIONS}

Here we present a high-resolution time series of benthic foraminifer stable isotopes from Site 849 . The record extends to $5 \mathrm{Ma}$ and is essentially complete over the last $4.4 \mathrm{Ma}$, with an average interval of 4 k.y. Because this site lies in the open Pacific Ocean, on the western flank of the East Pacific Rise at a water depth of $3851 \mathrm{~m}$, it is well suited as a proxy for the mean deep Pacific Ocean. Of the 1415 analyses reported here, $86 \%$ were from the preferred species $\mathrm{Cibi-}$ cides wuellerstorfi, although we detect no systematic variations in isotopic offsets between this species and Uvigerina peregrina, and combine data from the two species in a composite record.

The $\delta^{18} \mathrm{O}$ record from Site 849 compares well with other long $\delta^{18} \mathrm{O}$ data sets, including the other available long, continuous, highresolution benthic records from Atlantic Ocean Site 607 (Raymo et 

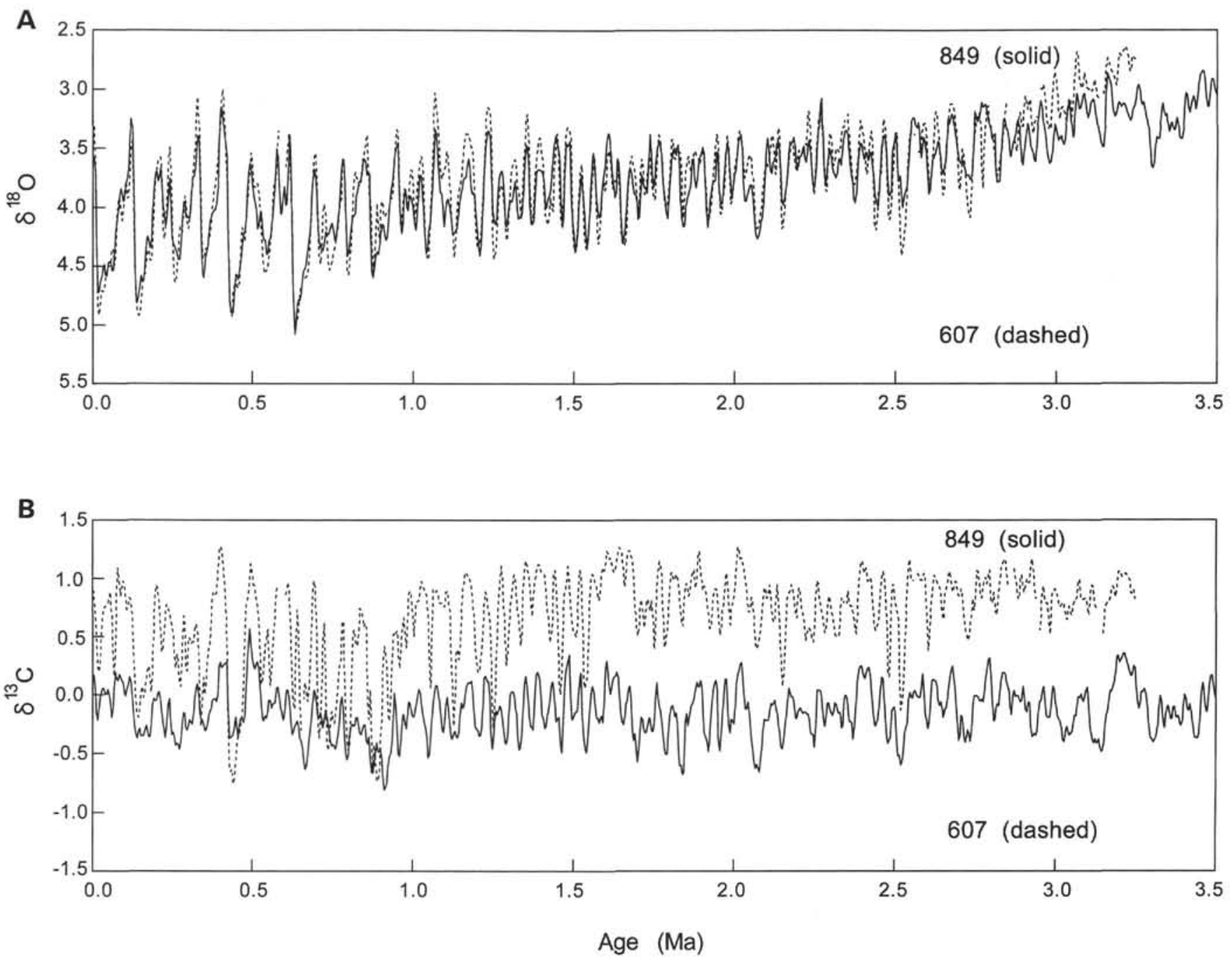

Figure 14. Stable isotope records from Pacific Site 849 and North Atlantic Site 607, smoothed with 19-k.y. Gaussian filter and interpolated to 4-k.y. sample spacing. A. $\delta^{18} \mathrm{O}$ vs. age. B. $\delta^{13} \mathrm{C}$ vs. age.

al., 1990, 1992) and Panama Basin Site 677 (Shackleton et al., 1990). The Site $849 \delta^{18} \mathrm{O}$ record confirms the major features of evolving glacial climate during the past $2.5 \mathrm{~m} . \mathrm{y}$. , and adds a new time scale and new high-resolution data back to $5 \mathrm{Ma}$, covering the full range of conditions from mid-Pliocene global warmth to the late Pleistocene glacial events.

The $\delta^{13} \mathrm{C}$ records are different in the Pacific Ocean and Panama Basin sites. This reflects local variations in low- $-{ }^{13} \mathrm{C}$ organic matter contributing to $\Sigma \mathrm{CO}_{2}$ in the relatively isolated Panama Basin. Variations in the Panama Basin to Pacific $\delta^{13} \mathrm{C}$ differences may reflect either changes in biological productivity over the basin, or variations in the basin's ventilation rate. Much of the variance in the Panama Basin to Pacific $\delta^{13} \mathrm{C}$ gradient appears to be random, with a "red" spectrum, as would be expected were changing rates of basin flushing associated with random variations in hydrothermal heat fluxes.

Using the record from Site 849 as a new standard for deep Pacific $\delta^{13} \mathrm{C}$ history over this time frame, we gained new insight into changing global chemical budgets of the ocean and biosphere. Over the last 2.4 m.y., the $\sim 100-\mathrm{k} . \mathrm{y}$. climate cycle, which is prevalent in the record of ice volume, is a less significant factor in the $\delta^{13} \mathrm{C}$ budget. Variations with a longer period (near 400 k.y.) and a strong 41-k.y. cycle are more prevalent in $\delta^{13} \mathrm{C}$. Changing continental biomass is a likely cause of variations at shorter periods, and the strength of the 41-k.y. period relative to that of precession points toward high-latitude biospheric processes. The weakness of the 100 -k.y. cycle in $\delta^{13} \mathrm{C}$ relative to that in $\delta^{18} \mathrm{O}$, however, suggests that sea level and the boreal forests of North America may not be the source of the biomass signal. The strength of several periodic signals in $\delta^{13} \mathrm{C}$ from 133 to 80 ka may imply nonlinear responses of $\delta^{13} \mathrm{C}$ to orbital eccentricity or some intermediate process. Phase of $\delta^{13} \mathrm{C}$ relative to $-\delta^{18} \mathrm{O}$ over the 41 - to 23-k.y. period bands is consistent with a biospheric response time of 1-2 k.y. This is too long to reflect changes in the mass of living forests, but it is appropriate for carbon in soils and shallow sediments. The $\delta^{13} \mathrm{C}$ variations at longer periods, perhaps including signals in the $\sim 100-k . y$. bands, most likely reflect the isotopic balance of erosion and deposition.

With a new Pacific stable isotope record, we also gained new insight into the history of global deep-water circulation. Significant events of reduced Atlantic-Pacific $\delta^{13} \mathrm{C}$ contrast occurred back to at least $1.5 \mathrm{Ma}$. The interval from $\sim 1.3$ to $2.1 \mathrm{Ma}$ stands out as a time of greater than average Atlantic-Pacific $\delta^{13} \mathrm{C}$ contrast to those of the late Pleistocene interglacial events, or earlier Pliocene events. Before $\sim 2.1$ $\mathrm{Ma}$, the Atlantic-Pacific contrast is mostly within the range of variations of the late Pleistocene, although variability is lower and the mean is similar to the past few interglacial events.

The $\delta^{13} \mathrm{C}$ contrast between the deep subantarctic (Site 704) and deep Pacific (Site 849) oceans evolves differently from the contrast between the deep North Atlantic and deep Pacific oceans. Before 2.9 $\mathrm{Ma}$ (with some uncertainty about exact timing), high $\delta^{13} \mathrm{C}$ in the 
A
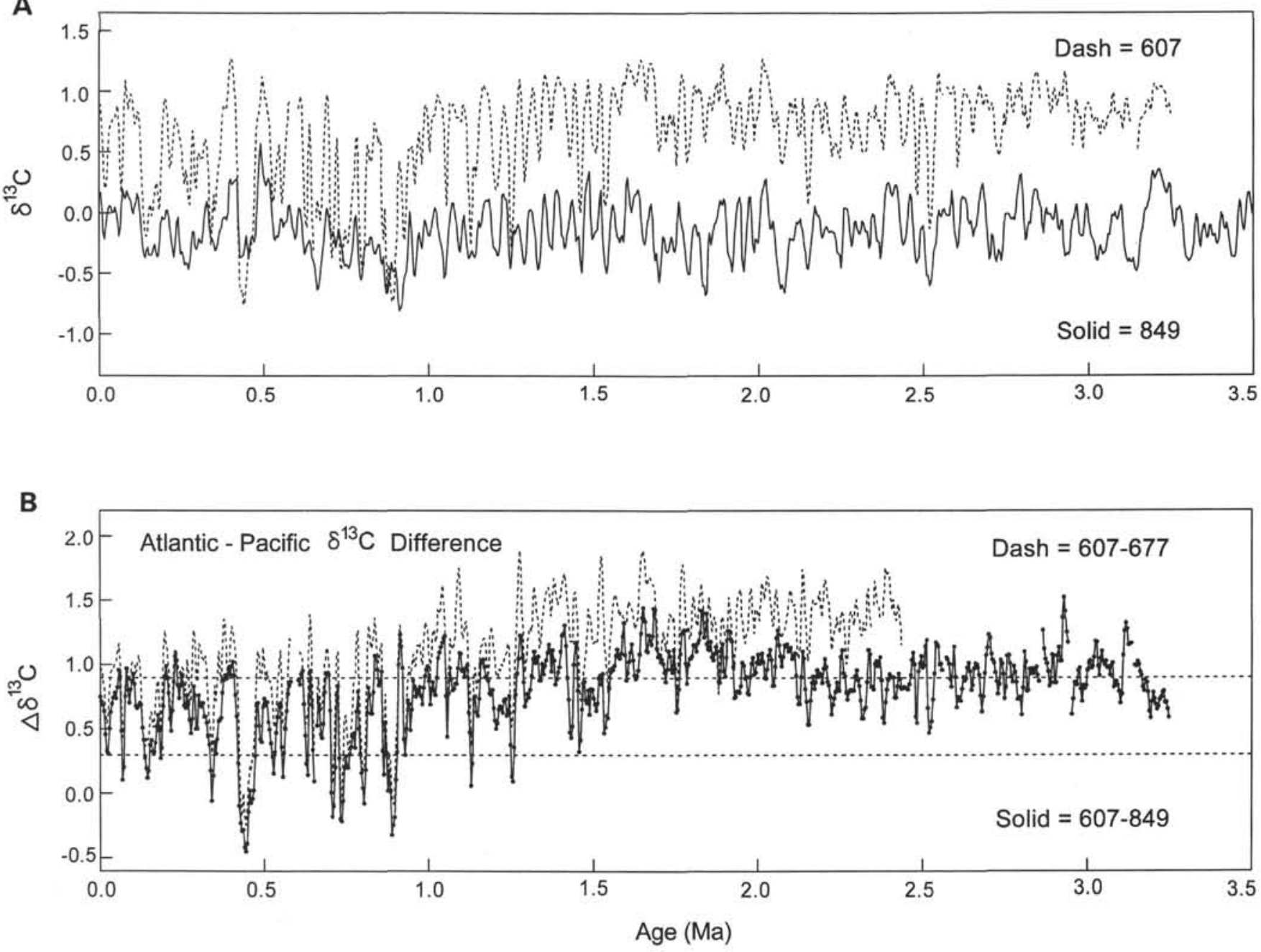

Figure 15. A. $\delta^{13} \mathrm{C}$ in Pacific Site 849 and North Atlantic Site 607, after interpolation to 4-k.y. intervals and smoothing with a 19-k.y. Gaussian filter. B. Carbon isotopic difference between deep North Atlantic and Pacific $\left(\Delta \delta^{13} \mathrm{C}_{(\mathrm{A}-\mathrm{P})}\right)$. The dotted line here is the Atlantic-Pacific difference calculated using Panama Basin Site 677 as the Pacific reference, and the solid line is the Atlantic-Pacific difference calculated using Site 849 as the Pacific reference. Horizontal dashed lines mark the range of variation in $\Delta \delta^{13} \mathrm{C}_{(\mathrm{PB}-\mathrm{P})}$ over the last glacial cycle of $0-120 \mathrm{k} . \mathrm{y}$.

deep Antarctic suggests rapid export of Atlantic deep waters into the CPDW. The $\delta^{13} \mathrm{C}$ values in the deep subantarctic between $\sim 1.7$ and $\sim 1.1 \mathrm{Ma}$ are almost always lower than values in the deep central Pacific, and similar features occurred back to at least $2.8 \mathrm{Ma}$. This suggests either the presence of a high- $\delta^{13} \mathrm{C}$ North Pacific deep-water source, or isolation of the circumantarctic as a nutrient trap.

To explain the apparently independent evolution in subantarctic to Pacific and North Atlantic to Pacific $\delta^{13} \mathrm{C}$ gradients, we hypothesize that at least two mechanisms must have contributed to these interocean $\delta^{13} \mathrm{C}$ gradients. Variation in the formation of deep waters in the North Atlantic may have been driven by changing Northern Hemisphere glacial climates. Variations in the export of deep water from the Atlantic may have been a function of wind stress at the southern tip of South America (Toggweiler and Samuels, 1993). We speculate that these two effects combined to make the deep North Atlantic and the subantarctic evolve in different ways relative to the mean ocean.

\section{ACKNOWLEDGMENTS}

We thank the crew and scientific party of Leg 138 for a successful venture at sea, and ODP for samples. We acknowledge financial support from USSAC and NSF. Parts of this study were completed while $\mathrm{ACM}$ was a visiting fellow at NOAA Geophysical Fluid Dynamics
Laboratory and the Atmosphere and Ocean Sciences Program of Princeton University, and ACM thanks both institutions for their hospitality. This paper benefited from discussions with J.R. Toggweiler, S. Manabe, K. Bryan, and J. Sarmiento as well as detailed reviews from L. Labeyrie, D. Lea, M. Raymo, and W. Ruddiman. We thank N.J. Shackleton for providing data from Site 677, and M. Raymo for data from Site 607 , and both for fruitful interactions for many years.

\section{REFERENCES}

Berggren, W.A., Kent, D.V., Flynn, J.J., and Van Couvering, J.A., 1985. Cenozoic geochronology. Geol. Soc. Am. Bull., 96:1407-1418.

Boyle, E.A., 1986. Paired carbon isotope and cadmium data from benthic foraminifera: implications for changes in oceanic phosphorus, oceanic circulation, and atmospheric carbon dioxide. Geochim. Cosmochim. Acta, 50:265-276.

Broecker, W.S., and Denton, G.H., 1989. The role of ocean-atmosphere reorganization in glacial cycles. Geochim. Cosmochim. Acta, 53:2465-2501.

\footnotetext{
-Abbreviations for names of organizations and publications in ODP reference lists follow the style given in Chemical Abstracts Service Source Index (published by American Chemical Society).
} 
Broecker, W.S., and Maier-Reimer, E., 1992. The influence of air and sea exchange on the carbon isotope distribution in the sea. Global Biogeochem. Cycles, 6:315-320.

Broecker, W.S., and Peng, T.-H., 1982. Tracers in the Sea: Palisades, NY (Eldigio Press).

Cande, S.C., and Kent, D.V., 1992. A new geomagnetic polarity time scale for the Late Cretaceous and Cenozoic. J. Geophys. Res., 97:13917-13951.

Chavez, F.P., and Barber, R.T., 1987. An estimate of new production in the equatorial Pacific. Deep-Sea Res. Part A, 34:1229-1243.

Christie, D.M., Duncan, R.A., McBirney, A.R., Richards, M.A., White, W.M., Harp, K.S., and Fox, C.G., 1992. Drowned islands downstream from the Galapagos hotspot imply extended speciation times. Nature, 355:246-248.

Clemens, S.C., Farrell, J.W., and Gromet, L.P., 1993. Synchronous changes in seawater strontium isotope composition and global climate. Nature, 363:607-610.

Craig, H., and Lupton, J.E., 1981. Helium-3 and mantle volatiles in the ocean and the oceanic crust. In Emiliani, C. (Ed.), The Sea (Vol. 7): The Oceanic Lithosphere: New York (Wiley), 391-428.

Curry, W.B., Duplessy, J.-C., Labeyrie, L.D., Oppo, D., and Kallel, N., 1988. Quaternary deep-water circulation changes in the distribution of $\delta^{13} \mathrm{C}$ of deep water $\mathrm{\Sigma CO}_{2}$ between the last glaciation and the Holocene. Paleoceanography, 3:317-342.

deMenocal, P.B., Oppo, D.W., Fairbanks, R.G., and Prell, W.L., 1992. Pleistocene $\delta^{13} \mathrm{C}$ variability of North Atlantic intermediate water. Paleoceanog. raphy, 7:229-250.

Des Marais, D.J., 1985. Carbon exchange between the mantle and the crust, and its effect upon the atmosphere: today compared to Archean time. In Sundquist, E.T., and Broecker, W.S. (Eds.) The Carbon Cycle and Atmospheric $\mathrm{CO}_{2}$ : Natural Variations Archaean to Present. Am. Geophys. Union, Geophys. Monogr. Ser., 32:602-611.

Detrick, R.S., Williams, D.L., Mudie, J.D., and Sclater, J.G., 1974. The Galapagos Spreading Centre: bottom-water temperatures and the significance of geothermal heating. Geophys. J. R. Astron. Soc., 38:627-637.

Duplessy, J.-C., Shackleton, N.J., Matthews, R.K., Prell, W.L., Ruddiman, W.F., Caralp, M. and Hendy, C.H., $1984,{ }^{13} \mathrm{C}$ record of benthic foraminifera in the last interglacial ocean: implications for the carbon cycle and the global deep water circulation. Quat. Res., 21:225-243.

Hagelberg, T., Shackleton, N., Pisias, N., and Shipboard Scientific Party, 1992. Development of composite depth sections for Sites 844 through 854 . In Mayer, L., Pisias, N., Janecek, T., et al., Proc. ODP, Init. Repts., 138 (Pt. 1): College Station, TX (Ocean Drilling Program), 79-85.

Hagelberg, T.K., Pisias, N.G., and Elgar, S.L., 1991. Linear and nonlinear couplings between orbital forcing and the marine $\delta^{18} \mathrm{O}$ record during the late Neogene. Paleoceanography, 6:729-746.

Hodell, D.A., and Venz, K., 1992. Toward a high-resolution stable isotopic record of the Southern Ocean during the Pliocene-Pleistocene (4.8 to 0.8 Ma). In Kennett, J.P., Warnke, D.A. (Eds.), The Antarctic Paleoenvironment: A Perspective on Global Change (Pt. 1). Am. Geophys. Union. Antarct. Res. Ser., 56:265-310.

Honjo, S., Spencer, D.W., and Gardner, W.D., 1992. A sediment trap intercomparison experiment in the Panama Basin, 1979. Deep-Sea Res., 39:333-358.

Imbrie, J., 1985. A theoretical framework for the Pleistocene ice ages. J. Geol. Soc. London, 142:417-432.

Imbrie, J., Boyle, E.A., Clemens, S.C., Duffy, A., Howard, W.R., Kukla, G., Kutzbach, J., Martinson, D.G., McIntyre, A., Mix, A.C., Molfino, B., Morley, J.J., Peterson, L.C., Pisias, N.G., Prell, W.L., Raymo, M.E., Shackleton, N.J., and Toggweiler, J.R., 1992. On the structure and origin of major glaciation cycles, 1. Linear responses to Milankovitch forcing. Paleoceanography, 7:701-738.

Imbrie, J., Hays, J.D., Martinson, D.G., McIntyre, A., Mix, A.C., Morley, J.J., Pisias, N.G., Prell, W.L., and Shackleton, N.J., 1984. The orbital theory of Pleistocene climate: support from a revised chronology of the marine $\delta^{18} \mathrm{O}$ record. In Berger, A., Imbrie, J., Hays, J., Kukla, G., and Saltzman, B. (Eds.), Milankovitch and Climate (Pt. 1): Dordrecht (D. Reidel), 269-305.

Imbrie, J., McIntyre, A., and Mix, A., 1989. Oceanic response to orbital forcing in the late Quaternary: observational and experimental strategies. In Berger, A., Schneider, S., and Duplessy, J.C. (Eds.), Climate and GeoSciences: Dordrecht (Kluwer Academic), 121-164.

Keigwin, L.D., 1982. Isotopic paleoceanography of the Caribbean and East Pacific: role of Panama uplift in late Neogene time. Science, 217:350-353.

Kroopnick, P., 1974. The dissolved $\mathrm{O}_{2}-\mathrm{CO}_{2}{ }^{-13} \mathrm{C}$ system in the eastern equatorial Pacific. Deep-Sea Res. Part A, 21:211-227.

Laird, N.P., 1971. Panama Basin Deep Water: properties and circulation. J. Mar. Res., 29:226-234.
Levitus, S., 1982. Climatological Atlas of the World Ocean. NOAA Prof. Pap., 13: Washington, DC (U.S. Govt. Printing Office).

Lonsdale, P., 1976. Abyssal circulation of the southeastern Pacific and some geological implications. J. Geophys. Res., 81:1163-1176.

, 1977. Inflow of bottom water to the Panama Basin. Deep-Sea Res. Part A, 24:1065-1101.

Martinson, D.G., Menke, W., and Stoffa, P.L., 1982. An inverse approach to signal correlation. J. Geophys. Res., 87:4807-4818.

Mayer, L., Pisias, N., Janecek, T., et al., 1992. Proc. ODP, Init. Repts., 138 (Pts. 1 and 2): College Station, TX (Ocean Drilling Program).

Mix, A.C., and Fairbanks, N.G., 1985. North Atlantic surface-ocean control of Pleistocene deep ocean circulation. Earth Planet. Sci. Lett., 73:231-243.

Mix, A.C., Pisias, N.G., Zahn, R., Rugh, W., Lopez, C., and Nelson, K., 1991. Carbon 13 in Pacific deep and intermediate waters, 0-370 Ka: implications for ocean circulation and Pleistocene $\mathrm{CO}_{2}$. Paleoceanography, 6:205-226.

Pedersen, T.F., 1983. Increased productivity in the eastern equatorial Pacific during the last glacial maximum (19,000 to 14,000 yr B.P.). Geology, 11:16-19.

Pedersen, T.F., Nielsen, B., and Pickering, M., 1991. Timing of late Quaternary productivity pulses in the Panama Basin and implications for atmospheric $\mathrm{CO}_{2}$. Paleoceanography, 6:657-678.

Pisias, N.G., Mix, A.C., and Zahn, R., 1990. Nonlinear response in the global climate system: evidence from benthic oxygen isotopic record in core RC13-110. Paleoceanography, 5:147-160.

Raymo, M.E., Hodell, D., and Jansen, E., 1992. Response of deep ocean circulation to initiation of Northern Hemisphere glaciation (3-2 Ma). Paleoceanography, 7:645-672.

Raymo, M.E., Ruddiman, W.F., Shackleton, N.J., and Oppo, D.W., 1990. Evolution of Atlantic-Pacific $\delta^{13} \mathrm{C}$ gradients over the last 2.5 m.y. Earth Planet. Sci. Lett., 97:353-368.

Ruddiman, W.F., Raymo, M., and McIntyre, A., 1989. Matuyama 41,000-year cycles: North Atlantic Ocean and Northern Hemisphere ice sheets. Earth Planet. Sci. Lett., 80:117-129.

Shackleton, N.J., 1974. Attainment of isotopic equilibrium between ocean water and the benthonic foraminifera genus Uvigerina: isotopic changes in the ocean during the last glacial. Les Meth. Quant. d'etude Var. Clim. au Cours du Pleist., Coll. Int. C.N.R.S., 219:203-209.

1977. Carbon-13 in Uvigerina: tropical rainforest history and the equatorial Pacific carbonate dissolution cycles. In Andersen, N.R., and Malahoff, A. (Eds.), The Fate of Fossil Fuel $\mathrm{CO}_{2}$ in the Oceans: New York (Plenum), 401-427.

Shackleton, N.J., Berger, A., and Peltier, W.R., 1990. An alternative astronomical calibration of the lower Pleistocene timescale based on ODP Site 677 Trans. R. Soc. Edinburgh, Earth Sci., 81:251-261.

Shackleton, N.J., and Shipboard Scientific Party, 1992. Sedimentation rates: toward a GRAPE density stratigraphy for Leg 138 carbonate sections. In Mayer, L., Pisias, N., Janecek, T., et al., Proc. ODP, Init. Repts., 138 (Pt. 1): College Station, TX (Ocean Drilling Program), 87-91.

Sundquist, E.T., 1993. The global carbon dioxide budget. Science, 259:934-941

Sykes, E.L., Keigwin, L.D., and Curry, W.B., 1991. Pliocene paleoceanography: circulation and oceanographic changes associated with the $2.4 \mathrm{Ma}$ glacial event. Paleoceanography, 6:245-257.

Toggweiler, J.R., and Samuels, B., 1993. Is the magnitude of the deep outflow from the Atlantic Ocean actually governed by southern hemisphere winds? In Heimann, M. (Ed.), The Global Carbon Cycle: Berlin (SpringerVerlag), 303-331.

Trenberth, K.E., Large, W.G., and Olson, J.G., 1990. The mean annual cycle in global ocean wind stress. J. Phys. Oceanogr., 20:1742-1760.

Van Andel, T.H., Heath, G.R., Malfait, B.T., Heinrichs, D.F., and Ewing, J.I., 1971. Tectonics of the Panama Basin, Eastern Equatorial Pacific. Geol. Soc. Am. Bull., 82:1489-1508.

Worthington, L.V., 1981. The water masses of the World Ocean: some results of a fine-scale census. In Warren, B.A., and Wunsch, C. (Eds.), Evolution of Physical Oceanography: Cambridge (MIT Press), 42-69.

Zahn, R., and Mix, A.C., 1991. Benthic foraminiferal $\delta^{18} \mathrm{O}$ in the ocean's temperature-salinity-density field: constraints on ice age thermohaline circulation. Paleoceanography, 6:1-20.

Zahn, R., Winn, K., and Sarnthein, M., 1986. Benthic foraminiferal $\delta^{13} \mathrm{C}$ and accumulation rates of organic carbon: Uvigerina peregrina group and Cibicidoides wuellerstorfi. Paleoceanography, 1:27-42.

Date of initial receipt: 8 March 1993

Date of acceptance: 11 March 1994

Ms 138SR-120 
A
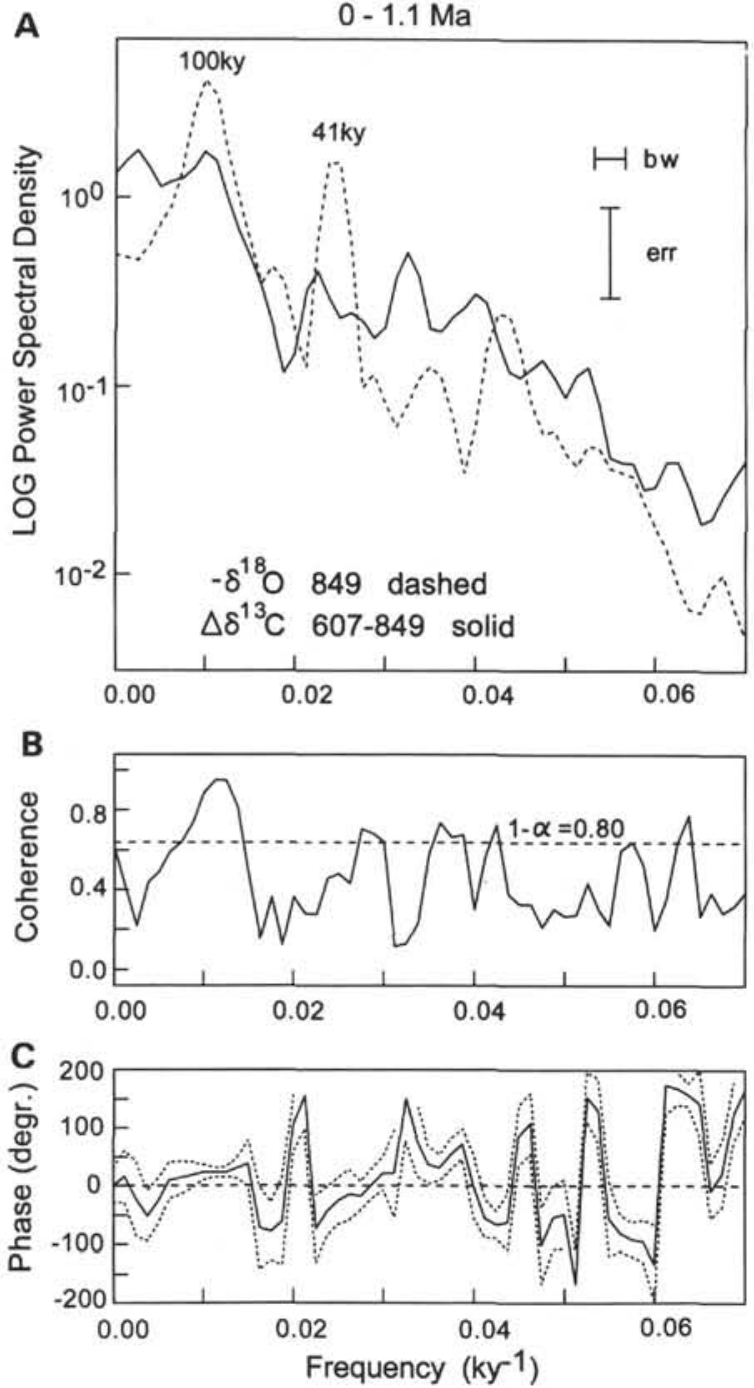

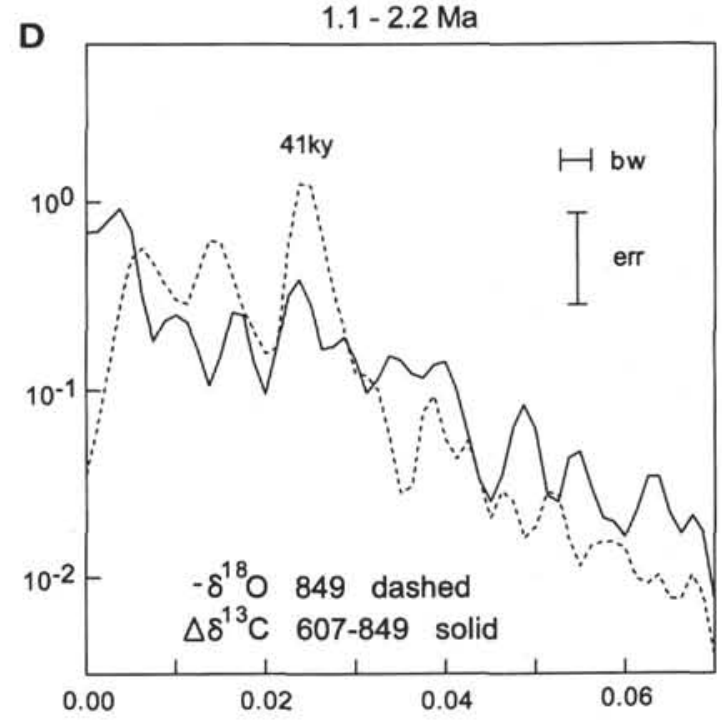

E
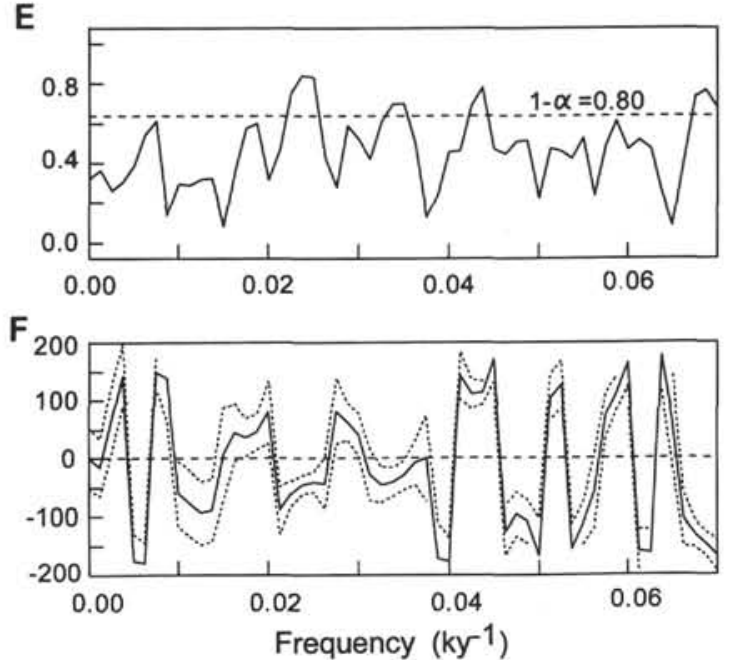

Figure 16. Spectra and cross spectra comparing the $\delta^{18} \mathrm{O}$ (approximate ice volume) and $\Delta \delta^{13} \mathrm{C}_{(\mathrm{A}-\mathrm{P})}$ (Site $607-$ Site 849$)$. A. Power spectra, 0-1.1 Ma. B. Coherency spectrum, $0-1.1 \mathrm{Ma}, \delta^{18} \mathrm{O}$ vs. $\Delta \delta^{13} \mathrm{C}_{\text {(A.P). }}$. C. Phase spectrum, $0-1.1 \mathrm{Ma},-\delta^{18} \mathrm{O}$ vs. $\Delta \delta^{13} \mathrm{C}_{(\mathrm{A} \cdot \mathrm{P})}$. D. Power spectra, 1.1-2.2 Ma. E. Coherency spectrum, 1.1-2.2 Ma, $\delta^{18} \mathrm{O}$ vs. $\Delta \delta^{13} \mathrm{C}_{(\mathrm{A}-\mathrm{P})}$. F. Phase spectrum, $1.1-2.2 \mathrm{Ma},-\delta^{18} \mathrm{O}$ vs. $\Delta \delta^{13} \mathrm{C}_{(\mathrm{A}-\mathrm{P}) \text {. }}$. 

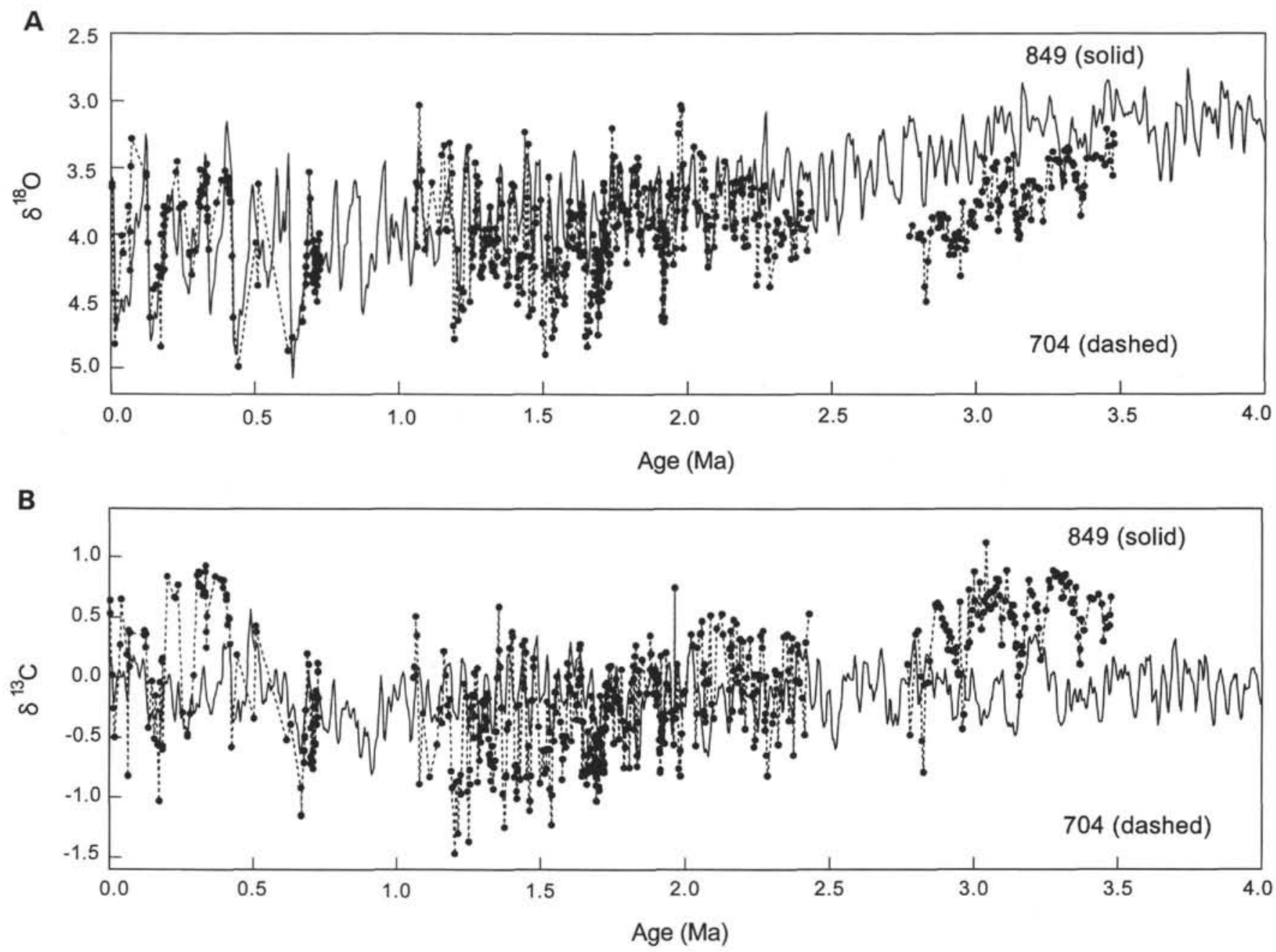

Figure 17. Isotope records from Pacific Site 849 and subantarctic Site 704 (Hodell, 1993; Hodell and Venz, 1992; data from Cibicides wuellerstorfi only with no smoothing or interpolation). A. $\delta^{18} \mathrm{O}$ vs. age. B. $\delta^{13} \mathrm{C}$ vs. age. 

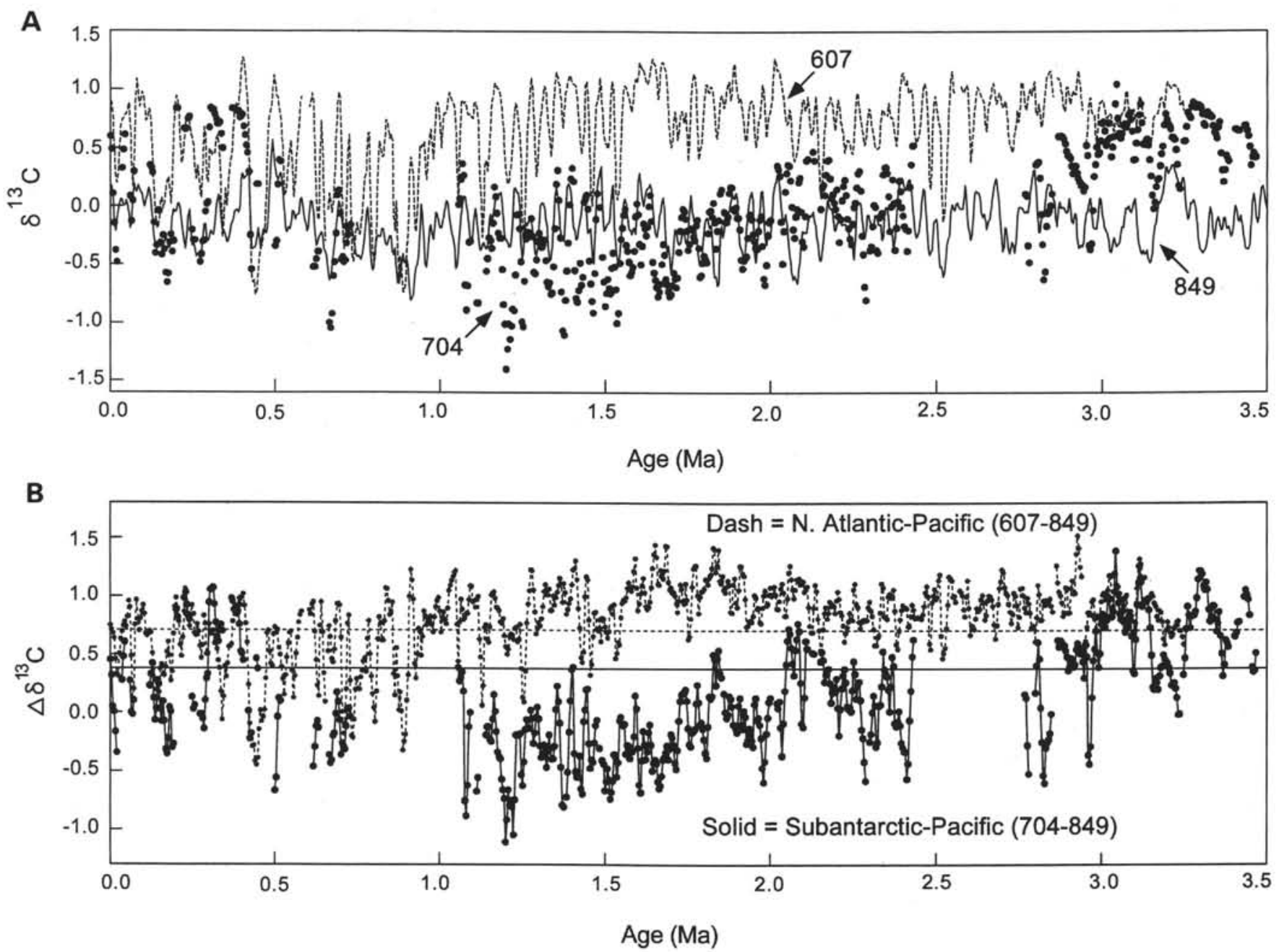

Figure 18. A. $\delta^{13} \mathrm{C}$ in Pacific Site 849, North Atlantic Site 607, and subantarctic Site 704, after interpolation to 4-k.y. intervals and smoothing with a 19-k.y. Gaussian filter. B. Carbon isotopic difference between deep North Atlantic Site 607 and Pacific Site 849 and between subantarctic Site 704 and Pacific Site 849 . The horizontal dashed line marks the level of the modern $\delta^{13} \mathrm{C}$ gradient between Sites 607 and 849 . The horizontal solid line marks the modern $\delta^{13} \mathrm{C}$ gradient between Sites 704 and 849. Note the change from large positive values of $\Delta \delta^{13} \mathrm{C}_{(\mathrm{S}-\mathrm{P})}$ below $2.9 \mathrm{Ma}$ to negative values of $\Delta \delta^{13} \mathrm{C}_{(\mathrm{S}-\mathrm{P})}$ in the younger intervals (especially from 1 to $2 \mathrm{Ma}$ ), and the lack of covariance between $\Delta \delta^{13} \mathrm{C}_{(\mathrm{S}-\mathrm{P})}$ and $\Delta \delta^{13} \mathrm{C}_{(\mathrm{A}-\mathrm{P})}$. 
APPENDIX A

Oxygen and Carbon Isotope Data for Site 849 With Three Depth Scales

\begin{tabular}{|c|c|c|c|c|c|c|c|c|c|c|c|c|c|}
\hline Section & Species & $\begin{array}{l}\text { Depth } \\
\text { (cm) }\end{array}$ & $\begin{array}{l}\text { Depth } \\
\text { (mbsf) }\end{array}$ & $\begin{array}{l}\text { Depth } \\
\text { (mcd) }\end{array}$ & $\begin{array}{l}\text { Depth } \\
\text { (rmcd) }\end{array}$ & $\delta^{1 \times} \mathrm{O}$ & $\delta^{13} \mathrm{C}$ & Section & Species & $\begin{array}{l}\text { Depth } \\
(\mathrm{cm})\end{array}$ & $\begin{array}{l}\text { Depth } \\
\text { (mbsf) }\end{array}$ & $\begin{array}{l}\text { Depth } \\
\text { (mcd) }\end{array}$ & $\begin{array}{l}\text { Depth } \\
\text { (rmcd) }\end{array}$ \\
\hline $849 \mathrm{~B}-\mathrm{IH}-1$ & C. wuellerstorfi & 7 & 0.07 & 0.07 & 0.07 & 3.66 & 0.21 & $849 \mathrm{C}-1 \mathrm{H}-4$ & C. wuellerstorfi & 117 & 6.53 & 7.28 & 7.28 \\
\hline $849 \mathrm{~B}-1 \mathrm{H}-\mathrm{I}$ & C. wuellerstorfi & 17 & 0.17 & 0.17 & 0.17 & 3.49 & 0.08 & $849 \mathrm{C}-1 \mathrm{H}-4$ & U. peregrina & 127 & 6.63 & 7.38 & 7.37 \\
\hline $849 \mathrm{~B}-\mathrm{IH}-\mathrm{I}$ & C. whellerstorfi & 28 & 0.28 & 0.28 & 0.28 & 3.31 & 0.19 & $849 \mathrm{C}-1 \mathrm{H}-4$ & C. wuellerstorfi & 137 & 6.73 & 7.48 & 7.47 \\
\hline $849 \mathrm{~B}-\mathrm{IH}-\mathrm{I}$ & C. wuellerstorfi & 44 & 0.44 & 0.44 & 0.45 & 4.17 & -0.15 & $849 \mathrm{D}-1 \mathrm{H}-1$ & C. wuellerstorfi & 21 & 4.21 & 7.51 & 7.47 \\
\hline $849 \mathrm{~B}-\mathrm{IH}-1$ & C. wuellerstorfi & 54 & 0.54 & 0.54 & 0.55 & 4.69 & -0.27 & $849 \mathrm{D}-\mathrm{IH}-\mathrm{I}$ & C. wuellerstorfi & 31 & 4.31 & 7.61 & 7.56 \\
\hline $849 \mathrm{~B}-1 \mathrm{H}-1$ & C. wuellerstorfi & 69 & 0.69 & 0.69 & 0.69 & 4.92 & -0.26 & $849 \mathrm{D}-\mathrm{IH}-\mathrm{I}$ & U. peregrina & 31 & 4.31 & 7.61 & 7.56 \\
\hline $849 \mathrm{~B}-1 \mathrm{H}-1$ & C. wuellerstorfi & 89 & 0.89 & 0.89 & 0.89 & 4.55 & -0.08 & $849 \mathrm{C}-1 \mathrm{H}-4$ & C. wuellerstorfi & 147 & 6.83 & 7.58 & 7.57 \\
\hline $849 \mathrm{~B}-1 \mathrm{H}-1$ & C. nuellerstorfi & 89 & 0.89 & 0.89 & 0.89 & 4.80 & -0.16 & $849 \mathrm{D}-1 \mathrm{H}-1$ & C. wuellerstorfi & 41 & 4.41 & 7.71 & 7.66 \\
\hline $849 B-1 \mathrm{H}-1$ & C. wuellerstorfi & 109 & 1.09 & 1.09 & 1.09 & 4.59 & 0.02 & $849 \mathrm{D}-1 \mathrm{H}-1$ & C. wuellerstorfi & 51 & 4.51 & 7.81 & 7.78 \\
\hline $849 \mathrm{~B}-1 \mathrm{H}-1$ & C. nuellerstorfi & 118 & 1.18 & 1.18 & 1.18 & 4.55 & 0.05 & $849 \mathrm{D}-\mathrm{IH}-\mathrm{I}$ & C. wuellerstorfi & 61 & 4.61 & 7.91 & 7.91 \\
\hline $849 B-1 \mathrm{H}-1$ & C. wuellerstorfi & 128 & 1.28 & 1.28 & 1.28 & 4.72 & 0.02 & $849 \mathrm{D}-\mathrm{IH}-\mathrm{I}$ & C. wuellerstorfi & 71 & 4.71 & 8.01 & 8.03 \\
\hline $849 \mathrm{~B}-1 \mathrm{H}-1$ & C. wuellerstorfi & 138 & 1.38 & 1.38 & 1.39 & 4.36 & 0.10 & $849 \mathrm{D}-\mathrm{IH}-1$ & C. wuellerstorfi & 81 & 4.81 & 8.11 & 8.13 \\
\hline $849 \mathrm{~B}-1 \mathrm{H}-1$ & C. wuellerstorfi & 148 & 1.48 & 1.48 & 1.50 & 4.46 & 0.05 & 849D-IH-I & C. wuellerstorfi & 91 & 4.91 & 8.21 & 8.24 \\
\hline $849 \mathrm{~B}-\mathrm{IH}-2$ & C. witellersterfi & 11 & 1.61 & 1.61 & 1.61 & 4.63 & -0.02 & $849 \mathrm{D}-\mathrm{IH}-\mathrm{I}$ & U. peregrina & 101 & 5.01 & 8.31 & 8.35 \\
\hline $849 \mathrm{~B}-\mathrm{IH}-2$ & C. wuellerstorfi & 38 & 1.88 & 1.88 & 1.85 & 4.47 & 0.07 & $849 \mathrm{D}-1 \mathrm{H}-1$ & C. wuellerstorfi & 111 & 5.11 & 8.41 & 8.49 \\
\hline $849 \mathrm{~B}-1 \mathrm{H}-2$ & C. wuellerstorfi & 48 & 1.98 & 1.98 & 1.94 & 4.45 & -0.04 & $849 \mathrm{D}-1 \mathrm{H}-1$ & U. peregrina & III & 5.11 & 8.41 & 8.49 \\
\hline $849 \mathrm{~B}-1 \mathrm{H}-2$ & C. wuellerstorfi & 68 & 2.18 & 2.18 & 2.17 & 4.54 & -0.21 & $849 \mathrm{D}-1 \mathrm{H}-1$ & C. wuellerstorfi & 121 & 5.21 & 8.51 & 8.61 \\
\hline $849 \mathrm{~B}-1 \mathrm{H}-2$ & C. wuellerstorfi & 78 & 2.28 & 2.28 & 2.31 & 4.57 & -0.11 & $849 \mathrm{D}-1 \mathrm{H}-1$ & U. peregrina & 121 & 5.21 & 8.51 & 8.61 \\
\hline $849 \mathrm{~B}-\mathrm{IH}-2$ & C. vuellerstorfi & 92 & 2.42 & 2.42 & 2.43 & 4.27 & 0.30 & $849 \mathrm{D}-\mathrm{IH}-1$ & C. wuellerstorfi & 131 & 5.31 & 8.61 & 8.71 \\
\hline $849 \mathrm{~B}-1 \mathrm{H}-2$ & C. wuellerstorfi & 101 & 2.51 & 2.51 & 2.49 & 4.14 & 0.13 & $849 \mathrm{D}-1 \mathrm{H}-1$ & $U$. peregrina & 131 & 5.31 & 8.61 & 8.71 \\
\hline $849 \mathrm{~B}-\mathrm{IH}-2$ & C, wuellerstorfi & 111 & 2.61 & 2.61 & 2.56 & 4.10 & 0.25 & 849D-IH-I & $U$. peregrina & 141 & 5.41 & 8.71 & 8.79 \\
\hline $849 \mathrm{C}-\mathrm{IH}-1$ & C. wuellerstorfi & 87 & 1.87 & 2.62 & 2.71 & 4.32 & -0.03 & $849 \mathrm{D}-1 \mathrm{H}-2$ & $U$. peregrina & 4 & 5.54 & 8.84 & 8.89 \\
\hline $849 \mathrm{~B}-\mathrm{IH}-2$ & C. wuellerstorfi & 123 & 2.73 & 2.73 & 2.75 & 3.95 & 0.12 & $849 \mathrm{D}-\mathrm{IH}-2$ & C. wuellerstorfi & 11 & 5.61 & 8.91 & 8.95 \\
\hline $849 \mathrm{C}-1 \mathrm{H}-1$ & C. wuellerstorfi & 97 & 1.97 & 2.72 & 2.80 & 3.83 & 0.22 & $849 \mathrm{D}-1 \mathrm{H}-2$ & C. wuellerstorfi & 21 & 5.71 & 9.01 & 9.05 \\
\hline $849 \mathrm{C}-1 \mathrm{H}-1$ & C. wuellerstorfi & 107 & 2.07 & 2.82 & 2.89 & 4.00 & 0.21 & 849D-1H-2 & C. wuellerstorfi & 31 & 5.81 & 9.11 & 9.16 \\
\hline $849 \mathrm{~B}-1 \mathrm{H}-2$ & C. wuellersterfi & 133 & 2.83 & 2.83 & 2.92 & 3.90 & 0.21 & $849 \mathrm{D}-1 \mathrm{H}-2$ & $U$. peregrina & 31 & 5.81 & 9.11 & 9.16 \\
\hline $849 B-1 \mathrm{H}-2$ & U. peregrina & 133 & 2.83 & 2.83 & 2.92 & 3.96 & 0.21 & $849 \mathrm{D}-\mathrm{IH}-2$ & C. wuellerstorfi & 41 & 5.91 & 9.21 & 9.27 \\
\hline $849 \mathrm{C}-\mathrm{IH}-1$ & U. peregrina & 117 & 2.17 & 2.92 & 2.96 & 3.71 & 0.20 & $849 \mathrm{D}-1 \mathrm{H}-2$ & U. peregrina & 41 & 5.91 & 9.21 & 9.27 \\
\hline $849 \mathrm{~B}-\mathrm{IH}-2$ & C. wuellerstorfi & 146 & 2.96 & 2.96 & 3.06 & 3.85 & 0.10 & $849 \mathrm{D}-1 \mathrm{H}-2$ & C. wuellerstorfi & 51 & 6.01 & 9.31 & 9.37 \\
\hline $849 B-1 \mathrm{H}-2$ & U. peregrina & 146 & 2.96 & 2.96 & 3.06 & 3.84 & -0.01 & $849 \mathrm{D}-1 \mathrm{H}-2$ & C. wuellerstorfi & 61 & 6.11 & 9.41 & 9.48 \\
\hline $849 \mathrm{C}-1 \mathrm{H}-2$ & C. wuellerstorfi & 7 & 2.43 & 3.18 & 3.15 & 4.00 & 0.17 & $849 \mathrm{D}-1 \mathrm{H}-2$ & C. wuellerstorfi & 71 & 6.21 & 9.51 & 9.60 \\
\hline $849 \mathrm{C}-1 \mathrm{H}-2$ & C. wuellerstorfi & 17 & 2.5 .3 & 3.28 & 3.24 & 3.95 & 0.09 & $849 \mathrm{D}-\mathrm{IH}-2$ & C. wuellerstorfi & 81 & 6.31 & 9.61 & 9.72 \\
\hline $849 \mathrm{C}-1 \mathrm{H}-2$ & C. wuellerstorfi & 27 & 2.63 & 3.38 & 3.33 & $3.91-$ & -0.06 & $849 \mathrm{D}-1 \mathrm{H}-2$ & C. wuellerstorfi & 91 & 6.41 & 9.71 & 9.82 \\
\hline $849 \mathrm{C}-1 \mathrm{H}-2$ & C. wuellerstorfi & 27 & 2.63 & 3.38 & 3.33 & 3.73 & -0.11 & $849 \mathrm{D}-1 \mathrm{H}-2$ & C. wuellerstorfi & 101 & 6.51 & 9.81 & 9.90 \\
\hline $849 \mathrm{C}-1 \mathrm{H}-2$ & C. wuellersterfi & 37 & 2.73 & 3.48 & 3.44 & 3.70 & 0.06 & $849 \mathrm{D}-1 \mathrm{H}-2$ & U. peregrina & 101 & 6.51 & 9.81 & 9.90 \\
\hline $849 \mathrm{C}-1 \mathrm{H}-2$ & C. wuellerstorfi & 37 & 2.73 & 3.48 & 3.44 & 3.79 & 0.10 & $849 \mathrm{D}-\mathrm{IH}-2$ & C. wuellerstorfi & III & 6.61 & 9.91 & 9.96 \\
\hline $849 \mathrm{C}-1 \mathrm{H}-2$ & C. wuellerstorfi & 47 & 2.83 & 3.58 & 3.55 & 3.78 & 0.05 & $849 \mathrm{D}-\mathrm{IH}-2$ & C. wuellerstorfi & 111 & 6.61 & 9.91 & 9.96 \\
\hline $849 \mathrm{C}-1 \mathrm{H}-2$ & C. wuellerstorfi & 57 & 2.93 & 3.68 & 3.66 & 3.30 & 0.23 & $849 \mathrm{D}-1 \mathrm{H}-2$ & $U$. peregrina & iII & 6.61 & 9.91 & 9.96 \\
\hline $849 \mathrm{C}-1 \mathrm{H}-2$ & C. wuellerstorfi & 67 & 3.03 & 3.78 & 3.77 & 3.23 & 0.12 & $849 \mathrm{D}-1 \mathrm{H}-2$ & U. peregrina & 121 & 6.71 & 10.01 & 10.03 \\
\hline $849 \mathrm{C}-1 \mathrm{H}-2$ & C. wuellerstorfi & 77 & 3.13 & 3.88 & 3.88 & 3.15 & -0.02 & $849 \mathrm{D}-1 \mathrm{H}-3$ & U. peregrina & 1 & 6.80 & 10.10 & 10.12 \\
\hline $849 \mathrm{C}-1 \mathrm{H}-2$ & C. wuellerstorfi & 87 & 3.23 & 3.98 & 3.98 & 3.27 & -0.02 & 849D-1H-3 & C. wuellerstorfi & 11 & 6.90 & 10.20 & 10.26 \\
\hline $849 \mathrm{C}-1 \mathrm{H}-2$ & C. wuellerstorfi & 97 & 3.33 & 4.08 & 4.08 & 4.13 & -0.23 & $849 \mathrm{D}-\mathrm{IH}-3$ & $U$. peregrina & 11 & 6.90 & 10.20 & 10.26 \\
\hline $849 \mathrm{C}-1 \mathrm{H}-2$ & U. peregrina & 107 & 3.43 & 4.18 & 4.18 & 4.42 & -0.30 & $849 \mathrm{D}-1 \mathrm{H}-3$ & $U$. peregrina & 21 & 7.00 & 10.30 & 10.41 \\
\hline $849 \mathrm{C}-1 \mathrm{H}-2$ & C. wuellerstorfi & 117 & 3.53 & 4.28 & 4.28 & 4.85 & -0.30 & $849 \mathrm{D}-\mathrm{IH}-3$ & C. wuellerstorfi & 31 & 7.10 & 10.40 & 10.52 \\
\hline $849 \mathrm{C}-1 \mathrm{H}-2$ & C. wuellerstorfi & 127 & 3.63 & 4.38 & 4.37 & 4.75 & -0.39 & $849 \mathrm{D}-1 \mathrm{H}-3$ & U. peregrina & 31 & 7.10 & 10.40 & 10.52 \\
\hline $849 \mathrm{C}-1 \mathrm{H}-2$ & U. peregrina & 127 & 3.63 & 4.38 & 4.37 & 4.84 & -0.25 & $849 \mathrm{D}-1 \mathrm{H}-3$ & C. wuellerstorfi & 41 & 7.20 & 10.50 & 10.59 \\
\hline $849 \mathrm{C}-1 \mathrm{H}-2$ & C. wuellerstorfi & 137 & 3.73 & 4.48 & 4.47 & 4.98 & -0.38 & $849 \mathrm{D}-1 \mathrm{H}-3$ & $U$. peregrina & 41 & 7.20 & 10.50 & 10.59 \\
\hline $849 \mathrm{C}-1 \mathrm{H}-2$ & C. wuellerstorfi & 147 & 3.83 & 4.58 & 4.56 & 4.70 & -0.45 & $849 \mathrm{D}-1 \mathrm{H}-3$ & $U$. peregrina & 61 & 7.40 & 10.70 & 10.75 \\
\hline $849 \mathrm{C}-1 \mathrm{H}-3$ & C. wuellerstorfi & 7 & 3.93 & 4.68 & 4.67 & 4.74 & -0.33 & $849 \mathrm{D}-1 \mathrm{H}-3$ & C. wuellerstorfi & 71 & 7.50 & 10.80 & 10.90 \\
\hline $849 \mathrm{C}-1 \mathrm{H}-3$ & $U$. peregrina & 17 & 4.03 & 4.78 & 4.77 & 4.76 & -0.25 & $849 \mathrm{D}-1 \mathrm{H}-3$ & $U$. peregrina & 71 & 7.50 & 10.80 & 10.90 \\
\hline $849 \mathrm{C}-1 \mathrm{H}-3$ & U. peregrina & 27 & 4.13 & 4.88 & 4.88 & 4.67 & -0.19 & $849 \mathrm{D}-\mathrm{IH}-3$ & $U$. peregrina & 81 & 7.60 & 10.90 & 11.05 \\
\hline $849 \mathrm{C}-1 \mathrm{H}-3$ & C. wuellerstorfi & 37 & 4.23 & 4.98 & 4.98 & 4.38 & -0.46 & $849 \mathrm{D}-1 \mathrm{H}-3$ & $U$. peregrina & 91 & 7.70 & 11.00 & 11.17 \\
\hline $849 \mathrm{C}-1 \mathrm{H}-3$ & C. wuellerstorfi & 47 & 4.33 & 5.08 & 5.08 & 4.72 & -0.39 & $849 \mathrm{~B}-2 \mathrm{H}-2$ & C. wuellerstorfi & 104 & 9.24 & 11.19 & 11.19 \\
\hline $849 \mathrm{C}-\mathrm{IH}-3$ & $U$. peregrina & 57 & 4.43 & 5.18 & 5.18 & 4.57 & -0.21 & $849 \mathrm{~B}-2 \mathrm{H}-2$ & $U$. peregrina & 104 & 9.24 & 11.19 & 11.19 \\
\hline $849 \mathrm{C}-1 \mathrm{H}-3$ & C. wuellerstorfi & 67 & 4.53 & 5.28 & 5.28 & 4.81 & -0.45 & $849 \mathrm{D}-1 \mathrm{H}-3$ & $U$. peregrina & 101 & 7.80 & 11.10 & 11.25 \\
\hline $849 \mathrm{C}-1 \mathrm{H}-3$ & C. wuellerstorfi & 77 & 4.63 & 5.38 & 5.38 & 4.52 & -0.49 & $849 \mathrm{~B}-2 \mathrm{H}-2$ & C. wuellerstorfi & 122 & 9.42 & 11.37 & 11.37 \\
\hline $849 \mathrm{C}-\mathrm{IH}-3$ & U. peregrina & 77 & 4.63 & 5.38 & 5.38 & 4.46 & -0.30 & $849 \mathrm{~B}-2 \mathrm{H}-2$ & $U$. peregrina & 122 & 9.42 & 11.37 & 11.37 \\
\hline $849 \mathrm{C}-1 \mathrm{H}-3$ & $U$. peregrina & 87 & 4.73 & 5.48 & 5.48 & 4.21 & -0.13 & $849 \mathrm{D}-1 \mathrm{H}-3$ & C. wuellerstorfi & 121 & 8.00 & 11.30 & 11.40 \\
\hline $849 \mathrm{C}-1 \mathrm{H}-3$ & C. wuellerstorfi & 97 & 4.83 & 5.58 & 5.58 & 4.26 & -0.37 & $849 \mathrm{D}-1 \mathrm{H}-3$ & U. peregrina & 121 & 8.00 & 11.30 & 11.40 \\
\hline $849 \mathrm{C}-1 \mathrm{H}-3$ & C. wuellerstorfi & 97 & 4.83 & 5.58 & 5.58 & 4.54 & -0.24 & $849 \mathrm{~B}-2 \mathrm{H}-2$ & $U$. peregrina & 131 & 9.51 & 11.46 & 11.46 \\
\hline $849 \mathrm{C}-1 \mathrm{H}-3$ & C. whellerstorfi & 107 & 4.93 & 5.68 & 5.68 & 3.98 & -0.22 & $849 \mathrm{~B}-2 \mathrm{H}-2$ & C. wuellerstorfi & 132 & 9.52 & 11.47 & 11.47 \\
\hline $849 \mathrm{C}-1 \mathrm{H}-3$ & C. wuellerstorfi & 117 & 5.03 & 5.78 & 5.78 & 4.38 & -0.35 & $849 \mathrm{~B}-2 \mathrm{H}-2$ & C. wuellerstorfi & 143 & 9.63 & 11.58 & 11.58 \\
\hline $849 \mathrm{C}-1 \mathrm{H}-3$ & C. wuellerstorfi & 127 & 5.13 & 5.88 & 5.89 & 4.39 & -0.34 & $849 \mathrm{~B}-2 \mathrm{H}-2$ & $U$. peregrina & 143 & 9.63 & 11.58 & 11.58 \\
\hline $849 \mathrm{C}-1 \mathrm{H}-3$ & $U$. peregrina & 127 & 5.13 & 5.88 & 5.89 & 4.21 & -0.31 & $849 \mathrm{~B}-2 \mathrm{H}-3$ & C. wuellerstorfi & 7 & 9.77 & 11.72 & 11.72 \\
\hline $849 \mathrm{C}-1 \mathrm{H}-3$ & C. wuellerstorfi & 137 & 5.23 & 5.98 & 5.99 & 4.16 & -0.41 & $849 \mathrm{~B}-2 \mathrm{H}-3$ & U. peregrina & 7 & 9.77 & 11.72 & 11.72 \\
\hline $849 \mathrm{C}-1 \mathrm{H}-3$ & C. wuellerstorfi & 147 & 5.33 & 6.08 & 6.08 & 4.46 & -0.42 & $849 \mathrm{~B}-2 \mathrm{H}-3$ & C. wuellerstorfi & 17 & 9.87 & 11.82 & 11.82 \\
\hline $849 \mathrm{C}-1 \mathrm{H}-4$ & U. peregrina & 7 & 5.43 & 6.18 & 6.18 & 4.35 & -0.34 & $849 \mathrm{~B}-2 \mathrm{H}-3$ & $U$. peregrina & 17 & 9.87 & 11.82 & 11.82 \\
\hline $849 \mathrm{C}-1 \mathrm{H}-4$ & C. wuellerstorfi & 17 & 5.53 & 6.28 & 6.28 & 4.49 & -0.45 & $849 \mathrm{~B}-2 \mathrm{H}-3$ & C. wuellerstorfi & 27 & 9.97 & 11.92 & 11.92 \\
\hline $849 \mathrm{C}-1 \mathrm{H}-4$ & U. peregrina & 17 & 5.53 & 6.28 & 6.28 & 4.41 & -0.23 & $849 \mathrm{~B}-2 \mathrm{H}-3$ & U. peregrina & 27 & 9.97 & 11.92 & 11.92 \\
\hline $849 \mathrm{C}-1 \mathrm{H}-4$ & C. umellerstorfi & 27 & 5.63 & 6.38 & 6.38 & 4.10 & -0.16 & $849 \mathrm{~B}-2 \mathrm{H}-3$ & C. wuellerstorfi & 38 & 10.08 & 12.03 & 12.03 \\
\hline $849 \mathrm{C}-1 \mathrm{H}-4$ & U. peregrina & 27 & 5.63 & 6.38 & 6.38 & 4.24 & -0.11 & $849 \mathrm{~B}-2 \mathrm{H}-3$ & C. wuellerstorfi & 47 & 10.17 & 12.12 & 12.12 \\
\hline $849 \mathrm{C}-1 \mathrm{H}-4$ & C. wuellerstorfi & 37 & 5.73 & 6.48 & 6.47 & 3,97 & 0.05 & $849 \mathrm{~B}-2 \mathrm{H}-3$ & $U$. peregrina & 47 & 10.17 & 12.12 & 12.12 \\
\hline $849 \mathrm{C}-1 \mathrm{H}-4$ & $U$. peregrina & 37 & 5.73 & 6.48 & 6.47 & 3.80 & -0.06 & $849 \mathrm{~B}-2 \mathrm{H}-3$ & C. wuellerstorfi & 57 & 10.27 & 12.22 & 12.22 \\
\hline $849 \mathrm{C}-1 \mathrm{H}-4$ & C. wuellerstorfi & 47 & 5.83 & 6.58 & 6.57 & 3.91 & -0.01 & $849 \mathrm{~B}-2 \mathrm{H}-3$ & $U$. peregrina & 57 & 10.27 & 12.22 & 12.22 \\
\hline $849 \mathrm{C}-1 \mathrm{H}-4$ & C. wuellerstorfi & 57 & 5.93 & 6.68 & 6.67 & 3.66 & -0.16 & $849 \mathrm{~B}-2 \mathrm{H}-3$ & C. wuellerstorfi & 67 & 10.37 & 12.32 & 12.32 \\
\hline $849 \mathrm{C}-1 \mathrm{H}-4$ & U. peregrina & 57 & 5.93 & 6.68 & 6.67 & 3.75 & 0.10 & $849 \mathrm{~B}-2 \mathrm{H}-3$ & U. peregrina & 67 & 10.37 & 12.32 & 12.32 \\
\hline $849 \mathrm{C}-1 \mathrm{H}-4$ & C. wheilerstorfi & 67 & 6.03 & 6.78 & 6.77 & $3.61-$ & -0.02 & $849 \mathrm{~B}-2 \mathrm{H}-3$ & C. wuellerstorfi & 87 & 10.57 & 12.52 & 12.52 \\
\hline $849 \mathrm{C}-1 \mathrm{H}-4$ & $U$. peregrina & 67 & 6.03 & 6.78 & 6.77 & 3.66 & -0.15 & $849 \mathrm{~B}-2 \mathrm{H}-3$ & $U$. peregrina & 87 & 10.57 & 12.52 & 12.52 \\
\hline $849 \mathrm{C}-1 \mathrm{H}-4$ & C. wuellerstorfi & 77 & 6.13 & 6.88 & 6.88 & $3.76-$ & -0.13 & $849 \mathrm{~B}-2 \mathrm{H}-3$ & C. wuellerstorfi & 97 & 10.67 & 12.62 & 12.62 \\
\hline $849 \mathrm{C}-1 \mathrm{H}-4$ & C. whellerstorfi & 77 & 6.13 & 6.88 & 6.88 & 3.56 & 0.15 & $849 \mathrm{~B}-2 \mathrm{H}-3$ & U. peregrina & 97 & 10.67 & 12.62 & 12.62 \\
\hline $849 \mathrm{C}-1 \mathrm{H}-4$ & U. peregrina & 77 & 6.13 & 6.88 & 6.88 & 3.84 & -0.15 & $849 \mathrm{~B}-2 \mathrm{H}-3$ & C. wuellerstorfi & 107 & 10.77 & 12.72 & 12.72 \\
\hline $849 \mathrm{C}-1 \mathrm{H}-4$ & C. wuellerstonfi & 87 & 6.23 & 6.98 & 6.98 & 3.89 & 0.11 & $849 \mathrm{~B}-2 \mathrm{H}-3$ & $U$. peregrina & 107 & 10.77 & 12.72 & 12.72 \\
\hline $849 \mathrm{C}-1 \mathrm{H}-4$ & C. wuellerstorfi & 97 & 6.33 & 7.08 & 7.08 & $3.61-$ & -0.04 & $849 \mathrm{~B}-2 \mathrm{H}-3$ & U. peregrina & 141 & 11.11 & 13.06 & 13.06 \\
\hline $849 \mathrm{C}-1 \mathrm{H}-4$ & C. wuellerstorfi & 107 & 6.43 & 7.18 & 7.18 & $3.64-$ & -0.03 & $849 \mathrm{~B}-2 \mathrm{H}-4$ & C. wuellerstorfi & 13 & 11.33 & 13.28 & 13.28 \\
\hline
\end{tabular}


APPENDIX A (continued).

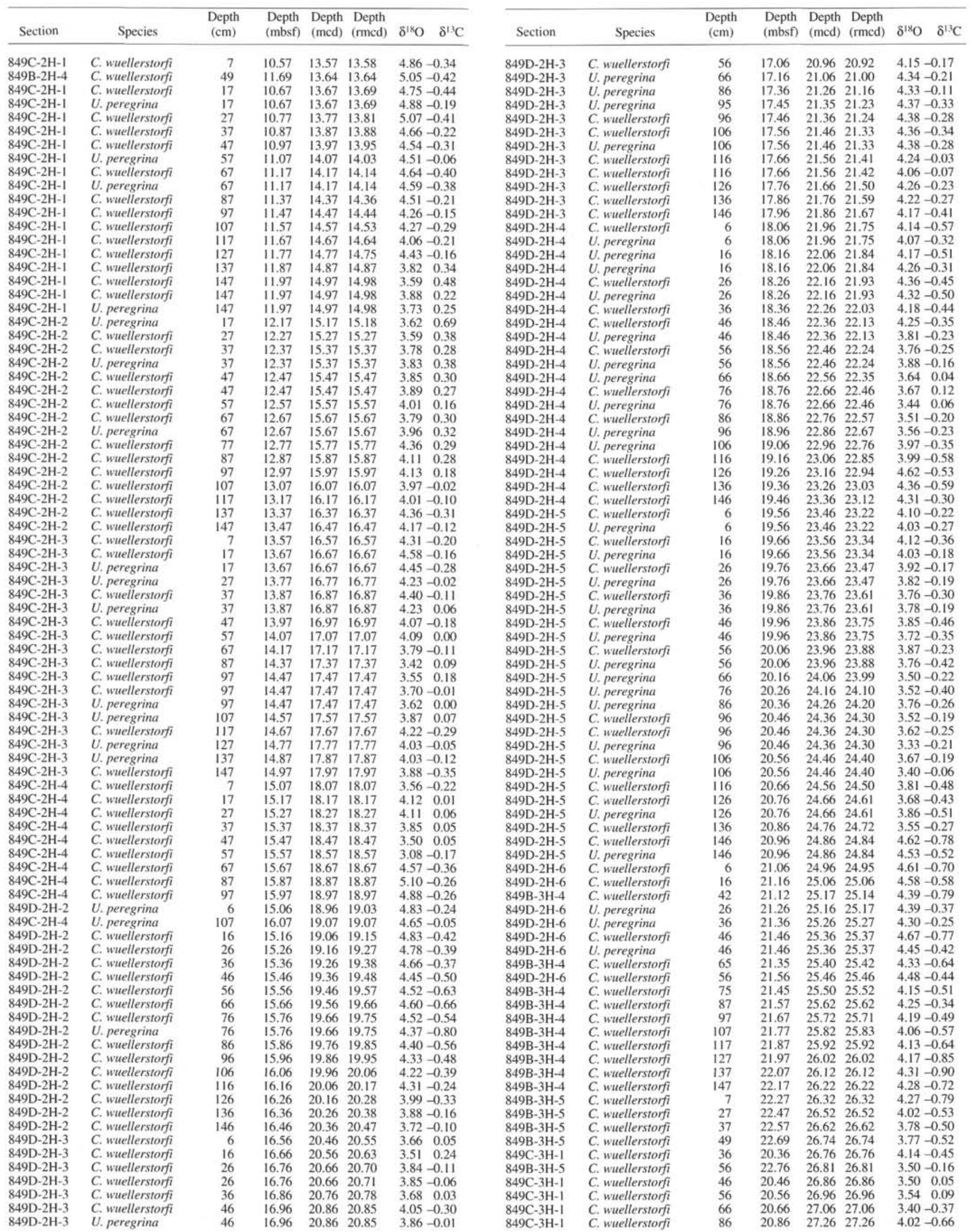


APPENDIX A (continued).

\begin{tabular}{|c|c|c|c|c|c|c|c|c|c|c|c|c|}
\hline Section & Species & $\begin{array}{l}\text { Depth } \\
(\mathrm{cm})\end{array}$ & $\begin{array}{l}\text { Depth } \\
\text { (mbsf) }\end{array}$ & $\begin{array}{l}\text { Depth } \\
\text { (med) }\end{array}$ & $\begin{array}{l}\text { Depth } \\
\text { (rmcd) }\end{array}$ & $\delta^{1 x} \mathrm{O} \quad \delta^{13} \mathrm{C}$ & Section & Species & $\begin{array}{l}\text { Depth } \\
(\mathrm{cm})\end{array}$ & $\begin{array}{l}\text { Depth } \\
\text { (mbst) }\end{array}$ & $\begin{array}{l}\text { Depth } \\
\text { (mcd) }\end{array}$ & $\begin{array}{l}\text { Depth } \\
\text { (rmcd) }\end{array}$ \\
\hline $849 \mathrm{C}-3 \mathrm{H}-\mathrm{I}$ & $U$. peregrina & 86 & 20.86 & 27.26 & 27.26 & $3.90-0.48$ & 849D-3H-5 & U. peregrina & 106 & 29.80 & 33.65 & 33.67 \\
\hline $849 \mathrm{C}-3 \mathrm{H}-\mathrm{I}$ & C. wuellerstorfi & 96 & 20.96 & 27.36 & 27.36 & $4.27-0.50$ & 849D-3H-5 & C. wuellerstorfi & 116 & 29.90 & 33.75 & 33.73 \\
\hline $849 \mathrm{C}-3 \mathrm{H}-1$ & C. wuellerstorfi & 106 & 21.06 & 27.46 & 27.46 & $4.34-0.22$ & 849D-3H-5 & $U$. peregrina & 116 & 29.90 & 33.75 & 33.73 \\
\hline $849 \mathrm{C}-3 \mathrm{H}-\mathrm{I}$ & C. wuellerstorfi & 116 & 21.16 & 27.56 & 27.56 & $4.17-0.12$ & $849 \mathrm{D}-3 \mathrm{H}-5$ & C. wuellerstorfi & 126 & 30.00 & 33.85 & 33.80 \\
\hline $849 \mathrm{C}-3 \mathrm{H}-1$ & C. wuellerstorfi & 126 & 21.26 & 27.66 & 27.66 & $3.87-0.13$ & $849 \mathrm{D}-3 \mathrm{H}-5$ & $U$. peregrina & 126 & 30.00 & 33.85 & 33.80 \\
\hline $849 \mathrm{C}-3 \mathrm{H}-\mathrm{I}$ & C. wuellerstorfi & 136 & 21.36 & 27.76 & 27.76 & $3.71-0.16$ & 849D-3H-5 & C. wuellerstorfi & 136 & 30.10 & 33.95 & 33.88 \\
\hline $849 \mathrm{C}-3 \mathrm{H}-\mathrm{I}$ & C. wuellerstorfi & 146 & 21.46 & 27.86 & 27.86 & $3.76-0.26$ & 849D-3H-5 & $U$. peregrina & 136 & 30.10 & 33.95 & 33.88 \\
\hline $849 \mathrm{C}-3 \mathrm{H}-2$ & C. wuellerstorfi & 6 & 21.56 & 27.96 & 27.96 & $4.06-0.32$ & 849D-3H-5 & C. wuellerstorfi & 146 & 30.20 & 34.05 & 33.99 \\
\hline $849 \mathrm{C}-3 \mathrm{H}-2$ & C, wuellerstorfi & 16 & 21.66 & 28.06 & 28.06 & $4.15-0.32$ & $849 \mathrm{D}-3 \mathrm{H}-6$ & C. wuellerstorfi & 6 & 30.30 & 34.15 & 34.15 \\
\hline $849 \mathrm{C}-3 \mathrm{H}-2$ & C. wuellerstorfi & 26 & 21.76 & 28.16 & 28.15 & $\begin{array}{ll}3.87 & 0.03\end{array}$ & 849D-3H-6 & C. wuellerstorfi & 16 & 30.40 & 34.25 & 34.37 \\
\hline $849 \mathrm{C}-3 \mathrm{H}-2$ & C. wuellerstorfi & 36 & 21.86 & 28.26 & 28.26 & $3.90-0.08$ & $849 \mathrm{D}-3 \mathrm{H}-6$ & C. wuellerstorfi & 26 & 30.50 & 34.35 & 34.63 \\
\hline $849 \mathrm{C}-3 \mathrm{H}-2$ & C. wuellerstorfi & 46 & 21.96 & 28.36 & 28.37 & $3.96-0.16$ & 849D-3H-6 & C. wuellerstorfi & 36 & 30.60 & 34.45 & 34.78 \\
\hline $849 \mathrm{C}-3 \mathrm{H}-2$ & C. wuellerstorfi & 56 & 22.06 & 28.46 & 28.47 & $4.09-0.23$ & 849D-3H-6 & C. wuellerstorfi & 46 & 30.70 & 34.55 & 34.85 \\
\hline $849 \mathrm{C}-3 \mathrm{H}-2$ & C. wuellerstorfi & 66 & 22.16 & 28.56 & 28.56 & $4.28-0.11$ & 849D-3H-6 & $U$. peregrina & 46 & 30.70 & 34.55 & 34.85 \\
\hline $849 \mathrm{C}-3 \mathrm{H}-2$ & C. wuellerstorfi & 76 & 22.26 & 28.66 & 28.66 & $4.04-0.08$ & 849D-3H-6 & C. wuellerstorfi & 56 & 30.80 & 34.65 & 34.89 \\
\hline $849 \mathrm{C}-3 \mathrm{H}-2$ & C. wuellerstorfi & 86 & 22.36 & 28.76 & 28.75 & 3.890 .02 & $849 \mathrm{D}-3 \mathrm{H}-6$ & $U$. peregrina & 56 & 30.80 & 34.65 & 34.89 \\
\hline $849 \mathrm{C}-3 \mathrm{H}-2$ & C. wuellerstorfi & 96 & 22.46 & 28.86 & 28.85 & $\begin{array}{ll}3.69 & 0.07\end{array}$ & 849D-3H-6 & C. wuellerstorfi & 66 & 30.90 & 34.75 & 34.93 \\
\hline $849 \mathrm{C}-3 \mathrm{H}-2$ & C. wuellerstorfi & 106 & 22.56 & 28.96 & 28.96 & $\begin{array}{ll}3.67 & 0.05\end{array}$ & 849D-3H-6 & U. peregrina & 66 & 30.90 & 34.75 & 34.93 \\
\hline $849 \mathrm{C}-3 \mathrm{H}-2$ & C. wuellerstorfi & 116 & 22.66 & 29.06 & 29.06 & $3.88-0.12$ & $849 \mathrm{D}-3 \mathrm{H}-6$ & C. wuellerstorfi & 76 & 31.00 & 34.85 & 34.97 \\
\hline $849 \mathrm{C}-3 \mathrm{H}-2$ & C. wuellerstorfi & 126 & 22.76 & 29.16 & 29.16 & $3.92-0.14$ & 849D-3H-6 & U. peregrina & 76 & 31.00 & 34.85 & 34.97 \\
\hline $849 \mathrm{C}-3 \mathrm{H}-2$ & C. wuellerstorfi & 136 & 22.86 & 29.26 & 29.25 & $4.31-0.26$ & 849D-3H-6 & C. wuellerstorfi & 86 & 31.10 & 34.95 & 35.01 \\
\hline $849 \mathrm{C}-3 \mathrm{H}-2$ & C. wuellerstorfi & 146 & 22.96 & 29.36 & 29.36 & $4.43-0.29$ & 849D-3H-6 & C. wuellerstorfi & 96 & 31.20 & 35.05 & 35.06 \\
\hline 849D-3H-3 & $U$. peregrina & 6 & 25.80 & 29.65 & 29.53 & $4.18-0.58$ & 849D-3H-6 & U. peregrina & 96 & 31.20 & 35.05 & 35.06 \\
\hline 849D-3H-3 & C. wuellerstorfi & 6 & 25.80 & 29.65 & 29.56 & $4.19-0.53$ & 849D-3H-6 & C. wuellerstorfi & 106 & 31.30 & 35.15 & 35.13 \\
\hline $849 \mathrm{D}-3 \mathrm{H}-3$ & C. wuellerstorfi & 16 & 25.90 & 29.75 & 29.68 & $4.07-0.45$ & $849 \mathrm{D}-3 \mathrm{H}-6$ & $U$. peregrina & 106 & 31.30 & 35.15 & 35.13 \\
\hline 849D-3H-3 & $U$. peregrina & 26 & 26.00 & 29.85 & 29.79 & $3.97-0.24$ & 849D-3H- 6 & $U$. peregrina & 116 & 31.40 & 35.25 & 35.27 \\
\hline 849D-3H-3 & $U$. peregrina & 36 & 26.10 & 29.95 & 29.89 & $3.65-0.10$ & 849D-3H-6 & C. wuellerstorfi & 126 & 31.50 & 35.35 & 35.45 \\
\hline $849 \mathrm{D}-3 \mathrm{H}-3$ & C. wuellerstorfi & 46 & 26.20 & 30.05 & 29.99 & $3.50-0.02$ & 849D-3H-6 & $U$. peregrina & 126 & 31.50 & 35.35 & 35.45 \\
\hline 849D-3H-3 & C. wuellerstorfi & 56 & 26.30 & 30.15 & 30.10 & $3.27 \quad 0.09$ & $849 \mathrm{D}-3 \mathrm{H}-6$ & C. wuellerstorfi & 136 & 31.60 & 35.45 & 35.60 \\
\hline 849D-3H-3 & $U$. peregrina & 56 & 26.30 & 30.15 & 30.10 & $3.06-0.04$ & 849D-3H-6 & $U$. peregrina & 136 & 31.60 & 35.45 & 35.60 \\
\hline 849D-3H-3 & C. wuellerstorfi & 66 & 26.40 & 30.25 & 30.21 & $3.38-0.05$ & 849D-3H-6 & C. wuellerstorfi & 146 & 31.70 & 35.55 & 35.71 \\
\hline 849D-3H-3 & U. peregrina & 66 & 26.40 & 30.25 & 30.21 & 3.220 .19 & 849D-3H-7 & C. wuellerstorfi & 6 & 31.80 & 35.65 & 35.78 \\
\hline 849D-3H-3 & C. wuellerstorfi & 76 & 26.50 & 30.35 & 30.31 & 3.620 .20 & 849D-3H-7 & C. wuellerstorfi & 16 & 31.90 & 35.75 & 35.86 \\
\hline 849D-3H-3 & C. wuellerstorfi & 86 & 26.60 & 30.45 & 30.40 & $\begin{array}{ll}3.76 & 0.03\end{array}$ & 849D-3H-7 & $U$. peregrina & 26 & 32.00 & 35.85 & 35.93 \\
\hline 849D-3H-3 & $U$. peregrina & 86 & 26.60 & 30.45 & 30.40 & $3.65-0.06$ & 849D-3H-7 & C. wuellerstorfi & 36 & 32.10 & 35.95 & 36.01 \\
\hline 849D-3H-3 & $U$. peregrina & 96 & 26.70 & 30.55 & 30.47 & $3.75-0.06$ & 849D-3H-7 & $U$. peregrina & 36 & 32.10 & 35.95 & 36.01 \\
\hline $849 \mathrm{D}-3 \mathrm{H}-3$ & C. wuellerstorfi & 106 & 26.80 & 30.65 & 30.55 & $4.08-0.16$ & $849 \mathrm{D}-3 \mathrm{H}-7$ & C. wuellerstorfi & 46 & 32.20 & 36.05 & 36.11 \\
\hline 849D-3H-3 & $U$. peregrina & 106 & 26.80 & 30.65 & 30.55 & $\begin{array}{lll}3.89 & 0.13\end{array}$ & 849D-3H-7 & U. peregrina & 46 & 32.20 & 36.05 & 36.11 \\
\hline 849D-3H-3 & C. wuellerstorfi & 116 & 26.90 & 30.75 & 30.65 & $3.66-0.26$ & 849D-3H-7 & C. wuellerstorfi & 56 & 32.30 & 36.15 & 36.22 \\
\hline 849D-3H-3 & $U$. peregrina & 116 & 26.90 & 30.75 & 30.65 & $3.98-0.29$ & 849D-3H-7 & $U$. peregrina & 56 & 32.30 & 36.15 & 36.22 \\
\hline 849D-3H-3 & C. wuellerstorfi & 126 & 27.00 & 30.85 & 30.77 & $4.26-0.30$ & 849D-3H-7 & C. wuellerstorfi & 66 & 32.40 & 36.25 & 36.35 \\
\hline 849D-3H-3 & $U$. peregrina & 126 & 27.00 & 30.85 & 30.77 & $4.19-0.41$ & 849D-3H-7 & U. peregrina & 66 & 32.40 & 36.25 & 36.35 \\
\hline 849D-3H-3 & C. wuellerstorfi & 136 & 27.10 & 30.95 & 30.90 & $4.06-0.16$ & 849D-3H-7 & $U$. peregrina & 76 & 32.50 & 36.35 & 36.51 \\
\hline $849 \mathrm{D}-3 \mathrm{H}-3$ & $U$. peregrina & 136 & 27.10 & 30.95 & 30.90 & $3.88-0.15$ & $849 \mathrm{D}-3 \mathrm{H}-7$ & C. wuellerstorfi & 76 & 32.50 & 36.35 & 36.52 \\
\hline $849 \mathrm{D}-3 \mathrm{H}-3$ & C. wuellerstorfi & 146 & 27.20 & 31.05 & 31.03 & $\begin{array}{ll}3.92 & 0.01\end{array}$ & 849D-3H-7 & $U$. peregrina & 76 & 32.50 & 36.35 & 36.52 \\
\hline 849D-3H-4 & C. wuellerstorfi & 16 & 27.40 & 31.25 & 31.24 & $4.00-0.20$ & $849 \mathrm{C}-4 \mathrm{H}-1$ & C. wuellerstorfi & 6 & 29.56 & 36.66 & 36.74 \\
\hline 849D-3H-4 & C. wuellerstorfi & 26 & 27.50 & 31.35 & 31.34 & $4.04-0.36$ & $849 \mathrm{C}-4 \mathrm{H}-1$ & C. wuellerstorfi & 16 & 29.66 & 36.76 & 36.85 \\
\hline 849D-3H-4 & C. wuellerstorfi & 36 & 27.60 & 31.45 & 31.45 & $4.28-0.44$ & $849 \mathrm{C}-4 \mathrm{H}-1$ & C. wuellerstorfi & 26 & 29.76 & 36.86 & 36.96 \\
\hline 849D-3H-4 & $U$. peregrina & 46 & 27.70 & 31.55 & 31.56 & $4.25-0.35$ & $849 \mathrm{C}-4 \mathrm{H}-1$ & C. wuellerstorfi & 36 & 29.86 & 36.96 & 37.08 \\
\hline 849D-3H-4 & C. wuellerstorfi & 56 & 27.80 & 31.65 & 31.67 & $4.34-0.34$ & $849 \mathrm{C}-4 \mathrm{H}-1$ & C. wuellerstorfi & 46 & 29.96 & 37.06 & 37.20 \\
\hline 849D-3H-4 & $U$. peregrina & 56 & 27.80 & 31.65 & 31.67 & $4.03-0.29$ & $849 \mathrm{C}-4 \mathrm{H}-1$ & C. wuellerstorfi & 56 & 30.06 & 37.16 & 37.29 \\
\hline 849D-3H-4 & C. wuellerstorfi & 66 & 27.90 & 31.75 & 31.77 & $4.24-0.29$ & $849 \mathrm{C}-4 \mathrm{H}-1$ & C. wuellerstorfi & 66 & 30.16 & 37.26 & 37.38 \\
\hline 849D-3H-4 & $U$. peregrina & 66 & 27.90 & 31.75 & 31.77 & $4.16-0.29$ & $849 \mathrm{C}-4 \mathrm{H}-2$ & C. wuellerstorfi & 6 & 30.28 & 37.38 & 37.47 \\
\hline 849D-3H-4 & C. wuellerstorfi & 76 & 28.00 & 31,85 & 31.88 & $4.17-0.39$ & $849 \mathrm{C}-4 \mathrm{H}-2$ & C. wuellerstorfi & 16 & 30.38 & 37.48 & 37.54 \\
\hline 849D-3H-4 & C. wuellerstorfi & 86 & 28.10 & 31.95 & 31.99 & $3.96-0.34$ & $849 \mathrm{C}-4 \mathrm{H}-2$ & C. wuellerstorfi & 26 & 30.48 & 37.58 & 37.61 \\
\hline 849D-3H-4 & C. wuellerstorfi & 96 & 28.20 & 32.05 & 32.12 & $3.85-0.05$ & $849 \mathrm{C}-4 \mathrm{H}-2$ & C. wuellerstorfi & 36 & 30.58 & 37.68 & 37.67 \\
\hline 849D-3H-4 & C. wuellerstorfi & 106 & 28.30 & 32.15 & 32.24 & $3.79-0.29$ & $849 \mathrm{C}-4 \mathrm{H}-2$ & C. wuellerstorfi & 46 & 30.68 & 37.78 & 37.73 \\
\hline 849D-3H-4 & U. peregrina & 106 & 28.30 & 32.15 & 32.24 & $\begin{array}{ll}3.67 & 0.02\end{array}$ & $849 \mathrm{C}-4 \mathrm{H}-2$ & C. wuellerstorfi & 56 & 30.78 & 37.88 & 37.80 \\
\hline $849 \mathrm{D}-3 \mathrm{H}-4$ & C. wuellerstorfi & 116 & 28.40 & 32.25 & 32.34 & $3.95 \quad 0.04$ & $849 \mathrm{C}-4 \mathrm{H}-2$ & C. wuellerstorfi & 66 & 30.88 & $37.98:$ & 37.89 \\
\hline $849 \mathrm{D}-3 \mathrm{H}-4$ & $U$. peregrina & 116 & 28.40 & 32.25 & 32.34 & $3.61-0.05$ & $849 \mathrm{C}-4 \mathrm{H}-2$ & C. wuellerstorfi & 76 & 30.98 & 38.08 & 38.04 \\
\hline 849D-3H-4 & C. wuellerstorfi & 126 & 28.50 & 32.35 & 32.41 & $\begin{array}{ll}3.71 & 0.12\end{array}$ & $849 \mathrm{C}-4 \mathrm{H}-2$ & C. wuellerstorfi & 86 & 31.08 & 38.18 & 38.22 \\
\hline 849D-3H-4 & U. peregrina & 126 & 28.50 & 32.35 & 32.41 & 3.640 .06 & $849 \mathrm{C}-4 \mathrm{H}-2$ & C. wuellerstorfi & 96 & 31.18 & 38.28 & 38.36 \\
\hline 849D-3H-4 & C. wuellerstorfi & 136 & 28.60 & 32.45 & 32.47 & $\begin{array}{ll}3.56 & 0.12\end{array}$ & $849 \mathrm{C}-4 \mathrm{H}-2$ & C. wuellerstorfi & 106 & 31.28 & 38.38 & 38.46 \\
\hline 849D-3H-4 & $U$. peregrina & 136 & 28.60 & 32.45 & 32.47 & 3.530 .04 & $849 \mathrm{C}-4 \mathrm{H}-2$ & C. wuellerstorfi & 116 & 31.38 & 38.48 & 38.56 \\
\hline 849D-3H-4 & C. wuellerstorfi & 146 & 28.70 & 32.55 & 32.52 & $\begin{array}{ll}3.55 & 0.13\end{array}$ & $849 \mathrm{C}-4 \mathrm{H}-2$ & C. wuellerstorfi & 126 & 31.48 & 38.58 & 38.65 \\
\hline 849D-3H-5 & C. wuellerstorfi & 6 & 28.80 & 32.65 & 32.58 & $\begin{array}{ll}3.62 & 0.14\end{array}$ & $849 \mathrm{C}-4 \mathrm{H}-2$ & C. wuellerstorfi & 136 & 31.58 & 38.68 & 38.74 \\
\hline 849D-3H-5 & C. wuellerstorfi & 16 & 28.90 & 32.75 & 32.62 & $\begin{array}{ll}3.83 & 0.16\end{array}$ & $849 \mathrm{C}-4 \mathrm{H}-2$ & C. wuellerstorfi & 146 & 31.68 & 38.78 & 38.82 \\
\hline $849 \mathrm{D}-3 \mathrm{H}-5$ & U. peregrina & 16 & 28.90 & 32.75 & 32.62 & $3.89-0.05$ & $849 \mathrm{C}-4 \mathrm{H}-2$ & C. wuellerstorfi & 146 & 31.68 & 38.78 & 38.82 \\
\hline 849D-3H-5 & C. wuellerstorfi & 26 & 29.00 & 32.85 & 32.69 & $\begin{array}{ll}3.95 & 0.11\end{array}$ & $849 \mathrm{C}-4 \mathrm{H}-3$ & C. wuellerstorfi & 6 & 31.78 & 38.88 & 38.90 \\
\hline 849D-3H-5 & C. wuellerstorfi & 36 & 29.10 & 32.95 & 32.78 & $3.91 \quad 0.19$ & $849 \mathrm{C}-4 \mathrm{H}-3$ & C. wuellerstorfi & 16 & 31.88 & 38.98 & 38.98 \\
\hline $849 \mathrm{D}-3 \mathrm{H}-5$ & $U$. peregrina & 36 & 29.10 & 32.95 & 32.78 & $\begin{array}{ll}3.74 & 0.14\end{array}$ & $849 \mathrm{C}-4 \mathrm{H}-3$ & C. wuellerstorfi & 26 & 31.98 & 39.08 & 39.08 \\
\hline 849D-3H-5 & C. wuellerstorfi & 46 & 29.20 & 33.05 & 32.90 & $3.95-0.30$ & 849D-4H-1 & C. wuellerstorfi & 16 & 32.66 & 39.21 & 39.15 \\
\hline 849D-3H-5 & $U$. peregrina & 46 & 29.20 & 33.05 & 32.90 & $3.93-0.19$ & $849 \mathrm{C}-4 \mathrm{H}-3$ & C. wuellerstorfi & 36 & 32.08 & 39.18 & 39.18 \\
\hline 849D-3H-5 & C. wuellerstorfi & 56 & 29.30 & 33.15 & 33.07 & $4.25-0.34$ & $849 \mathrm{D}-4 \mathrm{H}-1$ & C. wuellerstorfi & 26 & 32.76 & 39.31 & 39.22 \\
\hline 849D-3H-5 & U. peregrina & 56 & 29.30 & 33.15 & 33.07 & $4.06-0.24$ & $849 \mathrm{C}-4 \mathrm{H}-3$ & C. wuellerstorfi & 46 & 32.18 & 39.28 & 39.28 \\
\hline $849 \mathrm{D}-3 \mathrm{H}-5$ & C. wuellerstorfi & 66 & 29.40 & 33.25 & 33.28 & $4.30-0.33$ & 849D-4H-1 & C. wuellerstorfi & 36 & 32.86 & 39.41 & 39.29 \\
\hline 849D-3H-5 & C. wuellerstorfi & 66 & 29.40 & 33.25 & 33.28 & $4.40-0.31$ & $849 \mathrm{D}-4 \mathrm{H}-1$ & C. wuellerstorfi & 46 & 32.96 & 39.51 & 39.39 \\
\hline 849D-3H-5 & U. peregrina & 66 & 29.40 & 33.25 & 33.28 & $4.38-0.25$ & 849D-4H-I & C. wuellerstorfi & 66 & 33.16 & 39.71 & 39.78 \\
\hline 849D-3H-5 & $U$. peregrina & 66 & 29.40 & 33.25 & 33.28 & $4.40-0.29$ & 849D-4H-I & C. wuellerstorfi & 76 & 33.26 & 39.81 & 39.90 \\
\hline 849D-3H-5 & C. wuellerstorfi & 76 & 29.50 & 33.35 & 33.44 & $4.49-0.44$ & 849D-4H-1 & C. wuellerstorfi & 96 & 33.46 & 40.01 & 40.05 \\
\hline 849D-3H-5 & C. wuellerstorfi & 86 & 29.60 & 33.45 & 33.53 & $4.44-0.36$ & 849D-4H-1 & C. wuellerstorfi & 106 & 33.56 & 40.11 & 40.12 \\
\hline 849D-3H-5 & U. peregrina & 86 & 29.60 & 33.45 & 33.53 & $4.33-0.16$ & 849D-4H-1 & C. wuellerstorfi & 116 & 33.66 & 40.21 & 40.21 \\
\hline 849D-3H-5 & C. wuellerstorfi & 96 & 29.70 & 33.55 & 33.61 & $4.10-0.42$ & $849 \mathrm{D}-4 \mathrm{H}-1$ & C. wuellerstorfi & 126 & 33.76 & 40.31 & 40.34 \\
\hline 849D-3H-5 & U. peregrina & 96 & 29.70 & 33.55 & 33.61 & $4.26-0.34$ & 849D-4H-1 & C. wuellerstorfi & 136 & 33.86 & 40.41 & 40.48 \\
\hline 849D-3H-5 & C. wuellerstorfi & 106 & 29.80 & 33.65 & 33.67 & $4.20-0.39$ & $849 \mathrm{D}-4 \mathrm{H}-1$ & C. wuellerstorfi & 146 & 33.96 & 40.51 & 40.60 \\
\hline
\end{tabular}


APPENDIX A (continued).

\begin{tabular}{|c|c|c|c|c|c|c|c|c|c|c|}
\hline Section & Species & $\begin{array}{l}\text { Depth } \\
\text { (cm) }\end{array}$ & $\begin{array}{l}\text { Depth } \\
\text { (mbsf) }\end{array}$ & $\begin{array}{l}\text { Depth } \\
\text { (mcd) }\end{array}$ & $\begin{array}{l}\text { Depth } \\
\text { (rmcd) }\end{array}$ & $\delta^{1 x} O$ & Section & Species & $\begin{array}{l}\text { Depth } \\
\text { (cm) }\end{array}$ & $\begin{array}{l}\text { Depth } \\
\text { (mbsf) }\end{array}$ \\
\hline 849D-4H-2 & C. wuellerstorfi & 6 & 34.06 & 40.61 & 40.69 & $3.48-0.01$ & $849 \mathrm{C}-5 \mathrm{H}-1$ & C. wuellerstorfi & 76 & 39.76 \\
\hline 849D-4H-2 & C. wuellerstorfi & 16 & 34.16 & 40.71 & 40.77 & $\begin{array}{ll}3.51 & 0.28\end{array}$ & $849 \mathrm{C}-5 \mathrm{H}-1$ & C. wuellerstorfi & 86 & 39.86 \\
\hline 849D-4H-2 & C. wuellerstorfi & 16 & 34.16 & 40.71 & 40.78 & $3.50-0.03$ & $849 \mathrm{C}-5 \mathrm{H}-\mathrm{I}$ & C. wuellerstorfi & 96 & 39.96 \\
\hline 849D-4H-2 & C. wuellerstorfi & 26 & 34.26 & 40.81 & 40.86 & $3.28-0.13$ & $849 \mathrm{C}-5 \mathrm{H}-1$ & C. wuellerstorfi & 106 & 40.06 \\
\hline 849D-4H-2 & C. wuellerstorfi & 36 & 34.36 & 40.91 & 40.97 & $3.46-0.27$ & $849 \mathrm{C}-5 \mathrm{H}-1$ & C. wuellerstorfi & 116 & 40.16 \\
\hline 849D-4H-2 & C. wuellerstorfi & 46 & 34.46 & 41.01 & 41.12 & $3.53-0.17$ & $849 \mathrm{C}-5 \mathrm{H}-1$ & C. wuellerstorf $i$ & 126 & 40.26 \\
\hline 849D-4H-2 & C. wuellerstorfi & 56 & 34.56 & 41.11 & 41.26 & $4.00-0.37$ & $849 \mathrm{C}-5 \mathrm{H}-1$ & C. wuellerstorfi & 136 & 40.36 \\
\hline 849D-4H-2 & $U$. peregrina & 56 & 34.56 & 41.11 & 41.26 & $4.31-0.68$ & $849 \mathrm{C}-5 \mathrm{H}-1$ & C. wuellerstorfi & 146 & 40.46 \\
\hline 849D-4H-2 & C. wuellerstorfi & 66 & 34.66 & 41.21 & 41.34 & $4.25-0.35$ & $849 \mathrm{C}-5 \mathrm{H}-2$ & C. wuellerstorfi & 6 & 40.56 \\
\hline 849D-4H-2 & C. wuellerstorfi & 76 & 34.76 & 41.31. & 41.40 & $3.40 \quad 0.20$ & $849 \mathrm{C}-5 \mathrm{H}-2$ & C. wuellerstorfi & 16 & 40.66 \\
\hline $849 \mathrm{D}-4 \mathrm{H}-2$ & C. wuellerstorfi & 106 & 35.06 & 41.61 & 41.53 & $\begin{array}{ll}3.50 & 0.24\end{array}$ & $849 \mathrm{C}-5 \mathrm{H}-2$ & C, wuellerstorfi & 36 & 40.86 \\
\hline 849D-4H-2 & C. wuellerstorfi & 116 & 35.16 & 41.71 & 41.57 & $3.41 \quad 0.38$ & $849 \mathrm{C}-5 \mathrm{H}-2$ & C. wuellerstorfi & 46 & 40.96 \\
\hline 849D-4H-2 & C. wuellerstorfi & 136 & 35.36 & 41.91 & 41.75 & $4.11-0.21$ & $849 \mathrm{C}-5 \mathrm{H}-2$ & C. wuellerstorfi & 56 & 41.06 \\
\hline 849D-4H-2 & C. wuellerstorfi & 146 & 35.46 & 42.01 & 41.95 & $4.39-0.16$ & $849 \mathrm{C}-5 \mathrm{H}-2$ & C. wuellerstorfi & 66 & 41.16 \\
\hline 849D-4H-3 & C. wuellerstorfi & 6 & 35.56 & 42.11 & 42.15 & $4.28-0.11$ & $849 \mathrm{C}-5 \mathrm{H}-2$ & C. wuellerstorfi & 76 & 41.26 \\
\hline 849D-4H-3 & C. wuellerstorfi & 16 & 35.66 & 42.21 & 42.25 & $4.19-0.29$ & $849 \mathrm{C}-5 \mathrm{H}-2$ & C. wuellerstorfi & 86 & 41.36 \\
\hline 849D-4H-3 & C. wuellerstorfi & 26 & 35.76 & 42.31 & 42.32 & $\begin{array}{lll}4.11 & 0.01\end{array}$ & $849 \mathrm{C}-5 \mathrm{H}-2$ & C. wuellerstorfi & 96 & 41.46 \\
\hline 849D-4H-3 & C. wuellerstorfi & 36 & 35.86 & 42.41 & 42.38 & 3.710 .29 & $849 \mathrm{C}-5 \mathrm{H}-2$ & C. wuellerstorfi & 116 & 41.66 \\
\hline 849D-4H-3 & C. wuellerstorfi & 46 & 35.96 & 42.51 & 42.44 & $3.76-0.03$ & $849 \mathrm{C}-5 \mathrm{H}-2$ & C. wuellerstorfi & 136 & 41.86 \\
\hline 849D-4H-3 & C. wuellerstorfi & 56 & 36.06 & 42.61 & 42.51 & 3.690 .30 & $849 \mathrm{C}-5 \mathrm{H}-2$ & C. wuellerstorfi & 146 & 41.96 \\
\hline 849D-4H-3 & C. wuellerstorfi & 76 & 36.26 & 42.81 & 42.71 & $3.91-0.28$ & $849 \mathrm{C}-5 \mathrm{H}-3$ & C. wuellerstorf $i$ & 6 & 42.06 \\
\hline 849D-4H-3 & C. wuellerstorfi & 86 & 36.36 & 42.91 & 42.85 & $4.04-0.31$ & $849 \mathrm{C}-5 \mathrm{H}-3$ & C. wuellerstorfi & 16 & 42.16 \\
\hline 849D-4H-3 & $U$. peregrina & 86 & 36.36 & 42.91 & 42.85 & $4.31-0.62$ & $849 \mathrm{C}-5 \mathrm{H}-3$ & C. wuellerstorfi & 26 & 42.26 \\
\hline 849D-4H-3 & C. wuellerstorfi & 96 & 36.46 & 43.01 & 43.00 & $4.47-0.52$ & $849 \mathrm{C}-5 \mathrm{H}-3$ & C. wuellerstorfi & 36 & 42.36 \\
\hline 849D-4H-3 & C. wuellerstorfi & 106 & 36.56 & 43.11 & 43.13 & $4.23-0.48$ & $849 \mathrm{C}-5 \mathrm{H}-3$ & C. wuellerstorfi & 46 & 42.46 \\
\hline 849D-4H-3 & C. wuellerstorfi & 106 & 36.56 & 43.11 & 43.14 & $4.23-0.50$ & $849 \mathrm{C}-5 \mathrm{H}-3$ & C. wuellerstorfi & 56 & 42.56 \\
\hline 849D $-4 \mathrm{H}-3$ & C. wuellerstorfi & 116 & 36.66 & 43.21 & 43.24 & $4.32-0.32$ & $849 \mathrm{C}-5 \mathrm{H}-3$ & C. wuellerstorfi & 66 & 42.66 \\
\hline 849D-4H-3 & C. wuellerstorfi & 126 & 36.76 & 43.31 & 43.32 & $4.03-0.13$ & $849 \mathrm{C}-5 \mathrm{H}-3$ & C. wuellerstorfi & 76 & 42.76 \\
\hline 849D-4H-3 & C. wuellerstorfi & 136 & 36.86 & 43.41 & 43.39 & $4.08-0.18$ & $849 \mathrm{C}-5 \mathrm{H}-3$ & C. wuellerstorfi & 86 & 42.86 \\
\hline 849D-4H-3 & U. peregrina & 136 & 36.86 & 43.41 . & 43.39 & $3.95-0.17$ & 849D-5H-I & C. wuellerstorfi & 76 & 42.76 \\
\hline $849 \mathrm{D}-4 \mathrm{H}-3$ & $U$. peregrina & 146 & 36.96 & 43.51 & 43.46 & $3.74-0.19$ & 849D-5H-I & $U$. peregrina & 76 & 42.76 \\
\hline 849D-4H-4 & C. wuellerstorfi & 6 & 37.06 & 43.61 & 43.52 & $\begin{array}{ll}3.73 & 0.07\end{array}$ & $849 \mathrm{D}-5 \mathrm{H}-\mathrm{I}$ & $U$. peregrina & 86 & 42.86 \\
\hline 849D-4H-4 & $U$. peregrina & 6 & 37.06 & 43.61 & 43.52 & $\begin{array}{ll}3.76 & 0.10\end{array}$ & $849 \mathrm{D}-5 \mathrm{H}-\mathrm{I}$ & C. wuellerstorfi & 96 & 42.96 \\
\hline 849D-4H-4 & C. wuellerstorfi & 26 & 37.26 & 43.81 & 43.69 & $\begin{array}{ll}3.48 & 0.18\end{array}$ & 849D-5H-I & C. wuellerstorfi & 96 & 42.96 \\
\hline 849D-4H-4 & $U$. peregrina & 26 & 37.26 & 43.81 & 43.69 & $\begin{array}{ll}3.45 & 0.02\end{array}$ & $849 \mathrm{D}-5 \mathrm{H}-\mathrm{I}$ & C. wuellerstorfi & 106 & 43.06 \\
\hline 849D-4H-4 & C. wuellerstorfi & 36 & 37.36 & 43.91 & 43.82 & $\begin{array}{ll}3.59 & 0.09\end{array}$ & 849D-5H-I & C. wuellerstorfi & 116 & 43.16 \\
\hline 849D-4H-4 & $U$. peregrina & 36 & 37.36 & 43.91 & 43,82 & $3.73-0.07$ & 849D-5H-I & C. wuellerstorfi & 136 & 43,36 \\
\hline 849D-4H-4 & C. wuellerstorfi & 46 & 37.46 & 44.01 & 43.97 & $3.88-0.23$ & $849 \mathrm{D}-5 \mathrm{H}-\mathrm{I}$ & C. wuellerstorfi & 145 & 43.45 \\
\hline 849D-4H-4 & $U$. peregrina & 46 & 37.46 & 44.01 & 43.97 & $4.10-0.18$ & $849 \mathrm{D}-5 \mathrm{H}-2$ & C. wuellerstorfi & 6 & 43.56 \\
\hline 849D-4H-4 & C. wuellerstorfi & 56 & 37.56 & 44.11 & 44.10 & $4.09-0.18$ & 849D-5H-2 & C. wuellerstorfi & 26 & 43.76 \\
\hline 849D-4H-4 & C. wuellerstorfi & 66 & 37.66 & 44.21 & 44.20 & $4.10-0.33$ & 849D-5H-2 & C. wuellerstorfi & 36 & 43.86 \\
\hline 849D-4H-4 & C. wuellerstorfi & 76 & 37.76 & 44.31 & 44.28 & $4.01-0.09$ & $849 \mathrm{D}-5 \mathrm{H}-2$ & C. wuellerstorfi & 46 & 43.96 \\
\hline 849D-4H-4 & C. wuellerstorfi & 86 & 37.86 & 44.41 & 44.35 & $3.74-0.06$ & $849 \mathrm{D}-5 \mathrm{H}-2$ & C. wuellerstorfi & 56 & 44.06 \\
\hline 849D-4H-4 & $U$. peregrina & 96 & 37.96 & 44.51 & 44.43 & $3.78-0.50$ & 849D-5H-2 & C. wuellerstorfi & 66 & 44.16 \\
\hline 849D-4H-4 & C. wuellerstorfi & 106 & 38.06 & 44.61 & 44.52 & 3.690 .00 & 849D-5H-2 & C. wuellerstorfi & 76 & 44.26 \\
\hline 849D-4H-4 & C. wuellerstorfi & 116 & 38.16 & 44.71 & 44.62 & $\begin{array}{ll}3.56 & 0.24\end{array}$ & 849D-5H-2 & C. wuellerstorfi & 86 & 44.36 \\
\hline 849D-4H-4 & C. wuellerstorfi & 126 & 38.26 & 44.81 & 44.73 & $\begin{array}{ll}3.35 & 0.39\end{array}$ & 849D-5H-2 & C. wuellerstorfi & 96 & 44.46 \\
\hline 849D-4H-4 & C. wuellerstorfi & 136 & 38.36 & 44.91 & 44.83 & $\begin{array}{ll}3.38 & 0.19\end{array}$ & 849D-5H-2 & C. wuellerstorfi & 106 & 44.56 \\
\hline 849D-4H-4 & C. wuellerstorfi & 146 & 38.46 & 45.01 & 44.94 & $3.34 \quad 0.07$ & 849D-5H-2 & C. wuellerstorfi & 116 & 44.66 \\
\hline 849D-4H-5 & C. wuellerstorfi & 6 & 38.56 & 45.11 & 45.06 & $3.70-0.01$ & 849D-5H-2 & C. wuellerstorfi & 126 & 44.76 \\
\hline 849D-4H-5 & C. wuellerstorfi & 6 & 38.56 & 45.11 & 45.06 & $3.66-0.05$ & $849 \mathrm{D}-5 \mathrm{H}-2$ & C. wuellerstorfi & 136 & 44.86 \\
\hline 849D-4H-5 & C. wuellerstorfi & 16 & 38.66 & 45.21 & 45.19 & $\begin{array}{ll}3.85 & 0.16\end{array}$ & 849D-5H-2 & C. wuellerstorfi & 146 & 44.96 \\
\hline 849D-4H-5 & C. wuellerstorfi & 16 & 38.66 & 45.21 & 45.19 & $3.76 \quad 0.15$ & 849D-5H-3 & C. wuellerstorfi & 6 & 45.06 \\
\hline 849D-4H-5 & C. wuellerstorfi & 26 & 38.76 & 45.31 & 45.34 & $3.93 \quad 0.16$ & $849 \mathrm{D}-5 \mathrm{H}-3$ & C. wuellerstorfi & 16 & 45.16 \\
\hline 849D-4H-5 & C. wuellerstorfi & 46 & 38.96 & 45.51 & 45.57 & $\begin{array}{ll}3.53 & 0.23\end{array}$ & 849D-5H-3 & C. wuellerstorfi & 26 & 45.26 \\
\hline 849D-4H-5 & C. wuellerstorfi & 56 & 39.06 & 45.61 & 45.65 & $\begin{array}{ll}3.56 & 0.08\end{array}$ & $849 \mathrm{D}-5 \mathrm{H}-3$ & C. wuellerstorf $i$ & 36 & 45.36 \\
\hline 849D-4H-5 & $U$. peregrina & 56 & 39.06 & 45.61 . & 45.65 & $3.87-0.02$ & 849D-5H-3 & C. wuellerstorfi & 36 & 45.36 \\
\hline 849D-4H-5 & C. wuellerstorfi & 66 & 39.16 & 45.71 . & 45.74 & $\begin{array}{ll}3.66 & 0.22\end{array}$ & 849D-5H-3 & U. peregrina & 36 & 45.36 \\
\hline 849D-4H-5 & C. wuellerstorfi & 76 & 39.26 & 45.81 & 45.83 & $3.88-0.13$ & $849 \mathrm{D}-5 \mathrm{H}-3$ & C. wuellerstorfi & 46 & 45.46 \\
\hline 849D-4H-5 & U. peregrina & 76 & 39.26 & 45.81 & 45.83 & $3.85-0.14$ & $849 \mathrm{D}-5 \mathrm{H}-3$ & C. wuellerstorfi & 56 & 45.56 \\
\hline 849D-4H-5 & C. wuellerstorfi & 86 & 39,36 & 45.91 & 45.92 & $3.99-0.11$ & 849D-5H-3 & U. peregrina & 56 & 45.56 \\
\hline 849D-4H-5 & C. wuellerstorfi & 96 & 39.46 & 46.01 & 46.04 & $4.32-0.25$ & 849D-5H-3 & C. wuellerstorfi & 66 & 45.66 \\
\hline 849D-4H-5 & C. wuellerstorfi & 106 & 39.56 & 46.11 & 46.15 & $4.46-0.12$ & 849 D- $5 \mathrm{H}-3$ & C. wuellerstorfi & 76 & 45.76 \\
\hline 849D-4H-5 & U. peregrina & 106 & 39.56 & 46.11 & 46.15 & $4.44-0.34$ & $849 \mathrm{D}-5 \mathrm{H}-3$ & $U$. peregrina & 86 & 45.86 \\
\hline 849D-4H-5 & C. wuellerstorfi & 116 & 39.66 & 46.21 & 46.26 & $4.35-0.21$ & 849D-5H-3 & C. wuellerstorfi & 96 & 45.96 \\
\hline 849D-4H-5 & C. wuellerstorfi & 126 & 39.76 & 46.31 & 46.35 & $4.00-0.49$ & 849D-5H-3 & C. wuellerstorfi & 126 & 46.26 \\
\hline 849D-4H-5 & $U$. peregrina & 126 & 39.76 & 46.31 & 46.35 & $4.28-0.31$ & 849D-5H-4 & C. wuellerstorfi & 6 & 46.56 \\
\hline 849D-4H-5 & C. wuellerstorfi & 136 & 39.86 & 46.41 & 46.43 & $4.18-0.18$ & $849 \mathrm{D}-5 \mathrm{H}-4$ & C. wuellerstorfi & 16 & 46.66 \\
\hline 849D-4H-5 & C. wuellerstorfi & 146 & 39.96 & 46.51 & 46.50 & $4.19-0.18$ & 849D-5H-4 & C. wuellerstorfi & 26 & 46.76 \\
\hline 849D-4H-6 & C. wuellerstorfi & 6 & 40.06 & 46.61 & 46.57 & $4.06 \quad 0.02$ & $849 \mathrm{D}-5 \mathrm{H}-4$ & C. wuellerstorfi & 36 & 46.86 \\
\hline 849D-4H-6 & C. wuellerstorfi & 16 & 40.16 & 46.71 & 46.64 & $3.91-0.08$ & $849 \mathrm{D}-5 \mathrm{H}-4$ & C. wuellerstorfi & 46 & 46.96 \\
\hline 849D-4H-6 & C. wuellerstorfi & 26 & 40.26 & 46.81 & 46.73 & $3.70-0.04$ & $849 \mathrm{D}-5 \mathrm{H}-4$ & C. wuellerstorf $i$ & 46 & 46.96 \\
\hline 849D-4H-6 & C. wuellerstorfi & 36 & 40.36 & 46.91 & 46.85 & $\begin{array}{ll}3.66 & 0.13\end{array}$ & 849D-5H-4 & C. wuellerstorfi & 56 & 47.06 \\
\hline 849D-4H-6 & C. wuellerstorfi & 46 & 40.46 & 47.01 & 47.00 & $3.70-0.01$ & 849D-5H-4 & C. wuellerstorfi & 66 & 47.16 \\
\hline 849D-4H-6 & C. wuellerstorfi & 56 & 40.56 & 47.11 & 47.14 & $3.88-0.50$ & 849D-5H-4 & C. wuellerstorfi & 76 & 47.26 \\
\hline 849D-4H-6 & C. wuellerstorfi & 66 & 40.66 & 47.21 & 47.25 & $3.93-0.25$ & 849D-5H-4 & C. wuellerstorfi & 96 & 47.46 \\
\hline 849D-4H-6 & C. wuellerstorfi & 76 & 40.76 & 47.31 & 47.33 & $3.84-0.27$ & 849D-5H-4 & C. wuellerstorfi & 106 & 47.56 \\
\hline 849D-4H-6 & C. wuellerstorfi & 86 & 40.86 & 47.41 & 47.38 & $3.70-0.40$ & 849D-5H-4 & C. wuellerstorfi & 116 & 47.66 \\
\hline 849D-4H-6 & C. wuellerstorfi & 96. & 40.96 & 47.51 & 47.43 & $4.09-0.70$ & 849D-5H-4 & C. wuellerstorfi & 126 & 47.76 \\
\hline 849D-4H-6 & C. wuellerstorfi & 106 & 41.06 & 47.61 & 47.51 & $4.23-0.65$ & $849 \mathrm{D}-5 \mathrm{H}-4$ & C. whellerstorfi & 136 & 47.86 \\
\hline 849D-4H-6 & C. wuellerstorfi & 116 & 41.16 & 47.71 & 47.60 & $4.22-0.35$ & 849D-5H-4 & C. wuellerstorfi & 146 & 47.96 \\
\hline 849D-4H-6 & $U$. peregrina & 116 & 41.16 & 47.71 & 47.60 & $4.17-0.35$ & $849 \mathrm{D}-5 \mathrm{H}-5$ & C. wuellerstorf $i$ & 6 & 48.06 \\
\hline $849 \mathrm{C}-5 \mathrm{H}-1$ & C. wuellerstorfi & 36 & 39.36 & 47.51 & 47.62 & $4.02-0.60$ & 849D-5H-5 & C. wuellerstorfi & 16 & 48.16 \\
\hline $849 \mathrm{C}-5 \mathrm{H}-1$ & C. wuellerstorfi & 46 & 39.46 & 47.61 & 47.69 & $3.97-0.26$ & $849 \mathrm{D}-5 \mathrm{H}-5$ & U. peregrina & 16 & 48.16 \\
\hline 849D-4H-6 & C. wuellerstorfi & 126 & 41.26 & 47.81 & 47.70 & $3.88-0.43$ & 849D-5H-5 & C. wuellerstorfi & 26 & 48.26 \\
\hline $849 \mathrm{C}-5 \mathrm{H}-1$ & C. wuellerstorfi & 56 & 39.56 & 47.71 & 47.76 & $3.60-0.09$ & 849D-5H-5 & $U$. peregrina & 26 & 48.26 \\
\hline $849 \mathrm{C}-5 \mathrm{H}-1$ & C. wuellerstorfi & 66 & 39.66 & 47.81 & 47.83 & $3.66-0.17$ & 849D-5H-5 & C. wuellerstorfi & 36 & 48.36 \\
\hline
\end{tabular}


APPENDIX A (continued).

\begin{tabular}{|c|c|c|c|c|c|c|c|c|c|c|c|}
\hline Section & Species & $\begin{array}{l}\text { Depth } \\
(\mathrm{cm})\end{array}$ & $\begin{array}{l}\text { Depth } \\
\text { (mbsf) }\end{array}$ & $\begin{array}{l}\text { Depth } \\
\text { (mcd) }\end{array}$ & $\begin{array}{l}\text { Depth } \\
\text { (rmcd) }\end{array}$ & $\delta^{18} \mathrm{O} \quad \delta^{13} \mathrm{C}$ & Section & Species & $\begin{array}{l}\text { Depth } \\
(\mathrm{cm})\end{array}$ & $\begin{array}{l}\text { Depth } \\
\text { (mbsf) }\end{array}$ & $\begin{array}{l}\text { Depth } \\
\text { (mcd) }\end{array}$ \\
\hline $849 \mathrm{D}-5 \mathrm{H}-5$ & C. wuellerstorfi & 46 & 48.46 & 56.91 & 56.94 & $3.57-0.52$ & 849D-6H-3 & C. wuellerstorfi & 16 & 54.66 & 63.91 \\
\hline $849 \mathrm{D}-5 \mathrm{H}-5$ & U. peregrina & 46 & 48.46 & 56.91 & 56.94 & $3.57-0.70$ & 849D-6H-3 & C. wuellerstorfi & 26 & 54.76 & 64.01 \\
\hline 849D-5H-5 & C. wuellerstorfi & 56 & 48.56 & 57.01 & 57.03 & $3.74-0.34$ & 849D-6H-3 & C. wuellerstorfi & 36 & 54.86 & 64.11 \\
\hline 849D-5H-5 & C. wuellerstorfi & 56 & 48.56 & 57.01 & 57.03 & $3.71-0.31$ & 849D-6H-3 & $U$. peregrina & 36 & 54.86 & 64.11 \\
\hline 849D-5H-5 & $U$. peregrina & 56 & 48.56 & 57.01 & 57.03 & $3.94-0.62$ & $849 \mathrm{D}-6 \mathrm{H}-3$ & C. wuellerstorfi & 46 & 54.96 & 64.21 \\
\hline 849D-5H-5 & C. wuellerstorfi & 66 & 48.66 & 57.11 & 57.12 & $4.00-0.36$ & 849D-6H-3 & C. wuellerstorfi & 56 & 55.06 & 64.31 \\
\hline 849D-5H-5 & U. peregrina & 66 & 48.66 & 57.11 & 57.12 & $4.10-0.22$ & 849D-6H-3 & C. wuellerstorfi & 66 & 55.16 & 64.41 \\
\hline 849D-5H-5 & C. wuellerstorfi & 76 & 48.76 & 57.21 & 57.20 & $4.04-0.09$ & 849D-6H-3 & C. wuellerstorfi & 76 & 55.26 & $64.51+$ \\
\hline 849D-5H-5 & C. wuellerstorfi & 86 & 48.86 & 57.31 & 57.29 & $4.04-0.08$ & 849D-6H-3 & C. wuellerstorfi & 96 & 55.46 & $64.71 t$ \\
\hline 849D-5H-5 & C. wuellerstorfi & 96 & 48.96 & 57.41 & 57.39 & $3.80-0.16$ & 849D-6H-3 & C. wuellerstorfi & 116 & 55.66 & 64.91 \\
\hline 849D-5H-5 & U. peregrina & 96 & 48.96 & 57.41 & 57.39 & $3.73-0.19$ & 849D-6H-3 & C. wuellerstorfi & 126 & 55.76 & $65.01 \mathrm{t}$ \\
\hline 849D-5H-5 & U. peregrina & 106 & 49.06 & 57.51 & 57.49 & $3.57-0.41$ & 849D-6H-3 & U. peregrina & 126 & 55.76 & $65.01 \mathrm{t}$ \\
\hline 849D-5H-5 & C. wuellerstorfi & 116 & 49.16 & 57.61 & 57.59 & $3.77-0.21$ & $849 \mathrm{D}-6 \mathrm{H}-3$ & C. wuellerstorfi & 136 & 55.86 & $65.11 t$ \\
\hline 849D-5H-5 & U. peregrina & 116 & 49.16 & 57.61 & 57.59 & $3.79-0.33$ & 849D-6H-3 & C. wuellerstorfi & 146 & 55.96 & 65.21 \\
\hline 849D-5H-5 & C. wuellerstorfi & 126 & 49.26 & 57.71 & 57.70 & $\begin{array}{ll}3.79 & 0.05\end{array}$ & 849D-6H-3 & C. witellerstorfi & 146 & 55.96 & 65.216 \\
\hline 849D-5H-5 & U. peregrina & 126 & 49.26 & 57.71 & 57.70 & $3.71-0.26$ & 849D-6H-3 & U. peregrina & 146 & 55.96 & 65.21 \\
\hline 849D-5H-5 & C. wuellerstorfi & 136 & 49.36 & 57.81 & 57.82 & 3.540 .06 & 849D-6H-4 & C. wuellerstorfi & 6 & 56.06 & $65.31 \mathrm{C}$ \\
\hline 849D-5H-5 & C. wuellerstorfi & 146 & 49.46 & 57.91 & 57.92 & $\begin{array}{ll}3.50 & 0.23\end{array}$ & 849D-6H-4 & C. wuellerstorfi & 16 & 56.16 & $65.41 \mathrm{c}$ \\
\hline 849D-5H-6 & C. wuellerstorfi & 6 & 49.56 & 58.01 & 58.03 & $\begin{array}{ll}3.38 & 0.18\end{array}$ & 849D-6H-4 & C. wuellerstorfi & 26 & 56.26 & $65.51 \mathrm{c}$ \\
\hline 849D-5H-6 & C. wuellerstorfi & 26 & 49.76 & 58.21 & 58.22 & $3.40 \quad 0.23$ & 849D-6H-4 & C. wuellerstorfi & 36 & 56.36 & 65.61 \\
\hline 849D-5H-6 & C. wuellerstorfi & 36 & 49.86 & 58.31 & 58.30 & $\begin{array}{ll}3.38 & 0.37\end{array}$ & 849D-6H-4 & C. wuellerstorfi & 36 & 56.36 & 65.61 \\
\hline 849D-5H-6 & C. wuellerstorfi & 36 & 49.86 & 58.31 & 58.31 & $3.34 \quad 0.23$ & 849D-6H-4 & U. peregrina & 36 & 56.36 & 65.61 \\
\hline 849D-5H-6 & C. wuellerstorfi & 46 & 49.96 & 58.41 & 58.39 & $\begin{array}{ll}3.40 & 0.37\end{array}$ & 849D-6H-4 & C. wuellerstorfi & 46 & 56.46 & 65.71 \\
\hline 849D-5H-6 & C. wuellerstorfi & 56 & 50.06 & 58.51 & 58.48 & $\begin{array}{ll}3.60 & 0.24\end{array}$ & 849D-6H-4 & C. wuellerstorfi & 56 & 56.56 & 65.81 \\
\hline 849D-5H-6 & C. wuellerstorfi & 66 & 50.16 & 58.61 & 58.57 & 3.920 .21 & 849D-6H-4 & C. wuellerstorfi & 66 & 56.66 & 65.91 \\
\hline 849D-5H-6 & C. wuellerstorfi & 76 & 50.26 & 58.71 & 58.67 & $3.99-0.07$ & 849D-6H-4 & C. wuellerstorfi & 66 & 56.66 & 65.91 \\
\hline 849D-5H-6 & C. wuellerstorfi & 86 & 50.36 & 58.81 & 58.77 & $3.99-0.04$ & 849D-6H-4 & U. peregrina & 66 & 56.66 & 65.91 \\
\hline 849D-5H-6 & C. wuellerstorfi & 96 & 50.46 & $58.9 !$ & 58.88 & $3.94-0.18$ & 849D-6H-4 & C. wuellerstorfi & 76 & 56.76 & 66.01 \\
\hline 849D-5H-6 & C. wuellerstorfi & 106 & 50.56 & 59.01 & 59.00 & $3.89-0.21$ & 849D-6H-4 & C. wuellerstorfi & 86 & 56.86 & 66.11 \\
\hline 849D-5H-6 & C. wuellerstorfi & 116 & 50.66 & 59.11 & 59.12 & $3.86-0.03$ & 849D-6H-4 & C. wuellerstorfi & 96 & 56.96 & 66.21 \\
\hline 849D-5H-6 & C. wuellerstorfi & 126 & 50.76 & 59.21 & 59.23 & $3.86-0.01$ & 849D-6H-4 & U. peregrina & 96 & 56.96 & 66.21 \\
\hline 849D-5H-6 & C. wuellerstorfi & 136 & 50.86 & 59.31 & 59.34 & $3.77-0.01$ & 849D-6H-4 & C. wuellerstorfi & 106 & 57.06 & 66.31 \\
\hline 849D-5H-6 & C. wuellerstorfi & 146 & 50.96 & 59.41 & 59.44 & $3.84-0.41$ & 849D-6H-4 & U. peregrina & 116 & 57.16 & 66.41 \\
\hline 849D-5H-7 & C. wuellerstorfi & 6 & 51.06 & 59.51 & 59.53 & $3.74-0.11$ & 849D-6H-4 & C. wuellerstorfi & 126 & 57.26 & 66.51 \\
\hline 849D-5H-7 & C. wuellerstorfi & 16 & 51.16 & 59.61 & 59.62 & $3.84-0.45$ & 849D-6H-4 & C. wuellerstorfi & 136 & 57.36 & 66.61 \\
\hline 849D-5H-7 & C. wuellerstorfi & 26 & 51.26 & 59.71 & 59.71 & $3.96-0.44$ & 849D-6H-4 & C. wuellerstorfi & 136 & 57.36 & 66.61 \\
\hline 849D-5H-7 & C. wuellerstorfi & 36 & 51.36 & 59.81 & 59.81 & $3.78-0.32$ & 849D-6H-4 & C. wuellerstorfi & 146 & 57.46 & 66.71 \\
\hline $849 \mathrm{C}-6 \mathrm{H}-2$ & C. wuellerstorfi & 56 & 50.30 & 59.90 & 59.84 & $4.23-0.62$ & 849D-6H-5 & C. wuellerstorfi & 6 & 57.56 & 66.81 \\
\hline 849D-5H-7 & C. wuellerstorfi & 46 & 51.46 & 59.91 & 59.91 & $4.18-0.60$ & 849D-6H-5 & U. peregrina & 6 & 57.56 & 66.81 \\
\hline $849 \mathrm{C}-6 \mathrm{H}-2$ & C. whellerstorfi & 66 & 50.40 & 60.00 & 59.95 & $4.17-0.64$ & 849D-6H-5 & C. wuellerstorfi & 16 & 57.66 & 66.91 \\
\hline 849D-5H-7 & C. wuellerstorfi & 56 & 51.56 & 60.01 & 60.02 & $4.34-0.62$ & 849D-6H-5 & C. wuellerstorfi & 16 & 57.66 & 66.91 \\
\hline $849 \mathrm{C}-6 \mathrm{H}-2$ & C. wuellerstorfi & 76 & 50.50 & 60.10 & 60.06 & $4.22-0.69$ & 849D-6H-5 & U. peregrina & 16 & 57.66 & 66.91 \\
\hline $849 \mathrm{C}-6 \mathrm{H}-2$ & C. wuellerstorfi & 86 & 50.60 & 60.20 & 60.17 & $4.29-0.51$ & 849D-6H-5 & C. wuellerstorfi & 26 & 57.76 & 67.01 \\
\hline $849 \mathrm{C}-6 \mathrm{H}-2$ & C. wuellerstorfi & 96 & 50.70 & 60.30 & 60.30 & $4.20-0.75$ & 849D-6H-5 & C. wuellerstorfi & 36 & 57.86 & 67.11 \\
\hline $849 \mathrm{C}-6 \mathrm{H}-2$ & C. wuellerstorfi & 106 & 50.80 & 60.40 & 60.42 & $4.11-0.54$ & 849D-6H-5 & C. wuellerstorfi & 36 & 57.86 & 67.11 \\
\hline $849 \mathrm{C}-6 \mathrm{H}-2$ & C. wuellerstorfi & 116 & 50.90 & 60.50 & 60.52 & $4.09-0.51$ & 849D-6H-5 & C. wuellerstorfi & 46 & 57.96 & 67.21 \\
\hline $849 \mathrm{C}-6 \mathrm{H}-2$ & C. wuellerstorfi & 126 & 51.00 & 60.60 & 60.61 & $4.08-0.41$ & 849D-6H-5 & C. wuellerstorfi & 56 & 58.06 & 67.31 \\
\hline $849 \mathrm{C}-6 \mathrm{H}-2$ & C. wuellerstorfi & 136 & 51.10 & 60.70 & 60.70 & $3.82-0.13$ & 849D-6H-5 & C. wuellerstorfi & 66 & 58.16 & 67.41 \\
\hline $849 \mathrm{C}-6 \mathrm{H}-2$ & C. wuellerstorfi & 146 & 51.20 & 60.80 & 60.79 & $3.67-0.21$ & 849D-6H-5 & C. wuellerstorfi & 76 & 58.26 & 67.51 \\
\hline $849 \mathrm{C}-6 \mathrm{H}-3$ & C. wuellerstorfi & 6 & 51.30 & 60.90 & 60.90 & $3.25-0.25$ & 849D-6H-5 & C. wuellerstorfi & 86 & 58.36 & 67.61 \\
\hline $849 \mathrm{C}-6 \mathrm{H}-3$ & C. wuellerstorfi & 16 & 51.40 & 61.00 & 61.00 & $3.50-0.16$ & 849D-6H-5 & C. wuellerstorfi & 96 & 58.46 & 67.71 \\
\hline 849D-6H-1 & C. wuellerstorfi & 26 & 51.76 & 61.01 & 61.09 & $3.66-0.27$ & 849D-6H-5 & C. wuellerstorfi & 106 & 58.56 & 67.81 \\
\hline 849D-6H-1 & U. peregrina & 26 & 51.76 & 61.01 & 61.09 & $3.64-0.32$ & 849D-6H-5 & C. wuellerstorfi & 116 & 58.66 & 67.91 \\
\hline $849 \mathrm{C} \cdot 6 \mathrm{H}-3$ & C. wuellerstorfi & 26 & 51.50 & 61.10 & 61.10 & $3.38-0.33$ & 849D-6H-5 & C. whellerstorfi & 126 & 58.76 & 68.01 \\
\hline 849D-6H-1 & C. wuellerstorfi & 36 & 51.86 & 61.11 & 61.19 & $3.88-0.04$ & 849D-6H-5 & C. wuellerstorfi & 136 & 58.86 & 68.11 \\
\hline 849D-6H-1 & C. wuellerstorfi & 46 & 51.96 & 61.21 & 61.27 & $3.71-0.05$ & 849D-6H-5 & C. wuellerstorfi & 146 & 58.96 & 68.21 \\
\hline 849D-6H-1 & C. whellerstorfi & 56 & 52.06 & 61.31 & 61.36 & $\begin{array}{ll}3.59 & 0.09\end{array}$ & 849D-6H-6 & C. wuellerstorfi & 6 & 59.06 & 68.31 \\
\hline 849D-6H-1 & C. wuellerstorfi & 56 & 52.06 & 61.31 & 61.36 & $3.60-0.25$ & 849D-6H-6 & C. wuellerstorfi & 16 & 59.16 & 68.41 \\
\hline 849D-6H-1 & C. wuellerstorfi & 66 & 52.16 & 61.41 & 61.47 & $3.41-0.17$ & 849D-6H-6 & C. wuellerstorfi & 26 & 59.26 & 68.51 \\
\hline 849D-6H-1 & C. wuellerstorfi & 66 & 52.16 & 61.41 & 61.47 & $3.77-0.08$ & 849D-6H-6 & C. wuellerstorfi & 36 & 59.36 & 68.61 \\
\hline 849D-6H-1 & C. wuellerstorfi & 76 & 52.26 & 61.51 & 61.61 & $3.67-0.03$ & 849D-6H-6 & C. wuellerstorfi & 46 & 59.46 & 68.71 \\
\hline 849D-6H-1 & C. wuellerstorfi & 76 & 52.26 & 61.51 & 61.61 & $3.54 \quad 0.04$ & 849D-6H-6 & C. wuellerstorfi & 56 & 59.56 & 68.81 \\
\hline 849D-6H-1 & C. wuellerstorfi & 86 & 52.36 & 61.61 & 61.77 & $3.43-0.14$ & 849D-6H-6 & C. wuellerstorfi & 66 & 59.66 & 68.91 \\
\hline 849D-6H-1 & C. wuellerstorf $i$ & 106 & 52.56 & 61.81 & 62.00 & $3.46-0.25$ & 849D-6H-6 & C. wuellerstorfi & 76 & 59.76 & 69.01 \\
\hline 849D-6H-1 & C. wuellerstorfi & 116 & 52.66 & 61.91 & 62.07 & $3.99-0.43$ & 849D-6H-6 & C. wuellerstorfi & 86 & 59.86 & 69.11 \\
\hline 849D-6H-1 & C. wuellerstorfi & 126 & 52.76 & 62.01 & 62.12 & $3.97-0.48$ & 849D-6H-6 & C. wuellerstorfi & 96 & 59.96 & 69.21 \\
\hline 849D-6H-1 & C. wuellerstorfi & 136 & 52.86 & 62.11 & 62.17 & $4.13-0.59$ & 849D-6H-6 & C. wuellerstorfi & 106 & 60.06 & 69.31 \\
\hline 849D-6H-1 & C. wuellerstorfi & 146 & 52.96 & 62.21 & 62.23 & $3.84-0.36$ & 849D-6H-6 & C. wuellerstorfi & 116 & 60.16 & 69.41 \\
\hline 849D-6H-2 & C. wuellerstorfi & 6 & 53.06 & 62.31 & 62.31 & $3.91-0.30$ & $849 \mathrm{D}-6 \mathrm{H}-6$ & C. wuellerstorfi & 126 & 60.26 & 69.51 \\
\hline 849D-6H-2 & C. wuellerstorfi & 16 & 53.16 & 62.41 & 62.42 & $3.74-0.15$ & 849D-6H-6 & C. wuellerstorfi & 136 & 60.36 & 69.61 \\
\hline 849D-6H-2 & C. whellerstorfi & 26 & 53.26 & 62.51 & 62.57 & $\begin{array}{ll}3.43 & 0.07\end{array}$ & $849 \mathrm{D}-6 \mathrm{H}-6$ & C. wuellerstorfi & 146 & 60.46 & 69.71 \\
\hline 849D-6H-2 & C. wuellerstorfi & 36 & 53.36 & 62.61 & 62.73 & $3.47-0.02$ & $849 \mathrm{D}-6 \mathrm{H}-6$ & $U$. peregrina & 146 & 60.46 & 69.71 \\
\hline 849D-6H-2 & C. wuellerstorfi & 46 & 53.46 & 62.71 & 62.86 & 3.340 .00 & $849 \mathrm{C}-7 \mathrm{H}-1$ & C. wuellerstorfi & 76 & 58.76 & 69.71 \\
\hline 849D-6H-2 & C. wuellerstorfi & 56 & 53.56 & 62.81 & 62.95 & $3.55-0.06$ & 849D-6H-7 & C. wuellerstorfi & 6 & 60.56 & 69.81 \\
\hline 849D-6H-2 & C. wuellerstorfi & 66 & 53.66 & 62.91 & 63.02 & $3.66-0.33$ & 849D-6H-7 & C. wuellerstorfi & 16 & 60.66 & 69.91 \\
\hline 849D-6H-2 & C. wuellerstorfi & 76 & 53.76 & 63.01 & 63.08 & $3.75-0.21$ & $849 \mathrm{C}-7 \mathrm{H}-\mathrm{I}$ & C. wuellerstorfi & 96 & 58.96 & 69.91 \\
\hline 849D-6H-2 & C. wuellerstorfi & 86 & 53.86 & 63.11 & 63.16 & $3.65-0.14$ & $849 \mathrm{C}-7 \mathrm{H}-1$ & C. wuellerstorfi & 116 & 59.16 & 70.11 \\
\hline 849D-6H-2 & C. wuellerstorfi & 96 & 53.96 & 63.21 & 63.24 & $3.56-0.13$ & $849 \mathrm{C}-7 \mathrm{H}-1$ & C. wuellerstorfi & 126 & 59.26 & 70.21 \\
\hline 849D-6H-2 & C. wuellerstorfi & 106 & 54.06 & 63.31 & 63.34 & $3.49-0.14$ & $849 \mathrm{C}-7 \mathrm{H}-1$ & C. wuellerstorfi & 136 & 59.36 & 70.31 \\
\hline 849D-6H-2 & C. wuellerstorfi & 106 & 54.06 & 63.31 & 63.35 & $3.62-0.08$ & $849 \mathrm{C}-7 \mathrm{H}-1$ & C. wuellerstorfi & 146 & 59.46 & 70.41 \\
\hline 849D-6H-2 & C. wuellerstorfi & 116 & 54.16 & 63.41 & 63.49 & $3.48-0.16$ & 849D-7H-I & C. wuellerstorfi & 7 & 61.07 & 70.52 \\
\hline 849D-6H-2 & C. wuellerstorfi & 126 & 54.26 & 63.51 & 63.67 & $3.65-0.14$ & 849D-7H-1 & C. wuellerstorfi & 17 & 61.17 & 70.62 \\
\hline 849D-6H-2 & C. whellerstorfi & 136 & 54.36 & 63.61 & 63.78 & $3.45-0.19$ & 849D-7H-1 & C. wuellerstorfi & 27 & 61.27 & 70.72 \\
\hline 849D-6H-2 & C, wuellerstorfi & 146 & 54.46 & 63.71 & 63.85 & $3.30-0.13$ & 849D-7H-1 & C. whellerstorfi & 36 & 61.36 & 70.81 \\
\hline 849D-6H-3 & C. wuellerstorfi & 6 & 54.56 & 63.81 & 63.91 & $3.46-0.26$ & 849D-7H-I & C. wuellerstorfi & 46 & 61.46 & 70.91 \\
\hline 849D-6H-3 & U. peregrina & 6 & 54.56 & 63.81 & 63.91 & $3.60-0.01$ & 849D-7H-1 & C. wuellerstorfi & 56 & 61.56 & 71.01 \\
\hline
\end{tabular}


APPENDIX A (continued).

\begin{tabular}{|c|c|c|c|c|c|c|c|c|c|c|c|c|}
\hline Section & Species & $\begin{array}{l}\text { Depth } \\
(\mathrm{cm})\end{array}$ & $\begin{array}{l}\text { Depth } \\
\text { (mbsf) }\end{array}$ & $\begin{array}{l}\text { Depth } \\
\text { (mod) }\end{array}$ & $\begin{array}{l}\text { Depth } \\
\text { (rmcd) }\end{array}$ & $\delta^{18} \mathrm{O}$ & $\delta^{13} \mathrm{C}$ & Section & Species & $\begin{array}{l}\text { Depth } \\
(\mathrm{cm})\end{array}$ & $\begin{array}{l}\text { Depth } \\
\text { (mbsf) }\end{array}$ & $\begin{array}{l}\text { Depth } \\
\text { (mcd) }\end{array}$ \\
\hline 849D-7H-I & C. wuellerstorfi & 67 & 61.67 & 71.12 & 71.17 & 4.22 & -0.85 & $849 \mathrm{D}-7 \mathrm{H}-7$ & C. wuellerstorfi & 56 & 70.56 & 80.01 \\
\hline 849D-7H-1 & C. wuellerstorf $f$ & 76 & 61.76 & 71.21 & 71.24 & 3.84 & -0.45 & $849 \mathrm{C}-8 \mathrm{H}-1$ & C. wuellerstorfi & 76 & 68.26 & 80.06 \\
\hline 849D-7H-I & C. wuellerstorfi & 86 & 61.86 & 71.31 & 71.33 & 4.17 & -0.59 & $849 \mathrm{D}-7 \mathrm{H}-7$ & C. wuellerstorfi & 66 & 70.66 & 80.11 \\
\hline 849D-7H-1 & C. wuellerstorfi & 96 & 61.96 & 71.41 & 71.44 & 3.75 & -0.53 & $849 \mathrm{C}-8 \mathrm{H}-1$ & C. wuellerstorfi & 86 & 68.36 & 80.16 \\
\hline 849D-7H-1 & C. wuellerstorfi & 96 & 61.96 & 71.41 & 71.45 & 3.84 & -0.51 & $849 \mathrm{C}-8 \mathrm{H}-1$ & C. wuellerstorfi & 96 & 68.46 & 80.26 \\
\hline 849D-7H-1 & C. wuellerstorfi & 107 & 62.07 & 71.52 & 71.64 & 3.89 & -0.22 & $849 \mathrm{C}-8 \mathrm{H}-1$ & C. wuellerstorfi & 106 & 68.56 & 80.36 \\
\hline 849D-7H-1 & C. wuellerstorfi & 117 & 62.17 & 71.62 & 71.80 & 3.74 & -0.33 & $849 \mathrm{C}-8 \mathrm{H}-1$ & C. wuellerstorfi & 116 & 68.66 & 80.46 \\
\hline 849D-7H-I & C. wuellerstorfi & 127 & 62.27 & 71.72 & 71.91 & 3.45 & 0.07 & $849 \mathrm{C}-8 \mathrm{H}-1$ & C. wuellerstorfi & 126 & 68.76 & 80.56 \\
\hline $849 \mathrm{D}-7 \mathrm{H}-1$ & C. wuellerstorfi & 136 & 62.36 & 71.81 & 72.01 & 3.26 & -0.01 & $849 \mathrm{C}-8 \mathrm{H}-1$ & C. wuellerstorfi & 146 & 68.96 & 80.76 \\
\hline 849D-7H-1 & C. wuellerstorfi & 146 & 62.46 & 71.91 & 72.12 & 3.24 & -0.04 & $849 \mathrm{C}-8 \mathrm{H}-2$ & C. wuellerstorfi & 6 & 69.06 & 80.86 \\
\hline 849D-7H-2 & C. wuellerstorfi & 6 & 62.56 & 72.01 & 72.23 & 3.22 & 0.08 & $849 \mathrm{C}-8 \mathrm{H}-2$ & C. wuellerstorfi & 16 & 69.16 & 80.96 \\
\hline 849D-7H-2 & C. wuellerstorfi & 16 & 62.66 & 72.11 & 72.31 & 3.43 & -0.01 & $849 \mathrm{C}-8 \mathrm{H}-2$ & C. wuellerstorfi & 26 & 69.26 & 81.06 \\
\hline 849D-7H-2 & C. wuellerstorfi & 36 & 62.86 & 72.31 & 72.45 & 3.02 & -0.03 & $849 \mathrm{C}-8 \mathrm{H}-2$ & C. wuellerstorfi & 36 & 69.36 & 81.16 \\
\hline 849D-7H-2 & C. wuellerstorf $i$ & 46 & 62.96 & 72.41 & 72.52 & 3.70 & 0.01 & $849 \mathrm{C}-8 \mathrm{H}-2$ & C. wuellerstorfi & 46 & 69.46 & 81.26 \\
\hline $849 \mathrm{D}-7 \mathrm{H}-2$ & C. wuellerstorfi & 66 & 63.16 & 72.61 & 72.67 & 3.62 & -0.08 & $849 \mathrm{C}-8 \mathrm{H}-2$ & C. wuellerstorfi & 56 & 69.56 & 81.36 \\
\hline $849 \mathrm{D}-7 \mathrm{H}-2$ & C. wuellerstorfi & 76 & 63.26 & 72.71 & 72.74 & $3.5 \mathrm{I}$ & 0.01 & $849 \mathrm{C}-8 \mathrm{H}-2$ & C. wuellerstorfi & 66 & 69.66 & 81.46 \\
\hline 849D-7H-2 & C. wuellerstorfi & 86 & 63.36 & 72.81 & 72.83 & 3.39 & 0.21 & $849 \mathrm{C}-8 \mathrm{H}-2$ & C. wuellerstorfi & 76 & 69.76 & 81.56 \\
\hline 849D-7H-2 & C. wuellerstorfi & 116 & 63.66 & 73.11 & 73.16 & 3.49 & -0.14 & $849 \mathrm{C}-8 \mathrm{H}-2$ & C. wuellerstorfi & 86 & 69.86 & 81.66 \\
\hline $849 \mathrm{D}-7 \mathrm{H}-2$ & C. wuellerstorfi & 126 & 63.76 & 73.21 & 73.23 & 3.82 & -0.24 & $849 \mathrm{D}-8 \mathrm{H}-1$ & C. wuellerstorfi & 36 & 70.86 & 81.96 \\
\hline 849D-7H-2 & C. wuellerstorfi & 136 & 63.86 & 73.31 & 73.28 & 3.97 & -0.38 & $849 \mathrm{C}-8 \mathrm{H}-2$ & C. wuellerstorfi & 96 & 69.96 & 81.76 \\
\hline 849D-7H-2 & C. wuellerstorfi & 146 & 63.96 & 73.41 & 73.34 & 4.03 & -0.31 & $849 \mathrm{C}-8 \mathrm{H}-2$ & C. wuellerstorfi & 106 & 70.06 & 81.86 \\
\hline 849D-7H-3 & C. wuellerstorfi & 6 & 64.06 & 73.51 & 73.41 & 3.74 & -0.19 & $849 \mathrm{D}-8 \mathrm{H}-1$ & C. wuellerstorfi & 46 & 70.96 & 82.06 \\
\hline 849D-7H-3 & C. wuellerstorfi & 16 & 64.16 & 73.61 & 73.53 & 3.58 & 0.14 & $849 \mathrm{D}-8 \mathrm{H}-1$ & C. wuellerstorfi & 56 & 71.06 & 82.16 \\
\hline 849D-7H-3 & C. wuellerstorfi & 26 & 64.26 & 73.71 & 73.68 & 3.58 & 0.14 & $849 \mathrm{D}-8 \mathrm{H}-1$ & C. wuellerstorfi & 66 & 71.16 & 82.26 \\
\hline 849D-7H-3 & C. wuellerstorfi & 36 & 64.36 & 73.81 & 73.80 & 3.50 & 0.10 & $849 \mathrm{D}-8 \mathrm{H}-1$ & C. wuellerstorfi & 76 & 71.26 & 82.36 \\
\hline $849 \mathrm{D}-7 \mathrm{H}-3$ & C. wuellerstorfi & 46 & 64.46 & 73.91 & 73.91 & 3.52 & 0.16 & $849 \mathrm{D}-8 \mathrm{H}-\mathrm{I}$ & C. wuellerstorfi & 86 & 71.36 & 82.46 \\
\hline 849D-7H-3 & C. wuellerstorfi & 56 & 64.56 & 74.01 & 74.02 & 3.32 & 0.03 & $849 \mathrm{D}-8 \mathrm{H}-1$ & C. wuellerstorfi & 96 & 71.46 & 82.56 \\
\hline 849D-7H-3 & C. wuellerstorfi & 66 & 64.66 & 74.11 & 74.13 & 3.54 & -0.16 & $849 \mathrm{D}-8 \mathrm{H}-1$ & C. wuellerstorfi & 106 & 71.56 & 82.66 \\
\hline 849D-7H-3 & C. wuellerstorfi & 76 & 64.76 & 74.21 & 74.24 & 3.62 & -0.06 & $849 \mathrm{D}-8 \mathrm{H}-\mathrm{I}$ & C. wuellerstorfi & 116 & 71.66 & 82.76 \\
\hline 849D-7H-3 & C. wuellerstorfi & 86 & 64.86 & 74.31 & 74.35 & 3.77 & -0.04 & $849 \mathrm{D}-8 \mathrm{H}-\mathrm{I}$ & C. wuellerstorfi & 126 & 71.76 & 82.86 \\
\hline $849 \mathrm{D}-7 \mathrm{H}-3$ & C. wuellerstorfi & 96 & 64.96 & 74.41 & 74.48 & 3.70 & -0.17 & $849 \mathrm{D}-8 \mathrm{H}-1$ & C. wuellerstorfi & 136 & 71.86 & 82.96 \\
\hline 849D-7H-3 & C. wuellerstorfi & 96 & 64.96 & 74.41 & 74.48 & 3.61 & -0.30 & $849 \mathrm{D}-8 \mathrm{H}-1$ & C. wuellerstorfi & 146 & 71.96 & 83.06 \\
\hline 849D-7H-3 & C. wuellerstorfi & 106 & 65.06 & 74.51 & 74.59 & 3.63 & -0.08 & $849 \mathrm{D}-8 \mathrm{H}-2$ & C. wuellerstorfi & 6 & 72.06 & 83.16 \\
\hline 849D-7H-3 & C. wuellerstorfi & 116 & 65.16 & 74.61 & 74.67 & 3.17 & -0.15 & $849 \mathrm{D}-8 \mathrm{H}-2$ & C. wuellerstorfi & 16 & 72.16 & 83.26 \\
\hline 849D-7H-3 & C. wuellerstorfi & 126 & 65.26 & 74.71 & 74.74 & 3.32 & 0.05 & $849 \mathrm{D}-8 \mathrm{H}-2$ & C. wuellerstorfi & 26 & 72.26 & 83.36 \\
\hline 849D-7H-3 & C. wuellerstorfi & 136 & 65.36 & 74.81 & 74.81 & 3.29 & 0.11 & $849 \mathrm{D}-8 \mathrm{H}-2$ & $U$. peregrina & 36 & 72.36 & 83.46 \\
\hline 849D-7H-3 & C. wuellerstorfi & 146 & 65.46 & 74.91 & 74.88 & 3.18 & 0.20 & $849 \mathrm{D}-8 \mathrm{H}-2$ & C. wuellerstorfi & 46 & 72.46 & 83.56 \\
\hline 849D-7H-4 & C. wuellerstorfi & 6 & 65.56 & 75.01 & 74.97 & 3.22 & 0.30 & $849 \mathrm{D}-8 \mathrm{H}-2$ & $U$, peregrina & 46 & 72.46 & 83.56 \\
\hline 849D-7H-4 & C. wuellerstorfi & 16 & 65.66 & 75.11 & 75.07 & 3.37 & 0.10 & $849 \mathrm{D}-8 \mathrm{H}-2$ & $U$. peregrina & 56 & 72.56 & 83.66 \\
\hline 849D-7H-4 & C. wuellerstorf $i$ & 26 & 65.76 & 75.21 & 75.15 & 3.48 & 0.09 & $849 \mathrm{D}-8 \mathrm{H}-2$ & C. wuellerstorfi & 66 & 72.66 & 83.76 \\
\hline 849D-7H-4 & C. wuellerstorfi & 36 & 65.86 & 75.31 & 75.23 & 3.46 & -0.07 & $849 \mathrm{D}-8 \mathrm{H}-2$ & $U$. peregrina & 66 & 72.66 & 83.76 \\
\hline 849D-7H-4 & C. wuellerstorfi & 46 & 65.96 & 75.41 & 75.30 & 3.32 & -0.17 & $849 \mathrm{D}-8 \mathrm{H}-2$ & C. wuellerstorfi & 76 & 72.76 & 83.86 \\
\hline 849D-7H-4 & C. wuellerstorfi & 56 & 66.06 & 75.51 & 75.38 & 3.79 & -0.21 & $849 \mathrm{D}-8 \mathrm{H}-2$ & C. wuellerstorfi & 86 & 72.86 & 83.96 \\
\hline 849D-7H-4 & C. wuellerstorfi & 66 & 66.16 & 75.61 & 75.49 & 3.52 & -0.32 & $849 \mathrm{D}-8 \mathrm{H}-2$ & C. wuellerstorfi & 96 & 72.96 & 84.06 \\
\hline 849D-7H-4 & C. wuellerstorfi & 76 & 66.26 & 75.71 & 75.63 & 3.68 & -0.55 & $849 \mathrm{D}-8 \mathrm{H}-2$ & C. wuellerstorfi & 105 & 73.05 & 84.15 \\
\hline 849D-7H-4 & C. wuellerstorfi & 86 & 66.36 & 75.81 & 75.77 & 3.58 & -0.13 & $849 \mathrm{D}-8 \mathrm{H}-2$ & C. wuellerstorfi & 116 & 73.16 & 84.26 \\
\hline 849D-7H-4 & C. wuellerstorfi & 96 & 66.46 & 75.91 & 75.90 & 3.58 & -0.11 & $849 \mathrm{D}-8 \mathrm{H}-2$ & C. wuellerstorfi & 136 & 73.36 & 84.46 \\
\hline 849D-7H-4 & C. wuellerstorfi & 106 & 66.56 & 76.01 & 76.02 & 3.69 & -0.29 & $849 \mathrm{D}-8 \mathrm{H}-2$ & C. wuellerstorfi & 146 & 73.46 & 84.56 \\
\hline 849D-7H-4 & C. wuellerstorf $i$ & 116 & 66.66 & 76.11 & 76.12 & 3.69 & -0.52 & $849 \mathrm{D}-8 \mathrm{H}-3$ & C. wuellerstorfi & 6 & 73.56 & 84.66 \\
\hline 849D-7H-4 & C. wuellerstorfi & 126 & 66.76 & 76.21 & 76.21 & 3.75 & -0.36 & $849 \mathrm{D}-8 \mathrm{H}-3$ & C. wuellerstorfi & 16 & 73.66 & 84.76 \\
\hline 849D-7H-4 & C. wuellerstorfi & 146 & 66.96 & 76.41 & 76.39 & 3.70 & -0.29 & $849 \mathrm{D}-8 \mathrm{H}-3$ & C. wuellerstorfi & 26 & 73.76 & 84.86 \\
\hline 849D-7H-5 & C. whellerstorfi & 6 & 67.06 & 76.51 & 76.49 & 3.82 & -0.33 & $849 \mathrm{D}-8 \mathrm{H}-3$ & C. wuellerstorfi & 36 & 73.86 & 84.96 \\
\hline 849D-7H-5 & C. wuellerstorfi & 16 & 67.16 & 76.61 & 76.59 & 3.73 & -0.47 & $849 \mathrm{D}-8 \mathrm{H}-3$ & C. wuellerstorfi & 46 & 73.96 & 85.06 \\
\hline 849D-7H-5 & C. whellerstorfi & 26 & 67.26 & 76.71 & 76.70 & 3.77 & -0.31 & $849 \mathrm{D}-8 \mathrm{H}-3$ & $U$. peregrina & 56 & 74.06 & 85.16 \\
\hline 849D-7H-5 & C. whellerstorfi & 36 & 67.36 & 76.81 & 76.81 & 3.23 & 0.06 & $849 \mathrm{D}-8 \mathrm{H}-3$ & C. wuellerstorfi & 66 & 74.16 & 85.26 \\
\hline 849D-7H-5 & C. wuellerstorfi & 46 & 67.46 & 76.91 & 76.91 & 3.07 & -0.05 & $849 \mathrm{D}-8 \mathrm{H}-3$ & C. wuellerstorfi & 76 & 74.26 & 85.36 \\
\hline 849D-7H-5 & C. wuellerstorfi & 56 & 67.56 & 77.01 & 77.01 & 3.16 & 0.02 & $849 \mathrm{D}-8 \mathrm{H}-3$ & C. wuellerstorfi & 86 & 74.36 & 85.46 \\
\hline 849D-7H-5 & C. wuellerstorfi & 66 & 67.66 & 77.11 & 77.11 & 3.46 & -0.03 & $849 \mathrm{D}-8 \mathrm{H}-3$ & C. wuellerstorfi & 96 & 74.46 & 85.56 \\
\hline 849D-7H-5 & C. whellerstorfi & 76 & 67.76 & 77.21 & 77.21 & 3.22 & 0.01 & $849 \mathrm{D}-8 \mathrm{H}-3$ & C. wuellerstorfi & 106 & 74.56 & 85.66 \\
\hline 849D-7H-5 & C. wuellerstorfi & 86 & 67.86 & 77.31 & 77.31 & 3.21 & 0.01 & $849 \mathrm{D}-8 \mathrm{H}-3$ & C. wuellerstorfi & 116 & 74.66 & 85.76 \\
\hline $849 \mathrm{D}-7 \mathrm{H}-5$ & C. wuellerstorfi & 96 & 67.96 & 77.41 & 77.41 & 3.24 & -0.05 & $849 \mathrm{D}-8 \mathrm{H}-3$ & C. wuellerstorfi & 126 & 74.76 & 85.86 \\
\hline 849D-7H-5 & C. wuellerstorfi & 106 & 68.06 & 77.51 & 77.51 & 3.41 & -0.02 & $849 \mathrm{D}-8 \mathrm{H}-3$ & C. wuellerstorfi & 136 & 74.86 & 85.96 \\
\hline 849D-7H-5 & C. wuellerstorfi & 116 & 68.16 & 77.61 & 77.61 & 2.97 & -0.09 & $849 \mathrm{D}-8 \mathrm{H}-3$ & C. wuellerstorfi & 146 & 74.96 & 86.06 \\
\hline 849D-7H-5 & C. wuellerstorfi & 136 & 68.36 & 77.81 & 77.81 & 3.19 & 0.02 & $849 \mathrm{D}-8 \mathrm{H}-4$ & C. wuellerstorfi & 6 & 75.06 & 86.16 \\
\hline 849D-7H-5 & C. wuellerstorfi & 146 & 68.46 & 77.91 & 77.91 & 3.13 & -0.19 & $849 \mathrm{D}-8 \mathrm{H}-4$ & C. wuellerstorfi & 16 & 75.16 & 86.26 \\
\hline 849D-7H-6 & C. wuellerstorfi & 6 & 68.56 & 78.01 & 78.01 & 3.11 & 0.13 & $849 \mathrm{D}-8 \mathrm{H}-4$ & C. wuellerstorfi & 26 & 75.26 & 86.36 \\
\hline 849D-7H-6 & C. wuellerstorf $i$ & 16 & 68.66 & 78.11 & 78.11 & 3.19 & 0.15 & $849 \mathrm{D}-8 \mathrm{H}-4$ & C. wuellerstorfi & 36 & 75.36 & 86.46 \\
\hline 849D-7H-6 & C. wuellerstorfi & 26 & 68.76 & 78.21 & 78.21 & 3.28 & 0.30 & $849 \mathrm{D}-8 \mathrm{H}-4$ & C. wuellerstorfi & 46 & 75.46 & 86.56 \\
\hline 849D-7H-6 & C. wuellerstorf $i$ & 36 & 68.86 & 78.31 & 78.31 & 3.32 & 0.35 & $849 \mathrm{D}-8 \mathrm{H}-4$ & C. wuellerstorfi & 56 & 75.56 & 86.66 \\
\hline 849D-7H-6 & C. wuellerstorfi & 46 & 68.96 & 78.41 & 78.41 & 3.50 & 0.09 & $849 \mathrm{D}-8 \mathrm{H}-4$ & C. wuellerstorfi & 66 & 75.66 & 86.76 \\
\hline 849D-7H-6 & C. wuellerstorfi & 56 & 69.06 & 78.51 & 78.51 & 3.21 & -0.27 & $849 \mathrm{D}-8 \mathrm{H}-4$ & C. wuellerstorfi & 76 & 75.76 & 86.86 \\
\hline 849D-7H-6 & C. wuellerstorfi & 66 & 69.16 & 78.61 & 78.61 & 3.88 & -0.23 & $849 \mathrm{D}-8 \mathrm{H}-4$ & C. wuellerstorfi & 86 & 75.86 & 86.96 \\
\hline 849D-7H-6 & C. wuellerstorfi & 76 & 69.26 & 78.71 & 78.71 & 3.73 & -0.02 & $849 \mathrm{D}-8 \mathrm{H}-4$ & C. wuellerstorfi & 96 & 75.96 & 87.06 \\
\hline 849D-7H-6 & C. wuellerstorfi & 86 & 69.36 & 78.81 & 78.81 & 3.81 & -0.11 & $849 \mathrm{D}-8 \mathrm{H}-4$ & C. wuellerstorfi & 106 & 76.06 & 87.16 \\
\hline 849D-7H-6 & C. wuellerstorfi & 106 & 69.56 & 79.01 & 79.01 & 3.48 & 0.08 & $849 \mathrm{D}-8 \mathrm{H}-4$ & C. wuellerstorfi & 116 & 76.16 & 87.26 \\
\hline 849D-7H-6 & C. wuellerstorfi & 116 & 69.66 & 79.11 & 79.12 & 3.22 & 0.24 & $849 \mathrm{D}-8 \mathrm{H}-4$ & C. wuellerstorfi & 126 & 76.26 & 87.36 \\
\hline 849D-7H-6 & C. wuellerstorfi & 126 & 69.76 & 79.21 & 79.23 & 3.18 & 0.16 & $849 \mathrm{D}-8 \mathrm{H}-4$ & C. wuellerstorfi & 136 & 76.36 & 87.46 \\
\hline 849D-7H-6 & C. wuellerstorfi & 136 & 69.86 & 79.31 & 79.33 & 3.42 & 0.23 & $849 \mathrm{D}-8 \mathrm{H}-4$ & C. wuellerstorfi & 146 & 76.46 & 87.56 \\
\hline 849D-7H-6 & C. wuellerstorfi & 146 & 69.96 & 79.41 & 79.42 & 3.33 & 0.14 & $849 \mathrm{D}-8 \mathrm{H}-5$ & C. wuellerstorfi & 6 & 76.56 & 87.66 \\
\hline 849D-7H-7 & C. wuellerstorfi & 6 & 70.06 & 79.51 & 79.52 & 3.28 & 0.04 & $849 \mathrm{D}-8 \mathrm{H}-5$ & C. wuellerstorfi & 16 & 76.66 & 87.76 \\
\hline 849D-7H-7 & C. wuellerstorfi & 16 & 70.16 & 79.61 & 79.62 & 3.64 & 0.09 & $849 \mathrm{D}-8 \mathrm{H}-5$ & C. wuellerstorfi & 26 & 76.76 & 87.86 \\
\hline 849D-7H-7 & C. wuellerstorfi & 26 & 70.26 & 79.71 & 79.71 & 3.59 & 0.04 & $849 \mathrm{D}-8 \mathrm{H}-5$ & C. wuellerstorfi & 36 & 76.86 & 87.96 \\
\hline 849D-7H-7 & C. wuellerstorfi & 36 & 70.36 & 79.81 & 79.78 & 3.79 & -0.37 & $849 \mathrm{D}-8 \mathrm{H}-5$ & C. wuellerstorfi & 46 & 76.96 & 88.06 \\
\hline 849D-7H-7 & C. wuellerstorfi & 36 & 70.36 & 79.81 & 79.79 & 3.38 & -0.05 & $849 \mathrm{D}-8 \mathrm{H}-5$ & C. wuellerstorfi & 56 & 77.06 & 88.16 \\
\hline 849D-7H-7 & C. wuellerstorfi & 46 & 70.46 & 79.91 & 79.86 & 3.37 & -0.31 & $849 \mathrm{D}-8 \mathrm{H}-5$ & C. wuellerstorfi & 66 & 77.16 & 88.26 \\
\hline
\end{tabular}


APPENDIX A (continued).

\begin{tabular}{|c|c|c|c|c|c|c|c|c|c|c|}
\hline Section & Species & $\begin{array}{l}\text { Depth } \\
(\mathrm{cm})\end{array}$ & $\begin{array}{l}\text { Depth } \\
\text { (mbsf) }\end{array}$ & $\begin{array}{l}\text { Depth } \\
\text { (mcd) }\end{array}$ & $\begin{array}{l}\text { Depth } \\
\text { (rmcd) }\end{array}$ & $\delta^{18} \mathrm{O}$ & $\delta^{1,3} \mathrm{C}$ & Section & Species & $\begin{array}{c}\text { Depth } \\
(\mathrm{cm})\end{array}$ \\
\hline $849 \mathrm{D}-8 \mathrm{H}-5$ & C. whellerstorfi & 76 & 77.26 & 88.36 & 88.36 & 3,14 & 0.22 & 849D-9H-3 & C. wuellerstorfi & 86 \\
\hline 849D-8H-5 & C. wuellerstorfi & 86 & 77.36 & 88.46 & 88.46 & 3.16 & 0.40 & $849 \mathrm{D}-9 \mathrm{H}-3$ & C. wuellerstorfi & 106 \\
\hline $849 \mathrm{D}-8 \mathrm{H}-5$ & C. whellerstorfi & 96 & 77.46 & 88.56 & 88.57 & 3.07 & 0.42 & 849D-9H-3 & C. wuellerstorfi & 116 \\
\hline $849 \mathrm{D}-8 \mathrm{H}-5$ & C. wuellerstorfi & 106 & 77.56 & 88.66 & 88.69 & 3.13 & 0.20 & 849D-9H-3 & C. wuellerstorfi & 126 \\
\hline 849D-8H-5 & C. wuellerstorfi & 116 & 77.66 & 88.76 & 88.83 & 3.17 & 0.33 & $849 \mathrm{D}-9 \mathrm{H}-3$ & C. wuellerstorfi & 136 \\
\hline $849 \mathrm{D}-8 \mathrm{H}-5$ & C. wuellerstorfi & 126 & 77.76 & 88.86 & 88.97 & 3.11 & 0.29 & $849 \mathrm{D}-9 \mathrm{H}-3$ & C. wuellerstorfi & 146 \\
\hline $849 \mathrm{D}-8 \mathrm{H}-5$ & C. whellerstorfi & 136 & 77.86 & 88.96 & 89.09 & 3.13 & 0.39 & 849D-9H-4 & C. wuellerstorfi & 6 \\
\hline $849 \mathrm{D}-8 \mathrm{H}-5$ & C. wuellerstorfi & 146 & 77.96 & 89.06 & 89.20 & 3.12 & 0.34 & $849 \mathrm{D}-9 \mathrm{H}-4$ & C. wuellerstorfi & 16 \\
\hline $849 \mathrm{D}-8 \mathrm{H}-6$ & C. wuellerstorfi & 6 & 78.06 & 89.16 & 89.29 & 3.15 & 0.42 & 849D-9H-4 & C. wuellerstorfi & 26 \\
\hline $849 \mathrm{D}-8 \mathrm{H}-6$ & C. wuellerstorfi & 16 & 78.16 & 89.26 & 89.37 & 3.20 & 0.22 & 849D-9H-4 & C. wuellerstorfi & 36 \\
\hline $849 \mathrm{D}-8 \mathrm{H}-6$ & C. wuellerstorfi & 26 & 78.26 & 89.36 & 89.46 & 3.23 & 0.31 & $849 \mathrm{D}-9 \mathrm{H}-4$ & C. wuellerstorfi & 36 \\
\hline $849 \mathrm{D}-8 \mathrm{H}-6$ & C. wuellerstorfi & 36 & 78.36 & 89.46 & 89.55 & 3.21 & 0.27 & 849D-9H-4 & C. wuellerstorfi & 46 \\
\hline $849 \mathrm{D}-8 \mathrm{H}-6$ & C. wuellerstorfi & 46 & 78.46 & 89.56 & 89.65 & 3.27 & 0.17 & 849D-9H-4 & C. wuellerstorfi & 56 \\
\hline $849 \mathrm{D}-8 \mathrm{H}-6$ & C. wuellerstorfi & 56 & 78.56 & 89.66 & 89.76 & 3.29 & 0.22 & 849D-9H-4 & C. wuellerstorfi & 66 \\
\hline $849 \mathrm{D}-8 \mathrm{H}-6$ & C. wuellerstorfi & 66 & 78.66 & 89.76 & 89.87 & 3.24 & 0.10 & 849D-9H-4 & C. wuellerstorfi & 76 \\
\hline $849 \mathrm{C}-9 \mathrm{H}-1$ & C. wuellerstorfi & 36 & 77.36 & 89.96 & 89.91 & 3.23 & 0.22 & 849D-9H-4 & C. wuellerstorfi & 96 \\
\hline 849D-8H-6 & C. wuellerstorfi & 76 & 78.76 & 89.86 & 89.98 & 2.98 & 0.01 & $849 \mathrm{D}-9 \mathrm{H}-4$ & C. wuellerstorfi & 106 \\
\hline $849 \mathrm{C}-9 \mathrm{H}-1$ & C. wuellerstorfi & 46 & 77.46 & 90.06 & 90.02 & 3.21 & 0.21 & $849 \mathrm{D}-9 \mathrm{H}-4$ & C. wuellerstorfi & 116 \\
\hline $849 \mathrm{D}-8 \mathrm{H}-6$ & C. wuellerstorfi & 86 & 78.86 & 89.96 & 90.08 & 3.23 & 0.34 & 849D-9H-4 & C. wuellerstorfi & 126 \\
\hline $849 \mathrm{C}-9 \mathrm{H}-1$ & C. wuellerstorfi & 56 & 77.56 & 90.16 & 90.12 & 3.16 & 0.27 & $849 \mathrm{D}-9 \mathrm{H}-4$ & C. wuellerstorfi & 136 \\
\hline $849 \mathrm{D}-8 \mathrm{H}-6$ & C. wuellerstorfi & 96 & 78.96 & 90.06 & 90.17 & 3.09 & 0.28 & 849D-9H-4 & C. wuellerstorfi & 146 \\
\hline $849 \mathrm{C}-9 \mathrm{H}-1$ & C. wuellerstorfi & 66 & 77.66 & 90.26 & 90.22 & 3.13 & 0.27 & 849D-9H-5 & C. wuellerstorfi & 6 \\
\hline $849 \mathrm{C}-9 \mathrm{H}-1$ & C. wuellerstorfi & 76 & 77.76 & 90.36 & 90.32 & 2.99 & 0.18 & $849 \mathrm{D}-9 \mathrm{H}-5$ & C. wuellerstorfi & 6 \\
\hline $849 \mathrm{C}-9 \mathrm{H}-1$ & C. wuellerstorfi & 86 & 77.86 & 90.46 & 90.42 & 2.97 & -0.09 & $849 \mathrm{D}-9 \mathrm{H}-5$ & C. wuellerstorfi & 16 \\
\hline $849 \mathrm{C}-9 \mathrm{H}-1$ & C. wuellerstorfi & 96 & 77.96 & 90.56 & 90.53 & 2.92 & -0.04 & 849D-9H-5 & C. wuellerstorfi & 16 \\
\hline $849 \mathrm{C}-9 \mathrm{H}-1$ & C. wuellerstorfi & 106 & 78.06 & 90.66 & 90.64 & 3.08 & -0.22 & $849 \mathrm{D}-9 \mathrm{H}-5$ & C. wuellerstorfi & 26 \\
\hline $849 \mathrm{C}-9 \mathrm{H}-1$ & C, wuellerstorfi & 116 & 78.16 & 90.76 & 90.77 & 3.19 & 0.11 & $849 \mathrm{D}-9 \mathrm{H}-5$ & C. wuellerstorfi & 36 \\
\hline $849 \mathrm{C}-9 \mathrm{H}-\mathrm{I}$ & C. wuellerstorfi & 126 & 78.26 & 90.86 & 90.90 & 3.03 & -0.05 & $849 \mathrm{D}-9 \mathrm{H}-5$ & C. wuellerstorfi & 46 \\
\hline $849 \mathrm{C}-9 \mathrm{H}-1$ & C. wuellerstorfi & 136 & 78.36 & 90.96 & 91.01 & 3.22 & 0.12 & 849D-9H-5 & C. wuellerstorfi & 56 \\
\hline $849 \mathrm{C}-9 \mathrm{H}-1$ & C. wuellerstorfi & 146 & 78.46 & 91.06 & 91.12 & 3.21 & 0.01 & $849 \mathrm{D}-9 \mathrm{H}-5$ & C. wuellerstorfi & 66 \\
\hline $849 \mathrm{C}-9 \mathrm{H}-2$ & C. wuellerstorfi & 6 & 78.56 & 91.16 & 91.22 & 3.21 . & -0.05 & 849D-9H-5 & C. wuellerstorfi & 66 \\
\hline $849 \mathrm{C}-9 \mathrm{H}-2$ & C. wuellerstorfi & 6 & 78.56 & 91.16 & 91.22 & 3.25 & 0.18 & $849 \mathrm{D}-9 \mathrm{H}-5$ & C. wuellerstorfi & 76 \\
\hline $849 \mathrm{C}-9 \mathrm{H}-2$ & C. wuellerstorfi & 16 & 78.66 & 91.26 & 91.31 & 3.38 & -0.13 & 849D-9H-5 & C. wuellerstorfi & 86 \\
\hline $849 \mathrm{C}-9 \mathrm{H}-2$ & C. wuellerstorfi & 26 & 78.76 & 91.36 & 91.40 & 3.16 & -0.05 & 849D-9H-5 & C. wuellerstorfi & 96 \\
\hline $849 \mathrm{C}-9 \mathrm{H}-2$ & U. peregrina & 26 & 78.76 & 91.36 & 91.40 & 3.27 & -0.05 & $849 \mathrm{D}-9 \mathrm{H}-5$ & C. wuellerstorfi & 106 \\
\hline $849 \mathrm{C}-9 \mathrm{H}-2$ & C. wuellerstorfi & 36 & 78.86 & 91.46 & 91.48 & $3,44$. & -0.30 & 849D-9H-5 & C. wuellerstorfi & 116 \\
\hline $849 \mathrm{C}-9 \mathrm{H}-2$ & C. wuellerstorfi & 46 & 78.96 & 91.56 & 91.57 & 3.68 & -0.43 & $849 \mathrm{D}-9 \mathrm{H}-5$ & C. wuellerstorfi & 126 \\
\hline $849 \mathrm{C}-9 \mathrm{H}-2$ & $U$. peregrina & 56 & 79.06 & 91.66 & 91.66 & 3.73 & -0.35 & $849 \mathrm{D}-9 \mathrm{H}-5$ & C. wuellerstorfi & 136 \\
\hline $849 \mathrm{C}-9 \mathrm{H}-2$ & C. wuellerstorfi & 66 & 79.16 & 91.76 & 91.76 & 3.62 . & -0.37 & 849D-9H-5 & C. wuellerstorfi & 146 \\
\hline $849 \mathrm{C}-9 \mathrm{H}-2$ & C. wuellerstorfi & 76 & 79.26 & 91.86 & 91.85 & 3.66 & -0.44 & $849 \mathrm{D}-9 \mathrm{H}-6$ & C. wuellerstorfi & 6 \\
\hline $849 \mathrm{C}-9 \mathrm{H}-2$ & C. wuellerstorfi & 86 & 79.36 & 91.96 & 91.96 & 3.36 & -0.36 & $849 \mathrm{D}-9 \mathrm{H}-6$ & C. wuellerstorfi & 16 \\
\hline $849 \mathrm{C}-9 \mathrm{H}-2$ & C. wuellerstorfi & 96 & 79.46 & 92.06 & 92.07 & 3.43 & -0.38 & $849 \mathrm{D}-9 \mathrm{H}-6$ & C. wuellerstorfi & 26 \\
\hline $849 \mathrm{C}-9 \mathrm{H}-2$ & C. wuellerstorfi & 106 & 79.56 & 92.16 & 92.17 & 3.41 . & -0.31 & $849 \mathrm{D}-9 \mathrm{H}-6$ & C. wuellerstorfi & 36 \\
\hline $849 \mathrm{C}-9 \mathrm{H}-2$ & C. wuellerstorfi & 116 & 79.66 & 92.26 & 92.27 & 3.46 & -0.19 & $849 \mathrm{D}-9 \mathrm{H}-6$ & C. wuellerstorfi & 46 \\
\hline $849 \mathrm{C}-9 \mathrm{H}-2$ & C. wuellerstorfi & 126 & 79.76 & 92.36 & 92.36 & 3.22 & 0.01 & 849D-9H-6 & C. wuellerstorfi & 56 \\
\hline $849 \mathrm{C}-9 \mathrm{H}-2$ & C. wuellerstorfi & 136 & 79.86 & 92.46 & 92.46 & 3.06 & 0.05 & $849 \mathrm{D}-9 \mathrm{H}-6$ & C. wuellerstorfi & 66 \\
\hline $849 \mathrm{C}-9 \mathrm{H}-2$ & C. wuellerstorfi & 146 & 79.96 & 92.56 & 92.55 & 3.21 & 0.03 & 849D-9H-6 & $C$, wiellerstorfi & 76 \\
\hline $849 \mathrm{C}-9 \mathrm{H}-2$ & C. wuellerstorfi & 146 & 79.96 & 92.56 & 92.55 & 3.02 & -0.24 & $849 \mathrm{D}-9 \mathrm{H}-6$ & C. wuellerstorfi & 86 \\
\hline $849 \mathrm{C}-9 \mathrm{H}-3$ & C. wuellerstorfi & 6 & 80.06 & 92.66 & 92.66 & 3.30 & -0.40 & $849 \mathrm{D}-9 \mathrm{H}-6$ & C. whellerstorfi & 96 \\
\hline $849 \mathrm{C}-9 \mathrm{H}-3$ & C. wuellerstorfi & 16 & 80.16 & 92.76 & 92.76 & 3.19 & -0.24 & $849 \mathrm{D}-9 \mathrm{H}-6$ & C. wuellerstorfi & 106 \\
\hline $849 \mathrm{C}-9 \mathrm{H}-3$ & C. wuellerstorfi & 26 & 80.26 & 92.86 & 92.86 & 3.12 & -0.14 & 849D-9H-6 & C. wuellerstorfi & 116 \\
\hline 849D-9H-1 & C. wuellerstorfi & 16 & 80.16 & 93.06 & 92.94 & 3.46 & -0.12 & 849D-9H-6 & C. wuellerstorfi & 126 \\
\hline $849 \mathrm{C}-9 \mathrm{H}-3$ & C. wuellerstorfi & 36 & 80.36 & 92.96 & 92.97 & 3.25 & -0.11 & $849 \mathrm{D}-9 \mathrm{H}-6$ & C. wuellerstorfi & 136 \\
\hline $849 \mathrm{D}-9 \mathrm{H}-1$ & C. wuellerstorfi & 26 & 80.26 & 93.16 & 93.10 & 3.41 . & -0.06 & $849 \mathrm{D}-9 \mathrm{H}-6$ & C. wuellerstorfi & 146 \\
\hline $849 \mathrm{D}-9 \mathrm{H}-1$ & C. wuellerstorfi & 36 & 80.36 & 93.26 & 93.25 & 3.27 & -0.18 & $849 \mathrm{D}-9 \mathrm{H}-7$ & C. wuellerstorfi & 6 \\
\hline $849 \mathrm{D}-9 \mathrm{H}-1$ & C. wuellerstorfi & 46 & 80.46 & 93.36 & 93.37 & 3.26 & -0.23 & $849 \mathrm{D}-9 \mathrm{H}-7$ & C. wuellerstorfi & 16 \\
\hline $849 \mathrm{D}-9 \mathrm{H}-\mathrm{I}$ & C. wuellerstorfi & 56 & 80.56 & 93.46 & 93.48 & 3.38 & -0.23 & $849 \mathrm{D}-9 \mathrm{H}-7$ & C. wuellerstorfi & 26 \\
\hline $849 \mathrm{D}-9 \mathrm{H}-1$ & C. whellerstorfi & 66 & 80.66 & 93.56 & 93.58 & 3.32 & -0.02 & $849 \mathrm{D}-9 \mathrm{H}-7$ & C. wuellerstorfi & 36 \\
\hline 849D-9H-1 & C. wuellerstorfi & 66 & 80.66 & 93.56 & 93.58 & 3.35 & 0.07 & $849 \mathrm{D}-9 \mathrm{H}-7$ & C. wuellerstorfi & 46 \\
\hline 849D-9H-1 & C. wuellerstorfi & 76 & 80.76 & 93.66 & 93.67 & 3.30 & -0.18 & 849D-9H-7 & C. wuellerstorfi & 56 \\
\hline 849D-9H-I & U. peregrina & 86 & 80.86 & 93.76 & 93,77 & 3.15 & -0.24 & $849 \mathrm{C}-10 \mathrm{H}-2$ & C. wuellerstorfi & 16 \\
\hline $849 \mathrm{D}-9 \mathrm{H}-1$ & C. wuellerstorfi & 96 & 80.96 & 93.86 & 93.87 & 3.48 & -0.11 & $849 \mathrm{C}-10 \mathrm{H}-2$ & C. wuellerstorfi & 26 \\
\hline 849D-9H-I & C. wuellerstorfi & 106 & 81.06 & 93.96 & 93.97 & 3,40 & -0.27 & $849 \mathrm{C}-10 \mathrm{H}-2$ & C. wuellerstorfi & 36 \\
\hline $849 \mathrm{D}-9 \mathrm{H}-1$ & C. wuellerstorfi & 116 & 81.16 & 94.06 & 94.08 & 3.40 & -0.28 & $849 \mathrm{C}-10 \mathrm{H}-2$ & C. wuellerstorfi & 56 \\
\hline 849D-9H-1 & C. wuellerstorfi & 126 & 81.26 & 94.16 & 94.19 & 3.51 & -0.23 & $849 \mathrm{C}-10 \mathrm{H}-2$ & C. wuellerstorfi & 66 \\
\hline $849 \mathrm{D}-9 \mathrm{H}-\mathrm{I}$ & C. wuellerstorfi & 136 & 81.36 & 94.26 & 94.31 & 3.27 & -0.29 & $849 \mathrm{C}-10 \mathrm{H}-2$ & C. wuellerstorfi & 76 \\
\hline $849 \mathrm{D}-9 \mathrm{H}-1$ & C. wuellerstorfi & 146 & 81.46 & 94.36 & 94.43 & 3.15 & -0.05 & $849 \mathrm{C}-10 \mathrm{H}-2$ & C. wuellerstorfi & 86 \\
\hline $849 \mathrm{D}-9 \mathrm{H}-2$ & $U$. peregrina & 6 & 81.56 & 94.46 & 94.55 & 2.97 & 0.05 & $849 \mathrm{C}-10 \mathrm{H}-2$ & C. wuellerstorfi & 96 \\
\hline 849D-9H-2 & C. wuellerstorfi & 16 & 81.66 & 94.56 & 94.66 & 3.00 & 0.01 & $849 \mathrm{C}-10 \mathrm{H}-2$ & C. wuellerstorfi & 106 \\
\hline $849 \mathrm{D}-9 \mathrm{H}-2$ & C. woellerstorfi & 26 & 81.76 & 94.66 & 94.76 & 3.19 & -0.17 & $849 \mathrm{C}-10 \mathrm{H}-2$ & C. wuellerstorfi & 116 \\
\hline $849 \mathrm{D}-9 \mathrm{H}-2$ & C. wuellerstorfi & 36 & 81.86 & 94.76 & 94.85 & 3.25 & -0.17 & $849 \mathrm{C}-10 \mathrm{H}-2$ & C. wuellerstorfi & 126 \\
\hline $849 \mathrm{D}-9 \mathrm{H}-2$ & C. wuellerstorfi & 46 & 81.96 & 94.86 & 94.95 & 3.12 & -0.05 & $849 \mathrm{C}-10 \mathrm{H}-2$ & C. wuellerstorfi & 136 \\
\hline 849D-9H-2 & C. wuellerstorfi & 66 & 82.16 & 95.06 & 95.11 & 3.08 & -0.20 & $849 \mathrm{C}-10 \mathrm{H}-2$ & C. wuellerstorfi & 146 \\
\hline $849 \mathrm{D}-9 \mathrm{H}-2$ & C. wuellerstorfi & 76 & 82.26 & 95.16 & 95.20 & 2.99 & -0.25 & $849 \mathrm{D}-10 \mathrm{H}-1$ & C. wuellerstorfi & 46 \\
\hline $849 \mathrm{D}-9 \mathrm{H}-2$ & C. wuellerstorfi & 86 & 82.36 & 95.26 & 95.28 & 3.26 & -0.44 & $849 \mathrm{D}-10 \mathrm{H}-1$ & C. wuellerstorfi & 46 \\
\hline $849 \mathrm{D}-9 \mathrm{H}-2$ & C. wuellerstorfi & 96 & 82.46 & 95.36 & 95.37 & 3.15 & -0.32 & $849 \mathrm{D}-10 \mathrm{H}-1$ & C. wuellerstorfi & 61 \\
\hline 849D-9H-2 & C. wuellerstorfi & 106 & 82.56 & 95.46 & 95.47 & 2.96 & -0.41 & $849 \mathrm{D}-10 \mathrm{H}-1$ & C. wuellerstorfi & 76 \\
\hline $849 \mathrm{D}-9 \mathrm{H}-2$ & C. whellerstorfi & 116 & 82.66 & 95.56 & 95.58 & 2.86 & -0.31 & $849 \mathrm{D}-10 \mathrm{H}-1$ & C. wuellerstorfi & 91 \\
\hline 849D-9H-2 & C. wuellerstorfi & 146 & 82.96 & 95.86 & 95.92 & 2.84 & 0.11 & $849 \mathrm{D}-10 \mathrm{H}-1$ & C. wuellerstorfi & 106 \\
\hline $849 \mathrm{D}-9 \mathrm{H}-3$ & C. whellerstorfi & 6 & 83.06 & 95.96 & 96.04 & 3.00 & 0.06 & $849 \mathrm{D}-10 \mathrm{H}-1$ & C. wuellerstorfi & 121 \\
\hline 849D-9H-3 & C. wuellerstorfi & 16 & 83.16 & 96.06 & 96.14 & 3.16 & -0.30 & $849 \mathrm{D}-10 \mathrm{H}-1$ & C. wuellerstorfi & 136 \\
\hline $849 \mathrm{D}-9 \mathrm{H}-3$ & C. wuellerstorfi & 26 & 83.26 & 96.16 & 96.24 & 3.12 & -0.04 & $849 \mathrm{D}-10 \mathrm{H}-2$ & C. wuellerstorfi & 1 \\
\hline 849D-9H-3 & C. wuellerstorfi & 36 & 83.36 & 96.26 & 96.33 & 3.23 & -0.20 & $849 \mathrm{D}-10 \mathrm{H}-2$ & C. wuellerstorfi & 16 \\
\hline 849D-9H-3 & C. wuellerstorfi & 46 & 83.46 & 96.36 & 96.41 & 3.18 & -0.23 & $849 \mathrm{D}-10 \mathrm{H}-2$ & C. wuellerstorfi & 31 \\
\hline 849D-9H-3 & C. wuellerstorfi & 56 & 83.56 & 96.46 & 96.49 & 3.10 & 0.04 & $849 \mathrm{D}-10 \mathrm{H}-2$ & C. wuellerstorfi & 46 \\
\hline 849D-9H-3 & C. wuellerstorfi & 66 & 83.66 & 96.56 & 96.57 & 2.92 & 0.24 & $849 \mathrm{D}-10 \mathrm{H}-2$ & C. wuellerstorfi & 61 \\
\hline $849 \mathrm{D}-9 \mathrm{H}-3$ & C. wuellerstorfi & 76 & 83.76 & 96.66 & 96.64 & 2.94 & 0.16 & $849 \mathrm{D}-10 \mathrm{H}-2$ & C. wuellerstorfi & 76 \\
\hline
\end{tabular}


APPENDIX A (continued).

\begin{tabular}{|c|c|c|c|c|c|c|c|c|c|c|}
\hline Section & Species & $\begin{array}{l}\text { Depth } \\
(\mathrm{cm})\end{array}$ & $\begin{array}{l}\text { Depth } \\
\text { (mbsf) }\end{array}$ & $\begin{array}{ll}\text { Depth } & \text { Depth } \\
\text { (mcd) } & \text { (rmcd) }\end{array}$ & $\delta^{11 \pi} \mathrm{O} \quad \delta^{13} \mathrm{C}$ & Section & Species & $\begin{array}{l}\text { Depth } \\
(\mathrm{cm})\end{array}$ & $\begin{array}{l}\text { Depth } \\
\text { (mbsf) }\end{array}$ & $\begin{array}{ll}\text { Depth } & \text { Depth } \\
\text { (mcd) } & \text { (rmcd) }\end{array}$ \\
\hline $849 \mathrm{D}-10 \mathrm{H}-2$ & C. wuellerstorfi & 91 & 91.91 & 106.16106 .25 & $3.17-0.17$ & $849 \mathrm{D}-11 \mathrm{H}-4$ & C. wuellerstorfi & 46 & 103.96 & 118.81118 .81 \\
\hline $849 \mathrm{D}-10 \mathrm{H}-2$ & C. wuellerstorfi & 106 & 92.06 & $106.31 \quad 106.40$ & $2.97-0.27$ & 849D-1 IH-4 & C. wuellerstorfi & 61 & 104.11 & 118.96118 .96 \\
\hline 849D-10H-2 & C. whellerstorfi & 121 & 92.21 & 106.46106 .54 & $3.32-0.47$ & $849 \mathrm{D}-11 \mathrm{H}-4$ & C. wuellerstorfi & 76 & 104.26 & 119.11119 .11 \\
\hline $849 \mathrm{D}-10 \mathrm{H}-2$ & C. wuellerstorfi & 136 & 92.36 & 106.61106 .67 & $3.32-0.49$ & $849 \mathrm{D}-11 \mathrm{H}-4$ & C. wuellerstorfi & 91 & 104.41 & 119.26119 .26 \\
\hline $849 \mathrm{D}-10 \mathrm{H}-3$ & C. wuellerstorfi & 1 & 92.51 & 106.76106 .78 & $3.17-0.02$ & $849 \mathrm{D}-11 \mathrm{H}-4$ & C. wuellerstorfi & 106 & 104.56 & 119.41119 .41 \\
\hline 849D-10H-3 & C. wuellerstorfi & 16 & 92.66 & 106.91106 .89 & $3.02-0.03$ & $849 \mathrm{D}-11 \mathrm{H}-4$ & C. wuellerstorfi & 121 & 104.71 & 119.56119 .56 \\
\hline $849 \mathrm{D}-10 \mathrm{H}-3$ & C. wuellerstorfi & 31 & 92.81 & 107.06107 .02 & $2.79-0.04$ & 849D-11H-4 & C. wuellerstorfi & 136 & 104.86 & 119.71119 .71 \\
\hline $849 \mathrm{D}-10 \mathrm{H}-3$ & C. wuellerstorfi & 46 & 92.96 & 107.21107 .19 & 2.930 .08 & $849 \mathrm{D}-1 \mathrm{IH}-5$ & C. wuellerstorfi & 1 & 105.01 & 119.86119 .86 \\
\hline $849 \mathrm{D}-10 \mathrm{H}-3$ & C. wuellerstorfi & 61 & 93.11 & 107.36107 .39 & $2.99 \quad 0.00$ & $849 \mathrm{D}-11 \mathrm{H}-5$ & C. wuellerstorfi & 16 & 105.16 & 120.01120 .01 \\
\hline 849D-10H-3 & C. wuellerstorfi & 76 & 93.26 & $107.51 \quad 107.59$ & $2.91-0.13$ & 849D-11H-5 & C. wuellerstorfi & 31 & 105.31 & 120.16120 .16 \\
\hline $849 \mathrm{D}-10 \mathrm{H}-3$ & C. wuellerstorfi & 91 & 93.41 & $107.66 \quad 107.75$ & $3.17-0.27$ & $849 \mathrm{D}-11 \mathrm{H}-5$ & C. wuellerstorfi & 46 & 105.46 & $120.31 \quad 120.32$ \\
\hline $849 \mathrm{D}-10 \mathrm{H}-3$ & C. wuellerstorfi & 106 & 93.56 & $107.81 \quad 107.89$ & $3.46-0.38$ & $849 \mathrm{D}-11 \mathrm{H}-5$ & C. wuellerstorfi & 61 & 105.61 & 120.46120 .46 \\
\hline $849 \mathrm{D}-10 \mathrm{H}-3$ & C. wuellerstorfi & 121 & 93.71 & 107.96108 .00 & $3.12-0.13$ & 849D-11H-5 & C. wuellerstorfi & 76 & 105.76 & 120.61120 .61 \\
\hline $849 \mathrm{D}-10 \mathrm{H}-3$ & C. wuellerstorfi & 136 & 93.86 & 108.11108 .11 & 3.140 .01 & 849D-1 IH-5 & C. wuellerstorfi & 91 & 105.91 & 120.76120 .76 \\
\hline $849 \mathrm{D}-10 \mathrm{H}-4$ & C. wuellerstorfi & 1 & 94.01 & 108.26108 .22 & $3.08-0.10$ & $849 \mathrm{D}-11 \mathrm{H}-5$ & C. wuellerstorfi & 106 & 106.06 & 120.91120 .91 \\
\hline $849 \mathrm{D}-10 \mathrm{H}-4$ & C. wuellerstorfi & 16 & 94.16 & 108.41108 .35 & $2.97 \quad 0.08$ & $849 \mathrm{D}-11 \mathrm{H}-5$ & C. wuellerstorfi & 121 & 106.21 & $121,06121.06$ \\
\hline $849 \mathrm{D}-10 \mathrm{H}-4$ & C. wuellerstorfi & 31 & 94.31 & 108.56108 .48 & $3.05-0.04$ & 849D-11H-5 & C. wuellerstorfi & 136 & 106.36 & $121.21 \quad 121.22$ \\
\hline 849D-10H-4 & C. wuellerstorfi & 46 & 94.46 & 108.71108 .63 & $\begin{array}{ll}3.08 & 0.06\end{array}$ & 849D-11H-6 & C. wuellerstorfi & 1 & 106.51 & 121.36121 .36 \\
\hline $849 \mathrm{D}-10 \mathrm{H}-4$ & C. wuellerstorfi & 61 & 94.61 & 108.86108 .79 & $2.99-0.19$ & $849 \mathrm{D}-11 \mathrm{H}-6$ & C. wuellerstorfi & 16 & 106.66 & 121.51121 .51 \\
\hline 849D-10H-4 & C. wuellerstorfi & 76 & 94.76 & 109.01108 .97 & $3.48-0.35$ & $849 \mathrm{D}-11 \mathrm{H}-6$ & C. wuellerstorfi & 31 & 106.81 & 121.66121 .66 \\
\hline 849D-10H-4 & C. wuellerstorfi & 91 & 94.91 & 109.16109 .15 & $3.24-0.36$ & $849 \mathrm{D}-11 \mathrm{H}-6$ & C. wuellerstorfi & 46 & 106.96 & 121.81121 .81 \\
\hline $849 \mathrm{D}-10 \mathrm{H}-4$ & $C$, wuellerstorfi & 106 & 95.06 & 109.31109 .32 & $3.02-0.02$ & $849 \mathrm{D}-11 \mathrm{H}-6$ & C. wuellerstorfi & 91 & 107.41 & $122.26 \mid 22.26$ \\
\hline 849D-10H-4 & C. wuellerstorfi & 121 & 95.21 & 109.46109 .48 & $2.97-0.13$ & $849 \mathrm{D}-11 \mathrm{H}-6$ & C. wuellerstorfi & 106 & 107.56 & 122.41122 .41 \\
\hline $849 \mathrm{D}-10 \mathrm{H}-4$ & C. wuellerstorfi & 136 & 95.36 & 109.61109 .62 & $2.95-0.07$ & $849 \mathrm{D}-11 \mathrm{H}-6$ & C. wuellerstorfi & 121 & 107.71 & 122.56122 .56 \\
\hline 849D-10H-5 & C. wuellerstorfi & 1 & 95.51 & 109.76109 .77 & $3.14-0.13$ & $849 \mathrm{D}-11 \mathrm{H}-6$ & C. wuellerstorfi & 136 & 107.86 & 122.71122 .71 \\
\hline $849 \mathrm{D}-10 \mathrm{H}-5$ & C. wuellerstorfi & 16 & 95.66 & 109.91109 .91 & 3.150 .11 & $849 \mathrm{D}-11 \mathrm{H}-7$ & C. wuellerstorfi & 1 & 108.01 & 122.86122 .86 \\
\hline $849 \mathrm{D}-10 \mathrm{H}-5$ & C. wuellerstoifi & 31 & 95.81 & 110.06110 .05 & 3.130 .04 & $849 \mathrm{D}-11 \mathrm{H}-7$ & C. wuellerstorfi & 31 & 108.31 & 123.16123 .17 \\
\hline $849 \mathrm{D}-10 \mathrm{H}-5$ & C. wuellerstorfi & 46 & 95.96 & 110.21110 .19 & $3.20 \quad 0.11$ & $849 \mathrm{D}-11 \mathrm{H}-7$ & C. wuellerstorfi & 46 & 108.46 & 123.31123 .30 \\
\hline $849 \mathrm{D}-10 \mathrm{H}-5$ & C. wuellerstorfi & 61 & 96.11 & 110.36110 .34 & $\begin{array}{ll}3.13 & 0.02\end{array}$ & $849 \mathrm{D}-11 \mathrm{H}-7$ & C. wuellerstorfi & 61 & 108.61 & 123.46123 .46 \\
\hline 849D- $10 \mathrm{H}-5$ & C. wuellerstorfi & 76 & 96.26 & 110.51110 .50 & $3.14 \quad 0.02$ & $849 D-12 X-3$ & C. wuellerstorfi & 11 & 111.61 & $127.51 \quad 127.51$ \\
\hline $849 \mathrm{D}-10 \mathrm{H}-5$ & C. wuellerstorfi & 91 & 96.41 & 110.66110 .67 & $3.19-0.09$ & $849 D-12 X-3$ & C. wuellerstorfi & 31 & 111.81 & 127.71127 .71 \\
\hline $849 \mathrm{D}-10 \mathrm{H}-5$ & C. wuellerstorfi & 106 & 96.56 & 110.81110 .85 & $3.28-0.22$ & $849 D-12 X-3$ & C. wuellerstorfi & 51 & 112.01 & 127.91127 .91 \\
\hline $849 \mathrm{D}-10 \mathrm{H}-5$ & C. wuellerstorfi & 121 & 96.71 & 110.96111 .02 & $3.32-0.25$ & $849 D-12 X-3$ & C. wuellerstorfi & 91 & 112.41 & 128.31128 .31 \\
\hline $849 \mathrm{D}-10 \mathrm{H}-5$ & C. wuellerstorfi & 136 & 96.86 & 111.11111 .18 & $3.29-0.14$ & $849 D-12 X-3$ & C. wuellerstorfi & 111 & 112.61 & 128.51128 .51 \\
\hline $849 \mathrm{D}-10 \mathrm{H}-6$ & C. wuellerstorfi & 1 & 97.01 & 111.26111 .31 & $3.15-0.26$ & $849 \mathrm{D}-12 \mathrm{X}-4$ & C. whellerstorfi & i & 113.01 & 128.91128 .91 \\
\hline $849 \mathrm{D}-10 \mathrm{H}-6$ & C. wuellerstorfi & 16 & 97.16 & 111.41111 .44 & $3.10-0.03$ & $849 D-12 X-4$ & C. wuellerstorfi & 41 & 113.41 & 129.31129 .31 \\
\hline $849 \mathrm{D}-10 \mathrm{H}-6$ & C. wuellerstorfi & 31 & 97.31 & 111.56111 .55 & $3.18-0.03$ & $849 D-12 X-4$ & C. wuellerstorfi & 61 & 113.61 & 129.51129 .51 \\
\hline $849 \mathrm{D}-10 \mathrm{H}-6$ & C. wuellerstorfi & 46 & 97.46 & 111.71111 .67 & $3.18-0.08$ & $849 D-12 X-4$ & C. wuellerstorfi & 81 & 113.81 & 129.71129 .71 \\
\hline $849 \mathrm{D}-10 \mathrm{H}-6$ & C. wuellerstorfi & 61 & 97.61 & 111.86111 .80 & $3.31-0.02$ & $849 D-12 X-4$ & C. wuellerstorfi & 141 & 114.41 & $130.31 \quad 130.31$ \\
\hline 849D-10H-6 & C. wuellerstorfi & 76 & 97.76 & 112.01111 .96 & $3.18-0.08$ & $849 D-12 X-5$ & C. wuellerstorfi & 11 & 114.61 & $130.51 \quad 130.51$ \\
\hline $849 \mathrm{D}-10 \mathrm{H}-6$ & C. wuellerstorfi & 91 & 97.91 & 112.16112 .13 & $3.30-0.22$ & $849 D-12 X-5$ & C. wuellerstorfi & 31 & 114.81 & 130.71130 .71 \\
\hline 849D-10H-6 & C. wuellerstorfi & 106 & 98.06 & 112.31112 .29 & $3.25-0.05$ & $849 D-12 X-5$ & C. wuellerstorfi & 51 & 115.01 & 130.91130 .91 \\
\hline $849 \mathrm{D}-10 \mathrm{H}-6$ & C. wuellerstorfi & 121 & 98.21 & 112.46112 .43 & $3.10-0.05$ & $849 D-12 X-5$ & C. wuellerstorfi & 71 & 115.21 & 131.11131 .11 \\
\hline $849 \mathrm{D}-10 \mathrm{H}-6$ & C. wuellerstorfi & 136 & 98.36 & 112.61112 .57 & $3.11 \quad 0.23$ & $849 D-12 X-5$ & C. wuellerstorfi & 91 & 115.41 & 131.31131 .31 \\
\hline $849 \mathrm{C}-11 \mathrm{H}-2$ & C. wuellerstorfi & 16 & 97.66 & 112.86112 .92 & $\begin{array}{ll}3.13 & 0.08\end{array}$ & $849 D-12 X-5$ & C. wuellerstorfi & 131 & 115.81 & 131.71131 .71 \\
\hline $849 \mathrm{C}-11 \mathrm{H}-2$ & C. wuellerstorfi & 26 & 97.76 & 112.96113 .02 & $3.22-0.07$ & $849 D-12 X-6$ & C. wuellerstorfi & I & 116.01 & 131.91131 .91 \\
\hline $849 \mathrm{C}-11 \mathrm{H}-2$ & C. wuellerstorfi & 36 & 97.86 & 113.06113 .12 & $\begin{array}{ll}3.23 & 0.03\end{array}$ & $849 D-12 X-6$ & C. wuellerstorfi & 21 & 116.21 & 132.11132 .11 \\
\hline $849 \mathrm{C}-11 \mathrm{H}-2$ & C. wuellerstorfi & 46 & 97.96 & 113.16113 .23 & $3.22-0.23$ & $849 D-12 X-6$ & C. wuellerstorfi & 41 & 116.41 & $132.31 \quad 132.31$ \\
\hline $849 \mathrm{C}-11 \mathrm{H}-2$ & C. wuellerstorfi & 56 & 98.06 & 113.26113 .33 & $3.28-0.06$ & $849 D-12 X-6$ & C. wuellerstorfi & 61 & 116.61 & $132.51 \quad 132.51$ \\
\hline $849 \mathrm{C}-11 \mathrm{H}-2$ & C. wuellerstorfi & 66 & 98.16 & 113.36113 .43 & $3.28-0.04$ & $849 D-12 X-6$ & C. wuellerstorfi & 81 & 116.81 & 132.71132 .71 \\
\hline $849 \mathrm{C}-11 \mathrm{H}-2$ & C. wuellerstorfi & 76 & 98.26 & 113.46113 .53 & $3.03-0.25$ & $849 D-13 X-1$ & C. wuellerstorfi & 11 & 115.61 & $132.81 \quad 132.81$ \\
\hline $849 \mathrm{C}-11 \mathrm{H}-2$ & C. wuellerstorfi & 86 & 98.36 & 113.56113 .63 & $3.35-0.41$ & $849 D-12 X-6$ & C. wuellerstorfi & 101 & 117.01 & 132.91132 .91 \\
\hline $849 \mathrm{C}-11 \mathrm{H}-2$ & C. wuellerstorfi & 96 & 98.46 & 113.66113 .73 & $3.14-0.03$ & $849 D-13 X-1$ & C. wuellerstorfi & 31 & 115.81 & 133.01133 .01 \\
\hline $849 \mathrm{C}-11 \mathrm{H}-2$ & C. wuellerstorfi & 106 & 98.56 & 113.76113 .82 & $3.18-0.16$ & $849 D-12 X-6$ & C. wuellerstorfi & 119 & 117.19 & 133.09133 .09 \\
\hline $849 \mathrm{C}-11 \mathrm{H}-2$ & C. wuellerstorfi & 116 & 98.66 & 113.86113 .92 & $3.19-0.23$ & $849 D-13 X-1$ & C. wuellerstorfi & 51 & 116.01 & $133.21 \quad 133.21$ \\
\hline $849 \mathrm{C}-11 \mathrm{H}-2$ & C. wuellerstorfi & 126 & 98.76 & 113.96114 .01 & $3.15-0.18$ & 849D-13X-1 & C. wuellerstorfi & 71 & 116.21 & 133.41133 .41 \\
\hline $849 \mathrm{C}-11 \mathrm{H}-2$ & C. wuellerstorfi & 136 & 98.86 & 114.06114 .09 & $3.12-0.13$ & 849D-13X-1 & C. wuellerstorfi & 91 & 116.41 & 133.61133 .61 \\
\hline $849 \mathrm{C}-11 \mathrm{H}-2$ & C. wuellerstorfi & 146 & 98.96 & 114.16114 .18 & $3.14-0.41$ & $849 D-13 X-1$ & C. wuellerstorfi & 111 & 116.61 & $133.81 \quad 133.81$ \\
\hline $849 \mathrm{D}-11 \mathrm{H}-1$ & C, wuellerstorfi & 46 & 99.46 & 114.31114 .26 & $3.05-0.08$ & $849 D-13 X-1$ & C. wuellerstorfi & 131 & 116.81 & $134.01 \quad 134.01$ \\
\hline $849 \mathrm{D}-11 \mathrm{H}-1$ & C. wuellerstorfi & 61 & 99.61 & 114.46114 .42 & $3.26-0.02$ & 849D-13X-2 & C. wuellerstorfi & 1 & 117.01 & $134.21 \quad 134.21$ \\
\hline $849 \mathrm{D}-11 \mathrm{H}-1$ & C. wuellerstorfi & 76 & 99.76 & 114.61114 .51 & $3.21 \quad 0.00$ & $849 D-13 X-2$ & C. wuellerstorfi & 21 & 117.21 & $134.41 \quad 134.41$ \\
\hline $849 \mathrm{D}-11 \mathrm{H}-1$ & C. wuellerstorfi & 91 & 99.91 & 114.76114 .64 & $2.81 \quad 0.04$ & $849 D-13 X-2$ & C. wuellerstorfi & 41 & 117.41 & $134.61 \quad 134.61$ \\
\hline 849D-11H-1 & C. wuellerstorfi & 106 & 100.06 & 114.91114 .87 & $2.92-0.06$ & $849 D-13 X-2$ & C. wuellerstorfi & 61 & 117.61 & $134.81 \quad 134.81$ \\
\hline $849 \mathrm{D}-11 \mathrm{H}-1$ & C. wuellerstorfi & 121 & 100.21 & 115.06115 .00 & $3.36-0.04$ & $849 D-13 X-2$ & C. wuellerstorfi & 81 & 117.81 & $135.01 \quad 135.01$ \\
\hline 849D-11H-1 & C. wuellerstorfi & 136 & 100.36 & 115.21115 .13 & $3.42-0.12$ & $849 D-13 X-2$ & C. wuellerstorfi & 101 & 118.01 & $135.21 \quad 135.21$ \\
\hline $849 \mathrm{D}-11 \mathrm{H}-2$ & C. wuellerstorfi & 1 & 100.51 & 115.36115 .33 & $3.09 \quad 0.01$ & $849 D-13 X-2$ & C. wuellerstorfi & 121 & 118.21 & 135.41135 .41 \\
\hline $849 \mathrm{D}-11 \mathrm{H}-2$ & C. wuellerstorfi & 16 & 100.66 & 115.51115 .48 & $3.16-0.04$ & 849D-13X-2 & C. wuellerstorfi & 141 & 118.41 & 135.61135 .61 \\
\hline $849 \mathrm{D}-11 \mathrm{H}-2$ & C. wuellerstorfi & 31 & 100.81 & 115.66115 .62 & $3.26-0.06$ & $849 D-13 X-3$ & C. wuellerstorfi & 11 & 118.61 & 135.81135 .81 \\
\hline $849 \mathrm{D}-11 \mathrm{H}-2$ & C. wuellerstorfi & 46 & 100.96 & 115.81115 .78 & $2.94 \quad 0.09$ & $849 D-13 X-3$ & C. wuellerstorfi & 31 & 118.81 & $136.01 \quad 136.01$ \\
\hline $849 \mathrm{D}-11 \mathrm{H}-2$ & C. wuellerstorfi & 61 & 101.11 & 115.96115 .91 & $3.12-0.04$ & $849 D-13 X-3$ & C. wuellerstorfi & 51 & 119.01 & $136.21 \quad 136.21$ \\
\hline $849 \mathrm{D}-11 \mathrm{H}-2$ & C. wuellerstorfi & 76 & 101.26 & 116.11116 .06 & $3.08 \quad 0.00$ & 849D-13X-3 & C. wuellerstorfi & 91 & 119.41 & 136.61136 .61 \\
\hline $849 \mathrm{D}-11 \mathrm{H}-2$ & C. wuellerstorfi & 91 & 101.41 & 116.26116 .26 & $\begin{array}{ll}3.10 & 0.12\end{array}$ & $849 D-13 X-3$ & C. wuellerstorfi & 131 & 119.81 & 137.01137 .01 \\
\hline $849 \mathrm{D}-1 \mathrm{IH}-2$ & C. wuellerstorfi & 106 & 101.56 & 116.41116 .44 & $2.99-0.04$ & $849 D-13 X-4$ & C. wuellerstorfi & I & 120.01 & $137.21 \quad 137.21$ \\
\hline 849D-1 IH-2 & C. wuellerstorfi & 121 & 101.71 & 116.56116 .57 & $3.21-0.14$ & $849 D-13 X-4$ & C. wuellerstorfi & 41 & 120.41 & 137.61137 .61 \\
\hline 849D- $11 \mathrm{H}-2$ & C. wuellerstorfi & 136 & 101.86 & 116.71116 .70 & $2.97-0.26$ & 849D-13X-4 & C. wuellerstorfi & 61 & 120.61 & 137.81137 .81 \\
\hline $849 \mathrm{D}-11 \mathrm{H}-3$ & C. wuellerstorfi & 1 & 102.01 & 116.86116 .86 & $3.02-0.30$ & $849 D-13 X-4$ & C. whellerstorfi & 81 & 120.81 & 138.01138 .01 \\
\hline $849 \mathrm{D}-1 \mathrm{IH}-3$ & C. wuellerstorfi & 16 & 102.16 & 117.01117 .01 & $3.14-0.27$ & $849 D-13 X-4$ & C. wuellerstorfi & 101 & 121.01 & $138.21 \quad 138.21$ \\
\hline $849 \mathrm{D}-11 \mathrm{H}-3$ & C. wuellerstorfi & 31 & 102.31 & 117.16117 .16 & $3.05-0.04$ & $849 D-13 X-4$ & C. wuellerstorfi & 121 & 121.21 & $138.41 \quad 138.41$ \\
\hline $849 \mathrm{D}-11 \mathrm{H}-3$ & C. wuellerstorfi & 46 & 102.46 & 117.31117 .31 & $3.04-0.22$ & 849D-13X-4 & C. wuellerstorfi & 141 & 121.41 & 138.61138 .61 \\
\hline $849 \mathrm{D}-11 \mathrm{H}-3$ & C. wuellerstorfi & 61 & 102.61 & 117.46117 .46 & $2.98-0.33$ & $849 D-13 X-5$ & C. wuellerstorfi & 11 & 121.61 & 138.81138 .81 \\
\hline $849 \mathrm{D}-11 \mathrm{H}-3$ & C. wuellerstorfi & 76 & 102.76 & 117.61117 .61 & $3.17-0.04$ & $849 D-13 X-5$ & C. wuellerstorfi & 31 & 121.81 & 139.01139 .01 \\
\hline 849D-11H-3 & C. whellerstorfi & 91 & 102.91 & 117.76117 .76 & $3.11-0.12$ & $849 D-13 X-5$ & C. wuellerstorfi & 51 & 122.01 & $139.21 \quad 139.21$ \\
\hline $849 \mathrm{D}-1 \mathrm{IH}-3$ & C. whellerstorfi & 106 & 103.06 & 117.91117 .91 & $3.11-0.27$ & $849 D-13 X-5$ & C. wuellerstorfi & 91 & 122.41 & 139.61139 .61 \\
\hline $849 \mathrm{D}-11 \mathrm{H}-3$ & C. wuellerstorfi & 121 & 103.21 & 118.06118 .06 & $3.16-0.27$ & $849 D-13 X-6$ & C. wuellerstorfi & 21 & 123.21 & $140.41 \quad 140.41$ \\
\hline $849 \mathrm{D}-11 \mathrm{H}-3$ & C. wuellerstorfi & 136 & 103.36 & 118.21118 .21 & $3.35-0.31$ & $849 D-13 X-6$ & C. wuellerstorfi & 61 & 123.61 & $140.81 \quad 140.81$ \\
\hline $849 \mathrm{D}-11 \mathrm{H}-4$ & C. wuellerstorfi & 1 & 103.51 & 118.36118 .35 & $3.31-0.24$ & $849 D-13 X-6$ & C. wuellerstorfi & 81 & 123.81 & 141.01141 .01 \\
\hline $849 \mathrm{D}-11 \mathrm{H}-4$ & C. wuellerstorfi & 31 & 103.81 & 118.66118 .66 & $3.08-0.01$ & 849D-14X-1 & C. wuellerstorfi & 1 & 125.11 & 143.01143 .01 \\
\hline
\end{tabular}


APPENDIX A (continued).

\begin{tabular}{|c|c|c|c|c|c|c|}
\hline Section & Species & $\begin{array}{l}\text { Depth } \\
(\mathrm{cm})\end{array}$ & $\begin{array}{l}\text { Depth } \\
\text { (mbsf) }\end{array}$ & $\begin{array}{l}\text { Depth } \\
\text { (mepth } \\
\text { (rmcd) }\end{array}$ & $\delta^{18} \mathrm{O}$ & $\delta^{1.3} \mathrm{C}$ \\
\hline 849D-14X-1 & C. wuellerstorfi & 21 & 125.31 & $143.21 \quad 143.21$ & 3.23 & 0.16 \\
\hline 849D-14X-1 & C. wuellerstorfi & 41 & 125.51 & $143.41 \quad 143.41$ & 3.19 & 0.13 \\
\hline $849 \mathrm{D}-14 \mathrm{X}-1$ & C. wuellerstorfi & 81 & $|25.91|$ & $143.81 \quad 143.81$ & 3.07 & -0.17 \\
\hline $849 D-14 X-1$ & C. wuellerstorfi & 101 & 126.11 & $144.01 \quad 144.01$ & 3.40 & -0.35 \\
\hline 849D-14X-1 & C. wuellerstorfi & 121 & 126.31 & 144.21144 .21 & 3.43 & -0.16 \\
\hline $849 D-14 X-1$ & C. wuellerstorfi & 141 & $\mid 26.51$ & $144.41 \quad 144.41$ & 3.28 & -0.08 \\
\hline 849 D-14X-2 & C. wuellerstorfi & 11 & 126.71 & $|44.61| 44.61$ & 3.17 & -0.09 \\
\hline $849 D-14 X-2$ & C. wuellerstorfi & 31 & 126.91 & $144.81 \quad 144.81$ & 3.16 & -0.07 \\
\hline $849 D-14 X-2$ & C. wuellerstorfi & 51 & 127.11 & 145.01145 .01 & 3.07 & 0.01 \\
\hline $849 D-14 X-2$ & C. wuellerstorfi & 71 & 127.31 & $145.21 \quad 145.21$ & 3.08 & -0.15 \\
\hline $849 D-14 X-2$ & C. wuellerstorfi & 91 & 127.51 & $145.41 \backslash 45.41$ & 3.06 & -0.09 \\
\hline $849 D-14 X-2$ & C. wuellerstorfi & 111 & 127.71 & 145.61145 .61 & 3.33 & -0.10 \\
\hline 849D-14X-2 & C. wuellerstorfi & $13 i$ & 127.91 & $145.81 \quad 145.81$ & 3.38 & 0.01 \\
\hline 849D-14X-3 & C. wuellerstorfi & i & 128.11 & 146.01146 .01 & 3.19 & 0.12 \\
\hline $849 D-14 X-3$ & C. wuellerstorfi & 21 & 128.31 & $146.21 \mid 46.21$ & 3.09 & -0.01 \\
\hline $849 D-14 X-3$ & C. wuellerstorfi & 41 & 128.51 & $146.41 \quad 146.41$ & 3.09 & 0.00 \\
\hline 849D-14X-3 & C. wuellerstorfi & 61 & 128.71 & $146.61 \mid 46.61$ & 3.25 & -0.21 \\
\hline 849D-14X-3 & C. wuellerstorfi & 80 & 128.90 & $146.80 \quad 146.80$ & 3.37 & -0.29 \\
\hline 849D-14X-3 & C. wuellerstorfi & 121 & 129.31 & 147.21147 .21 & $3.45-$ & -0.11 \\
\hline $849 \mathrm{D}-14 \mathrm{X}-3$ & C. wuellerstorfi & 141 & 129.51 & 147.41147 .41 & 3.32 & -0.07 \\
\hline 849D-14X-4 & C. wuellerstorfi & II & 129.71 & $147.61 \quad 147.61$ & 3.37 & 0.12 \\
\hline $849 D-14 X-4$ & C. wuellerstorfi & 31 & 129.91 & $147.81 \backslash 47.81$ & $3.14-$ & -0.09 \\
\hline $849 D-14 X-4$ & C. wuellerstorfi & 71 & 130.31 & $148.21 \quad 148.21$ & $3.21-$ & -0.28 \\
\hline $849 \mathrm{D}-14 \mathrm{X}-4$ & C. wuellerstorfi & 111 & 130.71 & 148.61148 .61 & $3.51-$ & -0.49 \\
\hline $849 \mathrm{D}-14 \mathrm{X}-4$ & C. wuellerstorfi & 131 & 130.91 & $148.81 \quad 148.81$ & 3.55 & -0.48 \\
\hline $849 D-14 X-5$ & C. whellerstorfi & I & 131.11 & $149.01 \quad 149.01$ & 3.24 & -0.06 \\
\hline $849 D-14 X-5$ & C. wuellerstorfi & 21 & 131.31 & $149.21 \quad 149.21$ & 3.18 & -0.11 \\
\hline 849D-14X-5 & C. wuellerstorfi & 41 & 131.51 & $149.41 \quad 149.41$ & 3.24 & -0.05 \\
\hline $849 D-14 X-5$ & C. wuellerstorfi & 81 & 131.91 & 149.81149 .81 & $3.21-$ & -0.15 \\
\hline $849 D-14 X-5$ & C. whellerstorfi & 101 & 132.11 & 150.01150 .01 & $3.32-$ & -0.26 \\
\hline $849 D-14 X-5$ & C. wuellerstorfi & 121 & 132.31 & $150.21 \quad 150.21$ & $3.41-$ & -0.34 \\
\hline $849 D-14 X-5$ & C. wuellerstorfi & 141 & 132.51 & $150.41 \quad 150.41$ & 3.42 & -0.33 \\
\hline 849D-14X-6 & C. wuellerstorfi & 11 & $|32,7|$ & 150.61150 .61 & $3.22-$ & -0.10 \\
\hline $849 D-14 X-6$ & C. wuellerstorfi & 31 & 132.91 & 150.81150 .81 & $3.17-$ & -0.14 \\
\hline $849 D-14 X-6$ & C. whellerstorfi & 51 & 133.11 & 151.01151 .01 & 3.19 & -0.20 \\
\hline $849 D-14 X-6$ & C. wuellerstorfi & 71 & 133.31 & 151.21151 .21 & $3.20-$ & -0.14 \\
\hline 849D-14X-6 & C. wuellerstorfi & 91 & 133.51 & 151.41151 .41 & $3.24-$ & -0.19 \\
\hline 849D-14X-6 & C. wuellerstorfi & 111 & 133.71 & 151.61151 .61 & $3.23-$ & -0.17 \\
\hline $849 D-14 X-6$ & C. wuellerstorfi & 131 & 133.91 & 151.81151 .81 & $3.18-$ & -0.15 \\
\hline 849D-14X-7 & C. wuellerstorfi & 1 & 134.11 & $152.01 \quad 152.01$ & 3.13 & -0.05 \\
\hline 849D-14X-7 & C. wuellerstorfi & 21 & 134.31 & 152.21152 .21 & $3.12-$ & -0.03 \\
\hline
\end{tabular}


APPENDIX B

Age Model for Site 849

\begin{tabular}{|c|c|c|c|c|c|c|c|c|c|c|c|c|c|}
\hline $\begin{array}{l}\text { Depth } \\
\text { (rmcd) }\end{array}$ & $\begin{array}{l}\text { Age } \\
\text { (Ma) }\end{array}$ & $\begin{array}{l}\text { Depth } \\
\text { (rmcd) }\end{array}$ & $\begin{array}{l}\text { Age } \\
\text { (Ma) }\end{array}$ & $\begin{array}{l}\text { Depth } \\
\text { (rmcd) }\end{array}$ & $\begin{array}{l}\text { Age } \\
(\mathrm{Ma})\end{array}$ & $\begin{array}{l}\text { Depth } \\
\text { (rmcd) }\end{array}$ & $\begin{array}{l}\text { Age } \\
\text { (Ma) }\end{array}$ & $\begin{array}{l}\text { Depth } \\
\text { (rmcd) }\end{array}$ & $\begin{array}{l}\text { Age } \\
\text { (Ma) }\end{array}$ & $\begin{array}{l}\text { Depth } \\
\text { (rmcd) }\end{array}$ & $\begin{array}{l}\text { Age } \\
\text { (Ma) }\end{array}$ & $\begin{array}{l}\text { Depth } \\
\text { (rmcd) }\end{array}$ & $\begin{array}{l}\text { Age } \\
\text { (Ma) }\end{array}$ \\
\hline 0.0 & 0.0025 & 16.8 & 0.5526 & 33.6 & 1.2137 & 50.4 & 1.8142 & 67.2 & 2.3822 & 84.0 & 3.0265 & 100.8 & 3.6338 \\
\hline 0.2 & 0.0056 & 17.0 & 0.5627 & 33.8 & 1.2183 & 50.6 & 1.8207 & 67.4 & 2.3904 & 84.2 & 3.0323 & 101.0 & 3.6415 \\
\hline 0.4 & 0.0101 & 17.2 & 0.5713 & 34.0 & 1.2226 & 50.8 & 1.8262 & 67.6 & 2.3977 & 84.4 & 3.0391 & 101.2 & 3.6490 \\
\hline 0.6 & 0.0142 & 17.4 & 0.5787 & 34.2 & 1.2269 & 51.0 & 1.8325 & 67.8 & 2.4046 & 84.6 & 3.0466 & 101.4 & 3.6559 \\
\hline 0.8 & 0.0183 & 17.6 & 0.5853 & 34.4 & 1.2317 & 51.2 & 1.8424 & 68.0 & 2.4114 & 84.8 & 3.0544 & 101.6 & 3.6620 \\
\hline 1.0 & 0.0229 & 17.8 & 0.5918 & 34.6 & 1.2373 & 51.4 & 1.8543 & 68.2 & 2.4181 & 85.0 & 3.0622 & 101.8 & 3.6679 \\
\hline 1.2 & 0.0281 & 18.0 & 0.5981 & 34.8 & 1.2432 & 51.6 & 1.8633 & 68.4 & 2.4247 & 85.2 & 3.0701 & 102.0 & 3.6737 \\
\hline 1.4 & 0.0338 & 18.2 & 0.6044 & 35.0 & 1.2494 & 51.8 & 1.8699 & 68.6 & 2.4309 & 85.4 & 3.0780 & 102.2 & 3.6795 \\
\hline 1.6 & 0.0403 & 18.4 & 0.6113 & 35.2 & 1.2555 & 52.0 & 1.8751 & 68.8 & 2,4368 & 85.6 & 3.0861 & 102.4 & 3.6855 \\
\hline 1.8 & 0.0478 & 18.6 & 0.6197 & 35.4 & 1.2611 & 52.2 & 1.8794 & 69.0 & 2.4424 & 85.8 & 3.0944 & 102.6 & 3.6921 \\
\hline 2.0 & 0.0552 & 18.8 & 0.6299 & 35.6 & 1.2659 & 52.4 & 1.8828 & 69.2 & 2.4472 & 86.0 & 3.1028 & 102.8 & 3.6993 \\
\hline 2.2 & 0.0625 & 19.0 & 0.6399 & 35.8 & 1.2701 & 52.6 & 1.8865 & 69.4 & 2.4519 & 86.2 & 3.11113 & 103.0 & 3.7066 \\
\hline 2.4 & 0.0690 & 19.2 & 0.6483 & 36.0 & 1.2742 & 52.8 & 1.8925 & 69.6 & 2.4563 & 86.4 & 3.1197 & 103.2 & 3.7134 \\
\hline 2.6 & 0.0750 & 19.4 & 0.6555 & 36.2 & 1.2788 & 53.0 & 1.8994 & 69.8 & 2.4617 & 86.6 & 3.1280 & 103,4 & 3.7200 \\
\hline 2.8 & 0.0812 & 19.6 & 0.6622 & 36.4 & 1.2844 & 53.2 & 1.9056 & 70.0 & 2.4677 & 86.8 & 3.1357 & 103.6 & 3.7280 \\
\hline 3.0 & 0.0881 & 19.8 & 0.6687 & 36.6 & 1.2914 & 53.4 & 1.9110 & 70.2 & 2.4743 & 87.0 & 3,1425 & 103.8 & 3.7393 \\
\hline 3.2 & 0.0963 & 20.0 & 0.6750 & 36.8 & 1.2991 & 53.6 & 1.9160 & 70.4 & 2.4821 & 87.2 & 3.1491 & 104.0 & 3.7513 \\
\hline 3.4 & 0.1055 & 20.2 & 0.6808 & 37.0 & 1.3067 & 53.8 & 1.9214 & 70.6 & 2.4921 & 87.4 & 3.1558 & 104.2 & 3.7602 \\
\hline 3.6 & 0.1144 & 20.4 & 0.6864 & 37.2 & 1.3136 & 54.0 & 1.9278 & 70.8 & 2.5033 & 87.6 & 3.1631 & 104.4 & 3.7672 \\
\hline 3.8 & 0.1217 & 20.6 & 0.6921 & 37.4 & 1.3195 & 54.2 & 1.9352 & 71.0 & 2.5139 & 87.8 & 3.1706 & 104.6 & 3.7738 \\
\hline 4.0 & 0.1273 & 20.8 & 0.6985 & 37.6 & 1.3246 & 54.4 & 1.9431 & 71.2 & 2.5218 & 88.0 & 3.1777 & 104.8 & 3.7797 \\
\hline 4.2 & 0.1319 & 21.0 & 0.7064 & 37.8 & 1.3293 & 54.6 & 1.9491 & 71.4 & 2.5273 & 88.2 & 3.1841 & 105.0 & 3.7846 \\
\hline 4.4 & 0.1365 & 21.2 & 0.7160 & 38.0 & 1.3340 & 54.8 & 1.9529 & 71.6 & 2.5324 & 88.4 & 3.1902 & 105.2 & 3.7888 \\
\hline 4.6 & 0.1413 & 21.4 & 0.7268 & 38.2 & 1.3390 & 55.0 & 1.9553 & 71.8 & 2.5396 & 88.6 & 3.1963 & 105.4 & 3.7929 \\
\hline 4.8 & 0.1465 & 21.6 & 0.7385 & 38.4 & 1.3447 & 55.2 & 1.9576 & 72.0 & 2.5497 & 88.8 & 3.2025 & 105.6 & 3.7972 \\
\hline 5.0 & 0.1522 & 21.8 & 0.7508 & 38.6 & 1.3511 & 55.4 & 1.9602 & 72.2 & 2.5611 & 89.0 & 3.2088 & 105.8 & 3.8030 \\
\hline 5.2 & 0.1579 & 22.0 & 0.7626 & 38.8 & 1.3579 & 55.6 & 1.9633 & 72.4 & 2.5708 & 89.2 & 3.2152 & 106.0 & 3.8112 \\
\hline 5.4 & 0.1635 & 22.2 & 0.7721 & 39.0 & 1.3644 & 55.8 & 1.9669 & 72.6 & 2.5782 & 89.4 & 3.2215 & 106.2 & 3.8205 \\
\hline 5.6 & 0.1685 & 22.4 & 0.7791 & 39.2 & 1.3697 & 56.0 & 1.9704 & 72.8 & 2.5847 & 89.6 & 3.2279 & 106.4 & 3.8283 \\
\hline 5.8 & 0.1731 & 22.6 & 0.7843 & 39.4 & 1.3749 & 56.2 & 1.9738 & 73.0 & 2.5918 & 89.8 & 3.2342 & 106.6 & 3.8347 \\
\hline 6.0 & 0.1774 & 22.8 & 0.7896 & 39.6 & 1.3823 & 56.4 & 1.9771 & 73.2 & 2.6000 & 90.0 & 3.2406 & 106.8 & 3.8408 \\
\hline 6.2 & 0.1818 & 23.0 & 0.7976 & 39.8 & 1.3908 & 56.6 & 1.9804 & 73.4 & 2.6090 & 90.2 & 3.2470 & 107.0 & 3.8474 \\
\hline 6.4 & 0.1866 & 23.2 & 0.8093 & 40.0 & 1.4006 & 56.8 & 1.9838 & 73.6 & 2.6177 & 90.4 & 3.2537 & 107.2 & 3.8548 \\
\hline 6.6 & 0.1922 & 23.4 & 0.8223 & 40.2 & 1.4125 & 57.0 & 1.9873 & 73.8 & 2.6258 & 90.6 & 3.2608 & 107.4 & 3.8628 \\
\hline 6.8 & 0.1989 & 23.6 & 0.8325 & 40.4 & 1.4244 & 57.2 & 1.9913 & 74.0 & 2.6334 & 90.8 & 3.2680 & 107.6 & 3.8710 \\
\hline 7.0 & 0.2067 & 23.8 & 0.8391 & 40.6 & 1.4342 & 57.4 & 1.9957 & 74.2 & 2.6402 & 91.0 & 3.2752 & 107.8 & 3.8796 \\
\hline 7.2 & 0.2152 & 24.0 & 0.8436 & 40.8 & 1.4417 & 57.6 & 2.0009 & 74.4 & 2.6474 & 91.2 & 3.2822 & 108.0 & 3.8883 \\
\hline 7.4 & 0.2233 & 24.2 & 0.8476 & 41.0 & 1.4490 & 57.8 & 2.0065 & 74.6 & 2.6576 & 91.4 & 3.2887 & 108.2 & 3.8966 \\
\hline 7.6 & 0.2306 & 24.4 & 0.8525 & 41.2 & 1.4591 & 58.0 & 2.0123 & 74.8 & 2.6705 & 91.6 & 3.2952 & 108.4 & 3.9045 \\
\hline 7.8 & 0.2368 & 24.6 & 0.8592 & 41.4 & 1.4733 & 58.2 & 2.0183 & 75.0 & 2.6820 & 91.8 & 3.3026 & 108.6 & 3.9121 \\
\hline 8.0 & 0.2420 & 24.8 & 0.8680 & 41.6 & 1,4884 & 58.4 & 2.0240 & 75.2 & 2.6899 & 92.0 & 3.3112 & 108.8 & 3.9195 \\
\hline 8.2 & 0.2468 & 25.0 & 0.8774 & 41.8 & 1.4993 & 58.6 & 2.0294 & 75.4 & 2.6958 & 92.2 & 3.3198 & 109.0 & 3.9266 \\
\hline 8.4 & 0.2520 & 25.2 & 0.8858 & 42.0 & 1.5062 & 58.8 & 2.0345 & 75.6 & 2.7015 & 92.4 & 3.3279 & 109.2 & 3.9338 \\
\hline 8.6 & 0.2581 & 25.4 & 0.8927 & 42.2 & 1.5119 & 59.0 & 2.0394 & 75.8 & 2,7075 & 92.6 & 3.3356 & 109.4 & 3.9412 \\
\hline 8.8 & 0.2651 & 25.6 & 0.8987 & 42.4 & 1.5184 & 59.2 & 2.0442 & 76.0 & 2.7140 & 92.8 & 3.3430 & 109.6 & 3.9490 \\
\hline 9.0 & 0.2735 & 25.8 & 0.9042 & 42.6 & 1.5262 & 59.4 & 2.0492 & 76.2 & 2.7210 & 93.0 & 3.3496 & 109.8 & 3.9569 \\
\hline 9.2 & 0.2833 & 26.0 & 0.9096 & 42.8 & 1.5339 & 59.6 & 2.0547 & 76.4 & 2.7288 & 93.2 & 3.3556 & 110.0 & 3.9644 \\
\hline 9.4 & 0.2942 & 26.2 & 0.9153 & 43.0 & 1.5402 & 59.8 & 2.0608 & 76.6 & 2.7372 & 93.4 & 3.3622 & 110.2 & 3.9716 \\
\hline 9.6 & 0.3052 & 26.4 & 0.9218 & 43.2 & 1.5455 & 60.0 & 2.0676 & 76.8 & 2.7447 & 93.6 & 3.3705 & 110.4 & 3.9787 \\
\hline 9.8 & 0.3145 & 26.6 & 0.9298 & 43.4 & 1.5505 & 60.2 & 2.0749 & 77.0 & 2.7506 & 93.8 & 3.3801 & 110.6 & 3.9858 \\
\hline 10.0 & 0.3214 & 26.8 & 0.9388 & 43.6 & 1.5564 & 60.4 & 2.0826 & 77.2 & 2.7560 & 94.0 & 3.3887 & 110.8 & 3.9929 \\
\hline 10.2 & 0.3261 & 27.0 & 0.9483 & 43.8 & 1.5636 & 60.6 & 2.0901 & 77.4 & 2.7612 & 94.2 & 3.3947 & 111.0 & 4.0001 \\
\hline 10.4 & 0.3296 & 27.2 & 0.9571 & 44.0 & 1.5724 & 60.8 & 2.0977 & 77.6 & 2.7664 & 94.4 & 3.3995 & 111.2 & 4.0073 \\
\hline 10.6 & 0.3329 & 27.4 & 0.9640 & 44.2 & 1.5817 & 61.0 & 2.1056 & 77.8 & 2.7721 & 94.6 & 3.4056 & 111.4 & 4.0150 \\
\hline 10.8 & 0.3366 & 27.6 & 0.9696 & 44.4 & 1.5906 & 61.2 & 2.1134 & 78.0 & 2.7799 & 94.8 & 3.4134 & 111.6 & 4.0234 \\
\hline 11.0 & 0.3411 & 27.8 & 0.9746 & 44.6 & 1.5986 & 61.4 & 2.1205 & 78.2 & 2.7903 & 95.0 & 3.4221 & 111.8 & 4.0317 \\
\hline 11.2 & 0.3465 & 28.0 & 0.9806 & 44.8 & 1.6061 & 61.6 & 2.1268 & 78.4 & 2.8017 & 95.2 & 3.4311 & 112.0 & 4.0393 \\
\hline 11.4 & 0.3528 & 28.2 & 0.9890 & 45.0 & 1.6140 & 61.8 & 2.1337 & 78.6 & 2.8124 & 95.4 & 3.4402 & 112.2 & 4.0461 \\
\hline 11.6 & 0.3590 & 28.4 & 0.9996 & 45.2 & 1.6226 & 62.0 & 2.1428 & 78.8 & 2.8220 & 95.6 & 3.4490 & 112.4 & 4.0531 \\
\hline 11.8 & 0.3647 & 28.6 & 1.0099 & 45.4 & 1.6315 & 62.2 & 2.1528 & 79.0 & 2.8305 & 95.8 & 3.4574 & 112.6 & 4.0609 \\
\hline 12.0 & 0.3701 & 28.8 & 1.0184 & 45.6 & 1.6395 & 62.4 & 2.1634 & 79.2 & 2.8384 & 96.0 & 3.4648 & 112.8 & 4.0689 \\
\hline 12.2 & 0.3765 & 29.0 & 1.0259 & 45.8 & 1.6449 & 62.6 & 2.1736 & 79.4 & 2.8461 & 96.2 & 3.4709 & 113.0 & 4.0760 \\
\hline 12.4 & 0.3853 & 29.2 & 1.0340 & 46.0 & 1.6489 & 62.8 & 2.1828 & 79.6 & 2.8539 & 96.4 & 3.4765 & 113.2 & 4.0822 \\
\hline 12.6 & 0.3957 & 29.4 & 1.0432 & 46.2 & 1.6529 & 63.0 & 2.1916 & 79.8 & 2.8618 & 96.6 & 3.4819 & 113.4 & 4.0885 \\
\hline 12.8 & 0.4066 & 29.6 & 1.0521 & 46.4 & 1.6581 & 63.2 & 2.2007 & 80.0 & 2.8698 & 96.8 & 3.4874 & 113.6 & 4.0954 \\
\hline 13.0 & 0.4182 & 29.8 & 1.0594 & 46.6 & 1.6646 & 63.4 & 2.2103 & 80.2 & 2.8781 & 97.0 & 3.4933 & 113.8 & 4.1029 \\
\hline 13.2 & 0.4258 & 30.0 & 1.0656 & 46.8 & 1.6723 & 63.6 & 2.2204 & 80.4 & 2,8869 & 97.2 & 3.5003 & 114.0 & 4.1106 \\
\hline 13.4 & 0.4309 & 30.2 & 1.0715 & 47.0 & 1.6805 & 63.8 & 2.2299 & 80.6 & 2.8958 & 97.4 & 3.5086 & 114.2 & 4.1187 \\
\hline 13.6 & 0.4356 & 30.4 & 1.0783 & 47.2 & 1.6887 & 64.0 & 2.2383 & 80.8 & 2.9042 & 97.6 & 3.5174 & 114.4 & 4.1267 \\
\hline 13.8 & 0.4408 & 30.6 & 1.0869 & 47.4 & 1.6966 & 64.2 & 2.2460 & 81.0 & 2.9120 & 97.8 & 3.5263 & 114.6 & 4.1341 \\
\hline 14.0 & 0.4477 & 30.8 & 1.0969 & 47.6 & 1.7040 & 64.4 & 2.2537 & 81.2 & 2.9192 & 98.0 & 3.5350 & 114.8 & 4.1408 \\
\hline 14.2 & 0.4568 & 31.0 & 1.1060 & 47.8 & 1.7115 & 64.6 & 2.2610 & 81.4 & 2.9257 & 98.2 & 3.5436 & 115.0 & 4.1473 \\
\hline 14.4 & 0.4664 & 31.2 & 1.1135 & 48.0 & 1.7202 & 64.8 & 2.2679 & 81.6 & 2.9317 & 98.4 & 3.5519 & 115.2 & 4.1539 \\
\hline 14.6 & 0.4741 & 31.4 & 1.1196 & 48.2 & 1.7301 & 65.0 & 2.2749 & 81.8 & 2.9391 & 98.6 & 3.5599 & 115.4 & 4.1609 \\
\hline 14.8 & 0.4804 & 31.6 & 1.1261 & 48.4 & 1.7400 & 65.2 & 2.2818 & 82.0 & 2.9485 & 98.8 & 3.5667 & 115.6 & 4.1681 \\
\hline 15.0 & 0.4863 & 31.8 & 1.1341 & 48.6 & 1.7492 & 65.4 & 2.2893 & 82.2 & 2.9575 & 99.0 & 3.5721 & 115.8 & 4.1753 \\
\hline 15.2 & 0.4929 & 32.0 & 1.1441 & 48.8 & 1.7578 & 65.6 & 2.2978 & 82.4 & 2.9654 & 99.2 & 3.5768 & 116.0 & 4.1825 \\
\hline 15.4 & 0.5004 & 32.2 & 1.1555 & 49.0 & 1.7662 & 65.8 & 2.3074 & 82.6 & 2.9732 & 99.4 & 3.5812 & 116.2 & 4.1898 \\
\hline 15.6 & 0.5089 & 32.4 & 1.1671 & 49.2 & 1.7732 & 66.0 & 2.3168 & 82.8 & 2.9811 & 99.6 & 3.5859 & 116.4 & 4.1969 \\
\hline 15.8 & 0.5171 & 32.6 & 1.1781 & 49.4 & 1.7791 & 66.2 & 2.3256 & 83.0 & 2.9893 & 99.8 & 3.5915 & 116.6 & 4.2036 \\
\hline 16.0 & 0.5238 & 32.8 & 1.1879 & 49.6 & 1.7842 & 66.4 & 2.3350 & 83.2 & 2.9978 & 100.0 & 3.5992 & 116.8 & 4.2097 \\
\hline 16.2 & 0.5293 & 33.0 & 1.1960 & 49.8 & 1.7899 & 66.6 & 2.3466 & 83.4 & 3.0064 & 100.2 & 3.6086 & 117.0 & 4.2160 \\
\hline 16.4 & 0.5352 & 33.2 & 1.2027 & 50.0 & 1.7973 & 66.8 & 2.3596 & 83.6 & 3.0145 & 100.4 & 3.6179 & 117.2 & 4.2230 \\
\hline 16.6 & 0.5428 & 33,4 & 1.2086 & 50.2 & 1.8061 & 67.0 & 2.3720 & 83.8 & 3.0211 & 100.6 & 3.6261 & 117.4 & 4.2304 \\
\hline
\end{tabular}


A.C. MIX ET AL.

APPENDIX B (continued)

\begin{tabular}{|c|c|c|c|c|c|}
\hline $\begin{array}{l}\text { Depth } \\
\text { (rmcd) }\end{array}$ & $\begin{array}{l}\text { Age } \\
\text { (Ma) }\end{array}$ & $\begin{array}{l}\text { Depth } \\
\text { (rmcd) }\end{array}$ & $\begin{array}{l}\text { Age } \\
(\mathrm{Ma})\end{array}$ & $\begin{array}{l}\text { Depth } \\
\text { (rmcd) }\end{array}$ & $\begin{array}{l}\text { Age } \\
\text { (Ma) }\end{array}$ \\
\hline 117.6 & 4.2379 & 129.8 & 4.5641 & 142.0 & 4.7347 \\
\hline 117.8 & 4.2450 & 130.0 & 4.5664 & 142.2 & 4.7365 \\
\hline 118.0 & 4.2515 & 130.2 & 4.5688 & 142.4 & 4.7383 \\
\hline 118.2 & 4.2577 & 130.4 & 4.5712 & 142.6 & 4.7401 \\
\hline 118.4 & 4.2638 & 130.6 & 4.5735 & 142.8 & 4.7420 \\
\hline 118.6 & 4.2699 & 130.8 & 4.5759 & 143.0 & 4.7440 \\
\hline 118.8 & 4.2763 & 131.0 & 4.5782 & 143.2 & 4.7462 \\
\hline 119.0 & 4.2829 & 131.2 & 4.5806 & 143.4 & 4.7487 \\
\hline 119.2 & 4.2896 & 131.4 & 4.5830 & 143.6 & 4.7511 \\
\hline 119.4 & 4.2965 & 131.6 & 4.5853 & 143.8 & 4.7536 \\
\hline 119.6 & 4.3035 & 131.8 & 4.5877 & 144.0 & 4.7561 \\
\hline 119.8 & 4.3105 & 132.0 & 4.5900 & 144.2 & 4.7586 \\
\hline 120.0 & 4.3168 & 132.2 & 4.5924 & 144.4 & 4.7611 \\
\hline 120.2 & 4.3220 & 132.4 & 4.5950 & 144.6 & 4.7635 \\
\hline 120.4 & 4.3262 & 132.6 & 4.5980 & 144.8 & 4.7660 \\
\hline 120.6 & 4.3301 & 132.8 & 4.6012 & 145.0 & 4.7689 \\
\hline 120.8 & 4.3342 & 133.0 & 4.6045 & 145.2 & 4.7726 \\
\hline 121.0 & 4.3387 & 133.2 & 4.6078 & 145.4 & 4.7772 \\
\hline 121.2 & 4.3442 & 133.4 & 4.6111 & 145.6 & 4.7824 \\
\hline 121.4 & 4.3506 & 133.6 & 4.6143 & 145.8 & 4.7880 \\
\hline 121.6 & 4.3572 & 133.8 & 4.6176 & 146.0 & 4.7942 \\
\hline 121.8 & 4.3638 & 134.0 & 4.6209 & 146.2 & 4.8009 \\
\hline 122.0 & 4.3704 & 134.2 & 4.6242 & 146.4 & 4.8075 \\
\hline 122.2 & 4.3771 & 134.4 & 4.6275 & 146.6 & 4.8133 \\
\hline 122.4 & 4.3837 & 134.6 & 4.6308 & 146.8 & 4.8185 \\
\hline 122.6 & 4.3903 & 134.8 & 4.6341 & 147.0 & 4.8240 \\
\hline 122.8 & 4.3970 & 135.0 & 4.6375 & 147.2 & 4.8301 \\
\hline 123.0 & 4.4037 & 135.2 & 4.6415 & 147.4 & 4.8365 \\
\hline 123.2 & 4.4112 & 135.4 & 4.6465 & 147.6 & 4.8432 \\
\hline 123.4 & 4.4199 & 135.6 & 4.6520 & 147.8 & 4.8502 \\
\hline 123.6 & 4.4296 & 135.8 & 4.6571 & 148.0 & 4.8576 \\
\hline 123.8 & 4.4395 & 136.0 & 4.6620 & 148.2 & 4.8651 \\
\hline 124.0 & 4.4484 & 136.2 & 4.6667 & 148.4 & 4.8727 \\
\hline 124.2 & 4.4557 & 136.4 & 4.6714 & 148.6 & 4.8802 \\
\hline 124.4 & 4.4617 & 136.6 & 4.6762 & 148.8 & 4.8875 \\
\hline 124.6 & 4.4675 & 136.8 & 4.6809 & 149.0 & 4.8944 \\
\hline 124.8 & 4.4732 & 137.0 & 4.6857 & 149.2 & 4.9003 \\
\hline 125.0 & 4.4789 & 137.2 & 4.6904 & 149.4 & 4.9056 \\
\hline 125.2 & 4.4846 & 137.4 & 4.6947 & 149.6 & 4.9108 \\
\hline 125.4 & 4.4901 & 137.6 & 4.6979 & 149.8 & 4.9163 \\
\hline 125.6 & 4.4953 & 137.8 & 4.7001 & 150.0 & 4.9227 \\
\hline 125.8 & 4.5002 & 138.0 & 4.7017 & 150.2 & 4.9300 \\
\hline 126.0 & 4.5051 & 138.2 & 4.7033 & 150.4 & 4.9371 \\
\hline 126.2 & 4.5098 & 138.4 & 4.7048 & 150.6 & 4.9431 \\
\hline 126.4 & 4.5142 & 138.6 & 4.7064 & 150.8 & 4.9481 \\
\hline 126.6 & 4.5181 & 138.8 & 4.7079 & 151.0 & 4.9527 \\
\hline 126.8 & 4.5218 & 139.0 & 4.7095 & 151.2 & 4.9573 \\
\hline 127.0 & 4.5255 & 139.2 & 4.7110 & 151.4 & 4.9618 \\
\hline 127.2 & 4.5292 & 139.4 & 4.7126 & 151.6 & 4.9660 \\
\hline 127.4 & 4.5328 & 139.6 & 4.7141 & 151.8 & 4.9700 \\
\hline 127.6 & 4.5362 & 139.8 & 4.7157 & 152.0 & 4.9740 \\
\hline 127.8 & 4.5391 & 140.0 & 4.7172 & 152.2 & 4.9780 \\
\hline 128.0 & 4.5417 & 140.2 & 4.7187 & 152.4 & 4.9817 \\
\hline 128.2 & 4.5442 & 140.4 & 4.7203 & 152.6 & 4.9849 \\
\hline 128.4 & 4.5467 & 140.6 & 4.7219 & 152.8 & 4.9875 \\
\hline 128.6 & 4.5492 & 140.8 & 4.7237 & 153.0 & 4.9899 \\
\hline 128.8 & 4.5517 & 141.0 & 4.7255 & 153.2 & 4.9922 \\
\hline 129.0 & 4.5542 & 141.2 & 4.7273 & 153.4 & 4.9946 \\
\hline 129.2 & 4.5567 & 141.4 & 4.7292 & 153.6 & 4.9969 \\
\hline 129.4 & 4.5592 & 141.6 & 4.7310 & 153.8 & 4.9993 \\
\hline 129.6 & 4.5616 & 141.8 & 4.7328 & & \\
\hline
\end{tabular}


APPENDIX C

Smoothed, Interpolated Benthic Foraminifer Isotope Record for Site 849

\begin{tabular}{|c|c|c|c|c|c|c|c|c|c|c|c|}
\hline $\begin{array}{l}\text { Age } \\
\text { (Ma) }\end{array}$ & $\delta^{18} O$ & $\delta^{13} \mathrm{C}$ & $\begin{array}{l}\text { Age } \\
\text { (Ma) }\end{array}$ & $\delta^{1 x} O$ & $\delta^{13} \mathrm{C}$ & $\begin{array}{l}\text { Age } \\
\text { (Ma) }\end{array}$ & $\delta^{1 x} \mathrm{O}$ & $\delta^{13} \mathrm{C}$ & $\begin{array}{l}\text { Age } \\
\text { (Ma) }\end{array}$ & $\delta^{18} \mathrm{O}$ & $\delta^{1,3} \mathrm{C}$ \\
\hline 0.000 & 3.580 & 0.145 & 0.336 & 3.771 & -0.134 & 0.672 & 4.356 & -0.517 & 1.008 & 4.191 & -0.125 \\
\hline 0.004 & 3.576 & 0.170 & 0.340 & 4.243 & -0.202 & 0.676 & 4.277 & -0.402 & 1.012 & 4.065 & -0.067 \\
\hline 0.008 & 3.713 & 0.058 & 0.344 & 4.561 & -0.216 & 0.680 & 4.182 & -0.303 & 1.016 & 3.894 & 0.001 \\
\hline 0.012 & 4.341 & -0.154 & 0.348 & 4.597 & -0.250 & 0.684 & 3.976 & -0.225 & 1.020 & 3.746 & 0.048 \\
\hline 0.016 & 4.722 & -0.215 & 0.352 & 4.450 & -0.306 & 0.688 & 3.771 & -0.082 & 1.024 & 3.724 & 0.019 \\
\hline 0.020 & 4.715 & -0.136 & 0.356 & 4.398 & -0.302 & 0.692 & 3.676 & 0.040 & 1.028 & 3.832 & -0.076 \\
\hline 0.024 & 4.622 & -0.023 & 0.360 & 4.340 & -0.252 & 0.696 & 3.746 & 0.004 & 1.032 & 3.993 & -0.158 \\
\hline 0.028 & 4.594 & 0.033 & 0.364 & 4.210 & -0.175 & 0.700 & 3.927 & -0.097 & 1.036 & 4.214 & -0.229 \\
\hline 0.032 & 4.525 & 0.058 & 0.368 & 4.119 & -0.144 & 0.704 & 4.181 & -0.176 & 1.040 & 4.385 & -0.281 \\
\hline 0.036 & 4.481 & 0.050 & 0.372 & 4.077 & -0.117 & 0.708 & 4.304 & -0.190 & 1.044 & 4.362 & -0.363 \\
\hline 0.040 & 4.573 & 0.004 & 0.376 & 4.048 & -0.048 & 0.712 & 4.336 & -0.150 & 1.048 & 4.197 & -0.537 \\
\hline 0.044 & 4.581 & 0.005 & 0.380 & 4.025 & -0.037 & 0.716 & 4.352 & -0.202 & 1.052 & 4.138 & -0.508 \\
\hline 0.048 & 4.476 & 0.047 & 0.384 & 4.017 & -0.031 & 0.720 & 4.365 & -0.281 & 1.056 & 4.025 & -0.375 \\
\hline 0.052 & 4.459 & 0.005 & 0.388 & 3.971 & -0.056 & 0.724 & 4.298 & -0.220 & 1.060 & 3.835 & -0.206 \\
\hline 0.056 & 4.475 & -0.075 & 0.392 & 3.838 & 0.009 & 0.728 & 4.205 & -0.129 & 1.064 & 3.564 & -0.071 \\
\hline 0.060 & 4.537 & -0.190 & 0.396 & 3.410 & 0.248 & 0.732 & 4.224 & -0.188 & 1.068 & 3.339 & 0.015 \\
\hline 0.064 & 4.532 & -0.133 & 0.400 & 3.188 & 0.282 & 0.736 & 4.230 & -0.258 & 1.072 & 3.378 & 0.082 \\
\hline 0.068 & 4.392 & 0.062 & 0.404 & 3.148 & 0.236 & 0.740 & 4.198 & -0.331 & 1.076 & 3.593 & 0.081 \\
\hline 0.072 & 4.202 & 0.193 & 0.408 & 3.249 & 0.248 & 0.744 & 4.153 & -0.410 & 1.080 & 3.753 & -0.004 \\
\hline 0.076 & 4.141 & 0.142 & 0.412 & 3.350 & 0.260 & 0.748 & 4.134 & -0.434 & 1.084 & 3.873 & -0.060 \\
\hline 0.080 & 4.046 & 0.121 & 0.416 & 3.451 & 0.271 & 0.752 & 4.193 & -0.424 & 1.088 & 3.881 & -0.188 \\
\hline 0.084 & 3.903 & 0.179 & 0.420 & 3.552 & 0.283 & 0.756 & 4.276 & -0.444 & 1.092 & 4.009 & -0.302 \\
\hline 0.088 & 3.844 & 0.147 & 0.424 & 4.133 & -0.023 & 0.760 & 4.282 & -0.459 & 1.096 & 4.159 & -0.319 \\
\hline 0.092 & 3.903 & 0.113 & 0.428 & 4.787 & -0.364 & 0.764 & 4.172 & -0.415 & 1.100 & 4.033 & -0.199 \\
\hline 0.096 & 3.950 & 0.107 & 0.432 & 4.860 & -0.366 & 0.768 & 4.048 & -0.323 & 1.104 & 3.950 & -0.081 \\
\hline 0.100 & 3.890 & 0.019 & 0.436 & 4.896 & -0.353 & 0.772 & 3.881 & -0.211 & 1.108 & 3.929 & -0.017 \\
\hline 0.104 & 3.803 & -0.005 & 0.440 & 4.886 & -0.343 & 0.776 & 3.711 & -0.066 & 1.112 & 3.981 & -0.154 \\
\hline 0.108 & 3.758 & 0.055 & 0.444 & 4.714 & -0.276 & 0.780 & 3.590 & -0.015 & 1.116 & 4.042 & -0.275 \\
\hline 0.112 & 3.679 & 0.090 & 0.448 & 4.562 & -0.188 & 0.784 & 3.603 & -0.159 & 1.120 & 4.166 & -0.373 \\
\hline 0.116 & 3.431 & 0.155 & 0.452 & 4.577 & -0.276 & 0.788 & 3.816 & -0.345 & 1.124 & 4.235 & -0.372 \\
\hline 0.120 & 3.251 & 0.121 & 0.456 & 4.607 & -0.369 & 0.792 & 4.155 & -0.498 & 1.128 & 4.211 & -0.326 \\
\hline 0.124 & 3.303 & 0.001 & 0.460 & 4.537 & -0.266 & 0.796 & 4.414 & -0.553 & 1.132 & 4.194 & -0.308 \\
\hline 0.128 & 3.776 & -0.139 & 0.464 & 4.458 & -0.200 & 0.800 & 4.386 & -0.514 & 1.136 & 4.176 & -0.348 \\
\hline 0.132 & 4.433 & -0.267 & 0.468 & 4.335 & -0.205 & 0.804 & 4.306 & -0.358 & 1.140 & 4.091 & -0.367 \\
\hline 0.136 & 4.774 & -0.340 & 0.472 & 4.222 & -0.234 & 0.808 & 4.167 & -0.271 & 1.144 & 3.976 & -0.328 \\
\hline 0.140 & 4.795 & -0.371 & 0.476 & 4.197 & -0.178 & 0.812 & 4.075 & -0.249 & 1.148 & 3.888 & -0.150 \\
\hline 0.144 & 4.738 & -0.313 & 0.480 & 4.110 & 0.035 & 0.816 & 4.073 & -0.265 & 1.152 & 3.837 & -0.065 \\
\hline 0.148 & 4.650 & -0.286 & 0.484 & 3.842 & 0.275 & 0.820 & 4.049 & -0.258 & 1.156 & 3.758 & -0.112 \\
\hline 0.152 & 4.578 & -0.348 & 0.488 & 3.709 & 0.431 & 0.824 & 3.902 & -0.195 & 1.160 & 3.746 & -0.087 \\
\hline 0.156 & 4.628 & -0.344 & 0.492 & 3.628 & 0.571 & 0.828 & 3.846 & -0.196 & 1.164 & 3.742 & 0.010 \\
\hline 0.160 & 4.620 & -0.348 & 0.496 & 3.665 & 0.448 & 0.832 & 3.783 & -0.259 & 1.168 & 3.656 & 0.070 \\
\hline 0.164 & 4.432 & -0.300 & 0.500 & 3.790 & 0.327 & 0.836 & 3.777 & -0.326 & 1.172 & 3.587 & 0.103 \\
\hline 0.168 & 4.271 & -0.260 & 0.504 & 3.896 & 0.259 & 0.840 & 3.731 & -0.337 & 1.176 & 3.661 & 0.110 \\
\hline 0.172 & 4.246 & -0.303 & 0.508 & 3.954 & 0.225 & 0.844 & 3.627 & -0.300 & 1.180 & 3.823 & 0.102 \\
\hline 0.176 & 4.293 & -0.360 & 0.512 & 4.022 & 0.273 & 0.848 & 3.591 & -0.260 & 1.184 & 3.882 & 0.121 \\
\hline 0.180 & 4.345 & -0.360 & 0.516 & 4.181 & 0.286 & 0.852 & 3.610 & -0.256 & 1.188 & 3.875 & 0.029 \\
\hline 0.184 & 4.275 & -0.251 & 0.520 & 4.154 & 0.232 & 0.856 & 3.724 & -0.389 & 1.192 & 3.939 & -0.181 \\
\hline 0.188 & 4.040 & -0.093 & 0.524 & 4.060 & 0.087 & 0.860 & 3.722 & -0.418 & 1.196 & 4.084 & -0.273 \\
\hline 0.192 & 3.840 & -0.030 & 0.528 & 4.040 & -0.063 & 0.864 & 3.712 & -0.358 & 1.200 & 4.195 & -0.290 \\
\hline 0.196 & 3.708 & -0.050 & 0.532 & 4.203 & -0.204 & 0.868 & 4.197 & -0.513 & 1.204 & 4.350 & -0.308 \\
\hline 0.200 & 3.701 & -0.045 & 0.536 & 4.273 & -0.221 & 0.872 & 4.561 & -0.659 & 1.208 & 4.406 & -0.348 \\
\hline 0.204 & 3.778 & 0.019 & 0.540 & 4.278 & -0.182 & 0.876 & 4.594 & -0.666 & 1.212 & 4.326 & -0.345 \\
\hline 0.208 & 3.739 & 0.024 & 0.544 & 4.396 & -0.197 & 0.880 & 4.527 & -0.610 & 1.216 & 4.108 & -0.274 \\
\hline 0.212 & 3.666 & -0.035 & 0.548 & 4.386 & -0.137 & 0.884 & 4.419 & -0.515 & 1.220 & 3.828 & -0.073 \\
\hline 0.216 & 3.790 & -0.119 & 0.552 & 4.283 & -0.043 & 0.888 & 4.377 & -0.410 & 1.224 & 3.603 & 0.151 \\
\hline 0.220 & 3.976 & -0.221 & 0.556 & 4.260 & -0.049 & 0.892 & 4.396 & -0.486 & 1.228 & 3.457 & 0.161 \\
\hline 0.224 & 4.078 & -0.315 & 0.560 & 4.149 & -0.112 & 0.896 & 4.304 & -0.486 & 1.232 & 3.348 & 0.116 \\
\hline 0.228 & 4.153 & -0.366 & 0.564 & 4.061 & -0.083 & 0.900 & 4.207 & -0.454 & 1.236 & 3.355 & 0.119 \\
\hline 0.232 & 4.089 & -0.257 & 0.568 & 3.920 & -0.070 & 0.904 & 4.140 & -0.548 & 1.240 & 3.428 & 0.003 \\
\hline 0.236 & 3.907 & -0.088 & 0.572 & 3.748 & -0.066 & 0.908 & 4.149 & -0.700 & 1.244 & 3.706 & -0.297 \\
\hline 0.240 & 3.755 & -0.033 & 0.576 & 3.503 & 0.058 & 0.912 & 4.234 & -0.809 & 1.248 & 4.031 & -0.459 \\
\hline 0.244 & 3.957 & -0.200 & 0.580 & 3.576 & 0.068 & 0.916 & 4.276 & -0.791 & 1.252 & 4.098 & -0.405 \\
\hline 0.248 & 4.254 & -0.338 & 0.584 & 3.859 & -0.015 & 0.920 & 4.253 & -0.760 & 1.256 & 4.142 & -0.221 \\
\hline 0.252 & 4.312 & -0.321 & 0.588 & 4.059 & -0.124 & 0.924 & 4.077 & -0.601 & 1.260 & 4.112 & -0.139 \\
\hline 0.256 & 4.327 & -0.353 & 0.592 & 4.036 & -0.142 & 0.928 & 3.928 & -0.521 & 1.264 & 3.916 & -0.165 \\
\hline 0.260 & 4.363 & -0.431 & 0.596 & 3.902 & -0.214 & 0.932 & 3.826 & -0.497 & 1.268 & 3.751 & -0.128 \\
\hline 0.264 & 4.384 & -0.412 & 0.600 & 3.827 & -0.184 & 0.936 & 3.776 & -0.397 & 1.272 & 3.705 & -0.092 \\
\hline 0.268 & 4.443 & -0.421 & 0.604 & 3.979 & -0.032 & 0.940 & 3.630 & -0.169 & 1.276 & 3.688 & -0.124 \\
\hline 0.272 & 4.439 & -0.466 & 0.608 & 3.966 & 0.044 & 0.944 & 3.528 & 0.015 & 1.280 & 3.747 & -0.208 \\
\hline 0.276 & 4.307 & -0.397 & 0.612 & 3.691 & 0.037 & 0.948 & 3.476 & -0.115 & 1.284 & 3.934 & -0.301 \\
\hline 0.280 & 4.085 & -0.255 & 0.616 & 3.388 & -0.058 & 0.952 & 3.448 & -0.325 & 1.288 & 4.159 & -0.406 \\
\hline 0.284 & 3.953 & -0.156 & 0.620 & 3.731 & -0.228 & 0.956 & 3.804 & -0.503 & 1.292 & 4.159 & -0.419 \\
\hline 0.288 & 3.956 & -0.155 & 0.624 & 4.409 & -0.338 & 0.960 & 4.064 & -0.524 & 1.296 & 4.043 & -0.349 \\
\hline 0.292 & 4.079 & -0.274 & 0.628 & 4.786 & -0.319 & 0.964 & 4.220 & -0.366 & 1.300 & 3.974 & -0.179 \\
\hline 0.296 & 4.088 & -0.300 & 0.632 & 5.076 & -0.262 & 0.968 & 4.131 & -0.194 & 1.304 & 3.947 & 0.004 \\
\hline 0.300 & 4.076 & -0.272 & 0.636 & 4.989 & -0.253 & 0.972 & 3.891 & -0.164 & 1.308 & 3.948 & 0.031 \\
\hline 0.304 & 4.095 & -0.213 & 0.640 & 4.829 & -0.221 & 0.976 & 3.848 & -0.235 & 1.312 & 3.867 & 0.027 \\
\hline 0.308 & 3.941 & -0.235 & 0.644 & 4.779 & -0.262 & 0.980 & 4.003 & -0.287 & 1.316 & 3.779 & -0.011 \\
\hline 0.312 & 3.751 & -0.248 & 0.648 & 4.787 & -0.368 & 0.984 & 4.023 & -0.186 & 1.320 & 3.838 & -0.100 \\
\hline 0.316 & 3.736 & -0.140 & 0.652 & 4.725 & -0.393 & 0.988 & 3.922 & -0.057 & 1.324 & 4.022 & -0.182 \\
\hline 0.320 & 3.701 & -0.025 & 0.656 & 4.595 & -0.443 & 0.992 & 3.903 & -0.072 & 1.328 & 4.096 & -0.359 \\
\hline 0.324 & 3.563 & 0.059 & 0.660 & 4.525 & -0.560 & 0.996 & 3.943 & -0.133 & 1.332 & 4.078 & -0.466 \\
\hline 0.328 & 3.390 & 0.096 & 0.664 & 4.520 & -0.636 & 1.000 & 4.015 & -0.184 & 1.336 & 4.087 & -0.452 \\
\hline 0.332 & 3.411 & 0.011 & 0.668 & 4.449 & -0.613 & 1.004 & 4.132 & -0.187 & 1.340 & 4.035 & -0.344 \\
\hline
\end{tabular}


APPENDIX C (continued).

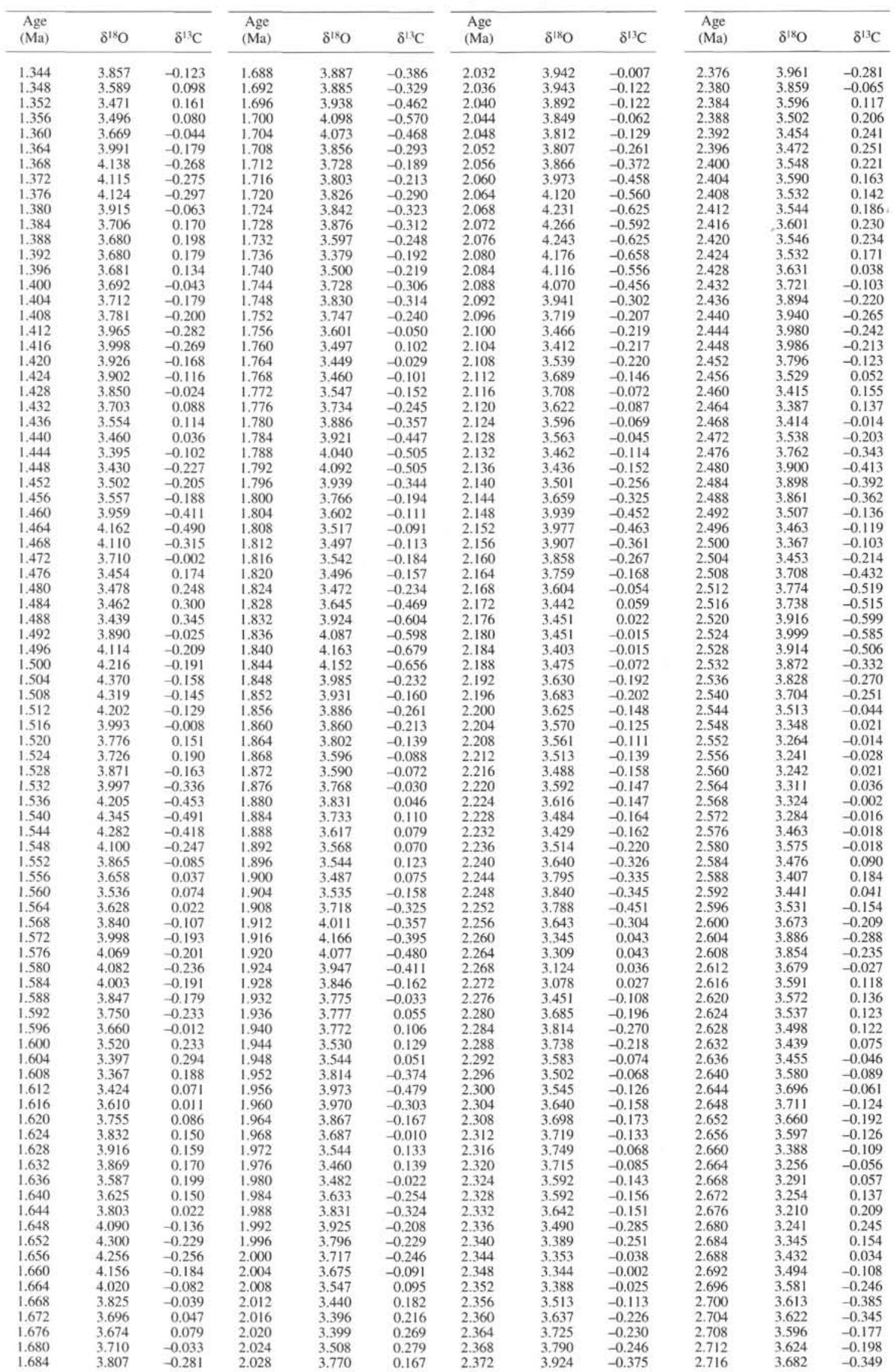


APPENDIX C (continued).

\begin{tabular}{|c|c|c|c|c|c|c|c|c|c|c|c|}
\hline $\begin{array}{l}\text { Age } \\
\text { (Ma) }\end{array}$ & $\delta^{18} \mathrm{O}$ & $\delta^{13} \mathrm{C}$ & $\begin{array}{l}\text { Age } \\
\text { (Ma) }\end{array}$ & $\delta^{1 x} O$ & $\delta^{13} \mathrm{C}$ & $\begin{array}{l}\text { Age } \\
(\mathrm{Ma})\end{array}$ & $\delta^{18} \mathrm{O}$ & $\delta^{13} \mathrm{C}$ & $\begin{array}{l}\text { Age } \\
\text { (Ma) }\end{array}$ & $\delta^{18} \mathrm{O}$ & $\delta^{1,3} \mathrm{C}$ \\
\hline 2.720 & 3.722 & -0.404 & 3.064 & 3.039 & -0.182 & 3.408 & 3.046 & -0.028 & 3.752 & 3.168 & 0.028 \\
\hline 2.724 & 3.729 & -0.353 & 3.068 & 3.094 & -0.075 & 3.412 & 3.160 & -0.125 & 3.756 & 3.276 & -0.020 \\
\hline 2.728 & 3.727 & -0.304 & 3.072 & 3.163 & -0.015 & 3.416 & 3.198 & -0.134 & 3.760 & 3.308 & -0.037 \\
\hline 2.732 & 3.766 & -0.339 & 3.076 & 3.164 & -0.025 & 3.420 & 3.145 & -0.083 & 3.764 & 3.341 & -0.053 \\
\hline 2.736 & 3.760 & -0.396 & 3.080 & 3.109 & 0.004 & 3.424 & 3.095 & -0.141 & 3.768 & 3.389 & -0.160 \\
\hline 2.740 & 3.679 & -0.311 & 3.084 & 3.056 & -0.037 & 3.428 & 3.062 & -0.220 & 3.772 & 3.416 & -0.285 \\
\hline 2.744 & 3.395 & -0.100 & 3.088 & 3.037 & -0.054 & 3.432 & 3.100 & -0.307 & 3.776 & 3.270 & -0.170 \\
\hline 2.748 & 3.189 & -0.010 & 3.092 & 3.101 & -0.014 & 3.436 & 3.169 & -0.366 & 3.780 & 3.128 & 0.052 \\
\hline 2.752 & 3.246 & -0.007 & 3.096 & 3.191 & 0.036 & 3.440 & 3.093 & -0.366 & 3.784 & 3.061 & 0.145 \\
\hline 2.756 & 3.274 & -0.005 & 3.100 & 3.241 & 0.065 & 3.444 & 2.961 & -0.370 & 3.788 & 3.009 & 0.137 \\
\hline 2.760 & 3.251 & -0.018 & 3.104 & 3.194 & -0.085 & 3.448 & 2.879 & -0.328 & 3.792 & 3.030 & 0.071 \\
\hline 2.764 & 3.194 & -0.048 & 3.108 & 3.116 & -0.275 & 3.452 & 2.861 & -0.148 & 3.796 & 3,116 & -0.019 \\
\hline 2.768 & 3.110 & -0.051 & 3.112 & 3.098 & -0.333 & 3.456 & 2.844 & 0.032 & 3.800 & 3.084 & 0.051 \\
\hline 2.772 & 3.150 & -0.037 & 3.116 & 3.084 & -0.383 & 3.460 & 2.855 & 0.104 & 3.804 & 3.045 & 0.184 \\
\hline 2.776 & 3.144 & -0.057 & 3.120 & 3.126 & -0.408 & 3.464 & 2.930 & 0.051 & 3.808 & 3.049 & 0.163 \\
\hline 2.780 & 3.127 & 0.044 & 3.124 & 3.219 & -0.379 & 3.468 & 3.073 & -0.091 & 3.812 & 3.105 & 0.022 \\
\hline 2.784 & 3.167 & 0.143 & 3.128 & 3.272 & -0.410 & 3.472 & 3.150 & -0.147 & 3.816 & 3.163 & -0.109 \\
\hline 2.788 & 3.230 & 0.220 & 3.132 & 3.332 & -0.406 & 3.476 & 3.145 & -0.104 & 3.820 & 3.167 & -0.156 \\
\hline 2.792 & 3.283 & 0.301 & 3.136 & 3.390 & -0.376 & 3.480 & 3.027 & 0.058 & 3.824 & 3.120 & -0.197 \\
\hline 2.796 & 3.328 & 0.319 & 3.140 & 3.448 & -0.450 & 3.484 & 2.919 & 0.157 & 3.828 & 3.062 & -0.292 \\
\hline 2.800 & 3.417 & 0.188 & 3.144 & 3.488 & -0.486 & 3.488 & 2.914 & 0.169 & 3.832 & 3.202 & -0.402 \\
\hline 2.804 & 3.393 & -0.034 & 3.148 & 3.482 & -0.470 & 3.492 & 2.961 & 0.117 & 3.836 & 3.280 & -0.386 \\
\hline 2.808 & 3.376 & -0.221 & 3.152 & 3.332 & -0.400 & 3.496 & 3.019 & 0.027 & 3.840 & 3.176 & -0.169 \\
\hline 2.812 & 3.693 & -0.217 & 3.156 & 3.031 & -0.244 & 3.500 & 3.043 & -0.024 & 3.844 & 3.003 & -0.043 \\
\hline 2.816 & 3.788 & -0.111 & 3.160 & 2.863 & -0.167 & 3.504 & 3.061 & -0.002 & 3.848 & 2.856 & -0.029 \\
\hline 2.820 & 3.777 & -0.075 & 3.164 & 2.905 & -0.128 & 3.508 & 3.095 & 0.047 & 3.852 & 2.883 & 0.037 \\
\hline 2.824 & 3.780 & -0.089 & 3.168 & 2.931 & -0.034 & 3.512 & 3.122 & 0.066 & 3.856 & 2.932 & 0.069 \\
\hline 2.828 & 3.546 & 0.043 & 3.172 & 2.977 & 0.036 & 3.516 & 3.092 & -0.014 & 3.860 & 2.979 & 0.015 \\
\hline 2.832 & 3.398 & 0.128 & 3.176 & 3.109 & 0.029 & 3.520 & 3.097 & 0.030 & 3.864 & 2.983 & -0.010 \\
\hline 2.836 & 3.254 & 0.193 & 3.180 & 3.198 & 0.066 & 3.524 & 3.108 & 0.102 & 3.868 & 2.925 & -0.105 \\
\hline 2.840 & 3.257 & 0.192 & 3.184 & 3.230 & 0.116 & 3.528 & 3.079 & 0.037 & 3.872 & 2.948 & -0.150 \\
\hline 2.844 & 3.339 & 0.181 & 3.188 & 3.203 & 0.200 & 3.532 & 3.092 & 0.018 & 3.876 & 3.131 & -0.248 \\
\hline 2.848 & 3.341 & 0.119 & 3.192 & 3.141 & 0.332 & 3.536 & 3.089 & 0.046 & 3.880 & 3.274 & -0.308 \\
\hline 2.852 & 3.427 & 0.070 & 3.196 & 3.111 & 0.338 & 3.540 & 3.045 & 0.002 & 3.884 & 3.358 & -0.312 \\
\hline 2.856 & 3.570 & 0.031 & 3.200 & 3.133 & 0.280 & 3.544 & 3.005 & -0.091 & 3.888 & 3.205 & -0.166 \\
\hline 2.860 & 3.554 & -0.107 & 3.204 & 3.147 & 0.301 & 3.548 & 3.021 & -0.163 & 3.892 & 3.130 & -0.051 \\
\hline 2.864 & 3.465 & -0.167 & 3.208 & 3.127 & 0.323 & 3.552 & 3.077 & -0.238 & 3.896 & 3.097 & -0.050 \\
\hline 2.868 & 3.434 & -0.021 & 3.212 & 3.125 & 0.356 & 3.556 & 3.133 & -0.319 & 3.900 & 3.030 & -0.010 \\
\hline 2.872 & 3.391 & 0.038 & 3.216 & 3.142 & 0.356 & 3.560 & 3.158 & -0.337 & 3.904 & 3.005 & 0.027 \\
\hline 2.876 & 3.322 & -0.013 & 3.220 & 3.182 & 0.313 & 3.564 & 3.177 & -0.324 & 3.908 & 3.043 & -0.007 \\
\hline 2.880 & 3.262 & -0.004 & 3.224 & 3.217 & 0.274 & 3.568 & 3.163 & -0.260 & 3.912 & 3.068 & 0.023 \\
\hline 2.884 & 3.307 & -0.011 & 3.228 & 3.246 & 0.228 & 3.572 & 3.125 & -0.095 & 3.916 & 3.037 & -0.059 \\
\hline 2.888 & 3.459 & -0.037 & 3.232 & 3.266 & 0.193 & 3.576 & 3.054 & 0.062 & 3.920 & 3.065 & -0.197 \\
\hline 2.892 & 3.607 & -0.057 & 3.236 & 3.225 & 0.161 & 3.580 & 2.951 & 0.105 & 3.924 & 3.361 & -0.313 \\
\hline 2.896 & 3.636 & -0.042 & 3.240 & 3.165 & 0.173 & 3.584 & 2.897 & 0.110 & 3.928 & 3.393 & -0.352 \\
\hline 2.900 & 3.510 & 0.072 & 3.244 & 3.145 & 0.246 & 3.588 & 3.015 & 0.086 & 3.932 & 3.242 & -0.331 \\
\hline 2.904 & 3.446 & 0.017 & 3.248 & 3.088 & 0.231 & 3.592 & 3.230 & 0.016 & 3.936 & 3.099 & -0.145 \\
\hline 2.908 & 3.348 & -0.123 & 3.252 & 3.003 & 0.090 & 3.596 & 3.314 & 0.068 & 3.940 & 3.011 & -0.058 \\
\hline 2.912 & 3.290 & -0.142 & 3.256 & 2.962 & -0.041 & 3.600 & 3.262 & 0.164 & 3.944 & 2.975 & -0.109 \\
\hline 2.916 & 3.384 & -0.062 & 3.260 & 3.004 & -0.114 & 3.604 & 3.222 & 0.137 & 3.948 & 2.962 & -0.094 \\
\hline 2.920 & 3.479 & -0.066 & 3.264 & 3.105 & -0.068 & 3.608 & 3.221 & 0.145 & 3.952 & 3.021 & -0.093 \\
\hline 2.924 & 3.502 & -0.257 & 3.268 & 3.132 & 0.028 & 3.612 & 3.198 & 0.184 & 3.956 & 3.124 & -0.082 \\
\hline 2.928 & 3.539 & -0.357 & 3.272 & 3.111 & 0.023 & 3.616 & 3.187 & -0.005 & 3.960 & 3.146 & 0.038 \\
\hline 2.932 & 3.595 & -0.352 & 3.276 & 3.178 & 0.053 & 3.620 & 3.233 & -0.204 & 3.964 & 3.141 & 0.071 \\
\hline 2.936 & 3.611 & -0.331 & 3.280 & 3.228 & 0.035 & 3.624 & 3.332 & -0.181 & 3.968 & 3.158 & 0.070 \\
\hline 2.940 & 3.454 & -0.346 & 3.284 & 3.277 & -0.026 & 3.628 & 3.436 & -0.132 & 3.972 & 3.177 & 0.082 \\
\hline 2.944 & 3.285 & -0.307 & 3.288 & 3.336 & -0.132 & 3.632 & 3.514 & -0.108 & 3.976 & 3.146 & 0.040 \\
\hline 2.948 & 3.179 & -0.135 & 3.292 & 3.491 & -0.282 & 3.636 & 3.599 & -0.234 & 3.980 & 3.137 & 0.019 \\
\hline 2.952 & 3.102 & -0.058 & 3.296 & 3.653 & -0.367 & 3.640 & 3.591 & -0.396 & 3.984 & 3.154 & -0.011 \\
\hline 2.956 & 3.142 & -0.044 & 3.300 & 3.664 & -0.380 & 3.644 & 3.450 & -0.318 & 3.988 & 3.189 & -0.083 \\
\hline 2.960 & 3.258 & 0.028 & 3.304 & 3.614 & -0.404 & 3.648 & 3.317 & -0.153 & 3.992 & 3.242 & -0.165 \\
\hline 2.964 & 3.339 & 0.070 & 3.308 & 3.474 & -0.388 & 3.652 & 3.240 & 0.007 & 3.996 & 3.286 & -0.222 \\
\hline 2.968 & 3.423 & -0.033 & 3.312 & 3.405 & -0.369 & 3.656 & 3.159 & 0.103 & 4.000 & 3.311 & -0.238 \\
\hline 2.972 & 3.530 & -0.167 & 3.316 & 3.419 & -0.342 & 3.660 & 3.159 & 0.054 & 4.004 & 3.301 & -0.196 \\
\hline 2.976 & 3.591 & -0.190 & 3.320 & 3.418 & -0.256 & 3.664 & 3.253 & -0.012 & 4.008 & 3.244 & -0.183 \\
\hline 2.980 & 3.626 & -0.188 & 3.324 & 3.341 & -0.116 & 3.668 & 3.414 & -0.082 & 4.012 & 3.160 & -0.196 \\
\hline 2.984 & 3.611 & -0.193 & 3.328 & 3.182 & -0.011 & 3.672 & 3.600 & -0.240 & 4.016 & 3.124 & -0.089 \\
\hline 2.988 & 3.530 & -0.066 & 3.332 & 3.120 & -0.058 & 3.676 & 3.595 & -0.292 & 4.020 & 3.150 & -0.036 \\
\hline 2.992 & 3.377 & 0.074 & 3.336 & 3.196 & -0.230 & 3.680 & 3.461 & -0.182 & 4.024 & 3.180 & -0.055 \\
\hline 2.996 & 3.298 & 0.055 & 3.340 & 3.225 & -0.282 & 3.684 & 3.344 & -0.025 & 4.028 & 3.225 & -0.056 \\
\hline 3.000 & 3.340 & -0.050 & 3.344 & 3.212 & -0.185 & 3.688 & 3.196 & 0.101 & 4.032 & 3.278 & -0.035 \\
\hline 3.004 & 3.399 & -0.125 & 3.348 & 3.292 & -0.117 & 3.692 & 3.010 & 0.225 & 4.036 & 3.223 & -0.065 \\
\hline 3.008 & 3.427 & -0.186 & 3.352 & 3.357 & -0.094 & 3.696 & 3.033 & 0.287 & 4.040 & 3.227 & -0.130 \\
\hline 3.012 & 3.410 & -0.209 & 3.356 & 3.314 & -0.146 & 3.700 & 3.033 & 0.321 & 4.044 & 3.281 & -0.181 \\
\hline 3.016 & 3.395 & -0.231 & 3.360 & 3.281 & -0.206 & 3.704 & 3.032 & 0.210 & 4.048 & 3.254 & -0.100 \\
\hline 3.020 & 3.440 & -0.281 & 3.364 & 3.326 & -0.202 & 3.708 & 3.046 & 0.070 & 4.052 & 3.173 & -0.047 \\
\hline 3.024 & 3.469 & -0.387 & 3.368 & 3.347 & -0.108 & 3.712 & 3.087 & -0.088 & 4.056 & 3.112 & 0.047 \\
\hline 3.028 & 3.418 & -0.398 & 3.372 & 3.311 & -0.102 & 3.716 & 3.209 & -0.229 & 4.060 & 3.109 & 0.198 \\
\hline 3.032 & 3.263 & -0.313 & 3.376 & 3.245 & -0.189 & 3.720 & 3.327 & -0.280 & 4.064 & 3.111 & 0.226 \\
\hline 3.036 & 3.161 & -0.269 & 3.380 & 3.281 & -0.191 & 3.724 & 3.292 & -0.102 & 4.068 & 3.130 & 0.093 \\
\hline 3.040 & 3.115 & -0.311 & 3.384 & 3.409 & -0.178 & 3.728 & 3.071 & 0.051 & 4.072 & 3.144 & 0.058 \\
\hline 3.044 & 3.162 & -0.344 & 3.388 & 3.418 & -0.243 & 3.732 & 2.758 & 0.151 & 4.076 & 3.186 & 0.006 \\
\hline 3.048 & 3.288 & -0.332 & 3.392 & 3.419 & -0.262 & 3.736 & 2.811 & 0.108 & 4.080 & 3.224 & -0.062 \\
\hline 3.052 & 3.403 & -0.315 & 3.396 & 3.349 & -0.226 & 3.740 & 2.945 & 0.031 & 4.084 & 3.244 & -0.113 \\
\hline 3.056 & 3.365 & -0.265 & 3.400 & 3.175 & -0.110 & 3.744 & 3.003 & 0.058 & 4.088 & 3.242 & -0.100 \\
\hline 3.060 & 3.180 & -0.177 & 3.404 & 3.035 & 0.000 & 3.748 & 3.060 & 0.076 & 4.092 & 3.185 & -0.189 \\
\hline
\end{tabular}


APPENDIX C (continued).

\begin{tabular}{|c|c|c|c|c|c|c|c|c|}
\hline $\begin{array}{l}\text { Age } \\
\text { (Ma) }\end{array}$ & $\delta^{18} \mathrm{O}$ & $\delta^{13} \mathrm{C}$ & $\begin{array}{l}\text { Age } \\
\text { (Ma) }\end{array}$ & $\delta^{18} \mathrm{O}$ & $\delta^{13} \mathrm{C}$ & $\begin{array}{l}\text { Age } \\
\text { (Ma) }\end{array}$ & $\delta^{18} \mathrm{O}$ & $\delta^{13} \mathrm{C}$ \\
\hline 4.096 & 3.212 & -0.270 & 4.392 & 3.139 & -0.046 & 4.688 & 3.138 & -0.030 \\
\hline 4.100 & 3.201 & -0.172 & 4.396 & 3.109 & 0.006 & 4.692 & 3.062 & 0.023 \\
\hline 4.104 & 3.177 & -0.154 & 4.400 & 3.085 & -0.015 & 4.696 & 3.074 & 0.003 \\
\hline 4.108 & 3.173 & -0.194 & 4.404 & 3.106 & 0.006 & 4.700 & 3.094 & -0.031 \\
\hline 4.112 & 3.146 & -0.188 & 4.408 & 3.152 & 0.055 & 4.704 & 3.156 & -0.119 \\
\hline 4.116 & 3.123 & -0.231 & 4.412 & 3.078 & 0.014 & 4.708 & 3.193 & -0.214 \\
\hline 4.120 & 3.093 & -0.195 & 4.416 & 2.955 & -0.052 & 4.712 & 3.199 & -0.193 \\
\hline 4.124 & 3.147 & -0.080 & 4.420 & 2.937 & -0.030 & 4.716 & 3.217 & -0.159 \\
\hline 4.128 & 3.221 & -0.015 & 4.424 & -9999.000 & -9999.000 & 4.720 & 3.192 & -0.193 \\
\hline 4.132 & 3.077 & 0.011 & 4.428 & -9999.000 & -9999.000 & 4.724 & 3.207 & -0.178 \\
\hline 4.136 & 2.875 & 0.029 & 4.432 & -9999.000 & -9999.000 & 4.728 & -9999.000 & -9999.000 \\
\hline 4.140 & 2.898 & -0.023 & 4.436 & -9999.000 & $-9999,000$ & 4.732 & -9999.000 & -9999.000 \\
\hline 4.144 & 3.057 & -0.054 & 4.440 & -9999.000 & -9999.000 & 4.736 & -9999.000 & -9999.000 \\
\hline 4.148 & 3.307 & -0.069 & 4.444 & -9999.000 & -9999.000 & 4.740 & -9999.000 & -9999.000 \\
\hline 4.152 & 3.380 & -0.094 & 4.448 & -9999.000 & -9999.000 & 4.744 & 3.211 & 0.170 \\
\hline 4.156 & 3.199 & -0.033 & 4.452 & -9999.000 & -9999.000 & 4.748 & 3.196 & 0.119 \\
\hline 4.160 & 3.118 & -0.008 & 4.456 & -9999.000 & -9999.000 & 4.752 & 3.178 & -0.076 \\
\hline 4.164 & 3.170 & -0.037 & 4.460 & -9999.000 & -9999.000 & 4.756 & 3.268 & -0.204 \\
\hline 4.168 & 3.213 & -0.045 & 4.464 & -9999.000 & -9999.000 & 4.760 & 3.306 & -0.150 \\
\hline 4.172 & 3.092 & 0.017 & 4.468 & -9999.000 & -9999.000 & 4.764 & 3.202 & -0.080 \\
\hline 4.176 & 3.019 & 0.036 & 4.472 & -9999.000 & -9999.000 & 4.768 & 3.117 & -0.055 \\
\hline 4.180 & 3.087 & -0.014 & 4.476 & -9999.000 & -9999.000 & 4.772 & 3.081 & -0.092 \\
\hline 4.184 & 3.088 & -0.005 & 4.480 & -9999.000 & -9999.000 & 4.776 & 3.082 & -0.107 \\
\hline 4.188 & 3.089 & 0.052 & 4.484 & -9999.000 & -9999.000 & 4.780 & 3.196 & -0.096 \\
\hline 4.192 & 3.090 & 0.101 & 4.488 & -9999.000 & -9999.000 & 4.784 & 3.326 & -0.068 \\
\hline 4.196 & 3.043 & 0.013 & 4.492 & -9999.000 & -9999.000 & 4.788 & 3.359 & 0.000 \\
\hline 4.200 & 3.072 & -0.083 & 4.496 & -9999.000 & -9999.000 & 4.792 & 3.265 & 0.075 \\
\hline 4.204 & 3.089 & -0.181 & 4.500 & -9999.000 & -9999.000 & 4.796 & 3.177 & 0.093 \\
\hline 4.208 & 3.019 & -0.258 & 4.504 & -9999.000 & -9999.000 & 4.800 & 3.107 & 0.012 \\
\hline 4.212 & 3.042 & -0.287 & 4.508 & -9999.000 & -9999.000 & 4.804 & 3.091 & -0.005 \\
\hline 4.216 & 3.099 & -0.250 & 4.512 & -9999.000 & -9999.000 & 4.808 & 3.112 & -0.029 \\
\hline 4.220 & 3.080 & -0.129 & 4.516 & -9999.000 & -9999.000 & 4.812 & 3.209 & -0.151 \\
\hline 4.224 & 3.047 & -0.128 & 4.520 & -9999.000 & -9999.000 & 4.816 & 3.309 & -0.248 \\
\hline 4.228 & 3.027 & -0.231 & 4.524 & -9999.000 & -9999.000 & 4.820 & 3.362 & -0.285 \\
\hline 4.232 & 3.008 & -0.284 & 4.528 & -9999.000 & -9999.000 & 4.824 & 3.397 & -0.228 \\
\hline 4.236 & 3.087 & -0.166 & 4.532 & 3.082 & -0.063 & 4.828 & 3.448 & -0.111 \\
\hline 4.240 & 3.142 & -0.080 & 4.536 & 3.079 & -0.046 & 4.832 & 3.423 & -0.102 \\
\hline 4.244 & 3.117 & -0.144 & 4.540 & 3.119 & -0.042 & 4.836 & 3.341 & -0.070 \\
\hline 4.248 & 3.117 & -0.232 & 4.544 & 3.191 & -0.139 & 4.840 & 3.343 & 0.016 \\
\hline 4.252 & 3.157 & -0.272 & 4.548 & 3.233 & -0.235 & 4.844 & 3.351 & 0.095 \\
\hline 4.256 & 3.257 & -0.287 & 4.552 & 3.258 & -0.188 & 4.848 & 3.212 & -0.024 \\
\hline 4.260 & 3.320 & -0.272 & 4.556 & 3.262 & -0.086 & 4.852 & 3.143 & -0.087 \\
\hline 4.264 & 3.306 & -0.239 & 4.560 & 3.236 & -0.057 & 4.856 & 3.175 & -0.180 \\
\hline 4.268 & 3.145 & -0.076 & 4.564 & 3.198 & -0.068 & 4.860 & 3.207 & -0.272 \\
\hline 4.272 & 3.084 & -0.023 & 4.568 & 3.154 & -0.034 & 4.864 & 3.210 & -0.280 \\
\hline 4.276 & 3.103 & -0.041 & 4.572 & 3.156 & -0.054 & 4.868 & 3.210 & -0.280 \\
\hline 4.280 & 3.138 & 0.019 & 4.576 & 3.168 & -0.094 & 4.872 & 3.256 & -0.312 \\
\hline 4.284 & 3.075 & 0.029 & 4.580 & 3.268 & -0.039 & 4.876 & 3.384 & -0.401 \\
\hline 4.288 & 2.893 & 0.007 & 4.584 & 3.265 & -0.021 & 4.880 & 3.511 & -0.490 \\
\hline 4.292 & 2.779 & 0.016 & 4.588 & 3.127 & -0.112 & 4.884 & 3.528 & -0.486 \\
\hline 4.296 & 2.905 & -0.056 & 4.592 & 3.121 & -0.247 & 4.888 & 3.528 & -0.453 \\
\hline 4.300 & 2.951 & -0.098 & 4.596 & 3.174 & -0.361 & 4.892 & 3.354 & -0.217 \\
\hline 4.304 & 2.996 & -0.156 & 4.600 & 3.269 & -0.358 & 4.896 & 3.232 & -0.080 \\
\hline 4.308 & 3.092 & -0.215 & 4.604 & 3.347 & -0.355 & 4.900 & 3.196 & -0.096 \\
\hline 4.312 & 3.048 & -0.152 & 4.608 & 3.326 & -0.240 & 4.904 & 3.218 & -0.072 \\
\hline 4.316 & 2.885 & -0.079 & 4.612 & 3.290 & -0.121 & 4.908 & 3.237 & -0.054 \\
\hline 4.320 & 2.879 & -0.125 & 4.616 & 3.219 & -0.142 & 4.912 & 3.219 & -0.120 \\
\hline 4.324 & 2.978 & -0.198 & 4.620 & 3.188 & -0.209 & 4.916 & 3.215 & -0.155 \\
\hline 4.328 & 2.947 & -0.163 & 4.624 & 3.223 & -0.278 & 4.920 & 3.268 & -0.208 \\
\hline 4.332 & 2.945 & -0.070 & 4.628 & 3.233 & -0.291 & 4.924 & 3.324 & -0.263 \\
\hline 4.336 & 3.031 & -0.014 & 4.632 & 3.211 & -0.260 & 4.928 & 3.388 & -0.320 \\
\hline 4.340 & 2.978 & -0.025 & 4.636 & 3.221 & -0.226 & 4.932 & 3.411 & -0.338 \\
\hline 4.344 & 3.031 & -0.137 & 4.640 & 3.277 & -0.294 & 4.936 & 3.411 & -0.323 \\
\hline 4.348 & 3.102 & -0.264 & 4.644 & 3.317 & -0.318 & 4.940 & 3.336 & -0.235 \\
\hline 4.352 & 3.098 & -0.242 & 4.648 & 3.342 & -0.271 & 4.944 & 3.220 & -0.125 \\
\hline 4.356 & 3.071 & -0.130 & 4.652 & 3.335 & -0.250 & 4.948 & 3.184 & -0.142 \\
\hline 4.360 & 3.034 & -0.155 & 4.656 & 3.252 & -0.302 & 4.952 & 3.185 & -0.173 \\
\hline 4.364 & 3.007 & -0.359 & 4.660 & 3.147 & -0.292 & 4.956 & 3.199 & -0.167 \\
\hline 4.368 & 2.898 & -0.344 & 4.664 & 3.100 & -0.316 & 4.960 & 3.220 & -0.167 \\
\hline 4.372 & 2.789 & -0.328 & 4.668 & 3.106 & -0.396 & 4.964 & 3.229 & -0.176 \\
\hline 4.376 & 2.678 & -0.273 & 4.672 & 3.093 & -0.328 & & & \\
\hline 4.380 & 2.762 & -0.304 & 4.676 & 3.080 & -0.261 & & & \\
\hline 4.384 & 2.984 & -0.338 & 4.680 & 3.110 & -0.223 & & & \\
\hline 4.388 & 3.115 & -0.206 & 4.684 & 3.201 & -0.090 & & & \\
\hline
\end{tabular}


APPENDIX D

Age Model for Site 677

\begin{tabular}{|c|c|c|c|c|c|c|c|c|c|c|c|c|}
\hline $\begin{array}{l}\text { Depth } \\
\text { (med) }\end{array}$ & $\begin{array}{l}\text { Age } \\
\text { (Ma) }\end{array}$ & $\begin{array}{l}\text { Depth } \\
\text { (mcd) }\end{array}$ & $\begin{array}{l}\text { Age } \\
\text { (Ma) }\end{array}$ & $\begin{array}{l}\text { Depth } \\
\text { (med) }\end{array}$ & $\begin{array}{l}\text { Age } \\
\text { (Ma) }\end{array}$ & $\begin{array}{l}\text { Depth } \\
\text { (mcd) }\end{array}$ & $\begin{array}{l}\text { Age } \\
\text { (Ma) }\end{array}$ & $\begin{array}{l}\text { Depth } \\
\text { (mcd) }\end{array}$ & $\begin{array}{l}\text { Age } \\
\text { (Ma) }\end{array}$ & $\begin{array}{l}\text { Depth } \\
\text { (mcd) }\end{array}$ & $\begin{array}{l}\text { Age } \\
\text { (Ma) }\end{array}$ & $\begin{array}{l}\text { Depth } \\
\text { (mcd) }\end{array}$ \\
\hline 0.0 & 0.0007 & 17.0 & 0.4174 & 28.9 & 0.7349 & 37.6 & 0.9431 & 46.1 & 1.1494 & 55.0 & 1.3501 & 63.5 \\
\hline 0.2 & 0.0032 & 17.2 & 0.4276 & 29.2 & 0.7431 & 37.7 & 0.9467 & 46.2 & 1.1510 & 55.1 & 1.3522 & 63.6 \\
\hline 0.4 & 0.0066 & 17.4 & 0.4371 & 29.3 & 0.7448 & 37.8 & 0.9493 & 46.3 & 1.1525 & 55.2 & 1.3549 & 63.7 \\
\hline 0.6 & 0.0101 & 17.6 & 0.4444 & 29.4 & 0.7470 & 37.9 & 0.9523 & 46.4 & 1.1539 & 55.3 & 1.3570 & 63.8 \\
\hline 0.8 & 0.0137 & 17.8 & 0.4502 & 29.5 & 0.7493 & 38.0 & 0.9555 & 46.5 & 1.1554 & 55.4 & 1.3588 & 63.9 \\
\hline 1.0 & 0.0176 & 18.0 & 0.4557 & 29.6 & 0.7512 & 38.1 & 0.9578 & 46.6 & 1.1570 & 55.5 & 1.3610 & 64.0 \\
\hline 1.2 & 0.0216 & 18.2 & 0.4608 & 29.7 & 0.7541 & 38.2 & 0.9600 & 46.7 & 1.1585 & 55.6 & 1.3632 & 64.1 \\
\hline 1.4 & 0.0255 & 18.4 & 0.4652 & 29.8 & 0.7560 & 38.3 & 0.9618 & 46.8 & 1.1600 & 55.7 & 1.3652 & 64.2 \\
\hline 1.6 & 0.0296 & 18.6 & 0.4695 & 29.9 & 0.7589 & 38.4 & 0.9635 & 46.9 & 1.1614 & 55.8 & 1.3670 & 64.3 \\
\hline 1.8 & 0.0336 & 18.8 & 0.4740 & 30.0 & 0.7609 & 38.5 & 0.9654 & 47.0 & 1.1627 & 55.9 & 1.3691 & 64.4 \\
\hline 2.0 & 0.0378 & 19.0 & 0.4785 & 30.1 & 0.7630 & 38.6 & 0.9671 & 47.1 & 1.1644 & 56.0 & 1.3708 & 64.5 \\
\hline 2.2 & 0.0415 & 19.2 & 0.4826 & 30.2 & 0.7651 & 38.7 & 0.9691 & 47.2 & 1.1656 & 56.1 & 1.3730 & 64.6 \\
\hline 2.4 & 0.0452 & 19.4 & 0.4854 & 30.3 & 0.7680 & 38.8 & 0.9714 & 47.3 & 1.1677 & 56.2 & 1.3752 & 64.7 \\
\hline 2.6 & 0.0486 & 19.6 & 0.4884 & 30.4 & 0.7700 & 38.9 & 0.9742 & 47.4 & 1.1703 & 56.3 & 1.3770 & 64.8 \\
\hline 2.8 & 0.0521 & 19.8 & 0.4906 & 30.5 & 0.7721 & 39.0 & 0.9762 & 47.5 & 1.1729 & 56.4 & 1.3790 & 64.9 \\
\hline 3.0 & 0.0556 & 20.0 & 0.4943 & 30.6 & 0.7750 & 39.1 & 0.9791 & 47.6 & 1.1750 & 56.5 & 1.3810 & 65.0 \\
\hline 3.2 & 0.0588 & 20.2 & 0.4976 & 30.7 & 0.7771 & 39.2 & 0.9819 & 47.7 & 1.1774 & 56.6 & 1.3830 & 65.1 \\
\hline 3,4 & 0.0619 & 20.4 & 0.5019 & 30.8 & 0.7787 & 39.3 & 0.9840 & 47.8 & 1.1798 & 56.7 & 1.3850 & 65.2 \\
\hline 3.6 & 0.0648 & 20.6 & 0.5071 & 30.9 & 0.7812 & 39.4 & 0.9878 & 47.9 & 1.1825 & 56.8 & 1.3870 & 65.3 \\
\hline 3.8 & 0.0679 & 20.8 & 0.5129 & 31.0 & 0.7841 & 39.5 & 0.9900 & 48.0 & 1.1852 & 56.9 & 1.3890 & 65.4 \\
\hline 4.0 & 0.0711 & 21.0 & 0.5193 & 31.1 & 0.7861 & 39.6 & 0.9930 & 48.1 & 1.1879 & 57.0 & 1.3910 & 65.5 \\
\hline 4.2 & 0.0746 & 21.2 & 0.5260 & 31.2 & 0.7880 & 39.7 & 0.9958 & 48.2 & 1.1901 & 57.1 & 1.3928 & 65.6 \\
\hline 4.4 & 0.0788 & 21.4 & 0.5344 & 31.3 & 0.7901 & 39.8 & 0.9985 & 48.3 & 1.1930 & 57.2 & 1.3950 & 65.7 \\
\hline 4.6 & 0.0837 & 21.6 & 0.5454 & 31.4 & 0.7920 & 39.9 & 1.0012 & 48.4 & 1.1958 & 57.3 & 1.3971 & 65.8 \\
\hline 4.8 & 0.0894 & 21.8 & 0.5556 & 31.5 & 0.7940 & 40.0 & 1.0047 & 48.5 & 1.1985 & 57.4 & 1.3990 & 65.9 \\
\hline 5.0 & 0.0959 & 22.0 & 0.5616 & 31.6 & 0.7960 & 40.1 & 1.0078 & 48.6 & 1.2011 & 57.5 & 1.4010 & 66.0 \\
\hline 5.2 & 0.1028 & 22.2 & 0.5661 & 31.7 & 0.7980 & 40.2 & 1.0107 & 48.7 & 1.2031 & 57.6 & 1.4030 & 66.1 \\
\hline 5.4 & 0.1093 & 22.4 & 0.5702 & 31.8 & 0.8000 & 40.3 & 1.0141 & 48.8 & 1.2059 & 57.7 & 1.4052 & 66.2 \\
\hline 5.6 & 0.1153 & 22.6 & 0.5744 & 31.9 & 0.8021 & 40.4 & 1.0167 & 48.9 & 1.2081 & 57.8 & 1.4070 & 66.3 \\
\hline 5.8 & 0.1210 & 22.8 & 0.5792 & 32.0 & 0.8035 & 40.5 & 1.0195 & 49.0 & 1.2109 & 57.9 & 1.4091 & 66.4 \\
\hline 6.0 & 0.1262 & 23.0 & 0.5841 & 32.1 & 0.8053 & 40.6 & 1.0241 & 49.1 & 1.2131 & 58.0 & 1.4110 & 66.5 \\
\hline 6.2 & 0.1305 & 23.2 & 0.5887 & 32.2 & 0.8072 & 40.7 & 1.0270 & 49.2 & 1.2160 & 58.1 & 1.4130 & 66.6 \\
\hline 6.4 & 0.1341 & 23.4 & 0.5940 & 32.3 & 0.8093 & 40.8 & 1.0299 & 49.3 & 1.2189 & 58.2 & 1.4148 & 66.7 \\
\hline 6.6 & 0.1374 & 23.6 & 0.5996 & 32.4 & 0.8113 & 40.9 & 1.0320 & 49.4 & 1.2210 & 58.3 & 1.4170 & 66.8 \\
\hline 6.8 & 0.1405 & 23.8 & 0.6060 & 32.5 & 0.8142 & 41.0 & 1.0341 & 49.5 & 1.2239 & 58.4 & 1.4191 & 66.9 \\
\hline 7.0 & 0.1436 & 23.9 & 0.6090 & 32.6 & 0.8170 & 41.1 & 1.0369 & 49.6 & 1.2260 & 58.5 & 1.4210 & 67.0 \\
\hline 7.2 & 0.1467 & 24.0 & 0.6120 & 32.7 & 0.8191 & 41.2 & 1.0382 & 49.7 & 1.2289 & 58.6 & 1.4230 & 67.1 \\
\hline 7.4 & 0.1501 & 24.1 & 0.6152 & 32.8 & 0.8220 & 41.3 & 1.0411 & 49.8 & 1.2311 & 58.7 & 1.4250 & 67.2 \\
\hline 7.6 & 0.1536 & 24.2 & 0.6173 & 32.9 & 0.8249 & 41.4 & 1.0431 & 49.9 & 1.2339 & 58.8 & 1.4271 & 67.3 \\
\hline 7.8 & 0.1578 & 24.3 & 0.6212 & 33.0 & 0.8268 & 41.5 & 1.0460 & 50.0 & 1.2360 & 58.9 & 1.4299 & 67.4 \\
\hline 8.0 & 0.1635 & 24.4 & 0.6240 & 33.1 & 0.8300 & 41.6 & 1.0473 & 50.1 & 1.2389 & 59.0 & 1.4319 & 67.5 \\
\hline 8.2 & 0.1714 & 24.5 & 0.6254 & 33.2 & 0.8331 & 41.7 & 1.0501 & 50.2 & 1.2410 & 59.1 & 1.4340 & 67.6 \\
\hline 8.4 & 0.1804 & 24.6 & 0.6293 & 33.3 & 0.8351 & 41.8 & 1.0522 & 50.3 & 1.2438 & 59.2 & 1.4363 & 67.7 \\
\hline 8.6 & 0.1888 & 24.7 & 0.6306 & 33.4 & 0.8379 & 41.9 & 1.0544 & 50.4 & 1.2451 & 59.3 & 1.4380 & 67.8 \\
\hline 8.8 & 0.1966 & 24.8 & 0.6341 & 33.5 & 0.8401 & 42.0 & 1.0563 & 50.5 & 1.2469 & 59.4 & 1.4401 & 67.9 \\
\hline 9.0 & 0.2040 & 24.9 & 0.6361 & 33.6 & 0.8430 & 42.1 & 1.0592 & 50.6 & 1.2479 & 59.5 & 1.4420 & 68.0 \\
\hline 9.2 & 0.2107 & 25.0 & 0.6389 & 33.7 & 0.8460 & 42.2 & 1.0619 & 51.1 & 1.2552 & 59.6 & 1.4441 & 68.1 \\
\hline 9.4 & 0.2161 & 25.1 & 0.6411 & 33.8 & 0.8484 & 42.3 & 1.0640 & 51.2 & 1.2580 & 59.7 & 1.4469 & 68.2 \\
\hline 9.6 & 0.2211 & 25.2 & 0.6439 & 33.9 & 0.8511 & 42.4 & 1.0660 & 51.3 & 1.2613 & 59.8 & 1.4490 & 68.3 \\
\hline 9.8 & 0.2256 & 25.3 & 0.6461 & 34.0 & 0.8541 & 42.5 & 1.0681 & 51.4 & 1.2642 & 59.9 & 1.4510 & 68.4 \\
\hline 10.0 & 0.2302 & 25.4 & 0.6489 & 34.1 & 0.8569 & 42.6 & 1.0709 & 51.5 & 1.2669 & 60.0 & 1.4530 & 68.5 \\
\hline 10.2 & 0.2344 & 25.5 & 0.6511 & 34.2 & 0.8591 & 42.7 & 1.0730 & 51.6 & 1.2712 & 60.1 & 1.4549 & 68.6 \\
\hline 10.4 & 0.2387 & 25.6 & 0.6542 & 34.3 & 0.8620 & 42.8 & 1.0750 & 51.7 & 1.2735 & 60.2 & 1.4561 & 68.7 \\
\hline 10.6 & 0.2430 & 25.7 & 0.6562 & 34.4 & 0.8650 & 42.9 & 1.0771 & 51.8 & 1.2773 & 60.3 & 1.4579 & 68.8 \\
\hline 10.8 & 0.2478 & 25.8 & 0.6592 & 34.5 & 0.8679 & 43.0 & 1.0800 & 51.9 & 1.2817 & 60.4 & 1.4591 & 68.9 \\
\hline 11.0 & 0.2526 & 25.9 & 0.6614 & 34.6 & 0.8701 & 43.1 & 1.0813 & 52.0 & 1.2842 & 60.5 & 1.4609 & 69.0 \\
\hline 11.2 & 0.2575 & 26.0 & 0.6641 & 34.7 & 0.8729 & 43.2 & 1.0841 & 52.1 & 1.2871 & 60.6 & 1.4621 & 69.1 \\
\hline 11.4 & 0.2627 & 26.1 & 0.6663 & 34.8 & 0.8751 & 43.3 & 1.0862 & 52.2 & 1.2890 & 60.7 & 1,4640 & 69.2 \\
\hline 11.6 & 0.2675 & 26.2 & 0.6692 & 34.9 & 0.8780 & 43.4 & 1.0884 & 52.3 & 1.2910 & 60.8 & 1.4661 & 69.3 \\
\hline 11.8 & 0.2718 & 26.3 & 0.6721 & 35.0 & 0.8809 & 43.5 & 1.0903 & 52.4 & 1.2930 & 60.9 & 1.4689 & 69.4 \\
\hline 12.0 & 0.2755 & 26.4 & 0.6742 & 35.1 & 0.8839 & 43.6 & 1.0932 & 52.5 & 1.2959 & 61.0 & 1.4711 & 69.5 \\
\hline 12.2 & 0.2800 & 26.5 & 0.6770 & 35.2 & 0.8858 & 43.7 & 1.0960 & 52.6 & 1.2979 & 61.1 & 1.4739 & 69.6 \\
\hline 12.4 & 0.2852 & 26.6 & 0.6791 & 35.3 & 0.8882 & 43.8 & 1.0989 & 52.7 & 1.3000 & 61.2 & 1.4760 & 69.7 \\
\hline 12.6 & 0.2918 & 26.7 & 0.6818 & 35.4 & 0.8901 & 43.9 & 1.1011 & 52.8 & 1.3020 & 61.3 & 1.4781 & 69.8 \\
\hline 12.8 & 0.2987 & 26.8 & 0.6838 & 35.5 & 0.8931 & 44.0 & 1.1040 & 52.9 & 1.3040 & 61.4 & 1.4809 & 69.9 \\
\hline 13.0 & 0.3050 & 26.9 & 0.6852 & 35.6 & 0.8959 & 44.1 & 1.1070 & 53.0 & 1.3060 & 61.5 & 1.4832 & 70.0 \\
\hline 13.2 & 0.3106 & 27.0 & 0.6871 & 35.7 & 0.8980 & 44.2 & 1.1100 & 53.1 & 1.3081 & 61.6 & 1.4881 & 70.1 \\
\hline 13.4 & 0.3163 & 27.1 & 0.6891 & 35.8 & 0.9000 & 44.3 & 1,1130 & 53.2 & 1.3109 & 61.7 & 1.4937 & 70.2 \\
\hline 13.6 & 0.3221 & 27.2 & 0.6910 & 35.9 & 0.9021 & 44.4 & 1.1159 & 53.3 & 1.3130 & 61.8 & 1.4969 & 70.3 \\
\hline 13.8 & 0.3279 & 27.3 & 0.6931 & 36.0 & 0.9049 & 44.5 & 1.1184 & 53.4 & 1.3149 & 61.9 & 1.4991 & 70.4 \\
\hline 14.0 & 0.3335 & 27.4 & 0.6961 & 36.1 & 0.9070 & 44.6 & 1.1202 & 53.5 & 1.3170 & 62.0 & 1.5020 & 70.5 \\
\hline 14.2 & 0.3388 & 27.5 & 0.6999 & 36.2 & 0.9090 & 44.7 & 1.1232 & 53.6 & 1.3192 & 62.1 & 1.5049 & 70.6 \\
\hline 14.4 & 0.3438 & 27.6 & 0.7030 & 36.3 & 0.9109 & 44.8 & 1.1261 & 53.7 & 1.3219 & 62.2 & 1.5073 & 70.7 \\
\hline 14.6 & 0.3482 & 27.7 & 0.7061 & 36.4 & 0.9130 & 44.9 & 1.1284 & 53.8 & 1.3240 & 62.3 & 1.5101 & 70.8 \\
\hline 14.8 & 0.3523 & 27.8 & 0.7099 & 36.5 & 0.9152 & 45.0 & 1.1303 & 53.9 & 1.3258 & 62.4 & 1.5131 & 70.9 \\
\hline 15.0 & 0.3564 & 27.9 & 0.7129 & 36.6 & 0.9171 & 45.1 & 1.1329 & 54.0 & 1.3280 & 62.5 & 1.5159 & 71.0 \\
\hline 15.2 & 0.3606 & 28.0 & 0.7151 & 36.7 & 0.9199 & 45.2 & 1.1350 & 54.1 & 1.3302 & 62.6 & 1.5181 & 71.1 \\
\hline 15.4 & 0.3646 & 28.1 & 0.7179 & 36.8 & 0.9220 & 45.3 & 1.1370 & 54.2 & 1.3329 & 62.7 & 1.5210 & 71.2 \\
\hline 15.6 & 0.3687 & 28.2 & 0.7200 & 36.9 & 0.9232 & 45.4 & 1.1385 & 54.3 & 1.3350 & 62.8 & 1.5239 & 71.3 \\
\hline 15.8 & 0.3732 & 28.3 & 0.7220 & 37.0 & 0.9261 & 45.5 & 1.1401 & 54.4 & 1.3370 & 62.9 & 1.5261 & 71.4 \\
\hline 16.0 & 0.3782 & 28.4 & 0.7241 & 37.1 & 0.9290 & 45.6 & 1.1419 & 54.5 & 1.3390 & 63.0 & 1.5289 & 71.5 \\
\hline 16.2 & 0.3840 & 28.5 & 0.7269 & 37.2 & 0.9320 & 45.7 & 1.1433 & 54.6 & 1.3411 & 63.1 & 1.5311 & 71.6 \\
\hline 16.4 & 0.3904 & 28.6 & 0.7290 & 37.3 & 0.9352 & 45.8 & 1.1453 & 54.7 & 1.3439 & 63.2 & 1.5339 & 71.7 \\
\hline 16.6 & 0.3984 & 28.7 & 0.7311 & 37.4 & 0.9378 & 45.9 & 1.1464 & 54.8 & 1.3460 & 63.3 & 1.5361 & 71.8 \\
\hline 16.8 & 0.4080 & 28.8 & 0.7335 & 37.5 & 0.9405 & 46.0 & 1.1477 & 54.9 & 1.3483 & 63.4 & 1.5389 & 71.9 \\
\hline
\end{tabular}


APPENDIX D (continued).

\begin{tabular}{|c|c|c|c|c|c|c|c|c|c|c|c|}
\hline $\begin{array}{l}\text { Depth } \\
\text { (mcd) }\end{array}$ & $\begin{array}{l}\text { Age } \\
\text { (Ma) }\end{array}$ & $\begin{array}{l}\text { Depth } \\
\text { (mcd) }\end{array}$ & $\begin{array}{l}\text { Age } \\
(\mathrm{Ma})\end{array}$ & $\begin{array}{l}\text { Depth } \\
\text { (med) }\end{array}$ & $\begin{array}{l}\text { Age } \\
(\mathrm{Ma})\end{array}$ & $\begin{array}{l}\text { Depth } \\
\text { (mcd) }\end{array}$ & $\begin{array}{l}\text { Age } \\
\text { (Ma) }\end{array}$ & $\begin{array}{l}\text { Depth } \\
\text { (mcd) }\end{array}$ & $\begin{array}{l}\text { Age } \\
(\mathrm{Ma})\end{array}$ & $\begin{array}{l}\text { Depth } \\
\text { (mcd) }\end{array}$ & $\begin{array}{l}\text { Age } \\
\text { (Ma) }\end{array}$ \\
\hline 72.0 & 1.7545 & 80.6 & 1.9731 & 89.5 & 2.0669 & 98.1 & 2.2561 & 106.7 & 2.4581 & 116.8 & 2.6239 \\
\hline 72.1 & 1.7550 & 80.7 & 1.9750 & 89.6 & 2.0681 & 98.2 & 2.2589 & 106.8 & 2.4591 & 116.9 & 2.6250 \\
\hline 72.2 & 1.7571 & 80.8 & 1.9761 & 89.7 & 2.0700 & 98.3 & 2.2611 & 106.9 & 2.4609 & 117.0 & 2.6261 \\
\hline 72.3 & 1.7577 & 80.9 & 1.9780 & 89.8 & 2.0720 & 98.4 & 2.2639 & 107.0 & 2.4620 & 117.1 & 2.6278 \\
\hline 72.4 & 1.7597 & 81.0 & 1.9800 & 89.9 & 2.0741 & 98.5 & 2.2661 & 107.1 & 2.4639 & 117.2 & 2.6295 \\
\hline 72.5 & 1.7604 & 81.1 & 1.9819 & 90.0 & 2.0760 & 98.6 & 2.2689 & 107.2 & 2.4649 & 117.3 & 2.6302 \\
\hline 72.6 & 1.7630 & 81.2 & $1.983 \mathrm{I}$ & 90.1 & 2.0781 & 98.7 & 2.2708 & 107.3 & 2.4661 & 117.4 & 2.6320 \\
\hline 72.7 & 1.7664 & 81.3 & 1.9850 & 90.2 & 2.0800 & 98.8 & 2.2744 & 107.4 & 2.4671 & 117.5 & 2.6329 \\
\hline 72.8 & 1.7674 & 81.4 & 1.9870 & 90.3 & 2.0821 & 98.9 & 2.2758 & 107.5 & 2.4690 & 117.6 & 2.6347 \\
\hline 72.9 & 1.7701 & 81.5 & 1.9889 & 90.4 & 2.0840 & 99.0 & 2.2781 & 107.6 & 2.4701 & 117.7 & 2.6358 \\
\hline 73.0 & 1.7720 & 81.6 & 1.9901 & 90.5 & 2.0861 & 99.1 & 2.2809 & 107.7 & 2.4719 & 117.8 & 2.6379 \\
\hline 73.1 & 1.7742 & 81.7 & 1.9911 & 90.6 & 2.0880 & 99.2 & 2.2831 & 107.8 & 2.4729 & 117.9 & 2.6390 \\
\hline 73.2 & 1.7761 & 81.8 & 1.9931 & 90.7 & 2.0900 & 99.3 & 2.2859 & 107.9 & 2.4744 & 118.0 & 2.6400 \\
\hline 73.3 & 1.7791 & 81.9 & 1.9950 & 90.8 & 2.0911 & 99.4 & 2.2881 & 108.0 & 2.4761 & 118.1 & 2.6411 \\
\hline 73.4 & 1.7810 & 82.0 & 1.9969 & 90.9 & 2.0932 & 99.5 & 2.2909 & 108.1 & 2.4771 & 118.2 & 2.6429 \\
\hline 73.5 & 1.7831 & 82.1 & 1.9981 & 91.0 & 2.0949 & 99.6 & 2.2931 & 108.2 & 2.4789 & 118.3 & 2.6440 \\
\hline 73.6 & 1.7859 & 82.2 & 1.9998 & 91.1 & 2.0974 & 99,7 & 2.2959 & 108.3 & 2.4801 & 118.4 & 2.6450 \\
\hline 73.7 & 1.7880 & 82.6 & 2.0061 & 91.2 & 2.0991 & 99.8 & 2.2982 & 108.4 & 2.4819 & 118.5 & 2.6461 \\
\hline 73.8 & 1.7900 & 82.7 & 2.0080 & 91.3 & 2.1010 & 99.9 & $2.300 \mathrm{~J}$ & 108.5 & 2.4829 & 118.6 & 2.6478 \\
\hline 73.9 & 1.7921 & 82.8 & 2.0091 & 91.4 & 2.1031 & 100.0 & 2.3031 & 109.2 & 2.5171 & 119.3 & 2.6561 \\
\hline 74.0 & 1.7949 & 82.9 & 2.0110 & 91.5 & 2.1050 & 100.1 & 2.3059 & 109.3 & 2.5180 & 119.4 & 2.6574 \\
\hline 74.1 & 1.7970 & 83.0 & 2.0121 & 91.6 & 2.1071 & 100.2 & 2.3081 & 109.4 & 2.5199 & 119.5 & 2.6589 \\
\hline 74.2 & 1.7991 & 83.1 & 2.0140 & 91.7 & 2.1090 & 100.3 & 2.3109 & 109.5 & 2.5210 & 119.6 & 2.6599 \\
\hline 74.3 & 1.8021 & 83,2 & 2.0151 & 91.8 & 2.1108 & 100.4 & 2.3130 & 109.6 & 2.5221 & 119.7 & 2.6611 \\
\hline 74.4 & 1.8059 & 83.3 & 2.0171 & 91.9 & 2.1129 & 100.5 & 2.3151 & 109.7 & 2.5239 & 119.8 & 2.6621 \\
\hline 74.5 & 1.8090 & 83.4 & 2.0189 & 92.0 & 2.1151 & 100.6 & 2.3179 & 109.8 & 2.5250 & 119.9 & 2.6639 \\
\hline 74.6 & 1.8122 & 83.5 & 2.0202 & 92.1 & 2.1169 & 100.7 & 2.3198 & 109.9 & 2.5268 & 120.0 & 2.6650 \\
\hline 74.7 & 1.8152 & 83.6 & 2.0219 & 92.2 & 2.1183 & 100.8 & 2.3224 & 110.0 & 2.5280 & 120.1 & 2.6660 \\
\hline 74.8 & 1.8191 & 83.7 & 2.0231 & 92.3 & 2.1200 & 100.9 & 2.3250 & 110.1 & 2.5291 & 120.2 & 2.6671 \\
\hline 74.9 & 1.8219 & 83.8 & 2.0249 & 92.4 & 2.1221 & 101.0 & 2.3272 & 110.2 & 2.5310 & 120.3 & 2.6681 \\
\hline 75.0 & 1.8241 & 83.9 & 2.0259 & 92.5 & 2.1240 & 101.1 & 2.3311 & 110.3 & 2.5321 & 120.4 & 2.6700 \\
\hline 75.1 & 1.8269 & 84.0 & 2.0261 & 92.6 & 2.1258 & 101.2 & 2.3329 & 110.4 & 2.5339 & 120.5 & 2.6710 \\
\hline 75.2 & 1.8290 & 84.1 & 2.0269 & 92.7 & 2.1279 & 101.3 & 2.3348 & 110.5 & 2.5351 & 120.6 & 2.6720 \\
\hline 75.3 & 1.8311 & 84.2 & 2.0275 & 92.8 & 2.1301 & 101.4 & 2.3374 & 110.6 & 2.5369 & 120.7 & 2.6731 \\
\hline 75.4 & 1.8339 & 84.3 & 2.0281 & 92.9 & 2.1321 & 101.5 & 2.3402 & 110.7 & 2.5379 & 120.8 & 2.6749 \\
\hline 75.5 & 1.8360 & 84.4 & 2.0289 & 93.0 & 2.1341 & 101.6 & 2.3429 & 110.8 & 2.5394 & 120.9 & 2.6760 \\
\hline 75.6 & 1.8381 & 84.5 & 2.0291 & 93.1 & 2.1370 & 101.7 & 2.3451 & 110.9 & 2.5411 & 121.0 & 2.6770 \\
\hline 75.7 & 1.8409 & 84.6 & 2.0299 & 93.2 & 2.1391 & 101.8 & 2.3479 & 111.0 & 2.5421 & 121.1 & 2.6781 \\
\hline 75.8 & 1.8431 & 84.7 & 2.0301 & 93,3 & 2.1420 & 101.9 & 2.3501 & 111.1 & 2.5439 & 121.2 & 2.6798 \\
\hline 75.9 & 1.8459 & 84.8 & 2.0309 & 93.4 & 2.1441 & 102.0 & 2.3529 & 111.2 & 2.5451 & 121.3 & 2.6809 \\
\hline 76.0 & 1.8480 & 84.9 & 2.0310 & 93.5 & 2.1462 & 102.1 & 2.3551 & 111.3 & 2.5461 & 121.4 & 2.6821 \\
\hline 76.1 & 1.8502 & 85.0 & 2.0318 & 93.6 & 2.1490 & 102.2 & 2.3580 & 111.4 & 2.5480 & 121.5 & 2.6838 \\
\hline 76.2 & 1.8521 & 85.1 & 2.0322 & 93,7 & 2.1512 & 102.3 & 2.3609 & 111.5 & 2.5491 & 121.6 & 2.6847 \\
\hline 76.3 & 1.8552 & 85.2 & 2.0331 & 93.8 & 2.1530 & 102.4 & 2.3631 & 111.6 & 2.5501 & 121.7 & 2.6857 \\
\hline 76.4 & 1.8590 & 85.3 & 2.0339 & 93.9 & 2.1552 & 102.5 & 2.3659 & 111.7 & 2.5520 & 121.8 & 2.6870 \\
\hline 76.5 & 1.8634 & 85.4 & 2.0341 & 94.0 & 2.1579 & 102.6 & 2.3689 & 111.8 & 2.5531 & 122.1 & 2.6911 \\
\hline 76.6 & 1.8667 & 85.5 & 2.0349 & 94.1 & 2.1598 & 102.7 & 2.3710 & 111.9 & 2.5549 & 122.2 & 2.6920 \\
\hline 76.7 & 1.8719 & 85.6 & 2.0359 & 94.2 & 2.1624 & 102.8 & 2.3741 & 112.0 & 2.5561 & 122.3 & 2.6930 \\
\hline 76.8 & 1.8760 & 85.7 & 2.0361 & 94.3 & 2.1651 & 102.9 & 2.3761 & 112.1 & 2.5579 & 122.4 & 2.6941 \\
\hline 76.9 & 1.8800 & 85.8 & 2.0370 & 94.4 & 2.1671 & 103.0 & 2.3791 & 112.2 & 2.5589 & 122.5 & 2.6959 \\
\hline 77.0 & 1.8839 & 85.9 & 2.0371 & 94.5 & 2.1691 & 103.1 & 2.3820 & 112.9 & 2.5691 & 122.6 & 2.6970 \\
\hline 77.1 & 1.8888 & 86.0 & 2.0379 & 94.6 & 2.1720 & 103.2 & 2.3849 & 113.0 & 2.5701 & 122.7 & 2.6980 \\
\hline 77.2 & 1.8920 & 86.1 & 2.0381 & 94.7 & 2.1740 & 103.3 & 2.3871 & 113.1 & 2.5711 & 122.8 & 2.6991 \\
\hline 77.3 & 1.8969 & 86.2 & 2.0390 & 94.8 & 2.1762 & 103.4 & 2.3900 & 113.2 & 2.5730 & 122.9 & 2.7009 \\
\hline 77.4 & 1.9010 & 86.3 & 2.0399 & 94.9 & 2.1789 & 103.5 & 2.3929 & 113.3 & 2.5741 & 123.0 & 2.7019 \\
\hline 77.5 & 1.9049 & 86.4 & 2.0401 & 95.0 & 2.1811 & 103.6 & 2.3951 & 113.4 & 2.5759 & 123.1 & 2.7026 \\
\hline 77.6 & 1.9079 & 86.5 & 2.0409 & 95.1 & 2.1839 & 103.7 & 2.3980 & 113.5 & 2.5771 & 123.2 & 2.7041 \\
\hline 77.7 & 1.9101 & 86.6 & 2.0411 & 95.2 & 2.1862 & 103.8 & 2.4009 & 113.6 & 2.5789 & 123.3 & 2.7051 \\
\hline 77.8 & 1.9129 & 86.7 & 2.0420 & 95.3 & 2.1881 & 103.9 & 2.4031 & 113.7 & 2.5800 & 123.4 & 2.7070 \\
\hline 77.9 & 1.9148 & 86.8 & 2.0429 & 95.4 & 2.1911 & 104.0 & 2.4059 & 113.8 & 2.5811 & 123.5 & 2.7080 \\
\hline 78.0 & 1.9174 & 86.9 & 2.0431 & 95.5 & 2.1931 & 104.1 & 2.4089 & 113.9 & 2.5829 & 123.6 & 2.7090 \\
\hline 78.1 & 1.9202 & 87.0 & 2.0439 & 95.6 & 2.1959 & 104.2 & 2.4110 & 114.0 & 2.5841 & 123.7 & 2.7099 \\
\hline 78.2 & 1.9230 & 87.1 & 2.0441 & 95.7 & 2.1980 & 104.3 & 2.4138 & 114.1 & 2.5858 & 123.8 & 2.7114 \\
\hline 78.3 & 1.9251 & 87.2 & 2.0450 & 95.8 & 2.2001 & 104.4 & 2.4159 & 114.2 & 2.5875 & 123.9 & 2.7130 \\
\hline 78.4 & 1.9280 & 87.3 & 2.0459 & 95.9 & 2.2030 & 104.5 & 2.4181 & 114.3 & 2.5882 & 124.0 & 2.7139 \\
\hline 78.5 & 1.9301 & 87.4 & 2.0461 & 96.0 & 2.2051 & 104.6 & 2.4191 & 114.4 & 2.5900 & 124.1 & 2.7151 \\
\hline 78.6 & 1.9331 & 87.5 & 2.0469 & 96.1 & 2.2080 & 104.7 & 2.4210 & 114.5 & 2.5911 & 124.2 & 2.7160 \\
\hline 78.7 & 1.9351 & 87.6 & 2.0471 & 96.2 & 2.2101 & 104.8 & 2.4230 & 114.6 & 2.5922 & 124.3 & 2.7170 \\
\hline 78.8 & 1.9381 & 87.7 & 2.0480 & 96.3 & 2.2130 & 104.9 & 2.4250 & 114.7 & 2.5939 & 124.4 & 2.7180 \\
\hline 78.9 & 1.9402 & 87.8 & 2.0489 & 96.4 & 2.2150 & 105.0 & 2.4270 & 115.1 & 2.6001 & 124.5 & 2.7199 \\
\hline 79.0 & 1.9432 & 87.9 & 2.0491 & 96.5 & 2.2171 & 105.1 & 2.4290 & 115.2 & 2.6010 & 124.6 & 2.7210 \\
\hline 79.1 & 1.9453 & 88.0 & 2.0499 & 96.6 & 2.2199 & 105.2 & 2.4309 & 115.3 & 2.6021 & 124.7 & 2.7220 \\
\hline 79.2 & 1.9482 & 88.1 & 2.0501 & 96.7 & 2.2223 & 105.3 & 2.4321 & 115.4 & 2.6039 & 124.8 & 2.7230 \\
\hline 79.3 & 1.9501 & 88.2 & 2.0509 & 96.8 & 2.2242 & 105.4 & 2.4340 & 115.5 & 2.6051 & 124.9 & 2.7240 \\
\hline 79.4 & 1.9519 & 88.3 & 2.0511 & 96.9 & 2.2271 & 105.5 & 2.4359 & 115.6 & 2.6069 & 125.0 & 2.7250 \\
\hline 79.5 & 1.9535 & 88.4 & 2.0520 & 97.0 & 2.2291 & 105.6 & 2.4380 & 115.7 & 2.6081 & 125.1 & 2.7263 \\
\hline 79.6 & 1.9552 & 88.5 & 2.0529 & 97.1 & 2.2319 & 105.7 & 2.4398 & 115.8 & 2.6091 & 125.2 & 2.7271 \\
\hline 79.7 & 1.9571 & 88.6 & 2.0531 & 97.2 & 2.2341 & 105.8 & 2.4420 & 115.9 & 2.6110 & 125.3 & 2.7290 \\
\hline 79.8 & 1.9584 & 88.7 & 2.0539 & 97.3 & 2.2368 & 105.9 & 2.4431 & 116.0 & 2.6121 & 125.4 & 2.7297 \\
\hline 79.9 & 1.9602 & 88.8 & 2.0540 & 97.4 & 2.2393 & 106.0 & 2.4451 & 116.1 & 2.6131 & 125.5 & 2.7311 \\
\hline 80.0 & 1.9622 & 88.9 & 2.0554 & 97.5 & 2.2412 & 106.1 & 2.4470 & 116.2 & 2.6151 & 125.6 & 2.7320 \\
\hline 80.1 & 1.9641 & 89.0 & 2.0571 & 97.6 & 2.2440 & 106.2 & 2.4490 & 116.3 & 2.6169 & 125.7 & 2.7330 \\
\hline 80.2 & 1.9652 & 89.1 & 2.0590 & 97.7 & 2.2462 & 106.3 & 2.4510 & 116.4 & 2.6180 & 125.8 & 2.7340 \\
\hline 80.3 & 1.9672 & 89.2 & 2.0610 & 97.8 & 2.2489 & 106.4 & 2.4529 & 116.5 & 2.6191 & 125.9 & 2.7350 \\
\hline 80.4 & 1.9691 & 89.3 & 2.0622 & 97.9 & 2.2511 & 106.5 & 2.4539 & 116.6 & 2.6209 & 126.0 & 2.7369 \\
\hline 80.5 & 1.9712 & 89.4 & 2.0650 & 98.0 & 2.2539 & 106.6 & 2.4559 & 116.7 & 2.6221 & 126.1 & 2.7379 \\
\hline
\end{tabular}


APPENDIX D (continued).

\begin{tabular}{|c|c|c|c|c|c|}
\hline $\begin{array}{l}\text { Depth } \\
\text { (mcd) }\end{array}$ & $\begin{array}{l}\text { Age } \\
(\mathrm{Ma})\end{array}$ & $\begin{array}{l}\text { Depth } \\
\text { (mcd) }\end{array}$ & $\begin{array}{l}\text { Age } \\
\text { (Ma) }\end{array}$ & $\begin{array}{l}\text { Depth } \\
\text { (mcd) }\end{array}$ & $\begin{array}{l}\text { Age } \\
\text { (Ma) }\end{array}$ \\
\hline 135.9 & 2.8920 & 145.1 & 3.0485 & 154.0 & 3.1750 \\
\hline 136.0 & 2.8944 & 145.2 & 3.0501 & 154.1 & 3.1765 \\
\hline 136.1 & 2.8971 & 145.3 & 3.0509 & 154.2 & 3.1780 \\
\hline 136.2 & 2.8999 & 145.7 & 3.0572 & 154.3 & 3.1795 \\
\hline 136.3 & 2.9020 & 145.8 & 3.0589 & 154.4 & 3.1805 \\
\hline 136.4 & 2.9051 & 145.9 & 3.0600 & 154.5 & 3.1820 \\
\hline 136.5 & 2.9071 & 146.0 & 3.0611 & 154.6 & 3.1836 \\
\hline 136.6 & 2.9101 & 146.1 & 3.0629 & 154.7 & 3.1852 \\
\hline 136.7 & 2.9121 & 146.2 & 3.0641 & 154.8 & 3.1863 \\
\hline 136.8 & 2.9149 & 146.3 & 3.0659 & 155.6 & 3.1981 \\
\hline 136.9 & 2.9171 & 146.4 & 3.0670 & 155.7 & 3.1990 \\
\hline 137.0 & 2.9199 & 146.5 & 3.0678 & 155.8 & 3.2007 \\
\hline 137.1 & 2.9221 & 146.6 & 3.0704 & 155.9 & 3.2018 \\
\hline 137.2 & 2.9249 & 146.7 & 3.0712 & 156.0 & 3.2035 \\
\hline 137.3 & 2.9270 & 146.8 & 3.0730 & 156.1 & 3.2049 \\
\hline 137.4 & 2.9290 & 146.9 & 3.0741 & 156.2 & 3.2060 \\
\hline 137.5 & 2.9310 & 147.0 & 3.0759 & 156.3 & 3.2079 \\
\hline 137.6 & 2.9328 & 147.1 & 3.0770 & 156.4 & 3.2091 \\
\hline 137.7 & 2.9349 & 147.2 & 3.0779 & 156.5 & 3.2108 \\
\hline 137.8 & 2.9372 & 147.5 & 3.0831 & 156.6 & 3.2112 \\
\hline 137.9 & 2.9399 & 147.6 & 3.0840 & 156.7 & 3.2131 \\
\hline 138.0 & 2.9412 & 147.7 & 3.0851 & 156.8 & 3.2149 \\
\hline 138.1 & 2.9440 & 147.8 & 3.0869 & 156.9 & 3.2161 \\
\hline 138.2 & 2.9460 & 147.9 & 3.0889 & 157.0 & 3.2179 \\
\hline 138.3 & 2.9480 & 148.0 & 3.0899 & 157.1 & 3.2190 \\
\hline 138.4 & 2.9499 & 148.1 & 3.0911 & 157.2 & 3.2201 \\
\hline 138.5 & 2.9510 & 148.2 & 3.0919 & 157.3 & 3.2219 \\
\hline 138.6 & 2.9520 & 148.3 & 3.0942 & 157.4 & 3.2231 \\
\hline 138.7 & 2.9530 & 148.4 & 3.0951 & 157.5 & 3.2249 \\
\hline 138.8 & 2.9541 & 148.5 & 3.0969 & 157.6 & 3.2261 \\
\hline 138.9 & 2.9559 & 148.6 & 3.0981 & 157.7 & 3.2279 \\
\hline 139.0 & 2.9569 & 148.7 & 3,0999 & 157.8 & 3.2290 \\
\hline 140.0 & 2.9681 & 148.8 & 3.1011 & 157.9 & 3.2301 \\
\hline 140.1 & 2.9689 & 148.9 & 3.1029 & 158.0 & 3.2319 \\
\hline 140.2 & 2.9700 & 149.0 & 3.1040 & 158.1 & 3.2335 \\
\hline 140.3 & 2.9711 & 149.1 & 3.1051 & 158.2 & 3.2351 \\
\hline 140.4 & 2.9738 & 149.2 & 3.1069 & 158.3 & 3.2360 \\
\hline 140.5 & 2.9758 & 149.3 & 3.1083 & 158.4 & 3.2371 \\
\hline 140.6 & 2.9782 & 149.4 & 3.1089 & 158.5 & 3.2389 \\
\hline 140.7 & 2.9800 & 150.0 & 3.1181 & 158.6 & 3.2401 \\
\hline 140.8 & 2.9819 & 150.1 & 3.1199 & 158.7 & 3.2419 \\
\hline 141.1 & 2.9891 & 150.2 & 3.1211 & 158.8 & 3.2431 \\
\hline 141.2 & 2.9909 & 150.3 & 3.1219 & 158.9 & 3.2449 \\
\hline 141.5 & 2.9971 & 150.4 & 3.1244 & 159.0 & 3.2460 \\
\hline 141.6 & 2.9989 & 150.5 & 3.1252 & 159.1 & 3.2469 \\
\hline 141.7 & 3.0001 & 150.6 & 3.1269 & 159.8 & 3.2572 \\
\hline 141.8 & 3.0019 & 150.7 & 3.1282 & 159.9 & 3.2588 \\
\hline 141.9 & 3.0035 & 150.8 & 3.1294 & 160.0 & 3.2605 \\
\hline 142.0 & 3.0051 & 150.9 & 3.1311 & 160.1 & 3.2621 \\
\hline 142.1 & 3.0061 & 151.0 & 3.1322 & 160.2 & 3.2630 \\
\hline 142.2 & 3.0071 & 151.1 & 3.1335 & 160.3 & 3.2641 \\
\hline 142.3 & 3.0089 & 151.2 & 3.1350 & 160.4 & 3.2659 \\
\hline 142.6 & 3.0131 & 151.3 & 3.1369 & 160.5 & 3.2671 \\
\hline 142.7 & 3.0141 & 151.4 & 3.1373 & 160.6 & 3.2689 \\
\hline 142.8 & 3.0159 & 151.5 & 3.1400 & 160.7 & 3.2705 \\
\hline 142.9 & 3.0169 & 151.6 & 3.1410 & 160.8 & 3.2721 \\
\hline 143,0 & 3.0185 & 151.7 & 3.1421 & 160.9 & 3.2730 \\
\hline 143.1 & 3.0202 & 151.8 & 3.1433 & 161.0 & 3.2743 \\
\hline 143.2 & 3.0219 & 151.9 & 3.1451 & 161.1 & 3.2759 \\
\hline 143.3 & 3.0229 & 152.0 & 3.1460 & 161.2 & 3.2770 \\
\hline 143.4 & 3.0245 & 152.1 & 3.1487 & 161.3 & 3.2785 \\
\hline 143.5 & 3.0261 & 152.2 & 3.1495 & 161.4 & 3.2800 \\
\hline 143.6 & 3.0271 & 152.3 & 3.1510 & 161.5 & 3.2812 \\
\hline 143.7 & 3.0281 & 152.4 & 3.1525 & 161.6 & 3.2831 \\
\hline 143.8 & 3.0301 & 152.5 & 3.1535 & 161.7 & 3.2841 \\
\hline 143.9 & 3.0319 & 152.6 & 3.1550 & 161.8 & 3.2859 \\
\hline 144.0 & 3.0330 & 152.7 & 3.1565 & 161.9 & 3.2871 \\
\hline 144.1 & 3.0339 & 152.8 & 3.1580 & 162.0 & 3.2889 \\
\hline 144.2 & 3.0355 & 152.9 & 3.1595 & 162.1 & 3.2900 \\
\hline 144.3 & 3.0372 & 153.0 & 3.1600 & 162.2 & 3.2911 \\
\hline 144.4 & 3.0389 & 153.1 & 3.1630 & 162.3 & 3.2929 \\
\hline 144.5 & 3.0400 & 153.2 & 3.1633 & 162.4 & 3.2946 \\
\hline 144.6 & 3.0412 & 153.3 & 3.1650 & 162.5 & 3.2962 \\
\hline 144.7 & 3.0429 & 153.4 & 3.1667 & 162.6 & 3.2972 \\
\hline 144.8 & 3.0440 & 153.7 & 3.1710 & & \\
\hline 144.9 & 3.0459 & 3.8 & 3.1720 & & \\
\hline
\end{tabular}


Appendix E

Age Model for Site 607

\begin{tabular}{|c|c|c|c|c|c|c|c|c|c|c|c|c|}
\hline $\begin{array}{l}\text { Depth } \\
\text { (mcd) }\end{array}$ & $\begin{array}{l}\text { Age } \\
(\mathrm{Ma})\end{array}$ & $\begin{array}{l}\text { Depth } \\
\text { (mcd) }\end{array}$ & $\begin{array}{l}\text { Age } \\
\text { (Ma) }\end{array}$ & $\begin{array}{l}\text { Depth } \\
\text { (mcd) }\end{array}$ & $\begin{array}{l}\text { Age } \\
\text { (Ma) }\end{array}$ & $\begin{array}{l}\text { Depth } \\
\text { (mcd) }\end{array}$ & $\begin{array}{l}\text { Age } \\
(\mathrm{Ma})\end{array}$ & $\begin{array}{l}\text { Depth } \\
\text { (mcd) }\end{array}$ & $\begin{array}{l}\text { Age } \\
\text { (Ma) }\end{array}$ & $\begin{array}{l}\text { Depth } \\
\text { (mcd) }\end{array}$ & $\begin{array}{l}\text { Age } \\
(\mathrm{Ma})\end{array}$ & $\begin{array}{l}\text { Depth } \\
\text { (med) }\end{array}$ \\
\hline 0.190 & 0.0029 & 9.727 & 0.2615 & 20.630 & 0.5301 & 32.534 & 0.8019 & 43.220 & 1.0549 & 53.046 & 1.3092 & 64.155 \\
\hline 0.380 & 0.0058 & 10.000 & 0.2649 & 20.690 & 0.5334 & 32.680 & 0.8052 & 43.375 & 1.0574 & 53.101 & 1.3124 & 64.300 \\
\hline 0.570 & 0.0088 & 10.273 & 0.2683 & 20.747 & 0.5367 & 32.880 & 0.8083 & 43.540 & 1.0598 & 53.173 & 1.3156 & 64.487 \\
\hline 0.780 & 0.0118 & 10.427 & 0.2716 & 20.803 & 0.5399 & 33.070 & 0.8113 & 43.668 & 1.0621 & 53.280 & 1.3188 & 64.626 \\
\hline 1.000 & 0.0148 & 10.665 & 0.2749 & 20.861 & 0.5431 & 33.240 & 0.8143 & 43.790 & 1.0644 & 53.443 & 1.3220 & 64.704 \\
\hline 1.230 & 0.0180 & 10.880 & 0.2782 & 20.926 & 0.5463 & 33.353 & 0.8171 & 43.957 & 1.0667 & 53.740 & 1.3252 & 64.805 \\
\hline 1.410 & 0.0212 & 11.080 & 0.2815 & 20.990 & 0.5493 & 33.433 & 0.8199 & 44.070 & 1.0690 & 53.965 & 1.3284 & 64.923 \\
\hline 1.590 & 0.0245 & 11.255 & 0.2847 & 21.065 & 0.5523 & 33.498 & 0.8226 & 44.145 & 1.0713 & 54.340 & 1.3315 & 65.053 \\
\hline 1.770 & 0.0278 & 11.405 & 0.2878 & 21.140 & 0.5552 & 33.563 & 0.8253 & 44.220 & 1.0736 & 54.540 & 1.3345 & 65.180 \\
\hline 1.963 & 0.0314 & 11.530 & 0.2910 & 21.215 & 0.5580 & 33.628 & 0.8279 & 44.333 & 1.0759 & 54.670 & 1.3375 & 65.270 \\
\hline 2.143 & 0.0350 & 11.680 & 0.2940 & 21.290 & 0.5607 & 33.688 & 0.8305 & 44.437 & 1.0783 & 54.753 & 1.3405 & 65.368 \\
\hline 2.285 & 0.0387 & 11.853 & 0.2970 & 21.380 & 0.5633 & 33.744 & 0.8332 & 44.537 & 1.0807 & 54.833 & 1.3434 & 65.480 \\
\hline 2.447 & 0.0425 & 12.040 & 0.3000 & 21.490 & 0.5659 & 33.801 & 0.8358 & 44.637 & 1.0832 & 54.927 & 1.3462 & 65.592 \\
\hline 2.657 & 0.0465 & 12.137 & 0.3029 & 21.640 & 0.5684 & 33.863 & 0.8384 & 44.730 & 1.0858 & 55.003 & 1.3489 & 65.762 \\
\hline 2.830 & 0.0504 & 12.222 & 0.3058 & 21.890 & 0.5707 & 33.927 & 0.8410 & 44.820 & 1.0885 & 55.067 & 1.3517 & 65.950 \\
\hline 2.965 & 0.0544 & 12.337 & 0.3086 & 22.210 & 0.5731 & 33.991 & 0.8437 & 44.928 & 1.0912 & 55.143 & 1.3543 & 66.080 \\
\hline 3.150 & 0.0584 & 12.417 & 0.3113 & 22.630 & 0.5754 & 34.056 & 0.8464 & 45.012 & 1.0942 & 55.240 & 1.3570 & 66.210 \\
\hline 3.370 & 0.0624 & 12.474 & 0.3140 & 22.930 & 0.5776 & 34.120 & 0.8491 & 45.093 & 1.0972 & 55.390 & 1.3596 & 66.337 \\
\hline 3.560 & 0.0662 & 12.530 & 0.3167 & 23.230 & 0.5798 & 34.195 & 0.8519 & 45.188 & 1.1004 & 55.690 & 1.3622 & 66.445 \\
\hline 3.730 & 0.0700 & 12.620 & 0.3193 & 23.667 & 0.6039 & 34.270 & 0.8547 & 45.290 & 1.1038 & 55.915 & 1.3648 & 66.553 \\
\hline 3.860 & 0.0737 & 12.705 & 0.3219 & 23.713 & 0.6063 & 34.353 & 0.8576 & 45.400 & 1.1074 & 56.154 & 1.3674 & 66.680 \\
\hline 4.010 & 0.0772 & 12.780 & 0.3244 & 23.763 & 0.6088 & 34.435 & 0.8605 & 45.528 & 1.1111 & 56.257 & 1.3700 & 66.830 \\
\hline 4.120 & 0.0806 & 12.867 & 0.3270 & 23.813 & 0.6114 & 34.530 & 0.8634 & 45.645 & 1.1150 & 56.360 & 1.3726 & 66.980 \\
\hline 4.270 & 0.0838 & 12.980 & 0.3295 & 23.940 & 0.6141 & 34.655 & 0.8665 & 45.757 & 1.1190 & 56.497 & 1.3752 & 67.092 \\
\hline 4.380 & 0.0870 & 13.093 & 0.3320 & 24.090 & 0.6168 & 34.766 & 0.8695 & 45.870 & 1.1232 & 56.610 & 1.3779 & 67.250 \\
\hline 4.483 & 0.0900 & 13.230 & 0.3345 & 24.243 & 0.6197 & 34.844 & 0.8727 & 45.983 & 1.1274 & 56.740 & 1.3806 & 67.430 \\
\hline 4.630 & 0.0928 & 13.368 & 0.3370 & 24.430 & 0.6228 & 34.945 & 0.8759 & 46.090 & 1.1316 & 56.853 & 1.3834 & 67.600 \\
\hline 4.702 & 0.0956 & 13.500 & 0.3395 & 24,655 & 0.6259 & 35.057 & 0.8791 & 46.202 & 1.1358 & 56.990 & 1.3862 & 67.730 \\
\hline 4.780 & 0.0983 & 13.750 & 0.3420 & 24.880 & 0.6292 & 35.170 & 0.8824 & 46.325 & 1.1399 & 57.083 & 1.3892 & 67.880 \\
\hline 4.870 & 0.1009 & 13.930 & 0.3446 & 25.003 & 0.6326 & 35.260 & 0.8857 & 46.448 & 1.1438 & 57.147 & 1.3922 & 68.030 \\
\hline 5.000 & 0.1034 & 14.080 & 0.3472 & 25.125 & 0.6361 & 35.350 & 0.8891 & 46.563 & 1.1477 & 57.211 & 1.3953 & 68.217 \\
\hline 5.090 & 0.1058 & 14.255 & 0.3498 & 25.248 & 0.6397 & 35.440 & 0.8924 & 46.690 & 1.1514 & 57.276 & 1.3985 & 68.330 \\
\hline 5.180 & 0.1082 & 14.430 & 0.3525 & 25.403 & 0.6433 & 35.537 & 0.8958 & 46.833 & 1.1549 & 57.340 & 1.4018 & 68.443 \\
\hline 5.294 & 0.1106 & 14.590 & 0.3552 & 25.590 & 0.6469 & 35.637 & 0.8991 & 46.955 & 1.1583 & 57.385 & 1.4052 & 68.630 \\
\hline 5.392 & 0.1129 & 14.780 & 0.3580 & 25.743 & 0.6505 & 35.737 & 0.9024 & 47.058 & 1.1615 & 57.430 & 1.4086 & 68.724 \\
\hline 5.458 & 0.1152 & 14.930 & 0.3608 & 25.904 & 0.6540 & 35.870 & 0.9057 & 47.162 & 1.1646 & 57.475 & 1.4122 & 68.819 \\
\hline 5.524 & 0.1175 & 15.080 & 0.3638 & 26.061 & 0.6575 & 36.020 & 0.9089 & 47.265 & 1.1676 & 57.558 & 1.4158 & 68.916 \\
\hline 5.590 & 0.1198 & 15.182 & 0.3669 & 26.217 & 0.6608 & 36.198 & 0.9121 & 47.388 & 1.1704 & 57.660 & 1.4195 & 69.014 \\
\hline 5.680 & 0.1221 & 15.315 & 0.3700 & 26.374 & 0.6640 & 36.390 & 0.9152 & 47.520 & 1.1732 & 57.747 & 1.4231 & 69.155 \\
\hline 5.747 & 0.1243 & 15.480 & 0.3733 & 26.530 & 0.6670 & 36.520 & 0.9183 & 47.632 & 1.1758 & 57.833 & 1.4268 & 69.305 \\
\hline 5.850 & 0.1267 & 15.590 & 0.3768 & 26.680 & 0.6699 & 36.707 & 0.9213 & 47.735 & 1.1785 & 57.920 & 1.4304 & 69.430 \\
\hline 5.930 & 0.1290 & 15.680 & 0.3803 & 26.793 & 0.6727 & 36.820 & 0.9242 & 47.855 & 1.1810 & 58.044 & 1.4339 & 69.555 \\
\hline 6.010 & 0.1314 & 15.830 & 0.3841 & 26.977 & 0.6753 & 37.020 & 0.9271 & 48.040 & 1.1835 & 58.118 & 1.4374 & 69.630 \\
\hline 6.095 & 0.1338 & 15.980 & 0.3879 & 27.130 & 0.6778 & 37.190 & 0.9299 & 48.205 & 1.1860 & 58.191 & 1.4408 & 69.717 \\
\hline 6.179 & 0.1362 & 16.092 & 0.3920 & 27.300 & 0.6801 & 37.383 & 0.9326 & 48.355 & 1.1885 & 58.278 & 1.4440 & 69.830 \\
\hline 6.264 & 0.1388 & 16.200 & 0.3961 & 27.397 & 0.6824 & 37.565 & 0.9353 & 48.460 & 1.1910 & 58.390 & 1.4472 & 69.942 \\
\hline 6.348 & 0.1413 & 16.324 & 0.4004 & 27.580 & 0.6846 & 37.740 & 0.9379 & 48.613 & 1.1935 & 58.615 & 1.4502 & 70.110 \\
\hline 6.433 & 0.1439 & 16.456 & 0.4048 & 27.730 & 0.6867 & 37.908 & 0.9405 & 48.770 & 1.1959 & 58.776 & 1.4532 & 70.222 \\
\hline 6.505 & 0.1466 & 16.580 & 0.4093 & 27.917 & 0.6887 & 38.095 & 0.9430 & 48.945 & 1.1985 & 58.904 & 1.4561 & 70.318 \\
\hline 6.550 & 0.1494 & 16.880 & 0.4139 & 28.030 & 0.6906 & 38.270 & 0.9455 & 49.090 & 1.2010 & 59.037 & 1.4588 & 70.430 \\
\hline 6.670 & 0.1522 & 17.180 & 0.4184 & 28.230 & 0.6926 & 38.490 & 0.9480 & 49.170 & 1.2036 & 59.200 & 1.4615 & 70.558 \\
\hline 6.730 & 0.1551 & 17.330 & 0.4229 & 28.361 & 0.6945 & 38.568 & 0.9505 & 49.282 & 1.2062 & 59.400 & 1.4642 & 70.655 \\
\hline 6.786 & 0.1580 & 17.630 & 0.4274 & 28.456 & 0.6963 & 38.646 & 0.9529 & 49.390 & 1.2089 & 59.610 & 1.4668 & 70.744 \\
\hline 6.840 & 0.1610 & 17.810 & 0.4318 & 28.550 & 0.6981 & 38.724 & 0.9554 & 49.480 & 1.2116 & 59.820 & 1.4694 & 70.846 \\
\hline 6.915 & 0.1640 & 17.900 & 0.4361 & 28.658 & 0.6999 & 38.790 & 0.9579 & 49.580 & 1.2144 & 59.976 & 1.4719 & 70.955 \\
\hline 7.007 & 0.1671 & 17.990 & 0.4402 & 28.743 & 0.7018 & 38.870 & 0.9604 & 49.688 & 1.2173 & 60.104 & 1.4744 & 71.080 \\
\hline 7.085 & 0.1702 & 18.080 & 0.4441 & 28.843 & 0.7036 & 38.990 & 0.9629 & 49.790 & 1.2201 & 60.215 & 1.4769 & 71.218 \\
\hline 7.160 & 0.1734 & 18.250 & 0.4479 & 28.967 & 0.7055 & 39.155 & 0.9655 & 49.887 & 1.2231 & 60.290 & 1.4794 & 71.332 \\
\hline 7.260 & 0.1765 & 18.380 & 0.4515 & 29.080 & 0.7074 & 39.305 & 0.9681 & 49.995 & 1.2261 & 60.365 & 1.4820 & 71.455 \\
\hline 7.420 & 0.1797 & 18.530 & 0.4550 & 29.170 & 0.7093 & 39.445 & 0.9708 & 50.100 & 1.2291 & 60.440 & 1.4845 & 71.620 \\
\hline 7.570 & 0.1829 & 18.755 & 0.4583 & 29.267 & 0.7113 & 39.585 & 0.9736 & 50.190 & 1.2322 & 60.528 & 1.4871 & 71.850 \\
\hline 7.770 & 0.1860 & 18.930 & 0.4615 & 29.380 & 0.7134 & 39.718 & 0.9764 & 50.320 & 1.2353 & 60.640 & 1.4898 & 72.070 \\
\hline 7.908 & 0.1891 & 19.080 & 0.4645 & 29.530 & 0.7156 & 39.820 & 0.9793 & 50.430 & 1.2384 & 60.706 & 1.4925 & 72.247 \\
\hline 8.077 & 0.1923 & 19.210 & 0.4674 & 29.643 & 0.7179 & 39.933 & 0.9824 & 50.520 & 1.2415 & 60.772 & 1.4952 & 72.393 \\
\hline 8.290 & 0.1954 & 19.390 & 0.4702 & 29.780 & 0.7203 & 40.070 & 0.9855 & 50.649 & 1.2447 & 60.838 & 1.4981 & 72.540 \\
\hline 8.365 & 0.1984 & 19.523 & 0.4730 & 29.918 & 0.7228 & 40.220 & 0.9888 & 50.777 & 1.2478 & 60.940 & 1.5010 & 72.700 \\
\hline 8.440 & 0.2015 & 19.620 & 0.4756 & 30.050 & 0.7255 & 40.362 & 0.9921 & 50.890 & 1.2509 & 61.013 & 1.5041 & 72.790 \\
\hline 8.515 & 0.2046 & 19.683 & 0.4783 & 30.243 & 0.7284 & 40.490 & 0.9956 & 51.040 & 1.2540 & 61.086 & 1.5072 & 72.880 \\
\hline 8.587 & 0.2076 & 19.747 & 0.4809 & 30.387 & 0.7315 & 40.612 & 0.9991 & 51.165 & 1.2571 & 61.197 & 1.5104 & 72.970 \\
\hline 8.642 & 0.2106 & 19.811 & 0.4835 & 30.530 & 0.7349 & 40.740 & 1.0028 & 51.290 & 1.2601 & 61.390 & 1.5137 & 73.088 \\
\hline 8.690 & 0.2137 & 19.876 & 0.4860 & 30.680 & 0.7384 & 40.885 & 1.0065 & 51.410 & 1.2631 & 61.615 & 1.5170 & 73.220 \\
\hline 8.735 & 0.2167 & 19.940 & 0.4886 & 30.780 & 0.7423 & 41.020 & 1.0102 & 51.530 & 1.2661 & 61.840 & 1.5205 & 73.413 \\
\hline 8.800 & 0.2197 & 19.996 & 0.4912 & 30.855 & 0.7464 & 41.170 & 1.0139 & 51.657 & 1.2692 & 61.990 & 1.5239 & 73.563 \\
\hline 8.850 & 0.2228 & 20.052 & 0.4939 & 30.955 & 0.7507 & 41.357 & 1.0176 & 51.785 & 1.2722 & 62.156 & 1.5275 & 73.703 \\
\hline 8.887 & 0.2259 & 20.105 & 0.4965 & 31.080 & 0.7552 & 41.470 & 1.0213 & 51.920 & 1.2751 & 62.284 & 1.5310 & 73.870 \\
\hline 8.933 & 0.2289 & 20.150 & 0.4993 & 31.207 & 0.7599 & 41.670 & 1.0249 & 52.066 & 1.2781 & 62.417 & 1.5345 & 74.050 \\
\hline 8.970 & 0.2321 & 20.195 & 0.5021 & 31.303 & 0.7646 & 41.783 & 1.0284 & 52.204 & 1.2812 & 62.559 & 1.5379 & 74.162 \\
\hline 9.000 & 0.2352 & 20.240 & 0.5049 & 31.431 & 0.7693 & 41.960 & 1.0318 & 52.343 & 1.2842 & 62.700 & 1.5413 & 74.275 \\
\hline 9.050 & 0.2384 & 20.295 & 0.5078 & 31.560 & 0.7740 & 42.185 & 1.0351 & 52.490 & 1.2872 & 62.892 & 1.5447 & 74.388 \\
\hline 9.088 & 0.2416 & 20.350 & 0.5108 & 31.640 & 0.7785 & 42.370 & 1.0383 & 52.613 & 1.2903 & 63.017 & 1.5479 & 74.500 \\
\hline 9.133 & 0.2449 & 20.405 & 0.5139 & 31.720 & 0.7829 & 42.560 & 1.0413 & 52.690 & 1.2933 & 63.155 & 1.5511 & 74.594 \\
\hline 9.218 & 0.2482 & 20.460 & 0.5170 & 31.900 & 0.7871 & 42.673 & 1.0443 & 52.765 & 1.2965 & 63.423 & 1.5542 & 74.689 \\
\hline 9.320 & 0.2515 & 20.508 & 0.5202 & 32.090 & 0.7911 & 42.785 & 1.0471 & 52.840 & 1.2996 & 63.610 & 1.5573 & 74.800 \\
\hline 9.480 & 0.2548 & 20.552 & 0.5235 & 32.267 & 0.7948 & 42.912 & 1.0498 & 52.915 & 1.3028 & 63.737 & 1.5602 & 74.928 \\
\hline 9.585 & 0.2582 & 20.587 & 0.5268 & 32.406 & 0.7985 & 43.067 & 1.0524 & 52.990 & 1.3060 & 63.980 & 1.5631 & 75.035 \\
\hline
\end{tabular}


APPENDIX E (continued).

\begin{tabular}{|c|c|c|c|c|c|c|c|c|c|c|c|}
\hline $\begin{array}{l}\text { Depth } \\
\text { (mcd) }\end{array}$ & $\begin{array}{l}\text { Age } \\
(\mathrm{Ma})\end{array}$ & $\begin{array}{l}\text { Depth } \\
\text { (mcd) }\end{array}$ & $\begin{array}{l}\text { Age } \\
\text { (Ma) }\end{array}$ & $\begin{array}{l}\text { Depth } \\
\text { (mcd) }\end{array}$ & $\begin{array}{l}\text { Age } \\
(\mathrm{Ma})\end{array}$ & $\begin{array}{l}\text { Depth } \\
\text { (mcd) }\end{array}$ & $\begin{array}{l}\text { Age } \\
\text { (Ma) }\end{array}$ & $\begin{array}{l}\text { Depth } \\
\text { (mcd) }\end{array}$ & $\begin{array}{l}\text { Age } \\
\text { (Ma) }\end{array}$ & $\begin{array}{l}\text { Depth } \\
\text { (med) }\end{array}$ & $\begin{array}{l}\text { Age } \\
\text { (Ma) }\end{array}$ \\
\hline 75.137 & 1.8176 & 86.185 & 2.0476 & 96.188 & 2.2816 & 107.390 & 2.5098 & 117.292 & 2.7523 & 125.500 & 2.9953 \\
\hline 75.250 & 1.8206 & 86.262 & 2.0509 & 96.320 & 2.2845 & 107.528 & 2.5153 & 117.410 & 2.7546 & 125.675 & 2.9981 \\
\hline 75.340 & 1.8237 & 86.338 & 2.0543 & 96.495 & 2.2875 & 107.667 & 2.5208 & 117.523 & 2.7569 & 125.900 & 3.0009 \\
\hline 75.430 & 1.8267 & 86.415 & 2.0578 & 96.713 & 2.2905 & 107.790 & 2.5236 & 117.633 & 2.7593 & 126.100 & 3.0038 \\
\hline 75.520 & 1.8297 & 86.490 & 2.0614 & 96.928 & 2.2935 & 107.905 & 2.5265 & 117.743 & 2.7617 & 126.265 & 3.0067 \\
\hline 75.625 & 1.8328 & 86.565 & 2.0651 & 97.075 & 2.2965 & 108.030 & 2.5294 & 117.855 & 2.7643 & 126.490 & 3.0096 \\
\hline 75.730 & 1.8358 & 86.740 & 2.0688 & 97.225 & 2.2996 & 108.210 & 2.5324 & 117.960 & 2.7668 & 126.740 & 3.0125 \\
\hline 75.820 & 1.8388 & 86.932 & 2.0726 & 97.525 & 2.3027 & 108.347 & 2.5354 & 118.050 & 2.7694 & 127.025 & 3.0154 \\
\hline 75.925 & 1.8418 & 87.060 & 2.0765 & 97.820 & 2.3058 & 108.515 & 2.5386 & 118.150 & 2.7721 & 127.250 & 3.0184 \\
\hline 76.055 & 1.8448 & 87.228 & 2.0804 & 98.100 & 2.3090 & 108.683 & 2.5419 & 118.255 & 2.7748 & 127.485 & 3.0214 \\
\hline 76.220 & 1.8477 & 87.340 & 2.0843 & 98.300 & 2.3122 & 108.815 & 2.5453 & 118.360 & 2.7776 & 127.700 & 3.0244 \\
\hline 76.385 & 1.8506 & 87.472 & 2.0881 & 98.405 & 2.3155 & 108.927 & 2.5488 & 118.441 & 2.7803 & 127.997 & 3.0275 \\
\hline 76.502 & 1.8536 & 87.620 & 2.0919 & 98.486 & 2.3188 & 109.040 & 2.5524 & 118.523 & 2.7831 & 128.207 & 3.0305 \\
\hline 76.600 & 1.8565 & 87.763 & 2.0956 & 98.568 & 2.3221 & 109.153 & 2.5561 & 118.615 & 2.7859 & 128.430 & 3.0336 \\
\hline 76.784 & 1.8594 & 87.920 & 2.0992 & 98.650 & 2.3255 & 109.264 & 2.5598 & 118.705 & 2.7886 & 128.600 & 3.0368 \\
\hline 76.886 & 1.8623 & 88.048 & 2.1027 & 98.740 & 2.3289 & 109.376 & 2.5636 & 118.780 & 2.7914 & 128.900 & 3.0400 \\
\hline 77.007 & 1.8652 & 88.260 & 2.1060 & 98.830 & 2.3322 & 109.487 & 2.5674 & 118.855 & 2.7941 & 129.100 & 3.0432 \\
\hline 77.118 & 1.8681 & 88.432 & 2.1093 & 98.920 & 2.3356 & 109.599 & 2.5711 & 118.930 & 2.7968 & 129.250 & 3.0465 \\
\hline 77.220 & 1.8710 & 88.560 & 2.1124 & 99.007 & 2.3391 & 109.710 & 2.5748 & 119.005 & 2.7994 & 129.460 & 3.0498 \\
\hline 77.285 & 1.8740 & 88.728 & 2.1153 & 99.092 & 2.3425 & 109.847 & 2.5783 & 119.080 & 2.8019 & 129.650 & 3.0531 \\
\hline 77.350 & 1.8769 & 88.842 & 2.1182 & 99.178 & 2.3459 & 110.003 & 2.5818 & 119.155 & 2.8045 & 129.822 & 3.0565 \\
\hline 77.500 & 1.8798 & 88.970 & 2.1209 & 99.263 & 2.3492 & 110.165 & 2.5851 & 119.230 & 2.8069 & 129.961 & 3.0599 \\
\hline 77.594 & 1.8827 & 89.140 & 2.1235 & 99.340 & 2.3526 & 110.360 & 2.5882 & 119.305 & 2.8094 & 130.100 & 3.0633 \\
\hline 77.689 & 1.8857 & 89.268 & 2.1261 & 99.400 & 2.3559 & 110.540 & 2.5912 & 119.380 & 2.8117 & 130.230 & 3.0668 \\
\hline 77.800 & 1.8887 & 89.375 & 2.1285 & 99.502 & 2.3591 & 110.690 & 2.5941 & 119.455 & 2.8141 & 130.332 & 3.0702 \\
\hline 77.900 & 1.8917 & 89.478 & 2.1309 & 99.602 & 2.3623 & 110.840 & 2.5968 & 119.530 & 2.8164 & 130.433 & 3.0737 \\
\hline 78.000 & 1.8947 & 89.590 & 2.1333 & 99.700 & 2.3654 & 110.990 & 2.5994 & 119.607 & 2.8187 & 130.533 & 3.0772 \\
\hline 78.100 & 1.8978 & 89.702 & 2.1355 & 99.790 & 2.3685 & 111.155 & 2.6019 & 119.690 & 2.8210 & 130.633 & 3.0806 \\
\hline 78.287 & 1.9008 & 89.815 & 2.1378 & 99.888 & 2.3715 & 111.290 & 2.6043 & 119.773 & 2.8233 & 130.732 & 3.0841 \\
\hline 78.400 & 1.9039 & 89.940 & 2.1400 & 100.000 & 2.3744 & 111.375 & 2.6067 & 119.840 & 2.8255 & 130.830 & 3,0875 \\
\hline 78.550 & 1.9071 & 90.190 & 2.1422 & 100.112 & 2.3773 & 111.460 & 2.6089 & 119.908 & 2.8278 & 130.950 & 3.0908 \\
\hline 78.800 & 1.9102 & 90.375 & 2.1444 & 100.225 & 2.3801 & 111.640 & 2.6112 & 119.993 & 2.8301 & 131.070 & 3.0941 \\
\hline 78.925 & 1.9134 & 90.560 & 2.1465 & 100.338 & 2.3828 & 111.777 & 2.6133 & 120.076 & 2.8324 & 131.185 & 3.0974 \\
\hline 79.073 & 1.9166 & 90.695 & 2.1487 & 100.450 & 2.3855 & 111.890 & 2.6155 & 120.154 & 2.8348 & 131.290 & 3.1006 \\
\hline 79.260 & 1.9198 & 90.808 & 2.1509 & 100.514 & 2.3881 & 112.040 & 2.6177 & 120.235 & 2.8372 & 131.395 & 3.1038 \\
\hline 79.470 & 1.9231 & 90.920 & 2.1531 & 100.579 & 2.3907 & 112.119 & 2.6198 & 120.316 & 2.8397 & 131.506 & 3.1069 \\
\hline 79.680 & 1.9263 & 91.020 & 2.1554 & 100.688 & 2.3932 & 112.198 & 2.6220 & 120.398 & 2.8423 & 131.620 & 3.1099 \\
\hline 79.900 & 1.9295 & 91.120 & 2.1577 & 100.820 & 2.3956 & 112.285 & 2.6243 & 120.480 & 2.8449 & 131.750 & 3.1129 \\
\hline 80.050 & 1.9328 & 91.220 & 2.1600 & 100.928 & 2.3981 & 112.390 & 2.6266 & 120.570 & 2.8477 & 131.823 & 3.1158 \\
\hline 80.350 & 1.9360 & 91.305 & 2.1624 & 101.013 & 2.4005 & 112.486 & 2.6289 & 120.659 & 2.8507 & 131.896 & 3.1187 \\
\hline 80.600 & 1.9393 & 91.390 & 2.1649 & 101.113 & 2.4028 & 112.578 & 2.6314 & 120.831 & 2.8570 & 131.980 & 3.1216 \\
\hline 80.800 & 1.9425 & 91.517 & 2.1674 & 101.250 & 2.4052 & 112.662 & 2.6340 & 121.003 & 2.8642 & 132.070 & 3.1244 \\
\hline 80.970 & 1.9457 & 91.625 & 2.1700 & 101.425 & 2.4076 & 112.754 & 2.6367 & 121.087 & 2.8681 & 132.148 & 3.1271 \\
\hline 81.108 & 1.9489 & 91.717 & 2.1727 & 101.650 & 2.4099 & 112.850 & 2.6396 & 121.167 & 2.8722 & 132.232 & 3.1299 \\
\hline 81.193 & 1.9522 & 91.800 & 2.1755 & 101.849 & 2.4123 & 112.955 & 2.6428 & 121.247 & 2.8765 & 132.705 & 3.1436 \\
\hline 81.287 & 1.9553 & 91.870 & 2.1784 & 102.048 & 2.4146 & 113.054 & 2.6461 & 121.327 & 2.8809 & 132.800 & 3.1463 \\
\hline 81.400 & 1.9585 & 91.940 & 2.1814 & 102.247 & 2.4170 & 113.150 & 2.6498 & 121.404 & 2.8855 & 132.913 & 3.1491 \\
\hline 81.550 & 1.9616 & 92.100 & 2.1845 & 102.480 & 2.4195 & 113.330 & 2.6538 & 121.477 & 2.8901 & 133.010 & 3.1519 \\
\hline 81.800 & 1.9647 & 92.293 & 2.1877 & 102.690 & 2.4219 & 113.485 & 2.6581 & 121.550 & 2.8947 & 133.100 & 3.1548 \\
\hline 81.950 & 1.9678 & 92.447 & 2.1911 & 102.930 & 2.4244 & 113.590 & 2.6627 & 121.615 & 2.8991 & 133.265 & 3.1577 \\
\hline 82.100 & 1.9708 & 92.620 & 2.1944 & 103.123 & 2.4270 & 113.710 & 2.6676 & 121.680 & 2.9035 & 133.391 & 3.1607 \\
\hline 82.250 & 1.9738 & 92.770 & 2.1979 & 103.285 & 2.4296 & 113.858 & 2.6727 & 121.770 & 2.9077 & 133.499 & 3.1637 \\
\hline 82.400 & 1.9768 & 92.877 & 2.2015 & 103.490 & 2.4323 & 114.019 & 2.6779 & 121.851 & 2.9118 & 133.613 & 3.1668 \\
\hline 82.600 & 1.9797 & 93.000 & 2.2051 & 103.710 & 2.4351 & 114.180 & 2.6830 & 121.916 & 2.9156 & 133.750 & 3.1700 \\
\hline 82.743 & 1.9826 & 93.144 & 2.2087 & 103.875 & 2.4379 & 114.330 & 2.6881 & 121.980 & 2.9192 & 133.900 & 3.1732 \\
\hline 82.901 & 1.9855 & 93.276 & 2.2123 & 104.003 & 2.4409 & 114.459 & 2.6928 & 122.049 & 2.9227 & 134.050 & 3.1765 \\
\hline 83,060 & 1.9883 & 93.400 & 2.2159 & 104.165 & 2.4439 & 114.587 & 2.6972 & 122.117 & 2.9260 & 134.200 & 3.1799 \\
\hline 83.197 & 1.9912 & 93.528 & 2.2195 & 104.390 & 2.4470 & 114.780 & 2.7014 & 122.207 & 2.9292 & 134.350 & 3.1834 \\
\hline 83.375 & 1.9939 & 93.700 & 2.2231 & 104.540 & 2.4502 & 114.960 & 2.7052 & 122.307 & 2.9323 & 134.500 & 3.1869 \\
\hline 83.515 & 1.9967 & 93.829 & 2.2266 & 104.765 & 2.4534 & 115.135 & 2.7088 & 122.407 & 2.9352 & 134.655 & 3.1906 \\
\hline 83.632 & 1.9995 & 93.957 & 2.2300 & 104.933 & 2.4567 & 115.300 & 2.7120 & 122.510 & 2.9380 & 134.820 & 3.1943 \\
\hline 83.760 & 2.0022 & 94.060 & 2.2334 & 105.071 & 2.4601 & 115.450 & 2.7151 & 123.059 & 2.9538 & 134.918 & 3.1980 \\
\hline 83.857 & 2.0049 & 94.150 & 2.2367 & 105.210 & 2.4634 & 115.593 & 2.7180 & 123.163 & 2.9563 & 135.032 & 3.2018 \\
\hline 84.040 & 2.0076 & 94.240 & 2.2400 & 105.419 & 2.4669 & 115.710 & 2.7207 & 123.300 & 2.9588 & 135.180 & 3.2056 \\
\hline 84.190 & 2.0103 & 94.330 & 2.2432 & 105.611 & 2.4702 & 115.800 & 2.7233 & 123.438 & 2.9613 & 135.308 & 3.2095 \\
\hline 84.302 & 2.0130 & 94.420 & 2.2463 & 105.790 & 2.4736 & 115.905 & 2.7258 & 123.570 & 2.9638 & 135.437 & 3.2133 \\
\hline 84.433 & 2.0157 & 94.550 & 2.2494 & 105.940 & 2.4770 & 116.017 & 2.7281 & 123.692 & 2.9663 & 135.593 & 3.2171 \\
\hline 84.573 & 2.0184 & 94.710 & 2.2524 & 106.115 & 2.4803 & 116.130 & 2.7304 & 123.820 & 2.9688 & 135.725 & 3.2210 \\
\hline 84.740 & 2.0212 & 94.900 & 2.2554 & 106.290 & 2.4835 & 116.243 & 2.7327 & 123.876 & 2.9714 & 135.860 & 3.2249 \\
\hline 84.920 & 2.0239 & 95.028 & 2.2584 & 106.440 & 2.4867 & 116.355 & 2.7348 & 123.931 & 2.9739 & 136.040 & 3.2287 \\
\hline 85.090 & 2.0267 & 95.157 & 2.2613 & 106.600 & 2.4898 & 116.467 & 2.7370 & 124.150 & 2.9765 & 136.173 & 3.2326 \\
\hline 85.277 & 2.0295 & 95.313 & 2.2642 & 106.790 & 2.4928 & 116.580 & 2.7392 & 124.400 & 2.9791 & 136.283 & 3.2364 \\
\hline 85.447 & 2.0324 & 95.481 & 2.2671 & 106.958 & 2.4957 & 116.709 & 2.7413 & 124.600 & 2.9818 & 136.393 & 3.2403 \\
\hline 85.592 & 2.0353 & 95.650 & 2.2700 & 107.094 & 2.4986 & 116.837 & 2.7435 & 124.753 & 2.9844 & 136.523 & 3.2441 \\
\hline 85.690 & 2.0382 & 95.762 & 2.2729 & 107.167 & 2.5015 & 116.948 & 2.7456 & 124.911 & 2.9871 & 136.657 & 3.2480 \\
\hline 85.895 & 2.0413 & 95.950 & 2.2758 & 107.240 & 2.5043 & 117.050 & 2.7478 & 125.070 & 2.9898 & & \\
\hline 86.060 & 2.0444 & 96.062 & 2.2787 & 107.315 & 2.5071 & 117.180 & 2.7500 & 125.320 & 2.9925 & & \\
\hline
\end{tabular}


APPENDIX F

Age Model for Site 704

\begin{tabular}{|c|c|c|c|c|c|c|c|c|c|c|c|c|}
\hline $\begin{array}{l}\text { Depth } \\
\text { (mbsf) }\end{array}$ & $\begin{array}{l}\text { Age } \\
\text { (Ma) }\end{array}$ & $\begin{array}{l}\text { Depth } \\
\text { (mbsf) }\end{array}$ & $\begin{array}{l}\text { Age } \\
(\mathrm{Ma})\end{array}$ & $\begin{array}{l}\text { Depth } \\
\text { (mbsf) }\end{array}$ & $\begin{array}{l}\text { Age } \\
\text { (Ma) }\end{array}$ & $\begin{array}{l}\text { Depth } \\
\text { (mbsf) }\end{array}$ & $\begin{array}{l}\text { Age } \\
\text { (Ma) }\end{array}$ & $\begin{array}{l}\text { Depth } \\
\text { (mbsf) }\end{array}$ & $\begin{array}{l}\text { Age } \\
(\mathrm{Ma})\end{array}$ & $\begin{array}{l}\text { Depth } \\
\text { (mbst) }\end{array}$ & $\begin{array}{l}\text { Age } \\
\text { (Ma) }\end{array}$ & $\begin{array}{l}\text { Depth } \\
\text { (mbsf) }\end{array}$ \\
\hline 0.07 & 0.0030 & 22.02 & 0.7090 & 64.61 & 1.3700 & 90.35 & 1.6780 & 112.01 & 1.8350 & 144.06 & 2.1780 & 163.53 \\
\hline 0.23 & 0.0090 & 22.02 & 0.7090 & 64.90 & 1.3750 & 90.64 & 1.6800 & 112.29 & 1.8380 & 144.39 & 2.1820 & 163.71 \\
\hline 0.41 & 0.0140 & 22.12 & 0.7090 & 65.24 & 1.3800 & 91.14 & 1.6830 & 112.62 & 1.8400 & 144.68 & 2.1850 & 163.82 \\
\hline 0.65 & 0.0180 & 22.12 & 0.7090 & 65.31 & 1.3810 & 91.25 & 1.6830 & 112.65 & 1.8410 & 144.95 & 2.1880 & 163.98 \\
\hline 1.25 & 0.0380 & 22.36 & 0.7100 & 65.50 & 1.3840 & 91.54 & 1.6850 & 113.00 & 1.8520 & 145.26 & 2.1910 & 164.01 \\
\hline 1.32 & 0.0410 & 22.98 & 0.7140 & 65.80 & 1.3890 & 91.85 & 1.6870 & 113.56 & 1.8670 & 145.55 & 2.1940 & 164.28 \\
\hline 1.75 & 0.0610 & 23.52 & 0.7170 & 66.11 & 1.3930 & 92.17 & 1.6880 & 114.12 & 1.8790 & 145.87 & 2.1970 & 164.45 \\
\hline 1.88 & 0.0650 & 23.52 & 0.7170 & 66.40 & 1.3960 & 92.46 & 1.6900 & 114.16 & 1.8800 & 146.18 & 2.2000 & 164.61 \\
\hline 2.06 & 0.0670 & 23.74 & 0.7180 & 66.81 & 1.4010 & 92.65 & 1.6900 & 114.31 & 1.8830 & 146.75 & 2.2080 & 164.84 \\
\hline 2.13 & 0.0690 & 24.48 & 0.7220 & 67.00 & 1.4030 & 92.75 & 1.6910 & 114.75 & 1.8900 & 147.05 & 2.2120 & 164.91 \\
\hline 2.28 & 0.0710 & 24.48 & 0.7220 & 67.61 & 1.4100 & 93.05 & 1.6910 & 114.91 & 1.8920 & 147.69 & 2.2210 & 165.08 \\
\hline 2.36 & 0.1220 & 25.02 & 0.7250 & 67.90 & 1.4130 & 93.34 & 1.6920 & 115.15 & 1.8950 & 147.95 & 2.2260 & 165.28 \\
\hline 2.36 & 0.1220 & 25.02 & 0.7250 & 68.24 & 1.4160 & 93.64 & 1.6920 & 115.21 & 1.8960 & 148.19 & 2.2310 & 165.32 \\
\hline 2.60 & 0.1260 & 25.12 & 0.7250 & 68.31 & 1.4170 & 93.95 & 1.6930 & 115.51 & 1.9010 & 148.54 & 2.2390 & 165.51 \\
\hline 2.72 & 0.1280 & 25.36 & 0.7270 & 68.50 & 1.4190 & 94.14 & 1.6930 & 115.62 & 1.9020 & 148.57 & 2.2390 & 165.64 \\
\hline 2.87 & 0.1350 & 48.33 & 1.0550 & 68.71 & 1.4210 & 94.25 & 1.6930 & 115.65 & 1.9020 & 148.72 & 2.2430 & 165.84 \\
\hline 3.15 & 0.1470 & 48.35 & 1.0570 & 69.11 & 1.4240 & 94.50 & 1.6940 & 115.96 & 1.9050 & 148.87 & 2.2470 & 165.96 \\
\hline 3.36 & 0.1560 & 48.65 & 1.0600 & 69.74 & 1.4300 & 94.80 & 1.6940 & 116.11 & 1.9060 & 149.10 & 2.2530 & 166.11 \\
\hline 3.44 & 0.1600 & 48.86 & 1.0630 & 70.50 & 1.4370 & 95.45 & 1.6960 & 116.75 & 1.9090 & 149.32 & 2.2580 & 166.14 \\
\hline 3.63 & 0.1680 & 49.12 & 1.0660 & 70.69 & 1.4390 & 95.62 & 1.6970 & 117.05 & 1.9110 & 149.55 & 2.2620 & 166.30 \\
\hline 3.78 & 0.1740 & 49.21 & 1.0700 & 70.88 & 1.4420 & 95.75 & 1.6970 & 117.35 & 1.9120 & 149.85 & 2.2670 & 166.41 \\
\hline 3.84 & 0.1750 & 49.35 & 1.0790 & 71.14 & 1.4460 & 96.00 & 1.6980 & 117.51 & 1.9130 & 150.07 & 2.2700 & 166.53 \\
\hline 3.98 & 0.1780 & 49.50 & 1.0900 & 71.31 & 1.4490 & 96.35 & 1.6990 & 117.63 & 1.9130 & 150.97 & 2.2760 & 166.82 \\
\hline 4.10 & 0.1830 & 49.85 & 1.1150 & 71.44 & 1.4520 & 96.65 & 1.7000 & 117.98 & 1.9150 & 151.12 & 2.2770 & 166.86 \\
\hline 4.21 & 0.1840 & 50.21 & 1.1400 & 71.77 & 1.4580 & 97.05 & 1.7020 & 118.11 & 1.9160 & 151.27 & 2.2780 & 167.18 \\
\hline 4.32 & 0.1850 & 50.36 & 1.1490 & 72.00 & 1.4620 & 97.25 & 1.7030 & 118.25 & 1.9170 & 151.42 & 2.2790 & 167.37 \\
\hline 4.41 & 0.1850 & 50.50 & 1.1570 & 72.12 & 1.4640 & 97.46 & 1.7040 & 118.41 & 1.9170 & 151.57 & 2.2820 & 167.76 \\
\hline 4.41 & 0.1850 & 50.62 & 1.1640 & 72.36 & 1.4670 & 97.77 & 1.7050 & 118.56 & 1.9180 & 151.72 & 2.2860 & 167.91 \\
\hline 4.64 & 0.2010 & 50.71 & 1.1700 & 72.56 & 1.4700 & 98.01 & 1.7060 & 118.86 & 1.9200 & 152.22 & 2.3030 & 168.03 \\
\hline 4.87 & 0.2260 & 50.85 & 1.1760 & 72.81 & 1.4740 & 98.35 & 1.7060 & 119.13 & 1.9220 & 152.32 & 2.3060 & 168.21 \\
\hline 4.91 & 0.2300 & 51.00 & 1.1800 & 72.95 & 1.4760 & 98.69 & 1.7070 & 119.17 & 1.9220 & 152.47 & 2.3110 & 168.32 \\
\hline 4.99 & 0.2390 & 51.35 & 1.1850 & 73.68 & 1.4930 & 99.00 & 1.7080 & 119.49 & 1.9250 & 152.62 & 2.3150 & 168.43 \\
\hline 5.13 & 0.2540 & 51.65 & 1.1900 & 73.87 & 1.4990 & 99.25 & 1.7090 & 119.75 & 1.9270 & 152.92 & 2.3230 & 168.51 \\
\hline 5.28 & 0,2720 & 51.86 & 1.1930 & 74.14 & 1.5090 & 99.57 & 1.7090 & 120.05 & 1.9290 & 153.07 & 2.3280 & 168.61 \\
\hline 5.28 & 0.2720 & 52.50 & 1.2020 & 74.31 & 1.5150 & 99.84 & 1.7100 & 120.35 & 1.9320 & 153.22 & 2.3340 & 168.78 \\
\hline 5.36 & 0.2810 & 52.85 & 1.2070 & 74.45 & 1.5200 & 100.10 & 1.7110 & 120.64 & 1.9350 & 153.37 & 2.3420 & 169.00 \\
\hline 5.46 & 0.2930 & 53.15 & 1.2130 & 74.60 & 1.5210 & 100.46 & 1.7130 & 120.67 & 1.9350 & 153.67 & 2.3540 & 169.11 \\
\hline 5.61 & 0.3050 & 53.36 & 1.2170 & 74.77 & 1.5220 & 100.75 & 1.7140 & 120.98 & 1.9390 & 153.72 & 2.3560 & 169.25 \\
\hline 5.75 & 0.3100 & 53.62 & 1.2230 & 75.71 & 1.5300 & 101.06 & 1.7150 & 121.25 & 1.9430 & 153.82 & 2.3600 & 169.43 \\
\hline 5.75 & 0.3100 & 53.71 & 1.2240 & 75.81 & 1.5310 & 101.35 & 1.7170 & 121.55 & 1.9510 & 154.12 & 2.3670 & 169.53 \\
\hline 5.75 & 0.3100 & 54.00 & 1.2330 & 75.95 & 1.5330 & 101.66 & 1.7180 & 121.85 & 1.9580 & 154.27 & 2.3710 & 169.71 \\
\hline 5.81 & 0.3120 & 54.35 & 1.2420 & 76.27 & 1.5380 & 101.96 & 1.7190 & 122.01 & 1.9620 & 154.42 & 2.3760 & 169.86 \\
\hline 5.81 & 0.3120 & 54.65 & 1.2470 & 76.37 & 1.5400 & 102.25 & 1.7200 & 122.15 & 1.9650 & 154.57 & 2.3810 & 170.11 \\
\hline 6.03 & 0.3190 & 54.86 & 1.2510 & 76.86 & 1.5440 & 102.55 & 1.7210 & 122.17 & 1.9650 & 154.87 & 2.3890 & 170.26 \\
\hline 6.21 & 0.3250 & 55.12 & 1.2540 & 77.11 & 1.5460 & 102.86 & 1.7220 & 122.31 & 1.9680 & 155.02 & 2.3920 & 170.45 \\
\hline 6.33 & 0.3280 & 55.21 & 1.2550 & 77.43 & 1.5490 & 103.20 & 1.7230 & 122.61 & 1.9720 & 155.17 & 2.3940 & 170.75 \\
\hline 6.57 & 0.3340 & 55.50 & 1.2580 & 77.86 & 1.5530 & 103.44 & 1.7240 & 122.91 & 1.9760 & 155.32 & 2.3960 & 170.91 \\
\hline 6.57 & 0.3340 & 55.85 & 1.2620 & 78.11 & 1.5560 & 103.75 & 1.7250 & 123.21 & 1.9790 & 155.92 & 2.4060 & 170.95 \\
\hline 6.62 & 0.3350 & 56.15 & 1.2650 & 78.92 & 1.5690 & 104.05 & 1.7260 & 123.67 & 1.9840 & 156.37 & 2.4150 & 171.05 \\
\hline 6.62 & 0.3350 & 56.38 & 1.2670 & 79.30 & 1.5750 & 104.69 & 1.7280 & 123.81 & 1.9850 & 156.52 & 2.4190 & 171.20 \\
\hline 6.78 & 0.3380 & 56.62 & 1.2700 & 79.31 & 1.5750 & 104.96 & 1.7290 & 124.25 & 1.9890 & 156.87 & 2.4300 & 171.54 \\
\hline 6.78 & 0.3380 & 56.71 & 1.2710 & 79.46 & 1.5770 & 105.02 & 1.7300 & 124.55 & 1.9920 & 157.35 & 2.7600 & 171.71 \\
\hline 6.95 & 0.3400 & 57.35 & 1.2790 & 79.68 & 1.5800 & 105.14 & 1.7300 & 124.85 & 1.9950 & 157.37 & 2.7700 & 171.79 \\
\hline 7.24 & 0.3690 & 57.51 & 1.2820 & 79.86 & 1.5820 & 105.25 & 1.7320 & 125.17 & 1.9990 & 157.47 & 2.7800 & 171.97 \\
\hline 7.44 & 0.3850 & 57.71 & 1.2850 & 80.41 & 1.5870 & 105.55 & 1.7360 & 126.84 & 2.0220 & 158.07 & 2.8000 & 172.14 \\
\hline 7.58 & 0.3960 & 57.91 & 1.2880 & 80.65 & 1.5890 & 105.71 & 1.7380 & 127.16 & 2.0270 & 158.37 & 2.8080 & 172.20 \\
\hline 7.61 & 0.3980 & 58.11 & 1.2910 & 80.82 & 1.5910 & 106.01 & 1.7420 & 127.77 & 2.0370 & 158.67 & 2.8170 & 172.46 \\
\hline 7.78 & 0.4080 & 58.21 & 1.2920 & 80.98 & 1.5930 & 106.07 & 1.7430 & 128.05 & 2.0400 & 158.82 & 2.8210 & 172.54 \\
\hline 7.78 & 0.4080 & 58.31 & 1.2940 & 81.57 & 1.5990 & 106.31 & 1.7460 & 128.34 & 2.0430 & 158.97 & 2.8270 & 172.61 \\
\hline 7.82 & 0,4090 & 58.51 & 1.2960 & 81.75 & 1.6010 & 106.48 & 1.7490 & 129.55 & 2.0530 & 159.12 & 2.8320 & 172.75 \\
\hline 7.92 & 0.4120 & 58.79 & 1.2990 & 81.86 & 1.6020 & 106.75 & 1.7530 & 129.85 & 2.0550 & 159.42 & 2.8430 & 172.91 \\
\hline 8.02 & 0.4160 & 59.01 & 1.3020 & 82.17 & 1.6060 & 107.08 & 1.7580 & 130.44 & 2.0590 & 159.57 & 2.8480 & 172.95 \\
\hline 8.09 & 0.4180 & 59.21 & 1.3040 & 83.31 & 1.6180 & 107.25 & 1.7600 & 130.75 & 2.0610 & 160.16 & 2.8690 & 173.05 \\
\hline 8.18 & 0.4210 & 59.40 & 1.3060 & 83.72 & 1.6230 & 107.25 & 1.7600 & 131.75 & 2.0650 & 160.21 & 2.8710 & 173.35 \\
\hline 8.52 & 0.4260 & 59.60 & 1.3080 & 83.96 & 1.6250 & 107.49 & 1.7630 & 131.85 & 2.0650 & 160.32 & 2.8750 & 173.47 \\
\hline 9.41 & 0.4450 & 59.79 & 1.3100 & 84.14 & 1.6280 & 107.85 & 1.7670 & 132.20 & 2.0670 & 160.47 & 2.8800 & 173.65 \\
\hline 12.31 & 0.5030 & 60.01 & 1.3130 & 84.34 & 1.6300 & 108.12 & 1.7710 & 132.61 & 2.0690 & 160.62 & 2.8860 & 173.70 \\
\hline 12.49 & 0.5110 & 60.16 & 1.3150 & 84.54 & 1.6320 & 108.16 & 1.7710 & 132.80 & 2.0700 & 160.77 & 2.8910 & 173.81 \\
\hline 12.52 & 0.5130 & 60.30 & 1.3170 & 84.76 & 1.6350 & 108.46 & 1.7750 & 133.80 & 2.0780 & 160.92 & 2.8960 & 174.00 \\
\hline 15.11 & 0.6170 & 60.52 & 1.3200 & 84.88 & 1.6370 & 108.75 & 1.7790 & 133.95 & 2.0800 & 161.07 & 2.9020 & 174.25 \\
\hline 15.32 & 0.6310 & 60.71 & 1.3220 & 84.98 & 1.6380 & 109.05 & 1.7840 & 134.25 & 2.0880 & 161.22 & 2.9070 & 174.41 \\
\hline 16.98 & 0.6670 & 60.92 & 1.3250 & 85.16 & 1.6400 & 109.35 & 1.7890 & 134.35 & 2.0910 & 161.37 & 2.9120 & 174.45 \\
\hline 16.98 & 0.6670 & 61.11 & 1.3260 & 85.41 & 1.6420 & 109.51 & 1.7930 & 134.55 & 2.0990 & 161.52 & 2.9170 & 174.55 \\
\hline 17.52 & 0.6780 & 61.30 & 1.3280 & 85.67 & 1.6440 & 109.62 & 1.7950 & 134.87 & 2.1100 & 161.67 & 2.9230 & 174.85 \\
\hline 17.52 & 0.6780 & 61.61 & 1.3300 & 85.86 & 1.6460 & 109.96 & 1.8040 & 136.36 & 2.1280 & 161.80 & 2.9270 & 175.46 \\
\hline 17.62 & 0.6800 & 61.90 & 1.3330 & 86.00 & 1.6470 & 110.11 & I. 8080 & 136.70 & 2.1310 & 161.97 & 2.9330 & 175.73 \\
\hline 17.62 & 0.6800 & 62.31 & 1.3370 & 86.56 & 1.6520 & 110.25 & 1.8110 & 140.78 & 2.1520 & 162.08 & 2.9370 & 176.30 \\
\hline 17.86 & 0.6830 & 62.50 & 1.3390 & 86.85 & 1.6540 & 110.56 & 1.8140 & 141.05 & 2.1530 & 162.21 & 2.9420 & 176.64 \\
\hline 18.48 & 0.6890 & 62.80 & 1.3420 & 87.75 & 1.6610 & 111.07 & 1.8200 & 141.35 & 2.1540 & 162.32 & 2.9460 & 176.81 \\
\hline 19.07 & 0.6930 & 63.11 & 1.3460 & 88.25 & 1.6630 & 111.12 & 1.8210 & 142.25 & 2.1580 & 162.35 & 2.9470 & 176.97 \\
\hline 20.52 & 0.7010 & 63.40 & 1.3490 & 88.54 & 1.6650 & 111.31 & 1.8240 & 142.71 & 2.1600 & 162.51 & 2.9530 & 177.15 \\
\hline 20.52 & 0.7010 & 63.74 & 1.3550 & 88.84 & 1.6660 & 111.46 & 1.8270 & 142.87 & 2.1620 & 162.76 & 2.9620 & 177.41 \\
\hline 20.62 & 0.7010 & 63.81 & 1.3560 & 89.54 & 1.6700 & 111.61 & 1.8300 & 143.11 & 2.1640 & 162.89 & 2.9660 & 177.44 \\
\hline 20.73 & 0.7020 & 64.00 & 1.3590 & 89.75 & 1.6720 & 111.75 & 1.8320 & 143.31 & 2.1670 & 163.26 & 2.9780 & 177.55 \\
\hline 21.48 & 0.7060 & 64.30 & 1.3640 & 90.05 & 1.6750 & 111.91 & 1.8340 & 143.45 & 2.1680 & 163.45 & 2.9840 & \\
\hline
\end{tabular}

